\title{
Reducing the Magnitude and Reshaping the Temporal Distribution of Residential Electrical Loads Purposed to Achieve a Zero Peak House in a Southern Ontario Climate
}

\author{
by \\ Andrea J. Pietila, B.Eng., Aerospace Engineering \\ Carleton University
}

\begin{abstract}
A thesis submitted to the
Faculty of Graduate and Postdoctoral Affairs

in partial fulfillment of the requirements for the degree of
\end{abstract}

Master of Applied Science in Mechanical Engineering

Ottawa-Carleton Institute for Mechanical and Aerospace Engineering

Department of Mechanical and Aerospace Engineering

Carleton University

Ottawa, Ontario

August 19, 2011

(C)Copyright

Andrea J. Pietila, 2011 
Library and Archives

Canada

Published Heritage Branch

395 Wellington Street

Ottawa ON K1A ON4

Canada
Bibliotheqque et

Archives Canada

Direction du

Patrimoine de l'édition

395, rue Wellington

Ottawa ON K1A ON4

Canada
Your file Votre référence

ISBN: 978-0-494-83065-9

Our file Notre référence

ISBN: 978-0-494-83065-9
NOTICE:

The author has granted a nonexclusive license allowing Library and Archives Canada to reproduce, publish, archive, preserve, conserve, communicate to the public by telecommunication or on the Internet, loan, distribute and sell theses worldwide, for commercial or noncommercial purposes, in microform, paper, electronic and/or any other formats.

The author retains copyright ownership and moral rights in this thesis. Neither the thesis nor substantial extracts from it may be printed or otherwise reproduced without the author's permission.
AVIS:

L'auteur a accordé une licence non exclusive permettant à la Bibliothèque et Archives Canada de reproduire, publier, archiver, sauvegarder, conserver, transmettre au public par télécommunication ou par l'Internet, prêter, distribuer et vendre des thèses partout dans le monde, à des fins commerciales ou autres, sur support microforme, papier, électronique et/ou autres formats.

L'auteur conserve la propriété du droit d'auteur et des droits moraux qui protège cette thèse. $\mathrm{Ni}$ la thèse ni des extraits substantiels de celle-ci ne doivent être imprimés ou autrement reproduits sans son autorisation.
In compliance with the Canadian Privacy Act some supporting forms may have been removed from this thesis.

While these forms may be included in the document page count, their removal does not represent any loss of content from the thesis.
Conformément à la loi canadienne sur la protection de la vie privée, quelques formulaires secondaires ont été enlevés de cette thèse.

Bien que ces formulaires aient inclus dans la pagination, il n'y aura aucun contenu manquant.

\section{Canadä}


The undersigned hereby recommends to the

Faculty of Graduate and Postdoctoral Affairs acceptance of the thesis

\title{
Reducing the Magnitude and Reshaping the Temporal Distribution of Residential Electrical Loads Purposed to Achieve a Zero Peak House in a Southern Ontario Climate
}

\author{
submitted by Andrea J. Pietila, B.Eng., Aerospace Engineering \\ Carleton University
}

in partial fulfillment of the requirements for the degree of

Master of Applied Science in Mechanical Engineering 
Professor Ian Beausoleil-Morrison, Thesis Supervisor

Professor Matthew Johnson

Professor Roger Milane

Dr. Guy Newsham

Professor William O'Brien

Professor Metin Yaras, Chair, Department of Mechanical and Aerospace Engineering

Ottawa-Carleton Institute for Mechanical and Aerospace Engineering Dcpartment of Mechanical anc Acrusuke Engneering

Carleton Unıversity

August, 2011 


\section{Abstract}

The Canadian residential sector contributes a significant portion to national secondary energy use, often with electricity use occurring concurrently with other major users causing a spike in demand. This can, in part, be attributed to the steady increase in summer space cooling, specifically in the province of Ontario. Mitigating the residential electricity use during hours of high demand will reduce the need for greenhouse gas intensive suppliers to meet the peaking demand.

A research project based upon building performance simulation was completed to address the challenge of high residential electricity demand in summer months in a Toronto, Ontario climate. The project examined the efficacy of energy use reduction techniques in newly constructed single-family homes, to determine a combination of effective techniques to eliminate a house's electricity demand when the provincial system is experiencing periods of peak demand. Many different techniques can mitigate high electricity demand. These techniques fall into three categories: architectural with external shading; technological - modifying thermal setpoints and demand side management; and changes in occupant behavior - efficient appliances and temporally shifting the use of appliances. A combination of effective techniques can significantly reduce on-peak demand, and combined with local energy generation and storage, aims for no electricity draw from the modelled house during peak grid demand.

To determine the most effective strategies from each category, a set of metrics were chosen to compare each technique. These metrics include comparing the electricity consumption of each variant annually and during the summer-weekday on-peak period, as well as correlating the electricity usage of the house annually, and on summer week-days to the demand on the provincial electricity distributer. This thesis describes the methods to model the house and the occupant behaviour in the building performance simulation program ESP-r, and presents the metrics for all simulated techniques. Metrics of combinations of effective strategies are presented, and finally local generation and storage is sized to achieve a zero peak house. 
To my mom, for her endless love and both mental and financial support. And to my family and friends who have cheered me on along the way. 


\section{Acknowledgments}

I would first like to acknowledge my supervisor, Professor Ian Beausoleil-Morrison. His constant supply of support, challenge, mentorship and motivation is truly appreciated, along with his ability to have a good laugh. He is and will continue to be, an amazing mentor.

Secondly, I would like to acknowledge Dr. Guy Newsham at the National Research Council's Institute for Research in Construction. His support and funding made this work possible.

To the Sustainable Building Energy Systems laboratory, these two years filled with ESP-r discussions, crossword puzzles, coffee breaks, and road trips have been full of fond memories. Special thanks goes to Stephanie Seemel for her supportive work. And a huge thank you to Briana Paige Kemery, Neil Saldanha, and Courtney Edwards for their support and friendship.

I would like to thank both Bart Lomanowski and Alex Ferguson at Natural Resources Canada, who helped answer my various ESP-r related queries.

I would like to acknowledge and thank all of my friends, who have been so understanding of my recent time-commitments and schedule. To those who took the time to help review this work, your input was very much appreciated.

Finally, to my family, whose love and support have pushed me time and again to achieve new heights. 


\section{Table of Contents}

Abstract $\quad$ iv

Acknowledgments $\quad$ vi

Table of Contents vii

List of Tables $\quad$ xiii

List of Figures $\quad$ xiv

Nomenclature $\quad$ xx

1 Introduction 1

1.1 The Ontario Flectricity System . . . . . . . . . . . . 2

1.1.1 Electricity Consumption at the Residential Level in Ontario . 2

1.2 Energy Efficient Housing . . . . . . . . . . . . . . . . 6

1.2.1 Zero Energy Houses Compared to Zero Peak Houses . . . . . . 7

1.3 Tochniques to Achicve a ZPII . . . . . . . . . . . . . . . 7

1.4 Typical Canadian New Construction Single Family Housing . . . . 8

1.5 Research Process . . . . . . . . . . . . . . . . . . 10

1.6 Rescarch Objectives . . . . . . . . . . . . . . . . 10

1.7 Thesis Outline . . . . . . . . . . . . . . 10

2 Building Performance Simulation and ESP-r $\quad 12$

2.1 Methods of Modelling . . . . . . . . . . . . . 12

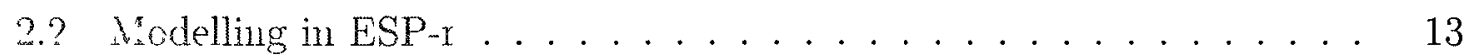

2.3 Material and Construction Specifications . . . . . . . . . 18

2.4 External Radiation Processes . . . . . . . . . . . . . . . 19 
2.5 Fcnestration . . . . . . . . . . . . . . . . . . . . 19

2.6 Insolation and Shading . . . . . . . . . . . . . . . . . 21

2.7 Treatment of Building Conditioning - HVAC and Infiltration . . . . 23

2.7.1 Heating and Air-Conditioning . . . . . . . . . . 24

2.7 .2 Infiltration and Ventilation . . . . . . . . . . 24

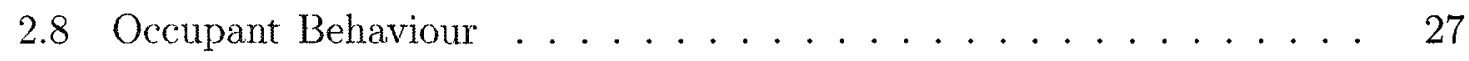

2.9 Closing Remarks . . . . . . . . . . . . . . . . 27

3 Base Case Design and Simulation Model $\quad 28$

3.1 Base Case Size, Orientation and Location . . . . . . . . . . . . 28

3.2 Materials and Constructions . . . . . . . . . . . . . . . . . 29

3.2.1 Basement Constructions and Assumptions . . . . . . . . 31

3.3 HVAC. Infiltration and Comfort Setpoints . . . . . . . . . . . . . . . . . . . . . . 33

3.3 .1 Component Specifications . . . . . . . . . . . . 33

3.3 .2 Infiltration . . . . . . . . . . . . . 34

3.3.3 Thermal Comfort Setpoints . . . . . . . . . . . . 34

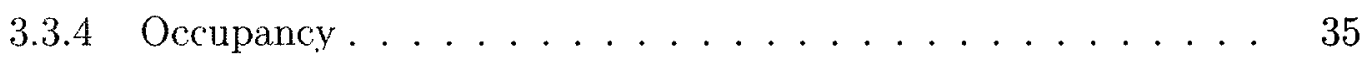

3.4 Final Base Case ESP-r Model $\ldots \ldots \ldots \ldots$

4 Modelling Residential Occupancy $\quad 38$

4.1 The Importance of Accurately Representing Occupancy . . . . . . . . 38

4.2 Aggregate Electricity Load Profile . . . . . . . . . . . . . . . . 40

4.2.1 Characterizing Dishwasher L'se . . . . . . . . . . . . 41

4.2 .2 Characterizing Clothes Dryer Use . . . . . . . . . . . 44

4.2.3 Characterizing Clothes-Washing Machine Use . . . . . . . . 46

4.2 .4 Characterizing Stove Use . . . . . . . . . . . . . . . . . . 48

4.2 .5 Characterizing Refrigerator Usc . . . . . . . . . . . . . 51

4.2 .6 Characterizing Deep Freezer Use . . . . . . . . . . . 53

4.2.7 Characterizing Small Appliances and Remaining Plug Loads . 54

4.2 .8 Final Completed Profile . . . . . . . . . . . . . 55

5 Variations on the Base Case with the Potential to Reduce On-Peak Electricity Consumption $\quad \mathbf{5 8}$

5.1 Variations of Architectural and Design Components . . . . . . . . 58

5.1 .1 Architectural Shading Features . . . . . . . . . . . 59 
5.1 .2 Shading by Vegetation . . . . . . . . . . . . . . . 60

5.1 .3 Window Design and Propertics ............. 61

5.1 .4 Fenestration Size and Distribution . . . . . . . . . . . 64

5.1 .5 Modifying Constructions . . . . . . . . . . . . 65

5.2 Technological Modifications with a Building . . . . . . . . . 66

5.2.1 Thermal Mass and Pre-Cooling Strategies . . . . . . . . 67

5.2 .2 Blind Actuation to Scnsed Conditions . . . . . . . . . . 70

5.2 .3 Cycling Air-Conditioning Lsage On-Peak . . . . . . . . . . 71

5.3 Changes in Occupant Behaviour . . . . . . . . . . . . . 72

5.4 Local Generation with the Potential for a Storage Component . . . 73

5.5 Closing Remarks . . . . . . . . . . . . . . . . . . 75

6 Performance Metrics $\quad \mathbf{7 7}$

6.1 Considerations When Choosing Metrics for Low Energy Houses . . 77

6.2 ZPH Metrics . . . . . . . . . . . . . . . . . . . . 78

6.2 .1 Annual Electricity Consumption . . . . . . . . . . 78

6.2.2 Summer Weekday On-Peak Electricity Consumption . . . . 78

6.2 .3 Annual Natural Gas Consumption . . . . . . . . . . . 79

6.2.4 Summer Wrekday and Annual Correlation . . . . . . . . . . 79

6.2.5 One Day Household Performance . . . . . . . . . . . 80

6.3 Closing Remarks . . . . . . . . . . . . . . . . . . . 81

7 Simulation Results of Variations on the Base Case 83

7.1 Architectural and Vegetative Shading . . . . . . . . . . . . 83

7.1.1 Summary of Key Shading Results . . . . . . . . . . . . . . 84

7.1 .2 Analysis of Shading Results . . . . . . . . . . . 85

7.2 Window Design and Properties . . . . . . . . . . . 86

7.2.1 Summary of Key Window Property Results . . . . . . . 87

7.2 .2 Analysis of Window Property Results . . . . . . . . . . . 88

7.3 Venetian Blinds . . . . . . . . . . . . . . . . . . . . 89

7.3.1 Summary of Key Venetian Blind Results . . . . . . . . . 90

7.3.2 Analysis of Venetian Blind Results . . . . . . . . . . . 90

7.4 Fenestration Area and Distribution . . . . . . . . . . . . . 91

7.4.1 Summary of Key Fenestration Results . . . . . . . . . . 91

7.4.2 Analysis of Fenestration Area and Distribution Results . . . 92 
7.5 Reflective Shingles . . . . . . . . . . . . . . . 95

7.5.1 Summary of Koy Reflective Shingle Results . . . . . . . . . 95

7.5.2 Analysis of Reflective Shingles Results . . . . . . . . . . 96

7.6 Thermal Mass and Pre-cooling Control Strategics . . . . . . . . . 97

7.6.1 Summary of Key Thermal Mass and Pre-Cooling Results . . . 97

7.6.2 Analysis of Concrete and Pre-Cooling Results . . . . . . . 98

7.7 Actuating Venctian Blinds . . . . . . . . . . . . . . . . . . 100

7.7.1 Summary of Key Results on Actuating Venetian Blinds . . . . 100

7.7.2 Analysis of Actuating Venetian Blind Results . . . . . . . 101

7.8 On-Peak Air-Conditioning Cycling . . . . . . . . . . . . . . 102

7.8.1 Summary of Key Air-Conditioning Cycling Results . . . . . 103

7.8.2 Analysis of Air-Conditioning Cycling Results . . . . . . . . . 104

7.9 Shifting Use of Appliances and Appliance Efficiency . . . . . . . . . 105

7.9.1 Summary of Key Appliance Use and Efficiency Results . . . . 105

7.9.2 Analysis of Shifting Use of Appliances and Appliance Efficiency 106

7.10 Outdoor Air Ventilation by Opening Windows or Using Ventilative Cooling . . . . . . . . . . . . . . . . . 107

7.10.1 Summary of Key Outdoor Air Ventilation Results . . . . . . . 107

7.10 .2 Analysis of Outdoor Air Ventilation . . . . . . . . . . . 108

7.11 Comparing the Use of a Representative Profile to Real House Electricity Demand Data . . . . . . . . . . . . . . . . . . . 109

7.11.1 Summary of Key Results in Comparing the Representative Profile to Real Orcupancy Profiles . . . . . . . . . . . . 110

7.11.2 Analysis of Comparing the Representative Profile to Real Occupancy Profiles . . . . . . . . . . . . . . . . 110

7.12 Svnthesis Summary of Results . . . . . . . . . . . . . . . . . 112

7.13 Closing Remarks . . . . . . . . . . . . . . . . . . . 114

8 Combinations of Effective Variants $\quad 116$

8.1 Effective Variants Used in Combinations . . . . . . . . . . . 116

8.2 Summary of Key Combination Results . . . . . . . . . . . . 118

8.3 Analysis of Combination Variants . . . . . . . . . . . . . 120

8.4 Closing Remarks . . . . . . . . . . . . . . . . . . . 124 
9 Local Generation and Storage Using a Photovoltaic and/or Battery System to Achieve a Zero-Peak Electricity Demand

9.1 Photoroltaic and Battery System Specifications . . . . . . . . . . . 126

9.2 Utilizing On-Peak PV Production to Meet On-Peak Household Demand126

9.3 Combining PV Production with Battcry Storage to Meet On-Peak Household Demand . . . . . . . . . . . . . . . . . . 128

9.4 Sizing Fcasibility . . . . . . . . . . . . . . . . . . . 129

9.5 Closing Remarks . . . . . . . . . . . . . . . . . . . 130

10 Conclusions and Recommendations 131

10.1 Conclusions of the Work Completed . . . . . . . . . . . . . . . 131

10.2 Recommendations for Future Work . . . . . . . . . . . . . 135

$\begin{array}{ll}\text { List of References } & 137\end{array}$

$\begin{array}{lll}\text { Appendix A Base Case Materials and Constructions } & 143\end{array}$

$\begin{array}{ll}\text { Appendix B Detailed Results } & 148\end{array}$

B.1 Shading Results Metrics Compared to the Base Case . . . . . . . . 148

B.2 Window Property Results Metrics Compared to the Base Case . . . 151

B.3 Venctian Blind Results Metrics Compared to the Base Case . . . . . 154

B.4 Fenestration Results Metries Compared to the Base Case . . . . . . . 157

B.5 Reflective Shingles Results . Metrics Compared to the Base Case . . 160

B.6 Thermal Mass and Pre-Cooling Results Metrics Compared to the Base Case ............................ 163

B.7 Actuating Venetian Blind Results Metrics Compared to the Base Case 166

B.8 Air-Conditioning Cycling Results Metrics Compared to the Base Case 169

B.9 Shifling Use of Appliances and Appliance Efficiency Results Metrics Compared to the Base Case . . . . . . . . . . . . . . . . 172

B.10 Outdoor Air Ventilation - Windows and Ventilative Cooling Results Metrics Compared to the Base Case . . . . . . . . . . . . 175

B.11 Testing the effect of different occupancy schedule . . . . . . 178

B.12 Effective Variant Combination Results Metrics Compared to the Base Case . . . . . . . . . . . . . . . . . . . 181 
C.1 Configuration File - *.cfg . . . . . . . . . . . . . . 185

C.2 Controls File - *.ctl . . . . . . . . . . . . . . . . . . . . 189

C.3 Air Infiltration File - *aim . . . . . . . . . . . . . . . . . . 191

C.4 HVAC Input File - *hvac . . . . . . . . . . . . . . . . 192

C.5 HRV Input File - *.vnt . . . . . . . . . . . . . . . . . . . . 192

C.6 AFN Input File ${ }^{*}$.afn . . . . . . . . . . . . . . . . 193

C.7 Electrical Networks Inputs File - * enf . . . . . . . . . . 196

C.8 Complex Fenestration Construction Input File - *.gsl . . . . . . . 197

C.9 Basement Input File - *.bsm . . . . . . . . . . . . . . . . . . . 198 


\section{List of Tables}

3.1 Exterior wall materials and constructions . . . . . . . . . 30

3.2 Main zone fenestration construction . . . . . . . . . . . . . 32

4.1 Electrical consumption of the representative profile of the dishwasher 43

4.2 Electrical consumption of the representative dryer electricity profile . 45

4.3 Electrical consumption of the representative clothes-washing machine

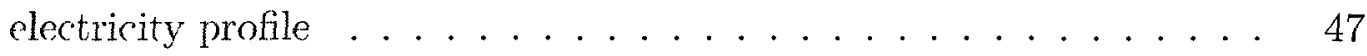

4.4 Electrical consumption of the representative profile of the stove . . . 50

5.1 Architectural shading variations . . . . . . . . . . . . 61

5.2 Window and glazing variations . . . . . . . . . . . . . . . 64

5.3 Variants that shift or reduce the household fenestration . . . . . . . 67

5.4 Actuating horizontal venetian blinds based on environmental triggers 71

5.5 Occupant bchaviour variations . . . . . . . . . . . . . 74

7.1 Main zone temperature float period on July $31 \ldots \ldots$. . . . . . . 99

7.2 Percentage of time that the blinds are closed with cach actuating blind variant . . . . . . . . . . . . . . . . . . 102

7.3 Synthesis summary of variant results . . . . . . . . . . . . 114

8.1 Six combination models . . . . . . . . . . . . . . . . . . . . . 119

A.1 Extcrior wall materials and constructions . . . . . . . . . . . . . . 144

A.2 Main floor / basement ceiling materials and constructions . . . . . . . 144

A.3 Main cciling materials and constructions . . . . . . . . . . . . 144

A.4 Basement floor materials and constructions . . . . . . . . . . . . 145

A.5 Basement wall materials and constructions . . . . . . . . . . . 145

A.6 Roof materials and constructions . . . . . . . . . . . . 145

A.7 Window frame materials and constructions . . . . . . . . . . 146

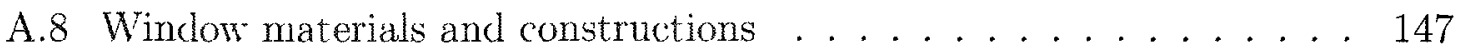




\section{List of Figures}

1.1 Power generation by type on August $1,2006[1] \ldots \ldots$

1.2 Average electricity use from a sample of houses in Southern Ontario [2] 4

1.3 Typical single family house design used as the base-case . . . . . . . . 9

2.1 A one-dimensional representation of a control volume wit hin an opaque surface . . . . . . . . . . . . . . . . 15

2.2 An internal surface node and its control volume . . . . . . . . . . 16

2.3 "Jump resistor" long-wave radiation connections between non-adjacent nodes in a CFC window . . . . . . . . . . . . . . 21

2.4 The visual representation of the projected image of shading and inso-

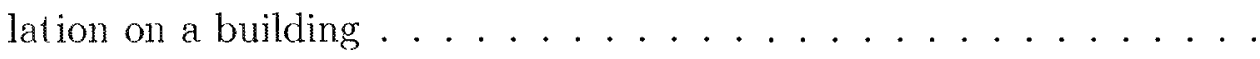

2.5 Set-up of an air-flow network representing natural ventilation in a single

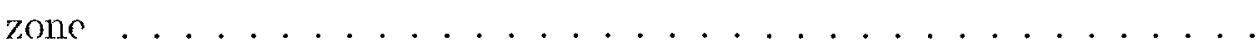

3.1 Thermal brirlging through the exterior wall of the building, shown as a top-vicw of the wall construction . . . . . . . . . . 31

3.2 Schematic of the basement insulation placement . . . . . . . . . 32

3.3 Wireframe base case in ESP-r . . . . . . . . . . . . 37

4.1 Elcetricity consumption on August 5, 2009 from an Ottawa house and the provincial grid demand . . . . . . . . . . . . . 39

4.2 Field measured time-of-use of the dishwasher . . . . . . . . . . . . 42

1.3 Dishwasher usage from ficld measured data, and the representative profile 44

4.4 Dryer usage from field measured data, and the representative profile . 46

4.5 Clothes-washing machine usage from field measured data, and the representative profile . . . . . . . . . . . . . 48

4.6 Field measured time-of-use of the stove . . . . . . . . . . . . . 49

4.7 Stove usage from field measured data, and the representative profile . 51

4.8 Refrigerator usage from field measured data, and the representative

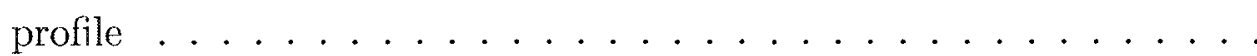


4.9 Freczer usage from ficld measured data, and the representative profile 54

4.10 Averaged profile of remaining plug loads . . . . . . . . . 55

4.11 Aggregation of appliances in the representative profile . . . . . . . 56

4.12 Representative profile of the occupant electricity usage . . . . . . 56

4.13 HVAC. non-HVAC and total clectricity consumption on July $31 \ldots 57$

$5.10 .5 \mathrm{~m}$ deep roof overhangs $\ldots \ldots \ldots \ldots \ldots$

$5.230 \mathrm{~cm}$ window awnings on the south-west building face . . . . . 60

5.3 Representation of the effect low-e coatings have in reducing entering long-wave solar radiation . . . . . . . . . . . . 62

5.4 Effectively closed venctian blinds at $80^{\circ} \ldots \ldots \ldots 63$

5.5 Shifting $50 \%$ of the south-west fenestration to the north-west and north-east sides . . . . . . . . . . . . . . . 65

5.6 Shifting $50 \%$ of the south-west fenestration to the north-west, northeast sides and south-east sides . . . . . . . . . . . . . 66

5.7 Thermal setpoints of the $\mathrm{PC} 1$ control strategy . . . . . . . . 68

5.8 Thermal setpoints of the $\mathrm{PC} 2$ control strategy . . . . . . . . . . . 69

5.9 Thermal setpoints of the PC3 control strategy . . . . . . . . . 70

5.10 Daily temporal variations of three pre-cooling strategies . . . . . . 76

6.1 Outdoor air drybulb temperature over each one day metric . . . . . 81

7.1 Summer weekday on-peak electricity consumption with architectural and vegetative shading variants $\ldots \ldots \ldots \ldots$

7.2 Solar gains entering the main zone on July 31, of the base case. $1 \mathrm{~m}$ roof overhangs and $50 \mathrm{~cm} \mathrm{STl}$ window awnings. . . . . . . . .

7.3 Summer weekday on-peak electricity consumption with modified window properties . . . . . . . . . . . . . . .

7.4 Solar gains entering on January 15 with the base case, the triple pane, reflective, low-e coated window variant and the $\rho=0.217$ reflective outer layer window variant $\ldots \ldots \ldots \ldots \ldots \ldots$

7.5 Summer weekday on-peak electricity consumption with venetian blind

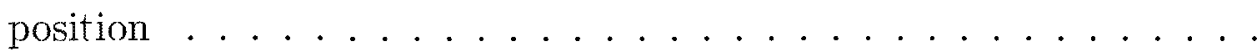

7.6 Summer weekday on-peak electricity consumption with fenestration alea and distribution . . . . . . . . . . . . . 92

7.7 Solar gains entering on July 31 in the base case and the variants that shift the fenestration distribution on the building . . . . . . . . 
7.8 Summer weckday on-pcak clectricity consumption with reflective shingles 95

7.9 Attic temperature on July 31 in the base case and reflective shingles variant . . . . . . . . . . . . . . . . 96

7.10 Summer weekday on-peak clectricity consumption with thermal mass

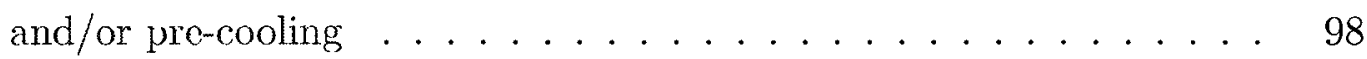

7.11 Main zone temperature variation from different pre-cooling schedules

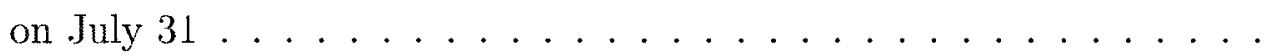

7.12 Summer weekday on-peak clectricity consumption with actuating venetian blinds . . . . . . . . . . . . . . . . . . . . 101

7.13 Summer-weckday on-peak electricity consumption with airconditioning cycling . . . . . . . . . . . . . . . . . . 103

7.14 Main temperature on July 31 in the base case and the air-conditioner cycling variant . . . . . . . . . . . . . . . . . . . 104

7.15 Summer weekday on-peak electricity consumption with changes to occupant behaviour . . . . . . . . . . . . . . 106

7.16 Summer weekday on-peak electricity consumption with use of outdoor air . . . . . . . . . . . . . . . . . . . 108

7.17 Electricity consumption on June 16 of the base case and open windows variant . . . . . . . . . . . . . . .

7.18 Summer weekday on-peak electricity consumption of the base case with the representative profile compared to real occupancy profiles from three Ottawa area houses . . . . . . . . . . . . . .

8.1 Summer weekday on-peak electricity consumption with a combination of effective variants . . . . . . . . . . . . . . . . 120

8.2 Electricity consumption on July 31 for Combinations 1, 2 and, 3 compared to the base . . . . . . . . . . . . . . 121

8.3 The main zone temperature on July 31 for Combinations 1,2 and, 3 compared to the base . . . . . . . . . . . . .

8.4 Electricity consumption on August 1 for Combinations 1.2 and, 3 comparcd to the base . . . . . . . . . . . . . . . . 123

9.1 Battery storage process . . . . . . . . . . . . . . . . . . . 127

9.2 PV production and household electricity demand on July $31 \ldots 129$

B.1 Annual clectricity consumption in G.J with various shading techniques 148

B.2 Annual natural gas consumption with various shading techniques . . 149 
B.3 Annual correlation between the residential consumption and provincial distribution . . . . . . . . . . . . . . . . . . 149

B.4 Summer weekday correlation between the residential consumption and provincial distribution . . . . . . . . . . . . . . 150

B.5 Annual electricity consumption in G.J with modified window properties 151

B.6 Annual natural gas consumption with modified window properties . . 152

B.7 Annual correlation between the residential consumption and provincial distribution with modified window propertics . . . . . . . . . 152

B.8 Summer weekday correlation betreen the residential consumption and provincial distribution with modificd window properties . . . . . . 153

B.9 Annual electricity consurnption in GJ with venetian blind position . . 154

B.10 Annual natural gas consumption with venetian blind position . . . . . 155

B.11 Annual correlation between the residential consumption and provincial distribution with venetian blind position . . . . . . . . 155

B.12 Sumner weekday correlation between the residential consumption and provincial distribution with venetian blind position . . . . . . 156

B.13 Annual electricity consumption in GJ with fenestration size and distribution . . . . . . . . . . . . . . . 157

B.14 Annual natural gas consumption with fenestration size and distribution 158

B.15 Annual correlation between the residential consumption and provincial distribution with fenestration size and distribution . . . . . . . 158

B.16 Summer weekday correlation between the residential consumption and provincial distribution with fenestration size and distribution . . . . 159

B.17 Annual elcctricity consumption in GJ with reflective shingles . . . . . 160

B.18 Annual natural gas consumption with reflective shingles . . . . . . . 161

B.19 Annual correlation between the residential consumption and provincial distribution with reflective shingles . . . . . . . . . . . . 161

B.20 Summer weekday correlation between the residential consumption and provincial distribution with reflective shingles . . . . . . . . . 162

B.21 Annual electricity consumption in GJ with thermal mass and/or precooling . . . . . . . . . . . . . . . . . 163

B.22 Anmual natural gas consumption with thermal mass and/or pre-cooling 164

B.23 Annual correlation between the residential consumption and provincial distribution with thermal mass and/or pre-cooling . . . . . . . . 164 
B.24 Summer weekday correlation between the residential consumption and provincial distribution with thermal mass and/or pre-cooling . . . . 165

B.25 Annual electricity consumption in GJ with actuating venetian blinds 166

B.26 Annual natural gas consumption with actuating renetian blinds . . . 167

B.27 Annual correlation between the residential consumption and provincial distribution with actuating venetian blinds . . . . . . . 167

B.28 Summer weckday correlation between the residential consumption and provincial distribution with actuating venetian blınds . . . . . . 168

B.29 Annual electricity consumption in GJ with air-conditioning cycling . 169

B.30 Annual natural gas consumption with air-conditioning cycling . . . 170

B.31 Annual correlation between the residential consumption and provincial distribution with air-conditioning cycling . . . . . . . . 170

B.32 Summer weekday correlation between the residential consumption and provincial distribution with air-conditioning cycling . . . . . . 171

B.33 Annual electricity consumption in G.J with changes to occupant behaviour . . . . . . . . . . . . . . . . . . 172

B.34 Annual natural gas consumption with changes to occupant behaviour 173

B.35 Annual correlation between the residential consunption and provincial distribution with changes to occupant behaviour . . . . . . 173

B.36 Summer weekday correlation between the residential consumption and provincial distribution with changes to occupant behaviour . . . . . 174

B.37 Annual clectricity consumption in GJ with use of outdoor air . . . 175

B.38 Annual natural gas consumption with use of outdoor air . . . . . 176

B.39 Annual correlation between the residential consumption and provincial distribution with use of outdoor arr . . . . . . . . 176

B.40 Summer weekday correlation between the residential consumption and provincial distribution with use of outdoor air . . . . . . . 177

B.41 Annual clectricity consumption in GJ with real occupancy schedules . 178

B.42 Annual natural gas consumption with real occupancy schedules . . . 179

B.43 Annual correlation between the residential consumption and provincial distribution with real occupancy schedules . . . . . . . . . 179

B.44 Summer weekday correlation between the residential consumption and provincial distribution with real occupancy schedules . . . . . . 180

B.45 Annual electricity consumption in GJ with a combination of variants 181 
B.46 Annual natural gas consumption with a combination of variants . . . 182

B.47 Annual correlation between the residential consumption and provincial distribution with a combination of variants . . . . . . . . . . . . 182

B.48 Summer weekday correlation between the residential consumption and provincial distribution with a combination of variants . . . . . . . 183

B.49 Electricity consumption on July 31 for Combinations 4.5 and, 6 compared to the base in kilojoules over each minute . . . . . . . . . 183

B.50 The main zone temperature on July 31 for Combinations 4,5 and, 6 compared to the base . . . . . . . . . . . . . . . 184

B.51 The main zone temperature on August 1 for Combinations 4, 5 and, 6 compared to the base ................... 184 


\section{Nomenclature}

\begin{tabular}{|c|c|c|}
\hline$A / C$ & Air-conditioner & \\
\hline$A C H$ & Volumetric flow rate of room air in air changes per hour & $a c / h$ \\
\hline$A F U E$ & Annual fuel utilization efficiency & \\
\hline$A I M-2$ & Alberta air infiltration model & \\
\hline$A F N$ & Air-flow network & \\
\hline$B P S$ & Building performance simulation & \\
\hline$C O P$ & Coefficient of performance & \\
\hline$c_{p}$ & Specific heat capacity & $J / k g K$ \\
\hline$C V$ & Control volume & \\
\hline$D H W$ & Domestic hot water & \\
\hline$D S M$ & Demand-side management & \\
\hline$G H G$ & Greenhouse gas & \\
\hline$H R V$ & Heat recovery ventilator & \\
\hline$H V A C$ & Heating, ventilation and air-conditioning & \\
\hline$I S H$ & Insolation and shading & \\
\hline IESO & Independent Electricity System Operator & \\
\hline Low $-e$ & Low-emissivity & \\
\hline$\dot{m}$ & Mass flow rate & $\mathrm{kg} / \mathrm{s}$ \\
\hline
\end{tabular}




$\begin{array}{lll}\text { OPA } & \text { Ontario Power Authority } & \\ P V & \text { Photovoltaic } & \\ P L R & \text { Part-load ratio } & \\ P L F & \text { Part-load factor } & W \\ q & \text { Heat flow } & W / \mathrm{m}^{2} \\ q^{\prime \prime} & \text { Heat flux } & W / \mathrm{m}^{3} \\ q^{\prime \prime \prime} & \text { Heat source } & \mathrm{m}^{2} \mathrm{~K} / \mathrm{W} \\ R S I & \text { Thermal resistance in SI units } & \\ S F H & \text { Single-family house } & \mathrm{K} \text { or }{ }^{\circ} \mathrm{C} \\ T & \text { Temperature } & \\ T O U & \text { Time-of-use } & W / \mathrm{m}^{2} \mathrm{~K} \\ U-v a l u e & \text { Overall heat transfer coefficient } & \\ Z E H & \text { Zero-energy house } & \\ Z P H & \text { Zero-peak energy house } & \end{array}$

Greek symbols 


\section{Chapter 1}

\section{Introduction}

Peak electrical consumption and its impact on the electrical grid is a growing concern in Ontario. Daily periods of high provincial demand make up the electrical peak, where the specific time of the peak differs based on the season. In the winter months, higher grid demand occurs in the morning and early evening - due to heating and lighting requirements. The summer peak occurs in the mid-afternoon when the outdoor temperature is the hottest, resulting in large cooling demand from both commercial and residential sectors. In 2002, a Hydro One report stated that $22 \%$ of summer peak demand is due to residential air-conditioning [3]. This clear demonstration of the residential impact on the electrical grid gives precedence to more research in mitigating household electricity loads.

Ontario experiences hot and humid summers, resulting in large residential space cooling use across the province. In 2007, four out of five Ontario households were equipped with an air-conditioning system [4]. Since then, the province has experienced continued high summer temperatures and high demand for electricity. In 2006, the grid experienced a record amount of electricity demand on August 1 of over 26,000 $\mathrm{MW}$, and temperatures in Southern Ontario above $30^{\circ} \mathrm{C}$ were recorded with higher humidity values increasing the perceived temperature [5], [6]. These statistics suggest a continued rise in the possession and use of residential space cooling. Modifying the design and operation of a house to minimize space cooling requirements during hours of peak electricity demand can alleviate grid-strain and associated greenhouse gas (GHG) emissions.

Current research into reducing the electricity demand in the residential sector is not as extensive as on the commercial level. Proper assessment of residential energy reduction can be done experimentally, using optimization tools or with building 
performance simulation.

Zero peak energy houses (ZPH) focus on reducing electricity consumption during peak hours [7], [8]. Combined with the rest of the grid, a ZPH has an averaging effect by reducing residential summer on-peak use when commercial demand is necessary, and shifting residential use to times where the rest of the grid demand is much lower. ZPHs have the benefit of not necessarily requiring as large renewable energy systems or large storage systems to meet their defined requirements. Achieving houses with low to zero peak electricity requirements through a combination of effective architectural, technological and occupant behaviour based techniques, combined with local energy generation using photovoltaic (PV) panels and energy storage using battery systems would be beneficial to the Ontario electricity market.

\subsection{The Ontario Electricity System}

The Ontario electricity supply is comprised of a base load, as well as a number of load following generation sources. The electricity demands above the base load are typically supplied by GHG intensive sources such as coal and simple-cycle gas turbines [1]. The main source of electricity in Ontario is nuclear, which meets the provinces base load requirements providing up to $11446 \mathrm{MW}$ of power [5]. With hourly demands changing over the course of the day - other generation systems are used to follow the fluctuating demands. The demand on August 1, 2006, which has the recorded high for provincial demand, is shown in Figure 1.1 which categorizes the electricity distribution by generation source. The load following capabilities of the GHG intensive sources such as coal and gas can be seen in Figure 1.1.

\subsubsection{Electricity Consumption at the Residential Level in Ontario}

The residential sector accounts for $17 \%$ of the secondary energy use in Canada and also accounts for $15 \%$ of Canada's GHG emissions [9]. Single family detached houses are the largest contributor - accounting for $59 \%$ of the residential stock [4] and contributing $11 \%$ of Canada's secondary energy use [9]. These statistics demonstrate the need to tackle residential energy consumption, specifically in single family homes. Even though space-cooling accounts for only $3 \%$ of Canadian residential energy use 


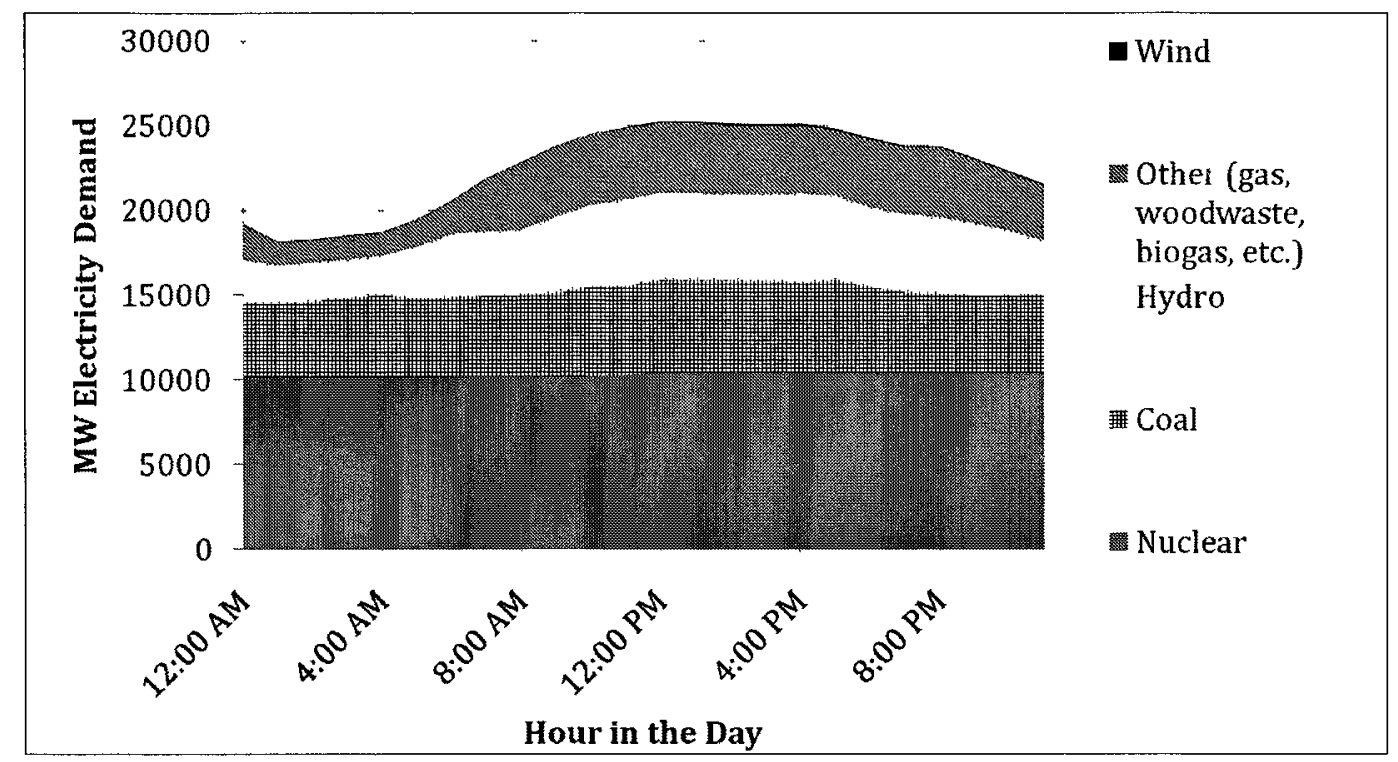

Figure 1.1: Power generation by type on August 1, 2006 [1]

[9], 28\% of electricity consumption in Ontario is due to the residential sector [10]. Larger houses and an increasing penetration rate of air-conditioning systems in Ontario make space-cooling an energy issue. The amount of occupied floor space with space cooling rose from $27 \%$ to $44 \%$ between 1990 and 2005 [9] which will further increase the magnitude of required space cooling province-wide. Ontario houses rely more heavily on electricity in the summer months for thermal comfort than in the winter when houses are typically heated with natural gas. Figure 1.2 shows the average hourly electricity use from a sample of up to 1300 houses in Southern Ontario [2]. The peaking periods in this figure occur during the warmer months between May 1 and October 31, demonstrating household electricity use for space cooling. 


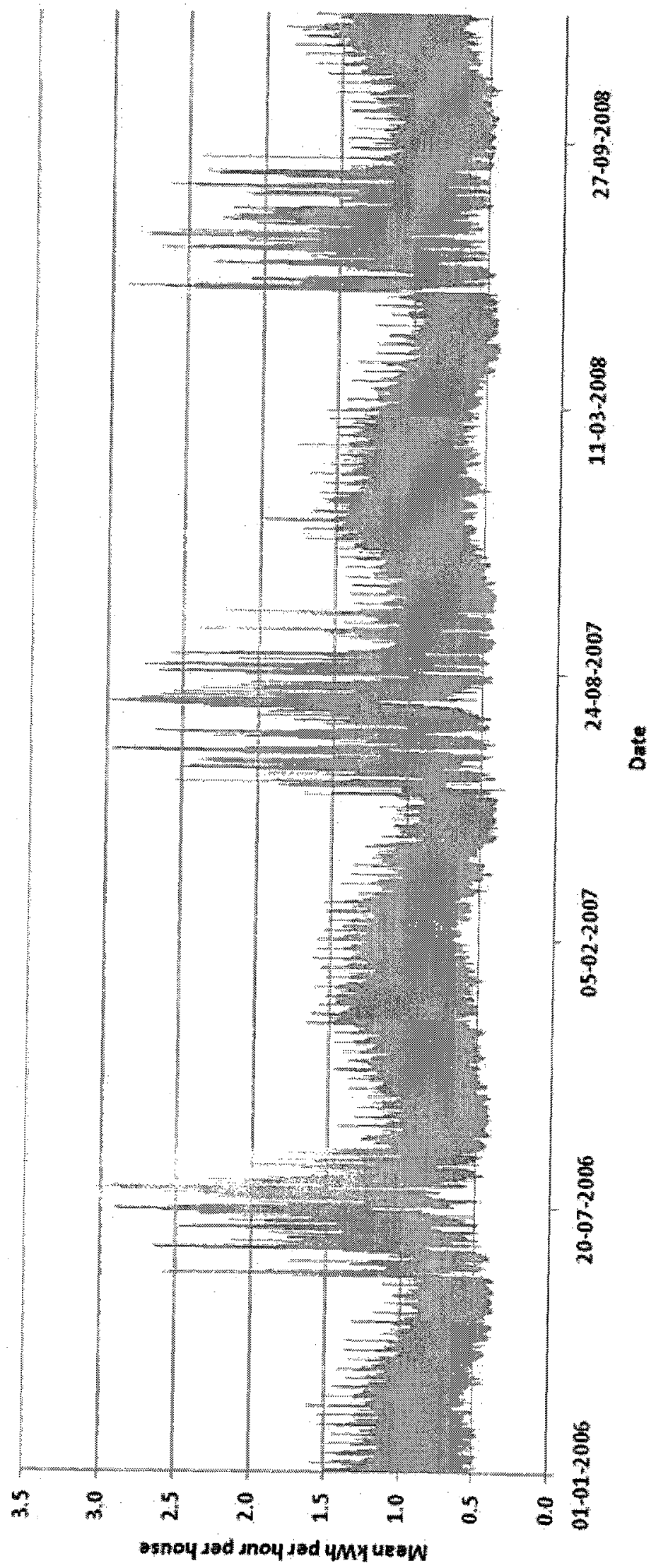

Figure 1.2: Average electricity use from a sample of houses in Southern Ontario [2] 
Several demand-side management (DSM) programs have been introduced in Ontario to reduce residential energy consumption on-peak. A time-of-use (TOU) pricing scheme, implemented across most of the province by 2011, increases the cost of using electricity on-peak (11:00 am to 5:00 pm local time) to almost double that of electricity off-peak (7:00 pm to 7:00 am local time) during the summer from May 1 to October 31 [11]. This offers homeowners an economic incentive to offset their on-peak electricity usage.

Another set of Ontario DSM programs involves actively controlling and reducing the air-conditioner's cycling time through either the Peaksaver or PowerShift program. These programs are voluntary, and allow the local electricity provider to cycle the airconditioner on and off at 15 minute intervals during specific periods of on-peak hours. Cycling the air-conditioner reduces electricity consumption due to space-cooling and minimizes the occurrence of simultaneous grid demand on the residential level by evenly redistributing the space-cooling demands of a number of houses. The Peaksaver program is the less stringent of the two, where the cycling is based on grid demand and/or high temperature. Peaksaver can only last up to 4 hours for a total of 40 aggregate hours over the year [12]. The PowerShift program cycles the air-conditioner in 15 minute intervals on-peak anytime the temperature outside rises above $27^{\circ} \mathrm{C}$ or the humidex is above $30^{\circ} \mathrm{C}$, a calculated value that represents the sensed temperature of the air to include the effects of humidity. The PowerShift program is still only valid during summer on-peak hours between May 1 and October 31.

A study on the effects of DSM methods in North America by Newsham and Bowker [13], demonstrates the potential of on-peak electricity reduction depending on the DSM program. The review by Newsham and Bowker indicates that DSM methods are helpful in alleviating large on-peak electricity usage by $5 \%$ with TOU pricing, and at least $30 \%$ with critical-peak pricing programs (very high on-peak electricity price on specific 'critical' days). Even with the potential for energy savings, DSM methods are relatively dependent on occupant behaviour. For instance, the Peaksaver and PowerShift have an opt-out option for a particular amount of time specified by the occupant [12]. If residents opt-out, or override the DSM methods, the on-peak electricity benefits are lost. Residential space cooling depends on the outdoor temperature, and the need for cooling comfort on extremely hot days can override any cost benefits of reducing electricity consumption with TOU pricing. 


\subsection{Energy Efficient Housing}

Beyond DSM, there are several methods currently used to reduce the energy demand from the residential sector. One approach is the use of a rating system for design and construction such as the LEED for Homes program, offered through the Canada Green Building Council [14]. Another is R-2000, offered through Natural Resources Canada [15]. Such programs require mandatory efficiency levels, and some allow for higher achievement levels. These systems aim to have the house perform better through efficient design and construction practises, but neither program is associated with the house during its operation.

In Ontario, government incentives are offered to promote energy efficient design and use of houses. The Ontario Power Authority (OPA) offers a feed-in tariff program such that the home-owner is paid a higher price for power produced locally, such as PV power, and sent back to the grid, than power supplied to the house from the grid [16].

The design of low or zero energy houses (ZEH) require zero net annual energy consumption [17]. In Canada, the Canadian Mortgage and Housing Corporation has launched the EQuilibrium Initiative to build 12 net-zero demonstration homes across the country [18]. ZEH and zero energy building (ZEB) projects can be found internationally, such as a community of near-ZEHs in Lenoir City, Tennessee [19], a ZEH test house in Lakeland, Florida [20], and a larger ZEB office in Singapore [21]. Achieving a ZEH includes incorporating energy efficient design techniques, but also the use of a renewable energy source (sun, wind or biomass), and potentially an energy storage system. ZEHs can be grid-connected such that they draw energy directly from the grid when needed but also feed excess energy from a local renewable energy source back to the grid, or they can be off-grid which requires a local storage system of the excess energy production. A ZEH will often have lower electricity consumption on-peak [19], but is not specifically designed to reach a zero peak. Other energy efficient housing options include ultra low-energy houses following the Passivhaus standards [22], or sustainable communities like the BedZED project in England which significantly reduces heating and cooling demands, as well as accounting for carbon dioxide emissions [23]. 


\subsubsection{Zero Energy Houses Compared to Zero Peak Houses}

Southern Ontario can see large temperature fluctuations on an annual basis, sometimes as much as $60^{\circ} \mathrm{C}$. Designing to meet these conditions in a zero energy setting can be difficult. Typical ZEHs, such as the Inspiration Minto Home built in Ontario, are designed to meet heating requirements by incorporating thermal mass in the floor, triple pane windows and significant amounts of insulation. The Inspiration Minto Home does not have any space-cooling allowance, instead opting for use of natural ventilation [24]. Hot days in southern Ontario typically coincide with days of high humidity. On August 1, 2006; overnight temperatures did not drop below $27^{\circ} \mathrm{C}$ in Toronto, Ontario [25]. Natural ventilation does not cool the house if the outdoor air temperature is above the indoor temperature or when overnight humidity levels maintain a warmer sensed temperature (combined heat and humidity). A ZEH without space cooling capacity can result in uncomfortable thermal conditions. Focusing solely on the peak hours allows for the use of an air-conditioning device while reducing the load on the grid during hours of high demand. Having a functional ZPH design for a Canadian climate provides an energy-efficient, cost-effective method to reduce GHG emissions and high residential consumption. The ZPH design focuses on managing the problem directly by reducing the electricity consumption during high use times.

The basis of this research is to achieve a ZPH for electricity consumption during the summer peak, 11:00 am to 5:00 pm local time. Achieving a $\mathrm{ZPH}$ requires a combination of design and behavioural changes in the house design and daily operation. It is important to be aware of the effect strategies used to attain a ZPH have on the on-peak electricity demand, as well as mid-peak and off-peak demands. It would be counter-productive to off-set all the peak electricity draw to a shoulder period (just before the peak hours, or just after), such that the peak is essentially shifted. This has the potential to shift the problem and not alleviate it.

\subsection{Techniques to Achieve a $\mathrm{ZPH}$}

Four broad categories encompass the design of a ZPH: design solutions; technological solutions; behavioural solutions; and local generation and storage.

Design solutions focus on passive changes to the house - altering the heat transfer and solar gains into the building envelope to reduce summer cooling requirements 
during peak hours. These strategies include shading with roof overhangs or window awnings, thermal mass, and altering the reflectivities of windows and shingles. Determining the electricity saving capabilities of passive design changes creates a basis for reduction requirements.

Technological solutions investigate household use of electricity through spacecooling and appliances. Some of these strategies can be coupled with the design options - such as space-cooling and thermal mass capabilities to offset the use of an air-conditioner to non-peak hours. Technological strategies can also incorporate window shading controls and controlled shifting of appliance-use. Increasing the efficiencies of household appliances will also affect on-peak electricity requirements, as will increasing the coefficient of performance (COP) of the air-conditioning system.

Behavioural solutions can be difficult to simulate and control as they focus on occupant behaviours and responses. Several studies have been done in Canada and internationally on the response of house occupants to feedback on their electricity usage, as well as incentives to offset electricity usage and time-of-use (TOU) pricing [26].The Ontario Peaksaver or PowerShift program is another method to reduce spacecooling requirements by allowing cycling control of residential air-conditioners over short periods of time in the summer.

With the implementation and modification of combinations of effective strategies, the consumption of electricity on-peak can be significantly reduced [19], [20]. With reduced on-peak demand, the effectiveness of a PV and/or battery system can be assessed to offset the remaining on-peak household load. This final technique of local power generation and storage has the potential to reduce the peak electricity requirements of a house to near zero [8], [27].

\subsection{Typical Canadian New Construction Single Family Housing}

With single family houses (SFHs) representing the largest portion of Canadian housing, focus is made on optimizing the design of a typical SFH. Ontario's population is centred in the southern part of the province, with the largest population density in Toronto, which coincidently experiences warmer summer temperatures. A four bedroom, SFH located in Toronto is used as the base case. The house design specifications were supplied by a local building company, and the house is a typical SFH, 
designed for the living comfort of its occupants. The house is designed to meet $\mathrm{R}$ 2000 standards - performance based standards. Currently, an R-2000 house will use approximately $30 \%$ less energy than one that is not built to R-2000 standards [15].

The house used for the base case is shown in Figure 1.3. The original design includes an unconditioned attic, basement and garage, and a conditioned main zone representing two-stories of living space.

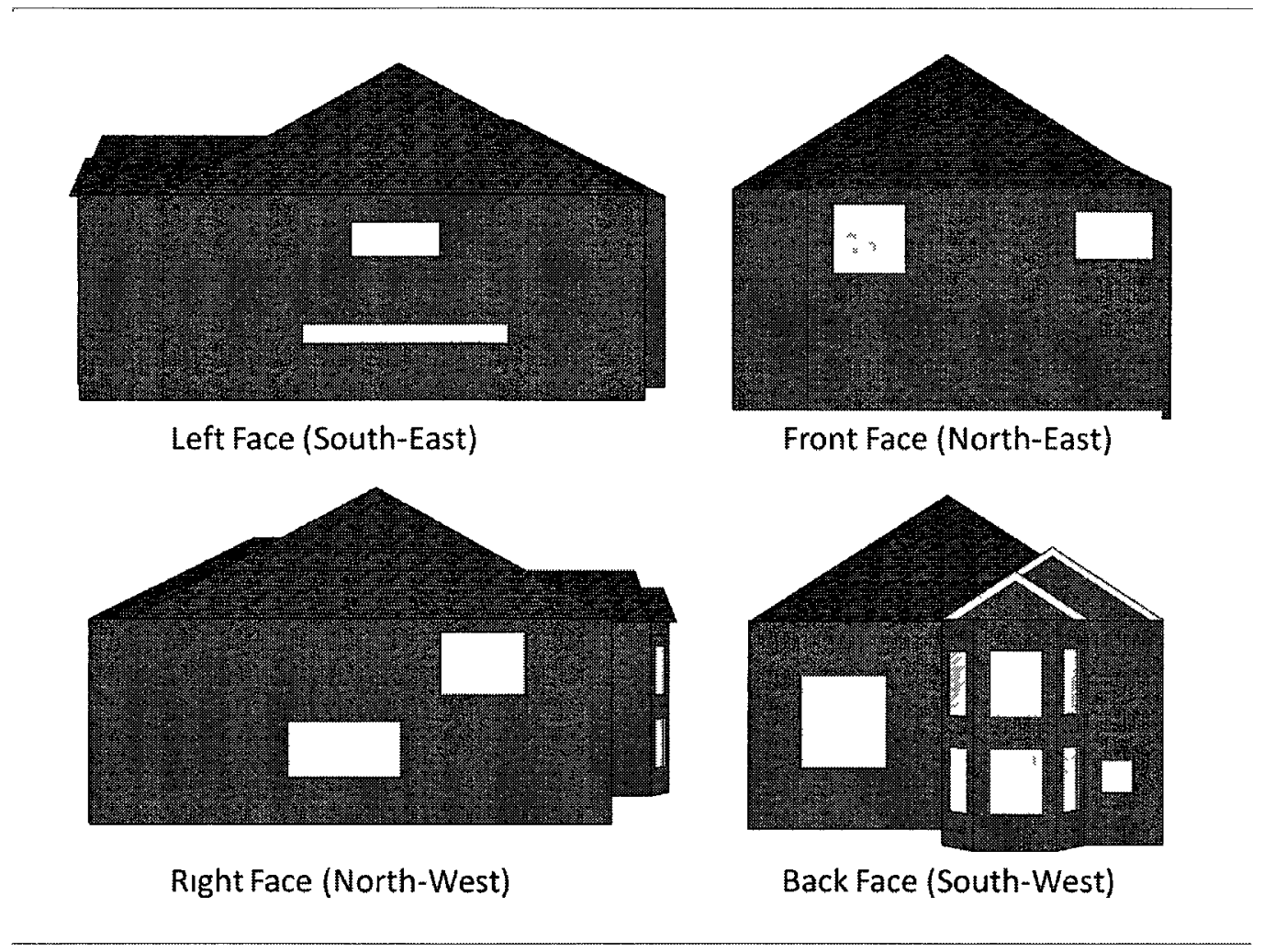

Figure 1.3: Typical single family house design used as the base-case

It is important to detail the base case approprately to mimic a typical SFH. This requires proper material and construction specifications, as well as heating, ventilation and air-conditioning (HVAC) information and occupant behaviour in electrical usage. The design and assumptions made for the base-case are described in detail in Chapter 3 and Chapter 4. 


\subsection{Research Process}

To properly modify a house design for space cooling conditions in a Southern Ontario climate, each variation must be properly compared to a datum. The datum in this research is the base case shown in Figure 1.3. Variations in design, technology, and behaviour can be assessed in direct comparison to the base case to properly determine their individual effect. Determining a combination of effective variations to achieve a zero peak electricity house requires an analysis of the results of each variant. There are many different ways to analyze each result, and require a focus beyond the sole reduction of electricity consumption during the peak hours. Any energy offset from electricity to natural gas for heating should be noted and taken into account. Choosing metrics that most accurately demonstrate the annual heating and cooling effects of each variant, as well as its peak reducing abilities is a critical part of the analysis. The metrics must properly identify how effective each measure is at achieving the overall goal. The metrics chosen and the rationale behind each one are explained in depth in Chapter 6.

\subsection{Research Objectives}

The research objectives are to determine a combination of design, technology and behavioural solutions with local generation and storage to achieve a ZPH. These objectives can be achieved through use of a building performance simulation software program to analyze the heat transfer and thermodynamic effects of each variant simulated. As such, the results of each simulation are compared using a set of metrics to properly analyze the magnitude of the effect of each variant and relative importance.

\subsection{Thesis Outline}

The thesis is organized as follows:

- Chapter 2 describes the building performance simulation (BPS) tool, ESP-r, used for simulating the base case and all variants.

- Chapter 3 details the ESP-r model of the base case as built from the specifications, and outlines the assumptions made. 
- Chapter 4 explains the specific occupant schedule derived for the purposes of this thesis, outlining the importance of choosing the schedule and describes the use of real data collected to create an aggregate daily electrical use profile.

- Chapter 5 describes the variant cases of the base case, subdivided into four categories of variations: building envelope, technological, behavioural and, local generation and storage.

- Chapter 6 describes the specific metrics used to quantify the simulation results.

- Chapter 7 examines the results of each variant.

- Chapter 8 exploits the most effective variants to create combinations to achieve low peak demand.

- Chapter 9 describes the implementation of a local generation and storage system to achieve a $\mathrm{ZPH}$.

- Chapter 10 concludes the research and offers recommendations for further work in this field. 


\section{Chapter 2}

\section{Building Performance Simulation and ESP-r}

Accurately modelling and simulating the behaviour of a house in a specific climate over a set time period requires a computer program with robust capabilities. There are several available building performance simulation (BPS) tools and packages [28], each of which are adapted to model various aspects of building performance (i.e. lighting, thermal, moisture, etc.). These programs approach simulations using a variety of methods that depend on factors such as the intended audience of the program, ease of implementation and required result time. In general, BPS is a computerized imitation of one or more areas of building operation and performance. Areas that are typically modelled include the thermal domain, ventilation and infiltration, lighting, etc. BPS can be used to estimate the behaviour of a house and can be very useful in research to determine the feasibility of certain design changes in a building. The program chosen to achieve results in the current work is ESP-r. This program is an opensource software, but is also extensively validated in international testing projects [29]. The following section briefly outlines the equations and components that affect the calculations required, the different methods used in modelling, and finally in more detail - the methods that ESP-r uses to perform building performance simulation.

\subsection{Methods of Modelling}

There are several approaches to estimating the response of a building to daily, seasonal or annual thermal variations. These methods vary significantly in the level of accuracy used to predict heat transfer in a building, the assumptions made, and the time 
required to solve the equations. On a very basic level, with set boundary conditions, different methods of solving the system should yield very similar heat transfers results. Heat transfer can be estimated using the overall heat transfer coefficient and estimates of the annual weather conditions. More complex methods use a control-volume heatbalance approach, which reduces the number of assumptions made and conducts building performance simulations at a complex level.

\subsection{Modelling in ESP-r}

ESP-r discretizes the building envelope into control volumes, and forms a system of heat balance equations based on the semi-implicit Crank Nicholson formulation, described in more detail within this section. This system of equations is formed and simultaneously solved at each timestep. The system of equations developed can become very complex when considering the various heat transfer modes of conduction, convection and radiation. Furthermore, these heat transfer effects occur between different states (gas to solid between room and walls, etc.) and different levels of opacity (opaque walls vs. transparent windows etc.). The building can also undergo conditioning from an HVAC system affecting the internal temperatures, as well as interact with the external environment. The following section details ESP-r's solving methods as explained in Clarke, 2001 [30]. Should more detail be needed, the reader is directed there.

To set up the heat balance equations, the building must be discretized into finite control volumes (CVs) representing regions with similar properties. These regions make up layers of opaque or transparent surfaces, air-spaces etc. Each layer in a construction contains three nodes, an internal node and a node at the each interface layer. A wall construction with ' $x$ ' number of layers will have ' $2 x+1$ ' nodes. Air regions with similar thermal behaviour, called zones, are represented by a single node. A space that is conditioned should be considered a separate zone from one that is not. Once the building has been discretized, a heat balance equation is set up for each node, expressing all the thermal interactions of the node with its neighbouring nodes. Finally, the system is solved to predict each nodal temperature and node-to-node heat flows at the given timestep.

The heat balance equations developed are discrete and make use of finite differences to replace the derivatives in the non-linear heat equations. These equations 
balance the heat transfer and sources of heat entering and leaving the CV.

When looking at an intra-constructional node, the following relation demonstrates the heat balance on the CV.

$$
\left\{\begin{array}{c}
\text { net heat generation } \\
\text { rate within } C V
\end{array}\right\}+\left\{\begin{array}{c}
\text { net heat conduction } \\
\text { rate into } C V
\end{array}\right\}=\left\{\begin{array}{c}
\text { storage of } \\
\text { heat in } C V
\end{array}\right\}
$$

In equation 2.1, the storage term represents the rate of change of the control volume's temperature, while the heat generation term represents heat addition to that node. ESP-r assumes one dimensional conduction for the building envelope, shown in Equation 2.2, a mathematical representation of Equation 2.1. The $q_{p l a n t}^{\prime \prime \prime}$ term in this case would represent radiant heating into the surface in question.

$$
q_{p l a n t}^{\prime \prime \prime}-\frac{d\left(q_{x}^{\prime \prime}\right)}{d(x)}=\rho c_{p} \frac{d T}{d t}
$$

Where $c_{p}$ is the specific heat capacity in $\mathrm{J} / \mathrm{kgK}$

$\rho$ is the density in $\mathrm{kg} / \mathrm{m}^{3}$

$d T / d t$ is the rate of change of temperature through the material

$q_{x}^{\prime \prime}$ represents the heat flux to the $\mathrm{CV}$, in the $\mathrm{x}$ direction, in $\mathrm{W} / \mathrm{m}^{2}$

and $q_{\text {plant }}^{\prime \prime \prime}$ is the heat injection from the plant source in $\mathrm{W} / \mathrm{m}^{3}$

The equation shown in Equation 2.2 can be approximated to a more useful form by integrating over the CV in question. The temperature-time derivative can also be approximated using a backwards difference scheme. The approximation around an intra-constructional node is based on the internal node ' $n$ ' in Figure 2.1. The two nodes on either side of node ' $n$ ' represent the flow path between the nodes in the building. A node in the middle of an opaque surface only interacts with its neighbouring nodes, following the one-dimensional heat flow through the wall. The air-point node, in the middle of a zone, interacts with the nodes from all the surrounding walls and windows and any effects associated with them.

The mathematical approximation of Equation2.2 is,

$$
\left(\rho c_{p} \Delta x \Delta y \Delta z\right) \frac{T_{n}^{t+\Delta t}-T_{n}^{t}}{\Delta t}=q_{n-1 \rightarrow n}-q_{n \rightarrow n+1}+q_{p l a n t}
$$




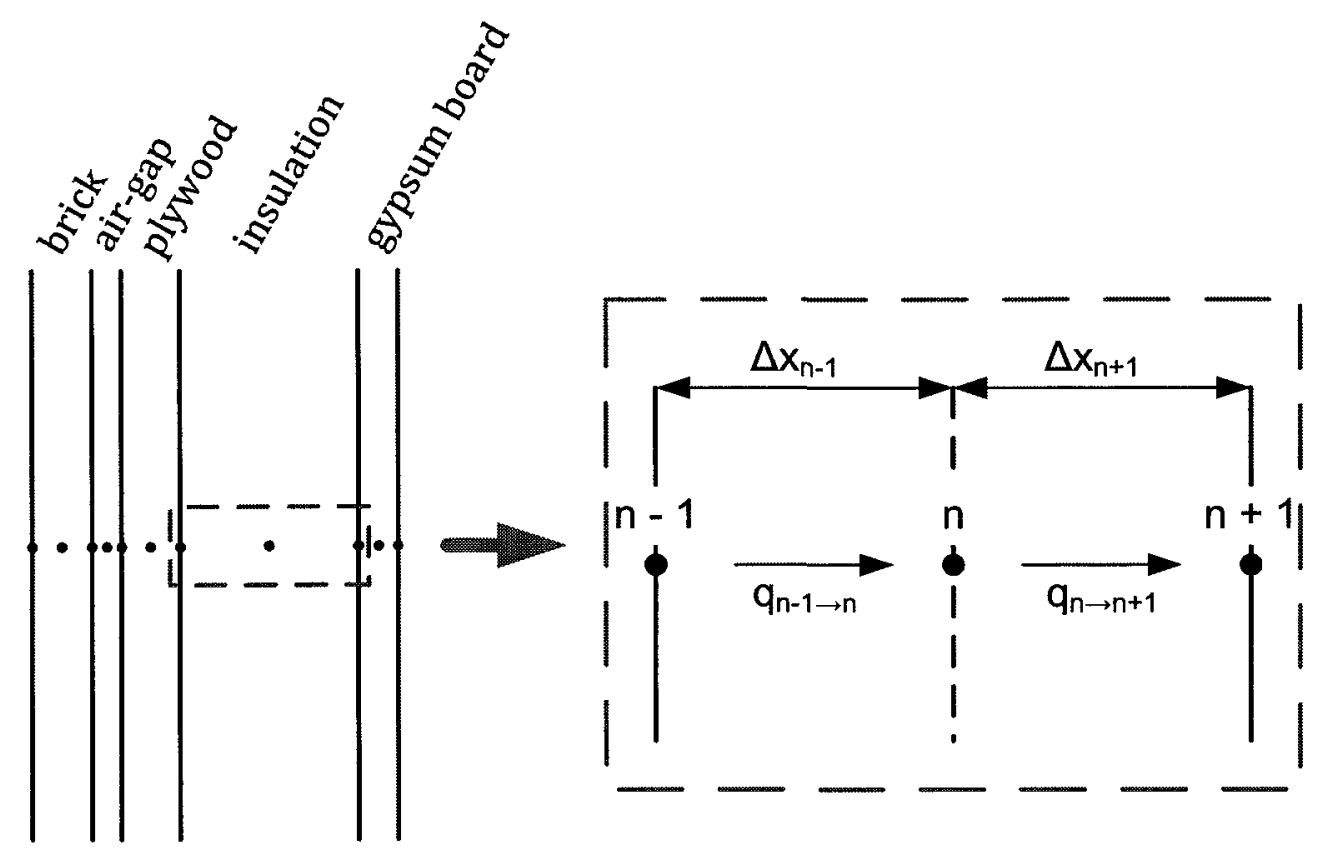

Figure 2.1: A one-dimensional representation of a control volume within an opaque surface

The heat flux terms $\left(q_{n-1 \rightarrow n}\right.$ and $\left.q_{n \rightarrow n+1}\right)$ are represented with heat transfer equations relating the temperature difference between the nodes with the thermal conductivity of the material, shown in Equation 2.4 for the heat flux between the ' $n$ ' and ' $n-1$ ' nodes, in its explicit form. The explicit form approximates the equation using present time-row temperatures. Conversely, an implicit scheme uses future time-row temperatures. This is shown in Equation 2.5 between nodes ' $n$ ' and ' $n-1$ '.

$$
\begin{gathered}
q_{n-1 \rightarrow n} \approx \frac{k_{n-1} \Delta y \Delta z}{\Delta x_{n-1}}\left(T_{n-1}^{t}-T_{n}^{t}\right) \\
q_{n-1 \rightarrow n} \approx \frac{k_{n-1} \Delta y \Delta z}{\Delta x_{n-1}}\left(T_{n-1}^{t+\Delta t}-T_{n}^{t+\Delta t}\right)
\end{gathered}
$$

The heat flux representation for internal surface nodes varies from Equations 2.4 and 2.5 as the node in question now faces multiple forms of excitation from the zone. A surface node is shown in Figure 2.2, with additional effects due to solar radiation $\left(q_{\text {solar }}\right)$, radiant energy from casual sources within the zone $\left(q_{\text {casual }}\right)$, and longwave radiation from other surfaces $\left(q_{r a d, s \rightarrow n}\right)$. A surface node also undergoes heat transfer 


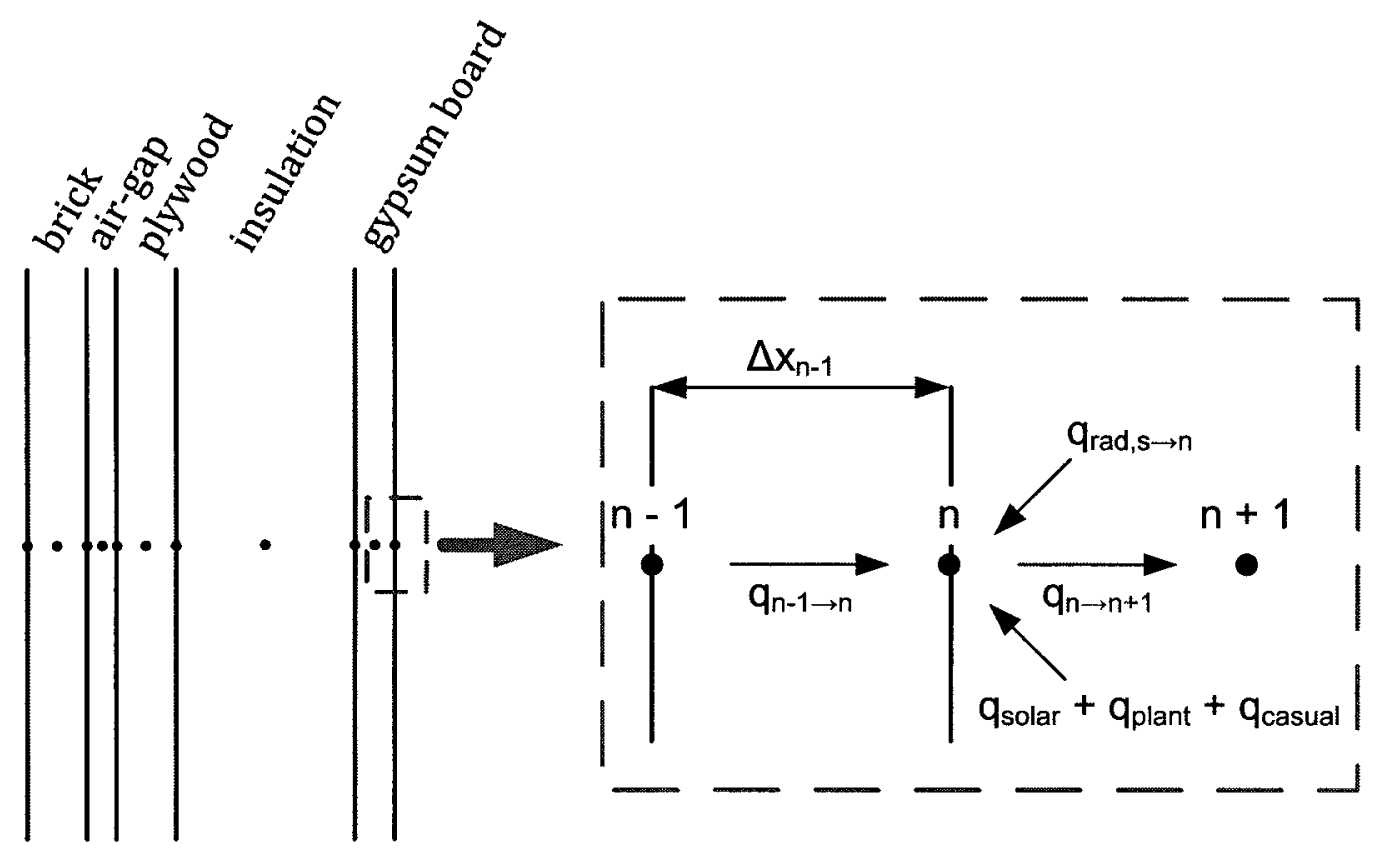

Figure 2.2: An internal surface node and its control volume

via convection with the zone air.

The explicit and implicit versions of the conduction heat transfer component of the heat balance on an internal surface node are the same as in Equations 2.4 and 2.5 between the surface node and the ' $n-1$ ' node within the wall. Conduction only occurs from one direction for the wall surface node. Casual gains are known quantities described in the input files, while solar gains and plant components are calculated on a timestep basis. The longwave radiation component is a summation of the effects from each surface seen by the node in question - making use of calculated view-factors. Finally, the convection heat transfer is calculated using the surface convection coefficient calculated at each timestep.

Air-point nodes differ from solid surface nodes as the zone air-point must take into consideration air flow from adjacent zones, as well as infiltration from the outdoors. The air-point nodes do not have any conductive or radiative heat transfer effects, but an advection term accounts for zone-to-zone ventilation and outdoor air infiltration. 
The heat balance for the zone air point is shown in Equation 2.6

$$
\left\{\begin{array}{c}
\text { net heat generation } \\
\text { rate within } C V
\end{array}\right\}+\left\{\begin{array}{c}
\text { advection } \\
\text { into } C V
\end{array}\right\}+\left\{\begin{array}{c}
\text { net heat convection } \\
\text { rate into } C V
\end{array}\right\}=\left\{\begin{array}{c}
\text { storage of } \\
\text { heat in } C V
\end{array}\right\}
$$

The advection term is similarly derived for both situations (zone-to-zone air flow, or outdoor air infiltration) and the explicitly derived equation is shown in Equation 2.7 .

$$
\left\{\begin{array}{l}
\text { advection } \\
\text { into zone }
\end{array}\right\}=\sum_{J=1}^{M} \dot{m}_{J \rightarrow I}^{t} c_{p}\left(T_{J}^{t}-T_{I}^{t}\right)
$$

Where $\dot{m}_{J \rightarrow I}^{t}$ is the mass flow rate in $\mathrm{kg} / \mathrm{s}$

$I$ is the current zone

$J$ is the interacting zone or outdoor air

Equation 2.7 can be applied to zone-to-zone air flow where $\mathrm{M}$ is the number of zones ventilating to the current zone and $J$ increases from one to $M$ representing each advection term. For outdoor air infiltration, $M=1$ and the $\mathrm{J}$ term is the outdoor air infiltration. The mass flow term $(\dot{m})$ depends on the user input, and can be described either through a constant value, scheduled values or a more complex control fluctuating the flow rate based on a wind speed, zone temperature etc. The method of calculating air-flow in the zone is described in detail in section 2.7.2.

The developed equations can be formed fully explicitly, fully implicitly, or with a weighting of each. The default in ESP-r is to equally weight both relations for the combined stability and accuracy. This form of weighting is also know as the Crank-Nicholson difference formulation.

Simultaneously solving the derived equations requires the manipulation of a large, sparse matrix of future timestep (unknown) nodal values - such as temperatures, plant injection requirements, etc. The present timestep (known) values make up a second matrix. The final heat balance equation made from these two matrices and their corresponding coefficients is concisely shown in equation 2.8 .

$$
A \theta^{t+\Delta t}=B \theta^{t}+C
$$


Where $A$ and $B$ represent the coefficient matrices for the future and present timesteps respectively.

$\theta^{t+\Delta t}$ and $\theta^{t}$ are the temperature matrices at the future and present timesteps respectively.

$C$ represents the known boundary terms.

Since the present timestep values and the boundary terms are always known, the right hand terms in Equation 2.8 can be combined into one matrix $Z$ where $B \theta^{t}+C=Z$ simplifying the expression to,

$$
A \theta^{t+\Delta t}=Z
$$

Solving for the unknown future timesteps $\theta^{t+\Delta t}$ in equation 2.9 can be solved as shown in Equation 2.10.

$$
\theta^{t+\Delta t}=A^{-1} Z
$$

The matrices for both present and future timesteps can become large with a complex, multi-zoned, building. ESP-r uses a partitioning method to directly solve Equation 2.9. Since the matrix $A$ is sparse and somewhat symmetrical, it can be partitioned into smaller sub-matrices that can be processed independently. This method of solving decreases the run-time for simulations, but introduces simplifying assumptions illustrated in Section 2.5.

\subsection{Material and Construction Specifications}

ESP-r maintains databases of materials, and typical building constructions that can be expanded and modified based on the needs of the project. These databases specify whether a material is opaque or transparent, as well as specific material properties. Constructions combine materials into layers that define the physical aspect of the building. These constructions extend to describe materials associated with active building elements - elements that alter their energy flows based on external excitations [31], such as PV panels for local energy generation. These special materials are initially described with the materials and constructions databases, but require additional inputs in the ESP-r to specify data on the function and performance of 
the element. Special materials use previous nodal values to modify future timestep nodal coefficients, and are therefore one timestep behind [31].

\subsection{External Radiation Processes}

The methods of estimating and treating solar shortwave radiation and external longwave radiation in the ESP-r environment are important for both opaque and transparent surfaces. The sun's position relative to a building is dependent on the altitude of the site, as well as the latitude, solar declination and time of day. Solar radiation can be considered to have three components: direct beam, ground reflected and sky diffuse. ESP-r requires the direct normal solar intensity and the diffuse solar on the horizontal as inputs for the treatment of solar radiation. The weather data used for this project is from the Canadian Weather Energy and Engineering data sets (CWEEDS) [25].

Shortwave flux on the external opaque surfaces of a building are partly reflected and absorbed, depending on the properties of the material. The absorbed portion will heat up the node in question and either conduct into the layer or re-release back to the external environment. Transparent surfaces can reflect and absorb, but also transmit incident solar radiation. Transmitted solar radiation causes internal surface insolation (discussed in Section 2.6).

Longwave radiation exchange is based on a material's ability to absorb and reflect incoming longwave radiation and subsequently emit longwave radiation back to its surrounding environment. The amount of radiation a surface receives from another depends on the view factor between the two surfaces, which is geometry dependent. As a default, ESP-r area-weights the view factors within the zone. A more accurate raytracing method of determining the view factors between internal surfaces is available, but was not used in the current simulations.

\subsection{Fenestration}

There are two ways of treating windows in ESP-r, either using the transparent multi-layer constructions (TMC) type, or using the complex fenestration construction (CFC) type. The TMC type for windows uses optical data for each glazing layer at 
the normal incidence angle and 5 other angles to describe the transmission, absorption and reflection at varying angles of incoming solar radiation. There are several pre-described window sets in ESP-r, but the creation of a new TMC construction can be done by importing data from an external program such as WINDOW 5 [32]. The TMC functionality in ESP-r lumps together the convective and radiative heat transfer within the gas gap of the glazing construction in order to minimize the complexity of the system and to comply with the current method of matrix solving in ESP-r (see Section 2.2). Furthermore, the TMC model in ESP-r does not easily allow for complex window types with different gap gases or coatings that reduce heat absorption using a low-emissivity (low-e) coating. Complex window constructions can be described with TMCs if the overall heat transfer coefficient (U-value) of the window is known. An iterative process of changing gas or glass properties is used to match the known U-value to the one calculated in ESP-r. Using blinds for shading is also limited with the TMC type, which only allows for the use of flat shades. Approximations can be made for slat-type blinds, but they do not account for any scattering due to angled blinds, nor does it account for interactions through the blinds (via convection or radiation).

The CFC type, used for the simulations in the current research, uses a similar method to the TMC type to calculate the effects of solar radiation on the zone but more accurately treats the processes through the window and allows for accurate treatment of complex window types and shading. This brief explanation of the methods used within the CFC module is based off of Lomanowski, 2008 [33] and should be referred to if a more detailed explanation is required.

The matrix solving method in ESP-r uses partitioning of a sparse matrix. Interactions between non-adjacent, intra-constructional nodes is not compatible with this solving method. Accurate representation of the radiative and convective heat transfers in the window gaps, as well as interactions across shading features, is done in the CFC module by separately calculating the heat transfer interactions. The individual layer solar and optical properties are calculated, and interactions between non-adjacent nodes are connected via "jump resistors", shown for the long-wave radiative case in Figure 2.3. The resultant internal and external nodal solutions of the windows are then introduced to the solving equations as energy source terms at the present timestep. As previously mentioned, ESP-r's default is the Crank-Nicholson method of weighting the implicit and explicit terms equally. Introducing more present 
term energy values essentially increases the explicitness of the system decreasing the stability at large timesteps. Using the CFC module for more accurate treatment of window and shading heat transfer interactions requires a lower timestep, of at most 10 minutes.

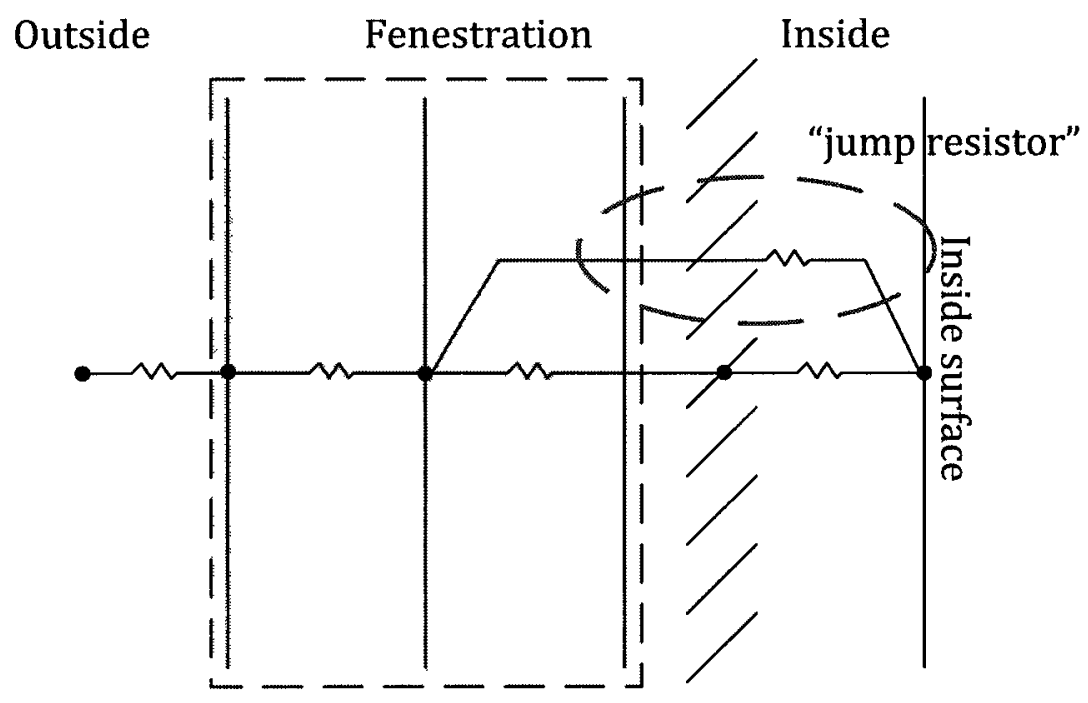

Figure 2.3: "Jump resistor" long-wave radiation connections between non-adjacent nodes in a CFC window

\subsection{Insolation and Shading}

Once solar radiation has passed through the fenestration, it is then absorbed and reflected on the internal surfaces, or re-transmitted back outside. ESP-r models the interior solar processes using an iterative method that aggregates the internal solar reflections and iteratively reduces them to absorption or transmission terms. As a default, there is no assumed shading on the external of the building and the insolation entering the zone is distributed by area-weighting over the surfaces in the zone. In situations requiring a more accurate treatment of the insolation distribution in the zone, such as use of thermal mass on specific surfaces or to account for shading on the exterior of the building, a ray-tracing insolation and shading (ISH) method is implemented as a separate module in ESP-r.

The methods used to calculate ISH are taken from Clarke, 2001 [30]. ISH calculations are based on the position of the sun and the geometry of any obstruction that 
is placed between the path of the suns rays and the building. The weather data is known on an hourly basis for the year of the simulation, thus insolation and shading calculations are done prior to performing a simulation. ISH calculations provide the solving equations with shading results for each external face of the building and the direct solar radiation distribution on internal faces due to transmission through transparent surfaces.

Shading in ESP-r is modelled using solar obstructions. No geometry is assumed to shade another unless it is explicitly classified as a solar obstruction (i.e. roof overhangs as part of the geometry do not affect the main zone). Calculating the shading is based on mathematically projecting the shadow image due to the obstruction along the path of the sun's rays onto the surface of the building. Transformation matrices convert the $\mathrm{x}, \mathrm{y}$ and $\mathrm{z}$ components of the vertices of the obstruction to create a two-dimensional projection onto the surface receiving shading, shown in Figure 2.4. The target face receiving shading is then superimposed with a grid and undergoes a containment test to determine if each grid point contains part of the projected image. As a default, ESP-r uses a 20 by 20 grid on each face, but a finer grid can be used.

Similar methods of projection are used when calculating insolation distribution in the zone. Each window is superimposed with a grid, whose points are projected onto the internal surfaces of the zone to determine the insolation patch and magnitude, shown in Figure 2.4 . 

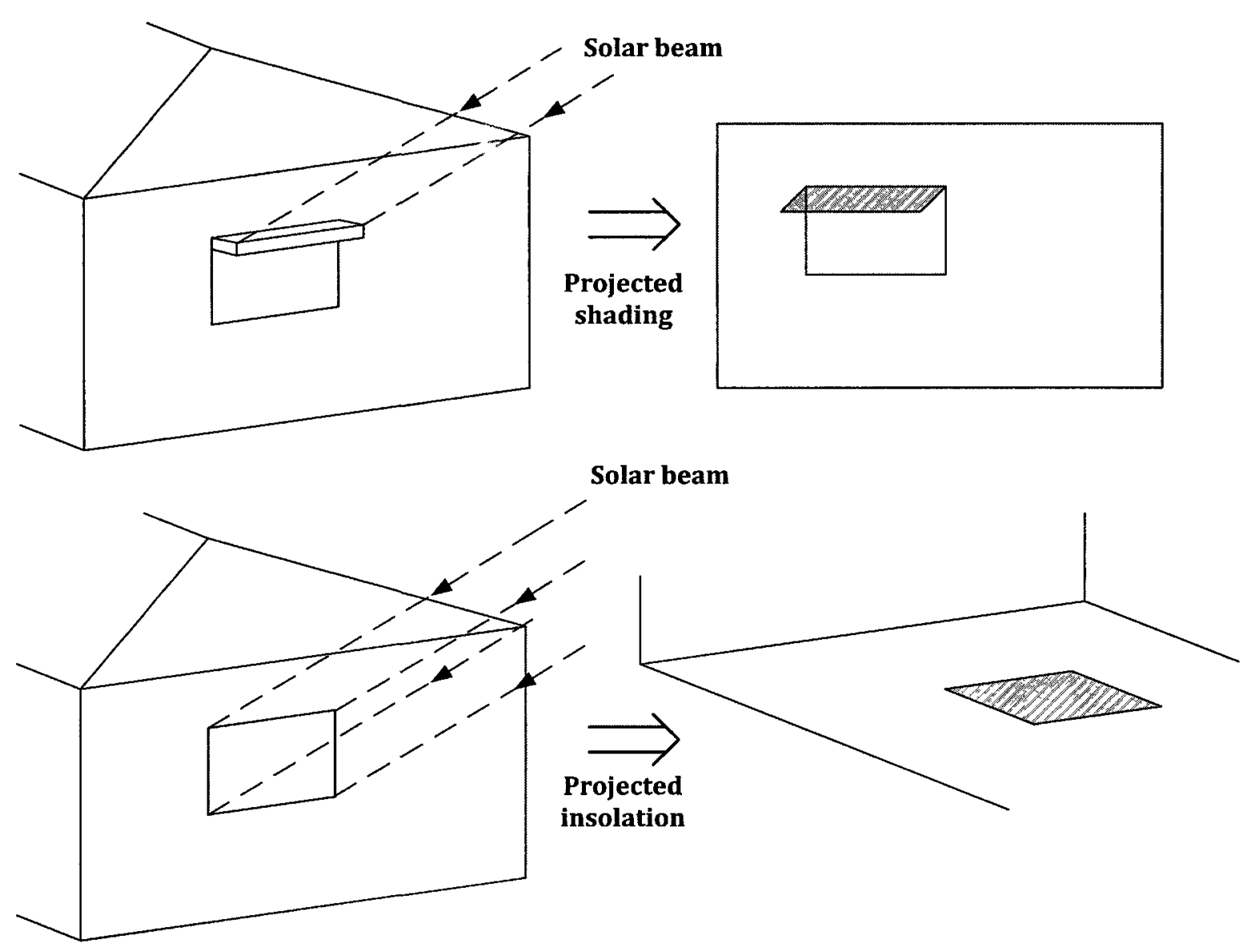

Figure 2.4: The visual representation of the projected image of shading and insolation on a building

\subsection{Treatment of Building Conditioning - HVAC and Infiltration}

It is possible to add many sub-components to the model of a bulding in ESP-r to create an accurate representation thermally and electrically of the building's behaviour. The focus in this section is on heating, cooling, ventilation, and infiltration of the building. 


\subsubsection{Heating and Air-Conditioning}

ESP-r allows for various representations of the heating and cooling system. Depending on the purpose of the simulation, the heating and cooling systems can be represented in an idealized fashion, or with an explicit, component based heating or cooling model. The explicit plant modelling of the heating or cooling system provides a detailed look at the performance of the system and its individual components. In cases where detailed performance results on the system are not required, the idealized model is sufficient. The idealized model accounts for the efficiencies or coefficient of performance of the component used for conditioning. This model also considers nonideal conditions during the heating and cooling seasons when the system will cycle to meet the zone temperature set-points. In such cases, the system is not running at its optimal efficiency - and a part-load ratio (PLR) and part-load factor (PLF), described in Equation 2.11, are used [34].

$$
\begin{gathered}
P L R=\frac{\text { hourly load }}{\text { avarlable capactty }} \\
P L F=\frac{\text { part load ef ficlency }}{\text { steady state efficiency }}
\end{gathered}
$$

Since specific heating and cooling components results are not necessary in this research, the idealized model is used. This still accounts for the furnace efficiency and the air-conditioner coefficient of performance (COP) and provides results in both heating and cooling injection, and natural gas and electricity consumption.

\subsubsection{Infiltration and Ventilation}

Outdoor air infiltration can be treated three ways. The first is based on a set value, either constant infiltration or an hourly varying schedule. The second uses the AIM2 air infiltration model, which calculates the natural air infiltration based on user input leakage paths with data from a house depressurization test, as well as leakage through the furnace flue. The third method of treating air infiltration is using a detailed air-flow network.

Using a set value is a rough estimate of infiltration. Accurate variations in the infiltration due to changes in outdoor temperature are not modelled. A constant air-flow value can be used for modelling ventilation between zones, such as the air movement between a main floor and an unconditioned basement zone which do not see the same variation in air temperature. 
The AIM-2 model calculates the air infiltration at each timestep based on stack and wind effects. If data is not available from a depressurization test (calculating the air change per hour ( $\mathrm{ACH}$ ) infiltration rate when the house is depressurized to $50 \mathrm{~Pa}$ ), ESP-r is capable of determining leakage rates based on a set energy tightness types; loose, average, present or energy tight. The AIM-2 model provides a more accurate assessment of outdoor air infiltration than a set value as it considers the stack and wind effects over time.

Detailed treatment of air flow in a building uses an air-flow network (AFN). An AFN requires a nodal network that characterizes the location and size of cracks or openings in the building envelope and connects them using a flow model. An example of the setup and use of an AFN is modelling open windows. First, the nodes need to be placed at each window as well as in the zone air point to connect all interactions of air-flow through the building. In such a case, not all the windows need to be connected, similar to a situation where cracks in the building envelope are modelled - it is at the users discretion as to how many connections to the outdoors exist and what size they are. Buoyancy effects can be incorporated through the height difference between the node and a datum - such as the height difference between a window node and the zone air-point node. Referring once again to the open window model, when choosing the location of each opening, the area of the opening must also be described. Furthermore, at least one node in the system must contain a known pressure. Nodes in general can be described by a single temperature, a single static pressure and the node's height relative to a datum. Nodes that lie on the boundary of the building envelope and the outdoors, experience wind-induced pressures. Such nodes require the wind speed, direction, vertical velocity profile and influence from local obstructions and terrain features to calculate the pressure. The ESP-r weather files contain values for hourly prevailing wind speed and direction. The other wind characteristics are calculated using experimental and empirical models.

In the case of modelling open windows in ESP-r, once the nodes have been placed at the openings, the nodes must be connected into a network. In this case, all window nodes connect to the zone air-point node. These connections are classified using a component flow model. The choice of model depends on the type of flow network being modelled (i.e modelling of air in a building or modelling air flow through a pipe). These models use known information such as pressures, areas and densities to determine the mass flow rate of the air. 
The AFN is solved using an iterative approach where the unknown nodal pressures are adjusted until the nodal mass imbalances are reduced to near nil. In the current example of opening windows, the internal node (zone air-point node) mass flows sum to zero, i.e. the total mass flow of air arriving at the air-point node must also leave via another path, shown in figure 2.5. Buoyancy effects are considered between nodes of varying heights.

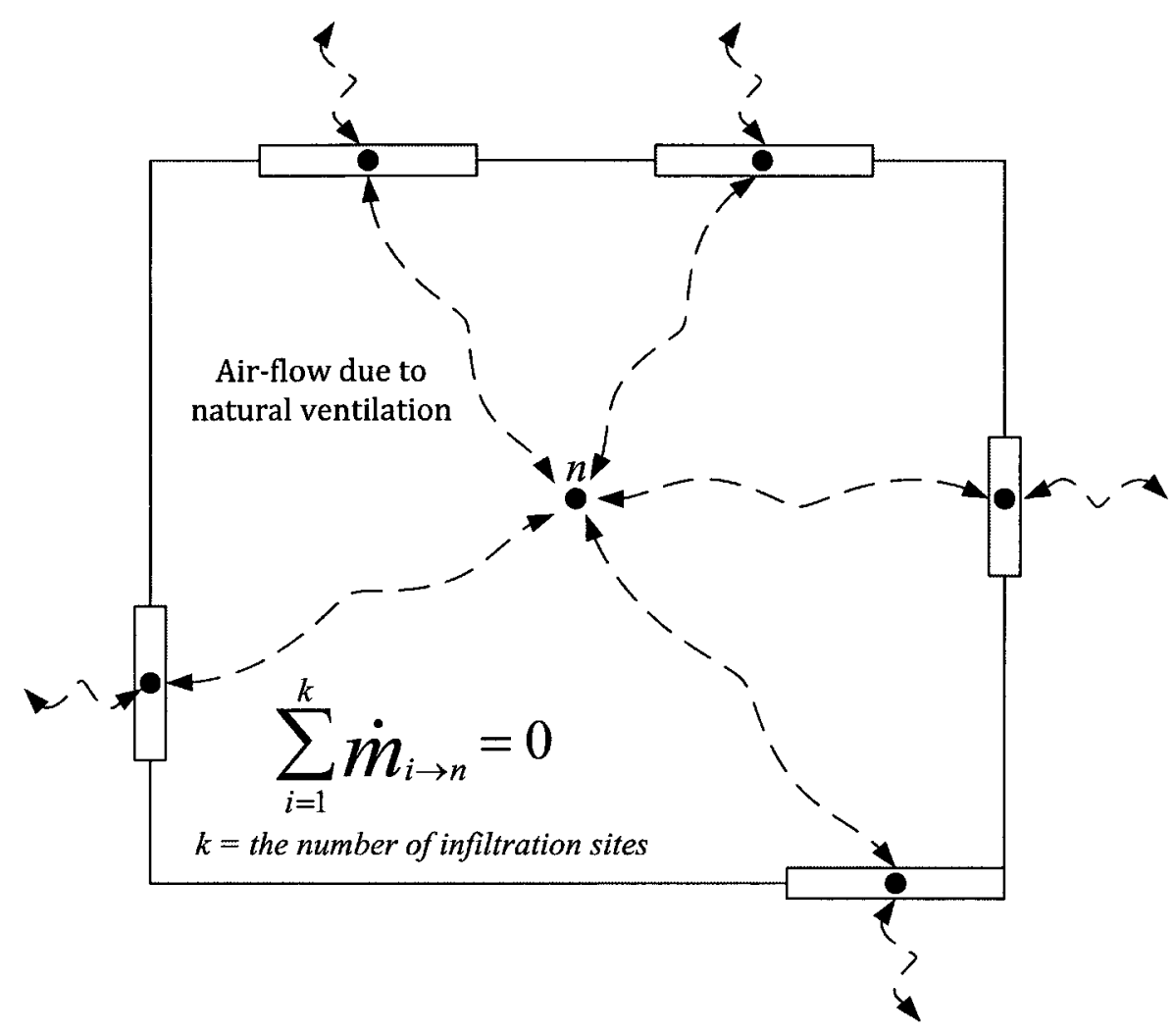

Figure 2.5: Set-up of an air-flow network representing natural ventilation in a single zone

Another way of ventilating the zone with outdoor air is the use of a heat recovery ventilator (HRV). An HRV is used to pre-condition incoming fresh air used to ventilate a zone. In ESP-r, the model is a heat exchanger and uses user input efficiency values and flow rates for a specific HRV model. 


\subsection{Occupant Behaviour}

Modelling occupant behaviour is a difficult task in BPS as humans behave in an unpredictable manner and accurately representing their daily habits is near-impossible. Studies done on electricity consumption of non-HVAC household items provides some direction [35]. Including occupants in a building model is important as they contribute to the overall electricity consumption with use of household appliances and lighting, as well as affecting the thermal conditions with heat released from appliances such as a stove. There are several ways to model the presence of people in a building. In the simplest form, occupant loads can be modelled by a casual gain daily profile by estimating the heat released from different sources for specific chunks of the day. This model is not ideal for detailed modelling as the loads are estimated over an hour, lacking the detail of peaks in consumption over shorter periods. If detailed timestep data is available for a daily or annual electricity use profile, it can be incorporated into the model as both electricity consumption and as casual gains. Since not all power consuming components in a house contribute to the heating load in a building, the convective and radiative heat transfers released can be prescribed as a percentage of the total electricity consumption.

\subsection{Closing Remarks}

Accurately representing the operation of a building is crucial for useful building performance results. BPS offers insight into the annual loads for heating and cooling of a building, as well as other environmental conditions on both a residential and commercial scale. ESP-r's robust capabilities for complex building design makes accurate design and operation in BPS easier. The material presented in this chapter introduced the aspects of BPS, specifically in ESP-r, that are used in following chapters to achieve of the goal of this work. With BPS, simulations on the annual behaviour of a residential house can be achieved. Following this brief explanatory chapter ESP-r, the design and operation of the specific model used in this research will be described including assumptions made during the model design phase leading to simulations results. 


\section{Chapter 3}

\section{Base Case Design and Simulation Model}

A detailed, well-documented base case is necessary to establish a datum for comparison when assessing techniques for reducing on-peak electricity consumption. The base case is the point of comparison for all design and operational variants. Modelling a base case requires documentation of the household components and assumptions made in the modelling process. An overview of the base case was given in Chapter 1 and offered statistical evidence supporting initial assumptions on house type, size and location. The current chapter expands on the initial base case outline. The description is broken down into components of house design, such as location and size, materials and constructions, HVAC and infiltration, and thermal comfort setpoints. A more detailed description of the assumed occupancy patterns in the base case is given in Chapter 4.

\subsection{Base Case Size, Orientation and Location}

Due to large energy demands from single family houses in Ontario [9], this building type is used for the simulation model. Detailed building and site plans for an SFH were provided by a local building company [36],[37]. The house is two stories with approximately 2950 conditioned square feet and the original design included a basement, attic-space and garage. Neither the attic-space nor the garage are conditioned and act as buffer zones between part of the conditioned living space and the outdoor environment. The placement of the attic-space between the incoming solar radiation and the main zone make it an important intermediate space. The garage is omitted from the base case because of its minimal interaction with the main zone.

The base case is oriented along a northeast axis, with the front facing northeast 
according to the site plans . A rendered image of the above-ground portion of the house was shown in Figure 1.3 on page 9.

The original plans had many windows distributed on all faces of the building. Increasing the number of surfaces in the model can significantly increase the simulation runtime. Having an exact replica of the fenestration distribution on the model does not offer much increased accuracy [38]. Simplifying the fenestration distribution was done by grouping sets of windows on each face based on their proximity and height. This method maintained the total area of the fenestration on each face including glazing and framing, but reduced the number of windows per wall to two, to maintain some accuracy in height of the windows. The south-west side of the building had the largest amount of fenestration, and was split into many smaller angled walls. This complex geometry was kept for the simulation to assess the effects of glazing and incoming solar radiation from the windows facing different directions.

The base case is located in Toronto, Ontario, Canada due to its hot and humid summers. Toronto is the most populated city in Canada, and the local electricity distribution experiences large grid strain in the summer due to air conditioning loads from the commercial downtown buildings and widespread residential neighbourhoods. This population density is further justification for using a Toronto location. Annual simulations were run in 2006 due to its hotter than average summer temperatures. August 1, 2006 recorded the summer record peak electricity demand in provincial history [5].

\subsection{Materials and Constructions}

Most of the building materials and layer-by-layer constructions were described in the provided building documentation [36],[37]. The house is designed to meet $\mathrm{R}$ 2000 standards for increased energy efficiency and air-tightness levels, using higher insulation values, energy efficient windows, and a high efficiency heating system [15]. These efficiency standards are modelled in the base case, but some requirements for $\mathrm{R}$-2000 relating to water use are not included as they do not affect the simulation results in electricity consumption. Domestic hot water (DHW) is assumed to be powered by natural gas, not electricity. The natural gas consumption due to DHW is not included in the results.

The exterior construction has five layers that include a brick outer layer and 


\begin{tabular}{|l|l|l|}
\hline Material & Thickness $(\mathbf{m m})$ & RSI $\left(\mathbf{m}^{2} \mathbf{K} / \mathbf{W}\right)$ \\
\hline \hline Brick & 102.5 & 0.11 \\
\hline Air Gap & 25.4 & 0.17 \\
\hline Plywood & 11.1 & 0.07 \\
\hline Fiberglass Insulation & 139.4 & 3.24 \\
\hline Gypsum Board & 12.5 & 0.08 \\
\hline
\end{tabular}

Table 3.1: Exterior wall materials and constructions

RSI $3.24 \mathrm{~m}^{2} \mathrm{~K} / \mathrm{W}$ fiberglass insulation, which accounts for thermal bridging effects. The complete external wall construction is listed in Table 3.1 which also shows the thickness and resistance values of each layer.

Thermal bridging occurs naturally in wood frame construction due to the higher conductivity of wood over fiberglass insulation, shown in Figure 3.1. This is difficult to simulate since the material layers span the entire wall, and breaking them down into sections of fiberglass and wood framing would significantly increase the number of surfaces and simulation runtime.

A simpler method for treating thermal bridging is described in the Model National Energy Code of Canada for Housing (MNECH) [39]. The MNECH method for calculating thermal resistance in building assemblies uses parallel path heat flows by calculating the summation of thermal resistances through the framing path, and another summation through the insulation path. These sums are combined using an area weighted approach to calculate an effective thermal resistance [39]. The effective thermal resistance is calculated using Equation 3.1.

$$
R S I_{\text {Total }}=\frac{100}{\frac{\text { \%of area with framing }}{R S I_{\text {framing }}}+\frac{\% \text { of area with insulation }}{R S I_{\text {2nsulataon }}}}
$$

The main zone and attic-space are separated by an insulation barrier that is RSI $9.0 \mathrm{~m}^{2} \mathrm{~K} / \mathrm{W}$. The remaining opaque constructions are listed in the Appendix A.

The main zone fenestration is double-glazed with a low-emissivity (low-e) coating and argon gas fill. The glazing sits in a casement window with a PVC frame. The base case fenestration also includes internal venetian blinds set to a constant open slat 


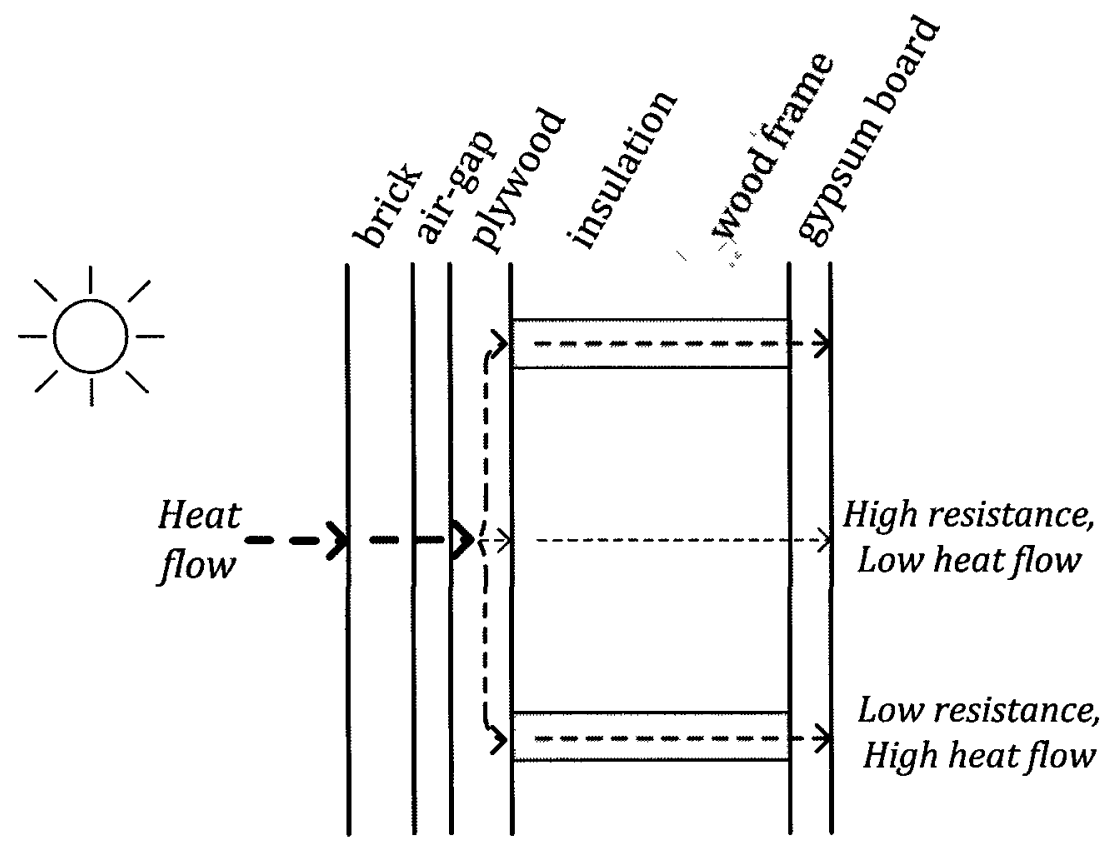

Figure 3.1: Thermal bridging through the exterior wall of the building, shown as a top-view of the wall construction

angle $\left(0^{\circ}\right.$ relative to the horizontal $)$. The main floor window construction is described in Table 3.2 and accounts for the 16 main zone windows, equivalent to $26.5 \mathrm{~m}^{2}$ of glazing. The five basement windows are double glazed air-fill casement windows with a PVC frame.

\subsubsection{Basement Constructions and Assumptions}

The basement of the house is comprised of a poured concrete floor and concrete walls. The walls have a drainage board on the outside face insulated with RSI 0.55 $\mathrm{m}^{2} \mathrm{~K} / \mathrm{W}$. The inside face of the basement walls are insulated with RSI $3.52 \mathrm{~m}^{2} \mathrm{~K} / \mathrm{W}$ fiberglass batts starting $20 \mathrm{~cm}$ from the floor, shown in Figure 3.2 which is based on the BASESIMP configurations [40].

Modelling a basement in ESP-r requires the wall insulation configuration, the dimensions and the heat loss distribution between each surface. The ESP-r dimensional input must be rectangular, however the base case geometry is not a proper rectangle 


\begin{tabular}{|l|l|}
\hline Material & Thickness $(\mathbf{m m})$ \\
\hline \hline Glass & 5.9 \\
\hline Argon Gap & 12.7 \\
\hline Low-e glass & 5.9 \\
\hline Air Gap & 12.7 \\
\hline Aluminum Venetian Blinds & 12.7 \\
\hline
\end{tabular}

Table 3.2: Main zone fenestration construction

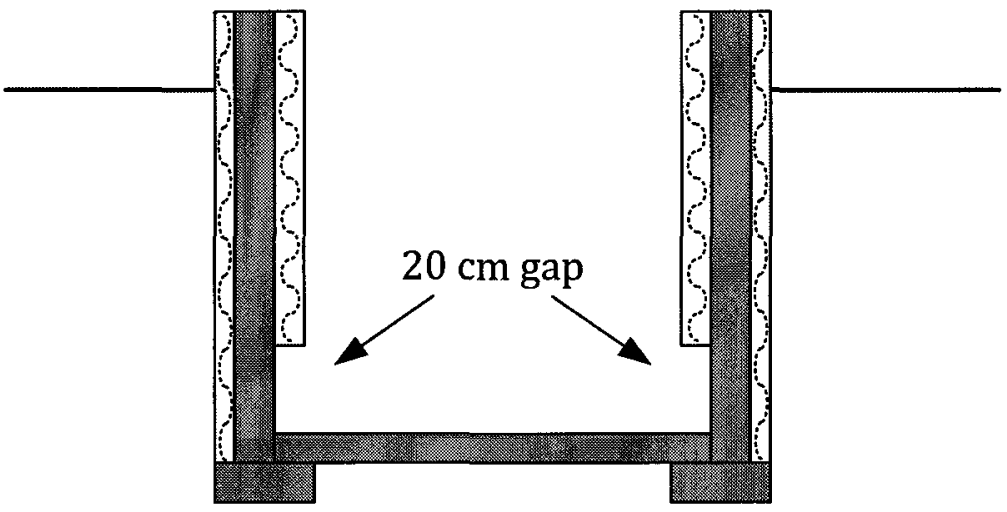

Figure 3.2: Schematic of the basement insulation placement

and lacks a specific length and width. An algorithm based on Bahnfleth and Pederson, 1990 [41] that uses the ratio of floor area to perimeter length as a length scale for correlating the heat loss from rectangular and L-shaped slab-on-grade floors was modified to extend to basements of various shapes by Beausoleil-Morrison, 1997 [42]. The equations for equivalent length and width are as follows,

$$
\begin{aligned}
L & =\frac{P}{4}+\frac{\sqrt{P^{2}-16 A}}{4} \\
W & =\frac{P}{4}-\frac{\sqrt{P^{2}-16 A}}{4}
\end{aligned}
$$

where $L$ is the length in $\mathrm{m}$

$W$ is the width in $\mathrm{m}$ $P$ is the perimeter in $\mathrm{m}$ $A$ is the floor area in $\mathrm{m}^{2}$ 
The basement heat loss area distribution is based on the percentage of area that each wall comprises of the total below grade area. This area-based method means that the floor has the most heat loss, and a short wall will have the least. The basement is not conditioned, but to simulate naturally occurring air flow between the main and basement zone, the basement is ventilated with air from the main floor. The ventilation rate is $300 \mathrm{~L} / \mathrm{s}$ between the zones. Preliminary testing with various ventilation rates shows that inter-zonal flow rates above $300 \mathrm{~L} / \mathrm{s}$ resulted in a small increase in basement temperature, while below this rate, the temperature difference between the main and basements zones is significant. The low sensitivity between basement temperature and ventilation rate above $300 \mathrm{~L} / \mathrm{s}$ justified this value as the minimum ventilation rate to meet an accurate representation of zone-to-zone ventilation.

\subsection{HVAC, Infiltration and Comfort Setpoints}

The building specifications describe the furnace HRV and infiltration. No specifications were provided for an air-conditioning unit and the size and COP are estimated based on house-size.

\subsubsection{Component Specifications}

The heating system is a $35 \mathrm{~kW}$ high efficiency natural gas fueled condensing furnace with a $95 \%$ annual fuel utilization efficiency (AFUE). Some simulation input data are not available in the building specifications such as the draft fan power and circulation fan power. ESP-r has internal default values for these inputs. The recommended default for draft fan power is $75 \mathrm{~W}$ [43]. The circulation fan power defaults to a scaled value of the furnace steady state capacity [44],

circulation fan power $=0.0194 \cdot$ furnace steady state capacity

Using Equation 3.4, the circulation fan power is $679 \mathrm{~W}$.

The HRV documentation stated a $66 \%$ efficiency at $-25^{\circ} \mathrm{C}$. The power draw of the fan at $0^{\circ} \mathrm{C}$ and $-25^{\circ} \mathrm{C}$ is $125 \mathrm{~W}$. The HRV inputs also required duct lengths, types, 
and insulation values. These were set to be flexible sealed ducts, $5 \mathrm{~m}$ in length and $152.4 \mathrm{~mm}$ diameter. The ducts are insulated to RSI $0.7 \mathrm{~m}^{2} \mathrm{~K} / \mathrm{W}$.

The air-conditioner is a $10.5 \mathrm{~kW}$ unit equivalent to 3 tons of refrigeration. This unit is large, but was chosen based on a week long simulation of the base case with near infinite space-cooling availability. This 'ideal' simulation demonstrated the maximum cooling requirements of the house if all of the demands could be met. The maximum demands neared $10.5 \mathrm{~kW}$ and as such, this size unit was used so that in its current state, the base case house would have available cooling to meet the zone temperature set point. This air-conditioner has a conservative COP value of 2.64 .

\subsubsection{Infiltration}

With an R-2000 rating, the house must be energy tight and pass a depressurization test to verify a low leakage rate. The $\mathrm{R}-2000$ specifications demand that this leakage rate must be at or below $1.5 \mathrm{ACH}$ when the house is depressurized to $50 \mathrm{~Pa}$. Unfortunately, further details of the depressurization test that was experimentally done on a built version of the house are not available, and could not be used in the ESP-r infiltration input file. Instead, the house is described as 'energy tight' and the ACH and estimated leakage areas are approximated in the ESP-r environment.

\subsubsection{Thermal Comfort Setpoints}

Thermal comfort setpoints are seasonally split between the winter period, October 1 to May 15, and summer period, May 16 to September 30. No air-conditioning is available in the winter time, and likewise for heating in the summer. The heating or cooling is injected using a basic controller which estimates the amount of cooling required to meet the setpoint temperature by the end of the simulation timestep. The temperature is sensed at the main zone air-point and heating or cooling is injected to the same zone air-point. The winter setpoint is $21^{\circ} \mathrm{C}$ and the summer setpoint is $24{ }^{\circ} \mathrm{C}$.

Without available cooling in the shoulder seasons like April or October when the outdoor temperature can be warm or high amounts of solar gains can penetrate the zone during the day, the house can overheat in the simulation environment. Overheating is not an accurate representation of a real house where an occupant is likely to open windows. Overheating during the day pre-heats the house so that there is an 
underestimation of heating loads overnight when the outdoor air temperature drops. Compensating for warm spring and fall daytime temperatures is modelled by mimicking open windows. ESP-r has a very basic window opening controller that infiltrates the zone with outdoor air based on the zone temperature. To handle any overheating, the windows open when the zone temperature is at or above $25^{\circ} \mathrm{C}$ during the winter period, and will close when the zone temperature drops to $23^{\circ} \mathrm{C}$. For the base case, the window openings are modelled with all windows open to $10 \%$ of the glazing area (the open area to outdoor air infiltration), an assumption taken from BeausoleilMorrison, 2009 [45]. This $10 \%$ area assumption is based on approximations relating to the presence of insect screens, portions of the window that cannot be opened and the fact that the entire window will not likely be opened by the occupant [45]. This window area is then used to calculate the air flow using the following relation,

$$
\dot{m}_{\text {arr }}=0.65 \cdot A_{\text {openıng }} \cdot(2 \rho \Delta P)^{1 / 2}
$$

Where $\dot{m}_{\text {arr }}$ is the mass flow of incoming air in $\mathrm{kg} / \mathrm{s}$

$A_{\text {opening }}$ is the open window area in $\mathrm{m}^{2}$

$\rho$ is the density of air in $\mathrm{kg} / \mathrm{m}^{3}$

and $\Delta P$ is the pressure difference across the window opening in $\mathrm{Pa}$

The pressure difference across the window is based on the wind induced pressures on each face, determined from wind speed and direction data in the weather file.

\subsubsection{Occupancy}

Representing occupancy is a non-trivial task, as it is hard to accurately predict the daily use of electricity by occupants and requires a lot of assumptions. Occupancy is not only an addition to the daily electricity demand from the house, but also contributes to the indoor temperature through internal gains. Not all of the appliance loads will contribute to heat gains in the zone, such as the clothes dryer that typically exhausts outdoors. The method used to import internal gains in ESP-r requires a single electricity profile, and heat release from the dryer is not disaggregated. All of the energy used in appliances other than the clothes dryer such as the stove, lighting and plug loads, can typically be assumed to be converted to heat gains in the zone [46]. In this model, $90 \%$ of the energy used by occupant for non-HVAC consumption is assumed to convert to heat gains. Over one day, the dryer contributes 
to approximately $8 \%$ of electricity consumed, shown in Chapter 4 . A daily estimate of $90 \%$ of the loads contributing to heat gains is a conservative estimate and accounts for some of the discrepancy regarding heat release from the clothes dryer. A description of the assumed occupancy pattern is described in Chapter 4 which will complete the description of the ESP-r base case model.

\subsection{Final Base Case ESP-r Model}

A wireframe of the base case in the ESP-r environment is shown in Figure 3.3. The simulation strategy for the base case and all variants is an annual simulation run at a one minute timestep. This short timestep was chosen in part due to the requirements of the module used to simulate the fenestration, which required a timestep less than 10 minutes for stability. The one minute timestep also allows for detailed simulation of electricity consumption as the occupancy schedule is based on minute data. 


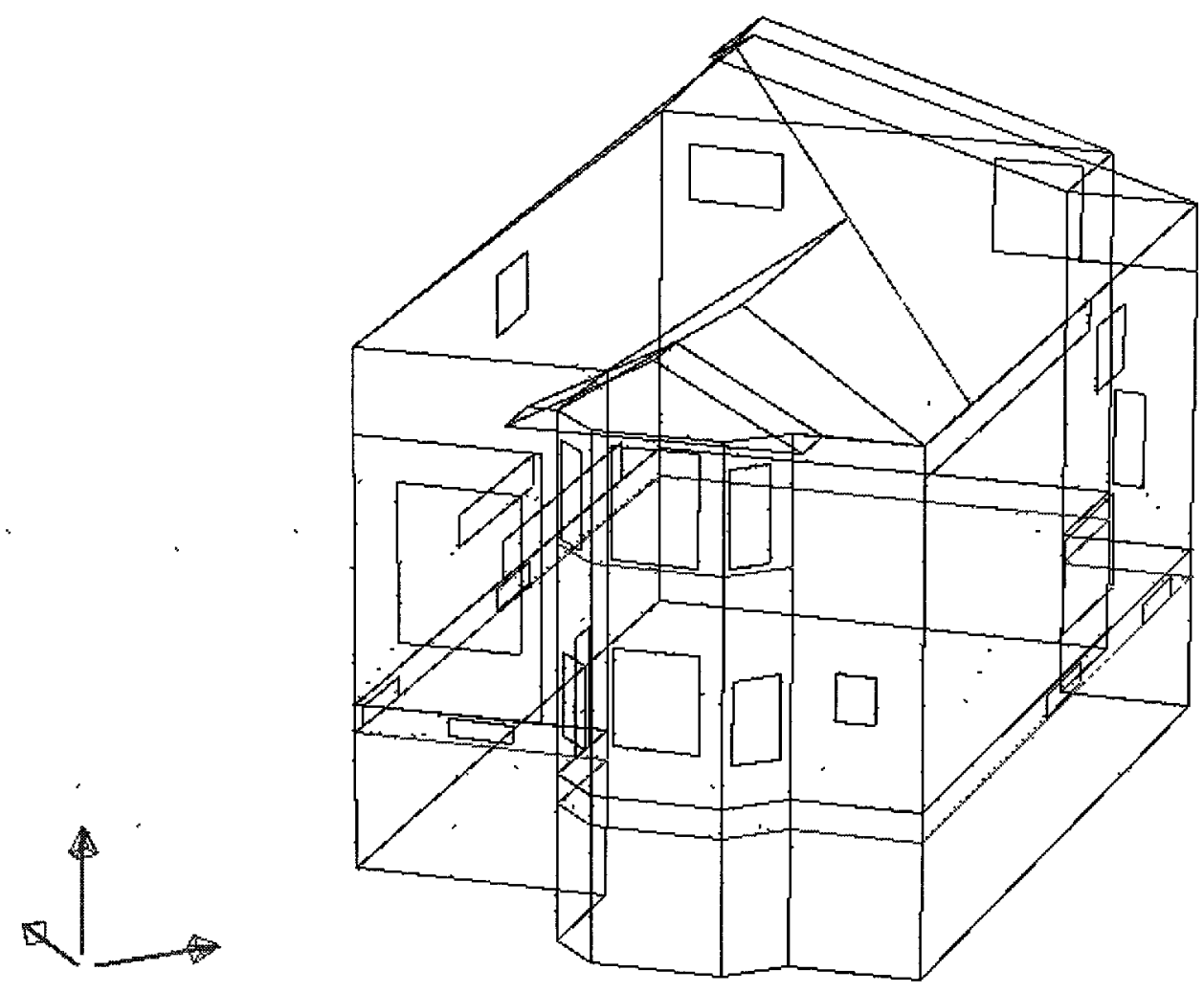

Figure 3.3: Wireframe base case in ESP-r 


\section{Chapter 4}

\section{Modelling Residential Occupancy}

Electricity demand in a house can be divided into two categories; HVAC and nonHVAC. Chapter 3 outlined the location, size, and construction, and HVAC specifications of the base case of the research, but lacked any description of non-HVAC demands, which are imperative in a realistic model. Occupant behaviour affects the on-peak electricity consumption with the use of appliances for cooking or cleaning, lighting and plug-load contributions that all make up the non-HVAC demands. Internal gains due to occupancy affect the air temperature, which reduce heating loads but increase cooling demand. Accurately describing an electricity use profile on a residential scale is difficult due to the complexity of variables involved such as number of occupants, occupant behaviour, location and time of year. This chapter describes the methods used to construct a realistic load profile from field measured data to complete the base case for this research.

\subsection{The Importance of Accurately Representing Occupancy}

Large appliances such as the stove, clothes dryer and dishwasher have large electricity demands. These appliances also expel heat, requiring more space-cooling to meet the zone setpoint in the summer. Coincident appliance and space-cooling use can cause spikes in a house's on-peak electricity consumption. The coincidence of household appliance use with space-cooling is shown below in Figure 4.1, which contains field measured non-HVAC electricity consumption from a house in Ottawa, Ontario on 
August 5, 2009[35]. This household usage profile is overlaid with the Ontario provincewide demand from the same day [47]. The on-peak period, between 11:00 am and 5:00 on local time, is marked on the figure between the vertical dotted lines. On this day, one-third of the household electricity demand occurred on-peak, and the spiking on-peak demands are nearly double that of the demands over the rest of the day.

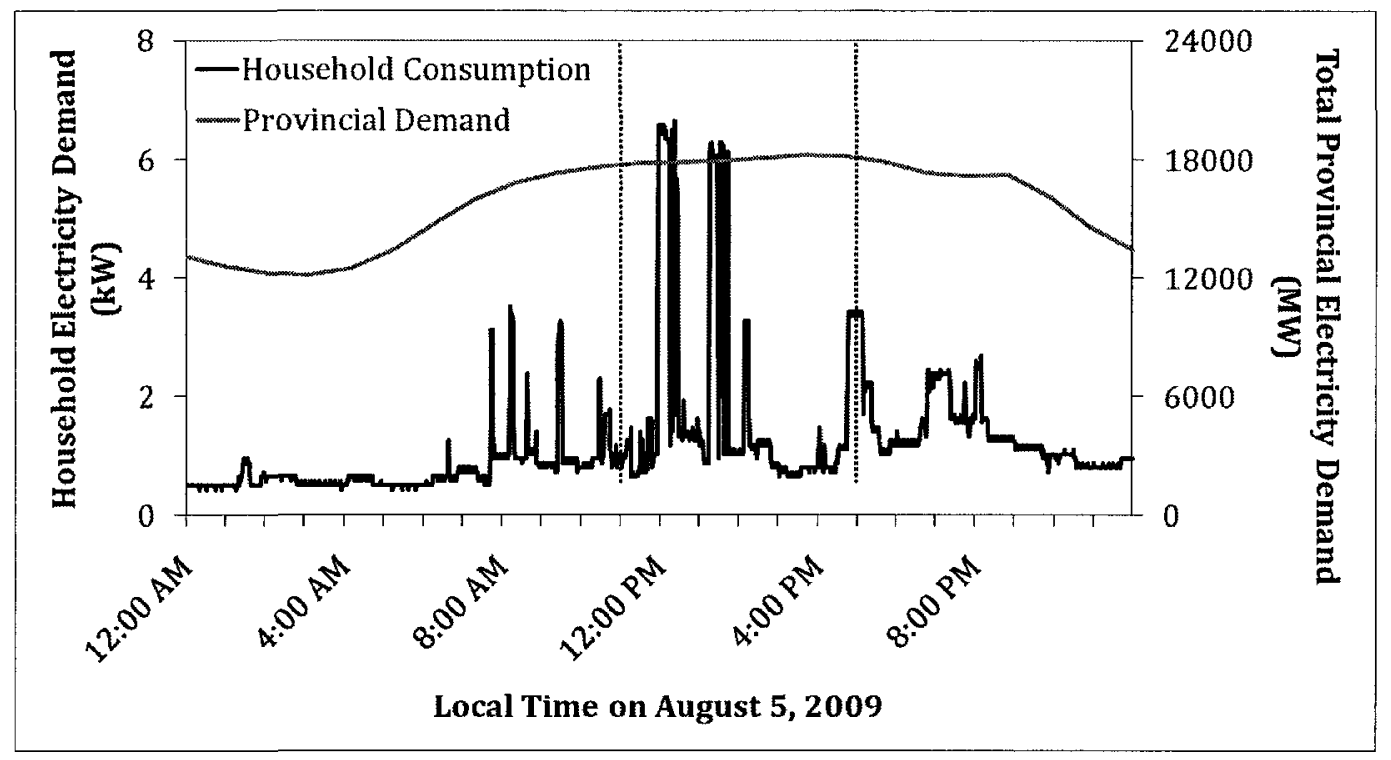

Figure 4.1: Electricity consumption on August 5, 2009 from an Ottawa house and the provincial grid demand

Occupancy has been represented previously in several studies. A study completed in New Zealand through the BRANZ group monitored 400 houses and their energy consumption based on fuel type, as well as room temperature [48]. In North America, occupant non-HVAC loads have also been monitored through the Florida Solar Energy Center in 1999 [49], with Hydro-Quebec between 1994 and 1996 [50], as well as a study completcd in 2010 in Ottawa by Saldanha [35].

A representative load profile is constructed based on data collected in the Ottawa area from several houses [51],[52]. The load profile is constructed as an aggregation of specific household appliances. Having the explicit electrical profile of each appliance allows for manipulation of the total occupancy profile in a day, and the high on-peak electricity use of specific appliances can be shifted off-peak as variants from the base case. There are seven separate appliance electricity profiles in the representative load 
profile: dishwasher, clothes dryer, clothes-washing machine, stove, refrigerator, deepfreezer, and computer. The remaining non-HVAC demands are included as described in Section 4.2.7. The following sections outline how the electricity consumption of each appliance is resolved from field measured data to create a representative nonHVAC electricity use profile.

\subsection{Aggregate Electricity Load Profile}

Non-HVAC residential electricity data was collected from 12 houses in the Ottawa, Ontario region from June 2009 to September 2010 in a study by Saldanha [35]. The non-HVAC draws from several houses were used in the study to determine accurate daily occupant electricity consumption. Only the summer 2009 data from the Saldanha study are used for this work as the current research is based on summer on-peak electricity reduction. Detailed data collection of specific appliances was done for 3 of the 12 houses in the Saldanha study, each with a different energy consumption category (either low consumption - below $5000 \mathrm{kWh} / \mathrm{yr}$, medium-to-high consumption - below $10000 \mathrm{kWh} / \mathrm{yr}$ or high consumption - above $10000 \mathrm{kWh} / \mathrm{yr}$ ). The chosen house from the Ottawa study to create a representative occupancy profile is considered a medium-to-high energy-use house with annual electricity consumption of $8877 \mathrm{kWh} / \mathrm{yr}$. The chosen house has electricity consumption data for the dishwasher, stove and clothes dryer. Beyond the Saldanha study, monitoring was done in a separate house in the Ottawa, Ontario area for short periods of time on a clothes-washing machine, refrigerator, freezer and personal computer. These specific appliance load profiles were amalgamated to make a complete representative profile. The data was collected at a one minute timestep in both studies. The number of days of data available for creating the occupancy profile is noted in each subsection of this chapter.

Creating a representative profile is a non-trivial task. For the purpose of the study, a single day profile is created and repeated each day of the simulation. A profile that repeats every day does not require an excessive amount of assumptions, while still demonstrating occupancy in the house. It is not an accurate representation for some appliances, such as the clothes washing machine or clothes dryer, but simulating their electricity draw every day represents the worst-case scenario in electricity consumption. This representative profile is based on real data but is not real data itself, and 
it was deemed unnecessary to create a profile over a longer period of time such as a week or month.

The steps to determining a representative profile are as follows:

1. The frequency of use is determined by looking at the number of times the appliance is used over the data collection period. This demonstrates the accuracy of placing this appliance in a daily use profile.

2. High-use times during the day are pinpointed by looking at the daily time-of-use of the appliance. The daily time-of-use profile is compiled by using the daily usage data to $\log$ the minutes in the day when the appliance registered use. Summing the totals for each minute of the day represents how many times the appliance is used at that time over the whole collection period. This determines an appropriate temporal placement of the appliance's electricity consumption in the representative profile.

3. The electricity use profile of the appliance over three days is compared to determine the size and shape of electricity demand. An average of these three days of electricity consumption is added to the representative profile.

The following sections of this chapter describe each set of field measured appliance data available and the process of determining an accurate electricity profile of each appliance for a one day profile. Since a daily profile is not completely accurate, the base case is also simulated using annual field measured data from the Saldanha study [35] to validate the use of a representative profile. This is described in Chapter 7.

\subsubsection{Characterizing Dishwasher Use}

The Saldanha data set contains 82 consecutive days of electricity consumption data for the dishwasher between July and September 2009. During this period, the dishwasher was used every day at least once, making it an accurate addition to a daily profile. The daily time-of-use is shown graphically in Figure 4.2 on a one-minute basis, where the time of day is on the horizontal axis and the frequency of dishwasher use at a given minute is on the vertical axis. 


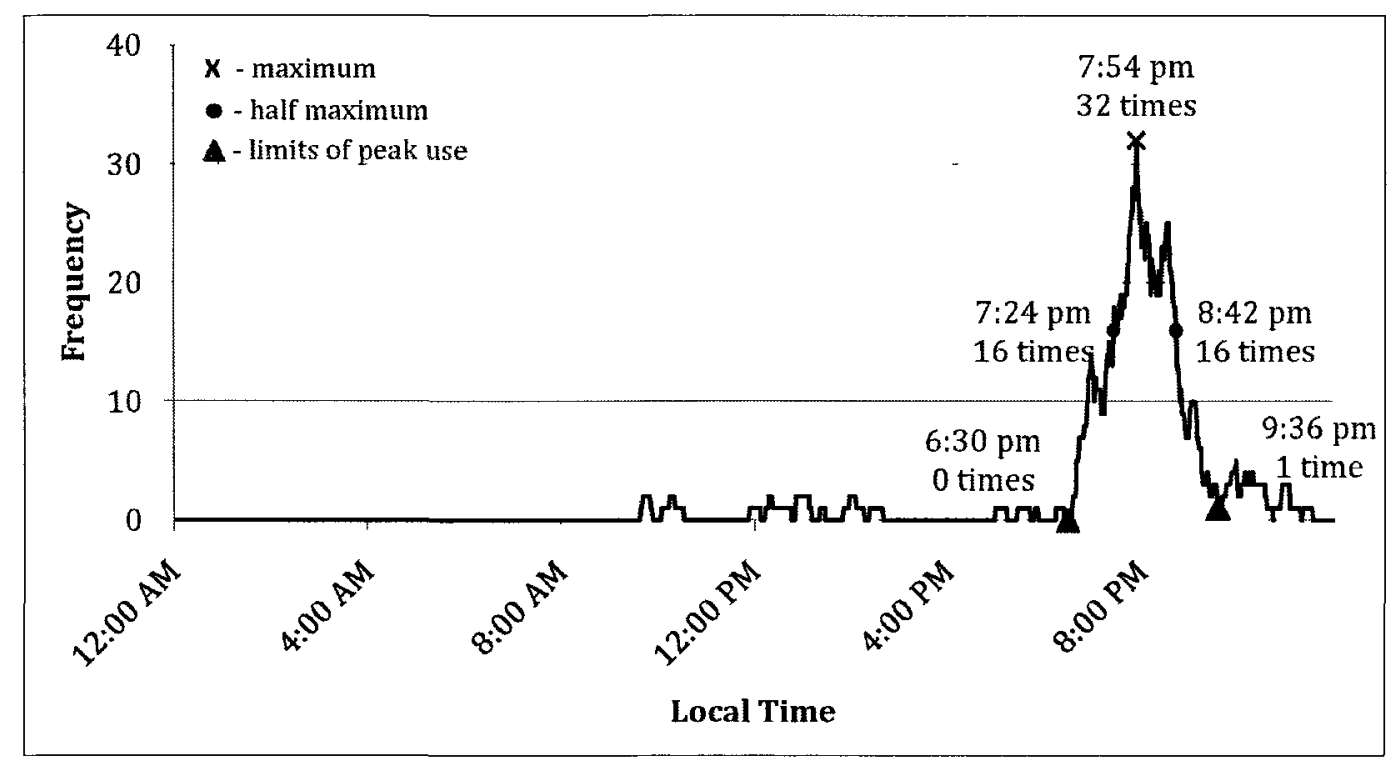

Figure 4.2: Field measured time-of-use of the dishwasher

Figure 4.2 shows two times of day, at half of the maximum frequency of use shown with circular markers, between which the largest amount of dishwasher use occurred. Between 7:24 pm and 8:42 pm, the dishwasher is used at least 20\% of the days. This peak in usage occurs quickly starting at 6:30 pm - as shown with the left-most triangular marker on the figure, and drops by 9:36 pm - shown with the right-most triangular marker. A maximum of 32 hits occurs at 7:54 pm when the dishwasher is used most often, shown as an ' $x$ ' on the figure. Based on the trend in these data, the start of the dishwasher in the representative profile is placed at 7:30 pm.

The final step in modelling the electricity profile of the dishwasher is determining the electricity consumption pattern. The dishwasher had a cycle time of approximately 80 minutes. The cycle length was an average, but little deviation existed in the cyclo length or consumption pattern. Figure 4.3(a) demonstrates actual dishwasher collection data on three separate days, while Figure $4.3(\mathrm{~b})$ shows the representative dishwasher profile.

From the field measured data, the dishwasher initially draws $0.2 \mathrm{~kW}$ of electricity for 6 to 8 minutes. Consumption then increases to $1.0 \mathrm{~kW}$ for 7 to 8 minutes. The electricity draw then drops to around $0.2 \mathrm{~kW}$, fluctuating just above and below this value by $+/-0.05 \mathrm{~kW}$ for 19 to 20 minutes, then drops to near $0 \mathrm{~kW}$ for 5 to 6 minutes. Consumption rises to $1 \mathrm{~kW}$ again for 19 to 21 minutes, and finishes with 


\begin{tabular}{|c|c|}
\hline Dishwasher Electrical Draw & Time \\
\hline \hline $0.2 \mathrm{~kW}$ & 8 minutes \\
\hline $1 \mathrm{~kW}$ & 7 minutes \\
\hline $0.2 \mathrm{~kW}$ & 20 minutes \\
\hline $0 \mathrm{~kW}$ & 6 minutes \\
\hline $1 \mathrm{~kW}$ & 19 minutes \\
\hline $0.2 \mathrm{~kW}$ & 13 minutes \\
\hline
\end{tabular}

Table 4.1: Electrical consumption of the representative profile of the dishwasher

cycling around $0.2 \mathrm{~kW}$. These values match the dishwasher trend for all the days of data monitored. An average of these numbers is used in the representative profile, and the small fluctuations of less than $0.1 \mathrm{~kW}$ were flattened out for simplicity. This dishwasher electricity draw is 73 minutes long, and is described in Table 1.1, and shown in Figure 4.3(b). 


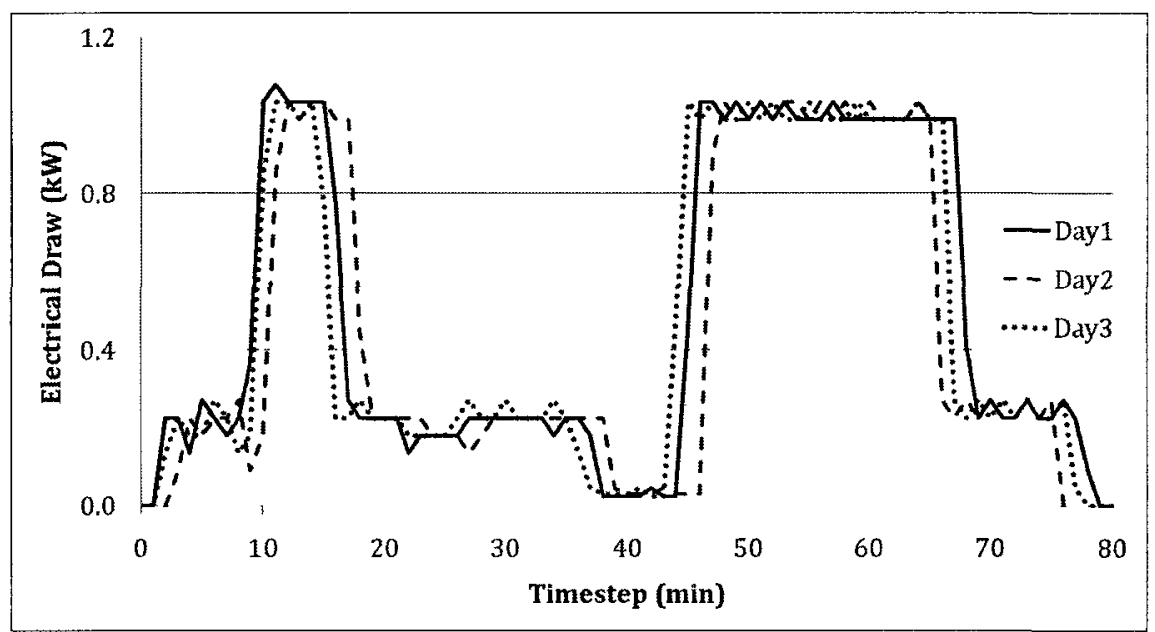

(a) Field measured dishwasher electricity consumption on three separate days

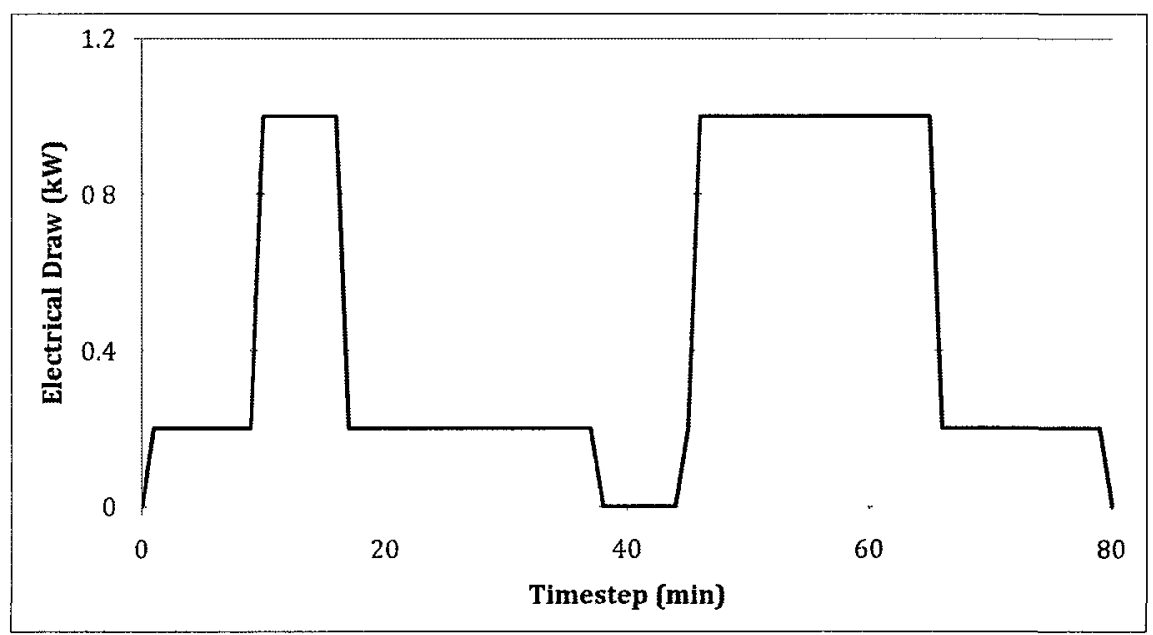

(b) Representative dishwasher profile

Figure 4.3: Dishwasher usage from (a) field measured data and (b) the representative profile

\subsubsection{Characterizing Clothes Dryer Use}

Over the 79 days of collection data for the clothes dryer which occurred between July and September 2009, there were 25 days of dryer usage, 15 of which occurred on weekdays. Incorporating the dryer on a daily basis represents a worst-case scenario of a house with very high demand. This is a clear example of the difficulties faced when attempting to accurately represent occupant behaviour.

The clothes dryer is used most often at 1:00 pm, and the highest hour of usage is 


\begin{tabular}{|c|c|}
\hline Dryer Electrical Draw & Time \\
\hline \hline $5.5 \mathrm{~kW}$ & 20 minutes \\
\hline $0.3 \mathrm{~kW}$ & 2 minutes \\
\hline $5.5 \mathrm{~kW}$ & 2 minutes \\
\hline $0.3 \mathrm{~kW}$ & 2 minutes \\
\hline $5.5 \mathrm{~kW}$ & 2 minutes \\
\hline $0.3 \mathrm{~kW}$ & 5 minutes \\
\hline
\end{tabular}

Table 4.2: Electrical consumption of the representative dryer electricity profile

between 12:00 pm and 1:00 pm. The clothes dryer usage is placed at 1:00 pm in the representative profile lying within the peak hours.

When the clothes dryer is used, it has a total cycle time of approximately 35 minutes. Figure 4.4(a) shows field measured data of the clothes dryer usage on three separate days. The representative profile in Figure 4.4(b) is established be averaging the length of time for the peaks and valleys of the electricity draw, which in Figure 4.4 (a) can be seen to be very similar. The initial electrical draw of $5.5 \mathrm{~kW}$ varies between 15 and 21 minutes in length, but the average is 20 minutes. The two cycling peaks occur between 5 and 7 minutes apart, fluctuating between $5.5 \mathrm{~kW}$ and $0.3 \mathrm{~kW}$. The end of the dryer profile has a trailing electrical draw of $0.3 \mathrm{~kW}$ that varies in length between a few minutes and up to 40 minutes. To maintain a finite profile for the clothes dryer, this float time is cut off at 5 minutes, and the total dryer electrical draw is 33 minutes in the representative profile. Table 4.2 demonstrates the values and times used for the representative clothes dryer profile. 


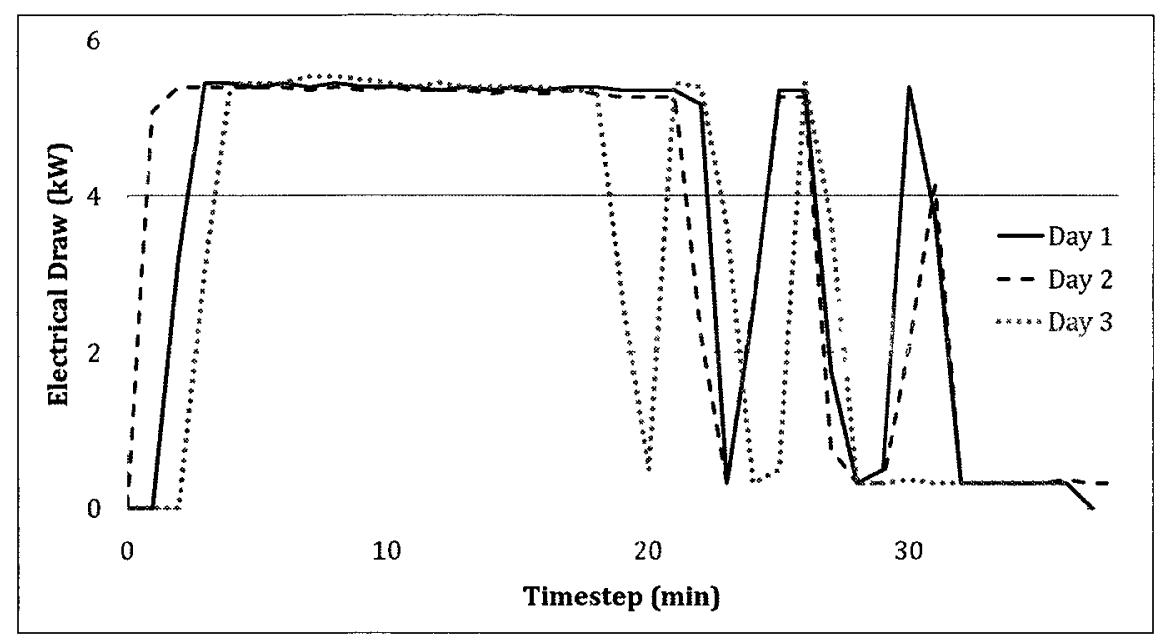

(a) Field measured electricity consumption of the clothes dryer on 3 separate days

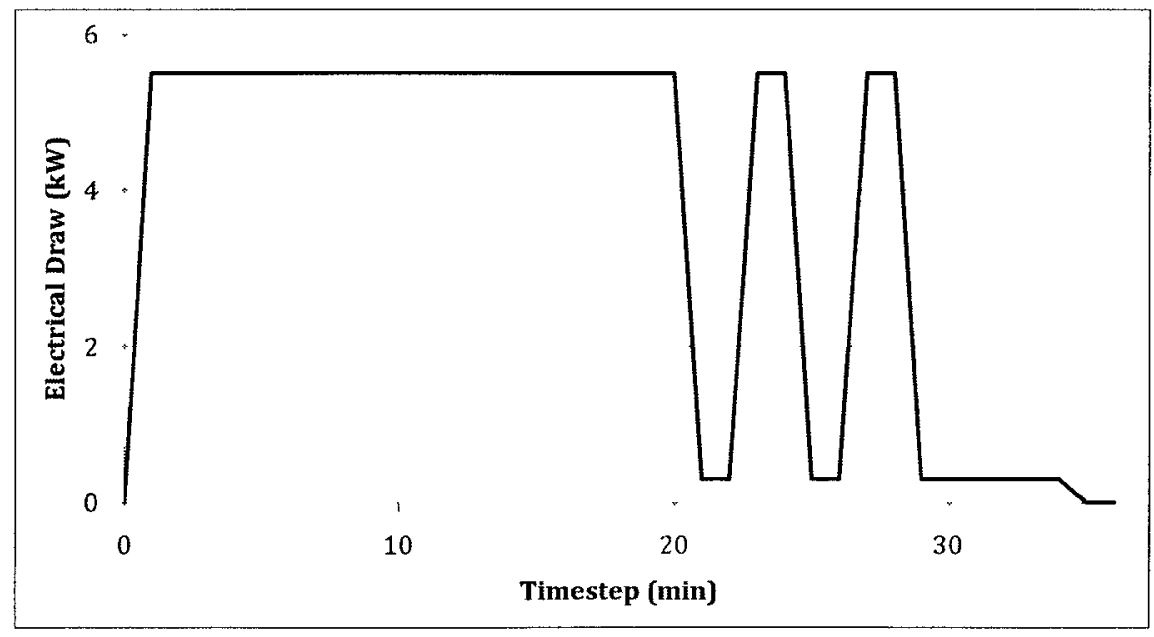

(b) Representative dryer profile

Figure 4.4: Dryer usage from (a) field measured data and (b) the representative profile

\subsubsection{Characterizing Clothes-Washing Machine Use}

Monitoring of the electricity consumption from a clothes-washing machine occurred over 20 consecutive days. The clothes-washing machine registered use on 12 of the days monitored. The same method is used to determine the largest daily time-of-use of the washing machine as with previous appliances, and the peak usage occurs at 8:30 am and 8:00 pm. Similar to the clothes dryer, the clothes-washing machine is not 


\begin{tabular}{|c|c|}
\hline $\begin{array}{c}\text { Clothes-Washing Machine } \\
\text { Electrical Draw }\end{array}$ & Time \\
\hline \hline $0.6 \mathrm{~kW}$ & 8 minutes \\
\hline $0.4 \mathrm{~kW}$ & 8 minutes \\
\hline $0.77 \mathrm{~kW}$ & 1 minute \\
\hline $0 \mathrm{~kW}$ & 6 minute \\
\hline $0.6 \mathrm{~kW}$ & 4 minutes \\
\hline $0.4 \mathrm{~kW}$ & 2 minutes \\
\hline $0.77 \mathrm{~kW}$ & 1 minute \\
\hline $0.5 \mathrm{~kW}$ & 5 minutes \\
\hline
\end{tabular}

Table 4.3: Electrical consumption of the representative clothes-washing machine electricity profile

an appliance typically used on a daily basis, but is still modelled in the representative electricity profile. Of the two high-use times, an arbitrary decision was made to place the use of the clothes-washing machine at 8:00 pm in the representative profile.

The electricity profile of the clothes-washing machine is consistent. There are two distinct periods of demand, one lasting 15 to 20 minutes and the second lasting 10 to 12 minutes. In the first period, the electrical draw rises to between 0.6 and $0.7 \mathrm{~kW}$ and fluctuates between these values for 6 to 8 minutes. The draw then drops to just above $0.4 \mathrm{~kW}$ for 6 to 8 minutes. This is followed by a short spike in electricity to almost $0.8 \mathrm{~kW}$. The clothes-washing machine draws no electricity for the following 5 to 6 minutes. The second period of consumption follows a similar pattern over a shorter time period. Figure 4.5 (a) shows the field measured data of the washing machine on three separate days. The clothes-washing machine electricity draw lasts 35 minutes, and details of the profile are listed in Table 4.3. Figure 4.5(b) shows the representative profile. 


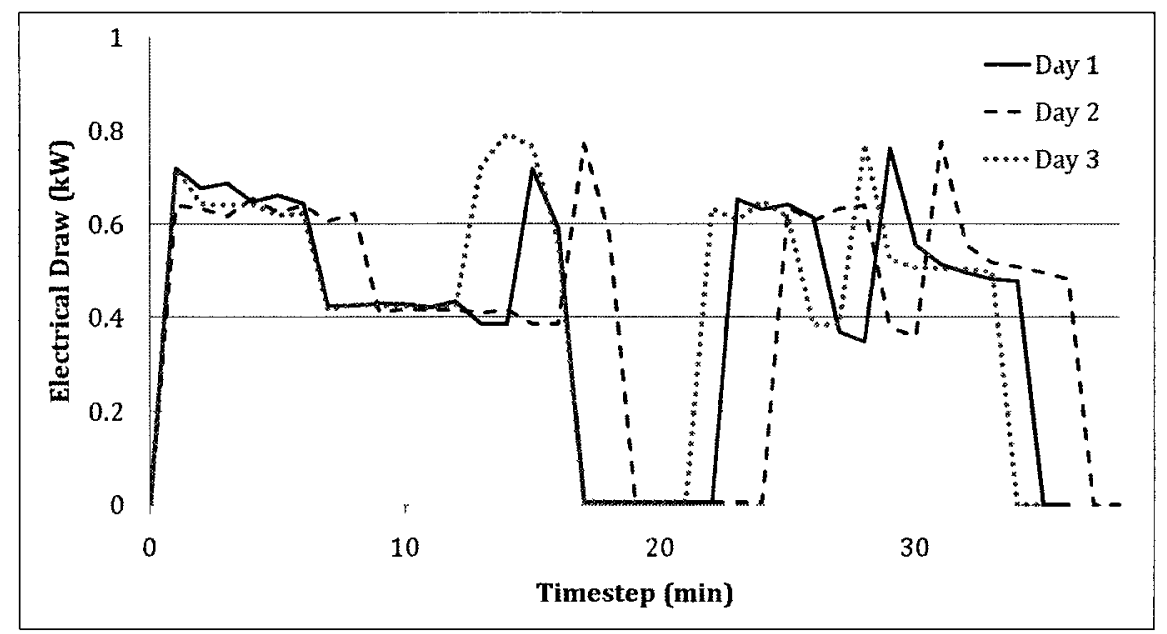

(a) Field measured electricity consumption of the clothes-washing machine on 3 separate days

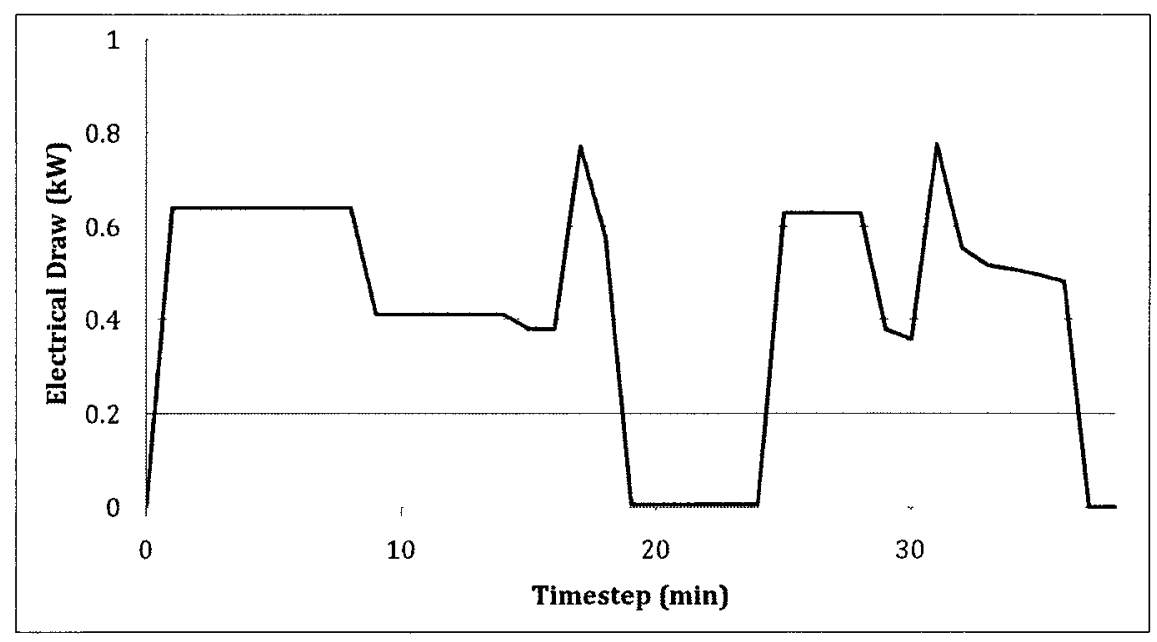

(b) Representative clothes-washing machine profile

Figure 4.5: Clothes-washing machine usage from (a) field measured data and (b) the representative profile

\subsubsection{Characterizing Stove Use}

A period of 102 days of data were collected for the stove between July and September 2009 , during which this appliance was operated at least once per day. The daily timeof-use of the stove demonstrated two distinct peaks, one at 7:54 am, coincident with a morning meal, followed by one at 5:36 pm, coincident with an evening meal. From the field measured data, there was a semi-regular electrical draw over the mid-day period. 
The time-of-use of the stove is shown in Figure 4.6 demonstrating the frequency the stove was used at each minute of the day. The large morning and afternoon peaks are marked with 'x's while one of the midday peaks is marked with a triangular marker at 12:12 pm. Figure 4.6 also demonstrates how the morning and early evening peak are easily identifiable whereas the time-of-day of the midday usage is not as restricted and demonstrates much higher variation.

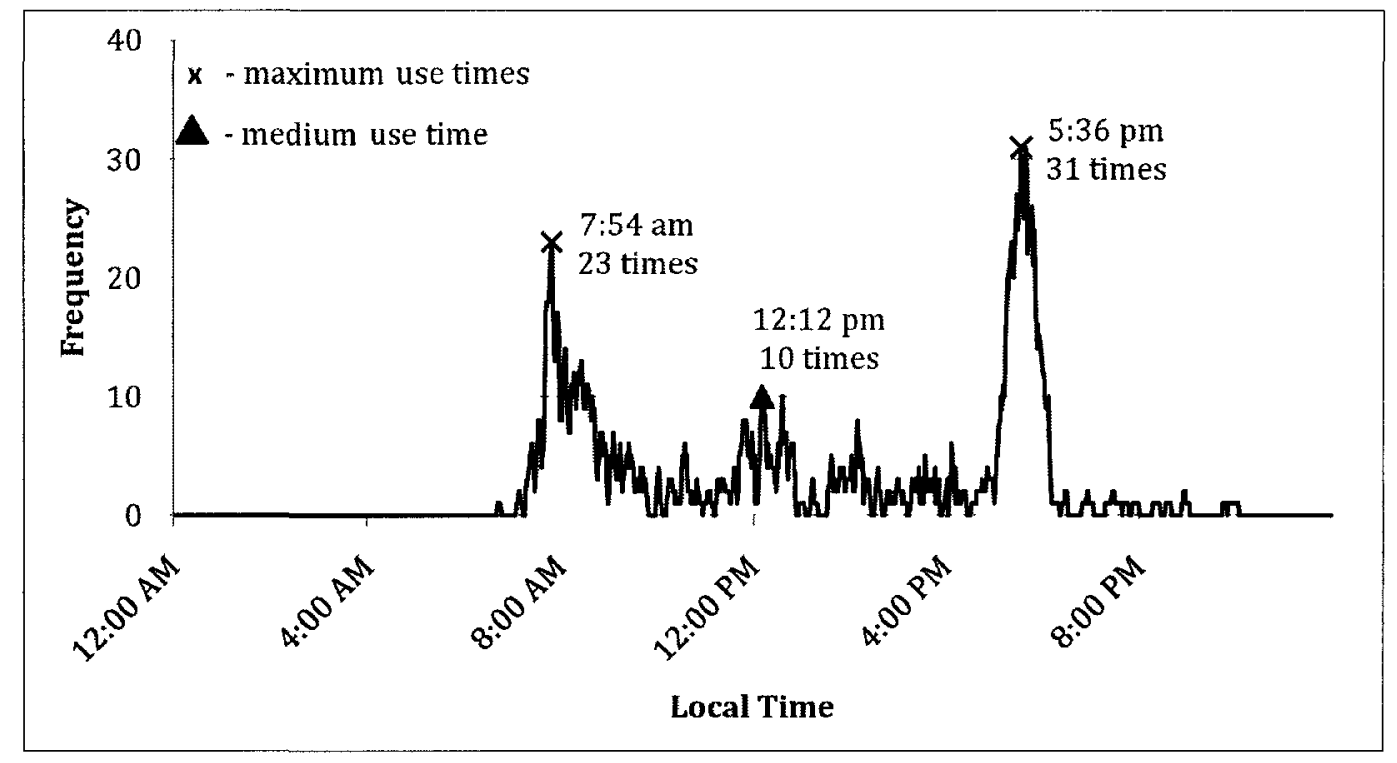

Figure 4.6: Field measured time-of-use of the stove

Each time the stove was used, the electricity draw was around $2.25 \mathrm{~kW}$, although at some times, there were smaller spikes in the data. Even though the stove is often used in the morning or afternoon, it is not necessarily on for the same amount of time. As can be seen in Figure 4.7(a), stove use may have been over two short periods in the morning or one longer period.

The stove use is set to three times per day in the representative profile. The length of time for the morning and evening use is the average length of time the stove is used at either the morning or evening maximum time-of-use $+/-0.5$ hours. The midday stove use is the averaged length of time the stove is used between 11:30 am and 1:00 pm. The morning use of the stove lasts up to 20 minutes, but the average length of morning stove use is approximately 10 minutes. The morning stove use starts at 7:44am. Midday, there is not a single location of typical stove use, and the representative profile has midday stove use at $12: 30 \mathrm{pm}$, which is in the middle of the 


\begin{tabular}{|c|c|}
\hline Stove Electrical Draw & Time and Time of Day \\
\hline \hline $2.25 \mathrm{~kW}$ & 10 minutes at $7: 45 \mathrm{am}$ \\
\hline $2.25 \mathrm{~kW}$ & 10 minutes at $12: 30 \mathrm{pm}$ \\
\hline $2.25 \mathrm{~kW}$ & 25 minutes at $5: 30 \mathrm{pm}$ \\
\hline
\end{tabular}

Table 4.4: Electrical consumption of the representative profile of the stove

trend and lasts 10 minutes. In the evening, the stove use is longer, with a minimum of approximately 10 minutes and a maximum of over 30 minutes. Evening stove use in the representative profile is situated at 5:30 pm, with a 25 minute duration. The representative stove profile is concisely described in Table 4.4 and shown in Figure $4.7(\mathrm{~b})$. 


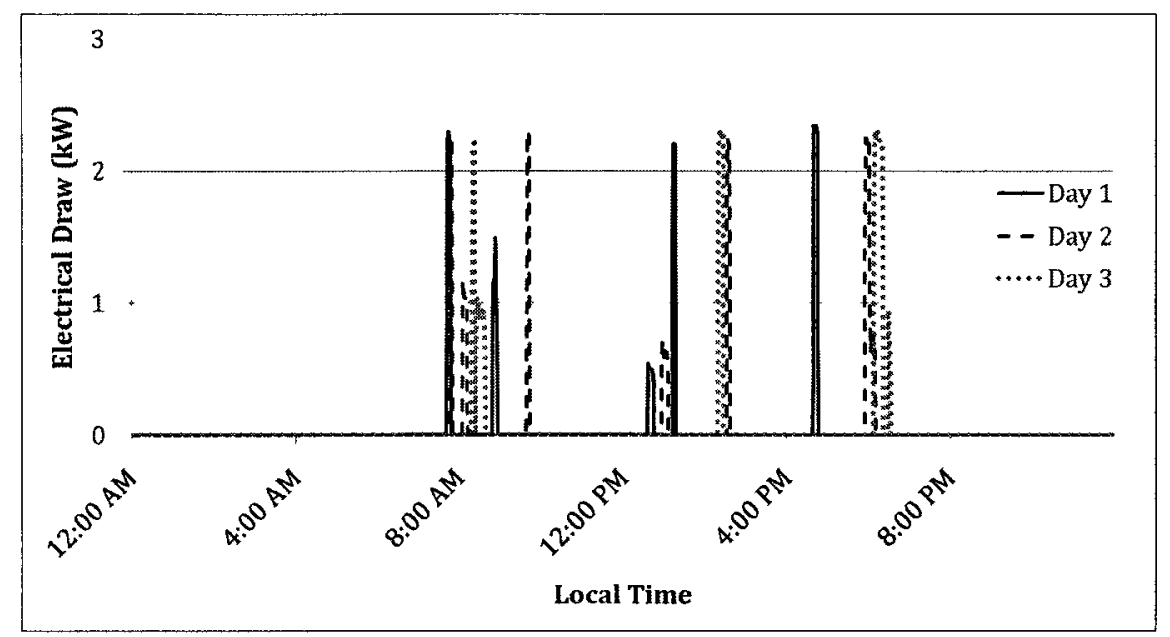

(a) Field measured electricity consumption of the stove on 3 separate days

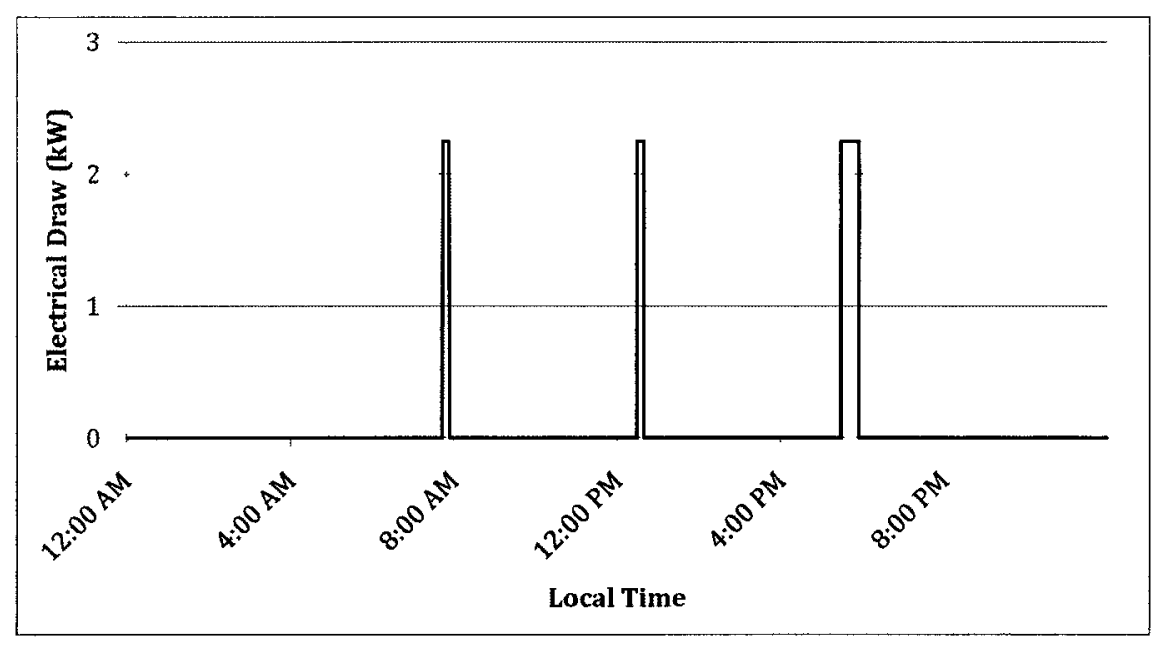

(b) Representative profile of the stove electricity profile

Figure 4.7: Stove usage from (a) field measured data and (b) the representative profile

\subsubsection{Characterizing Refrigerator Use}

The electricity consumption of a refrigerator was monitored for 16 days in July 2009. Due to the consistency in electricity draw from the on-off cycling behaviour of refrigerating units, the process of finding a typical electricity profile for the refrigerator is comparatively straightforward. A short segment showing three days of refrigerator data demonstrate this consistency in Figure 4.8(a). The length of the on-period of each refrigerator cycle varies between 6 minutes and 25 minutes, and the average 
on-period cycle length is 11 minutes. The length of the off-period of each refrigerator cycle varies between 11 and 16 minutes, and the average off-period cycle length is 15 minutes. When the refrigerator is using power, the electrical draw is between 0.14 $\mathrm{kW}$ and $0.16 \mathrm{~kW}$. The representative profile cycling time is 11 minutes on, drawing between $0.13 \mathrm{~kW}$ and $0.15 \mathrm{~kW}$, and 14 minutes off. The field measured data has two daily peaks of around $0.4 \mathrm{~kW}$ for approximately 15 minutes, that occur early in the morning and late afternoon. The two larger peaks were placed at 1:00 am and 5:55 pm. A snapshot of the representative refrigerator profile is shown in Figure 4.8(b) between midnight and approximately 2:30 am. 


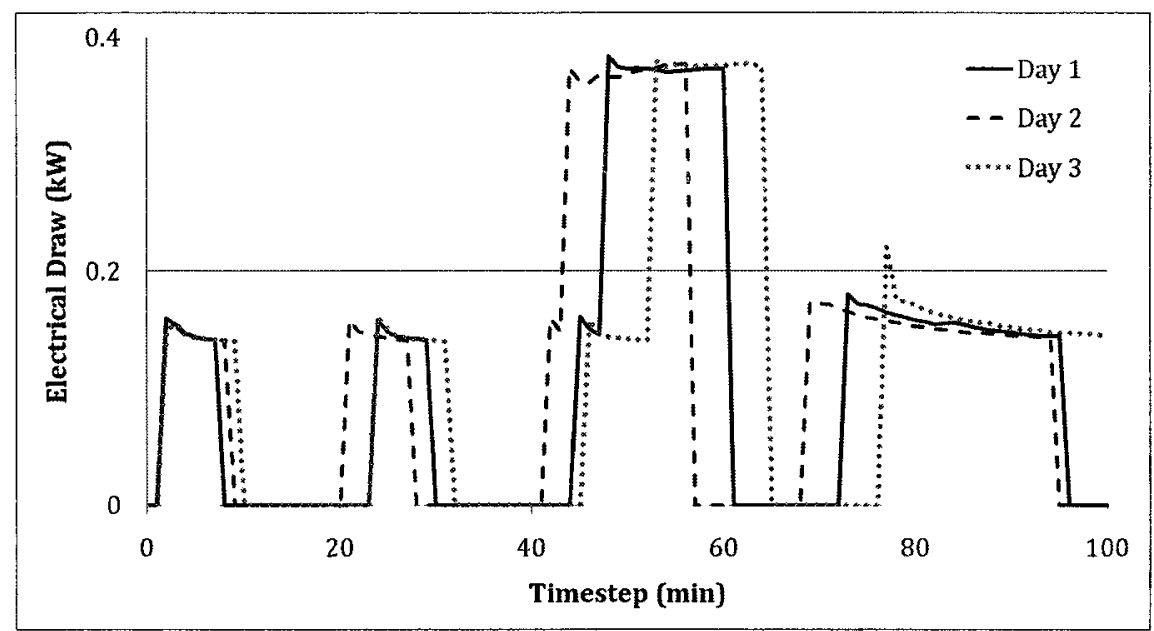

(a) Field measured electricity consumption of the refrigerator over 3 separate days

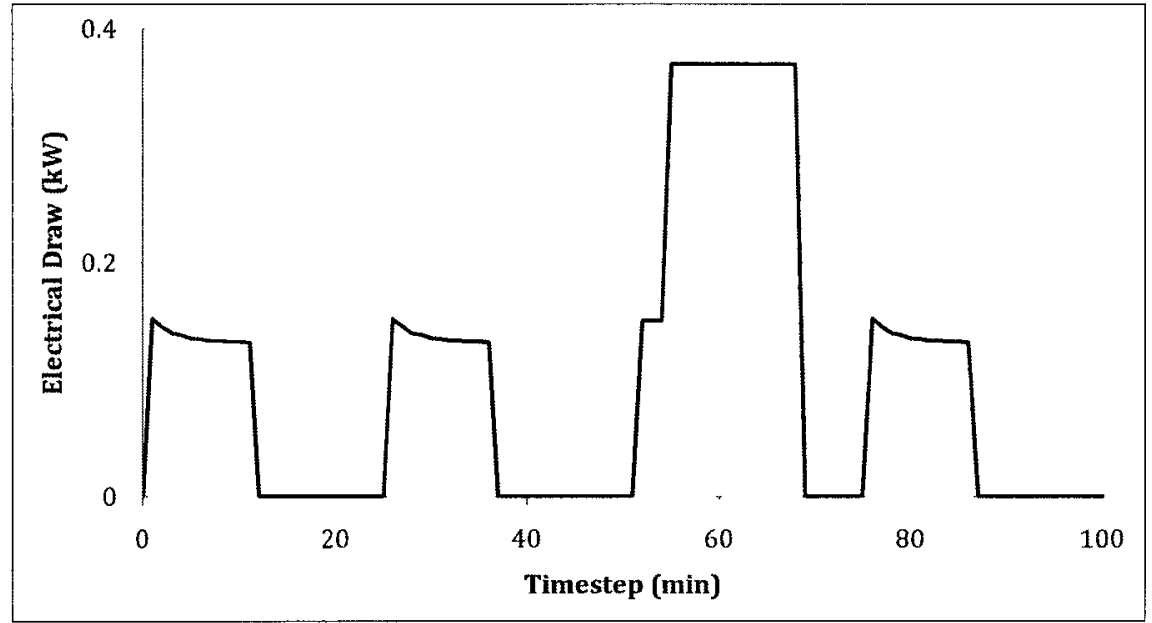

(b) Representative refrigerator electricity profile

Figure 4.8: Refrigerator usage from (a) field measured data and (b) the representative profile

\subsubsection{Characterizing Deep Freezer Use}

The electricity consumption of a deep freezer was monitored for 8 days in May 2009. The freezer has a similar cycling behaviour to the refrigerator. The field measured cycling patterns are shown in Figure 4.9(a). The freezer cycles on for approximately 14 minutes and off for 20 minutes. During the on-period, the freezer electricity demand spikes to $0.25 \mathrm{~kW}$ and drops to $0.18 \mathrm{~kW}$ at the end of the cycle. One cycle of the 
representative freezer profile is shown in Figure 4.9(b).

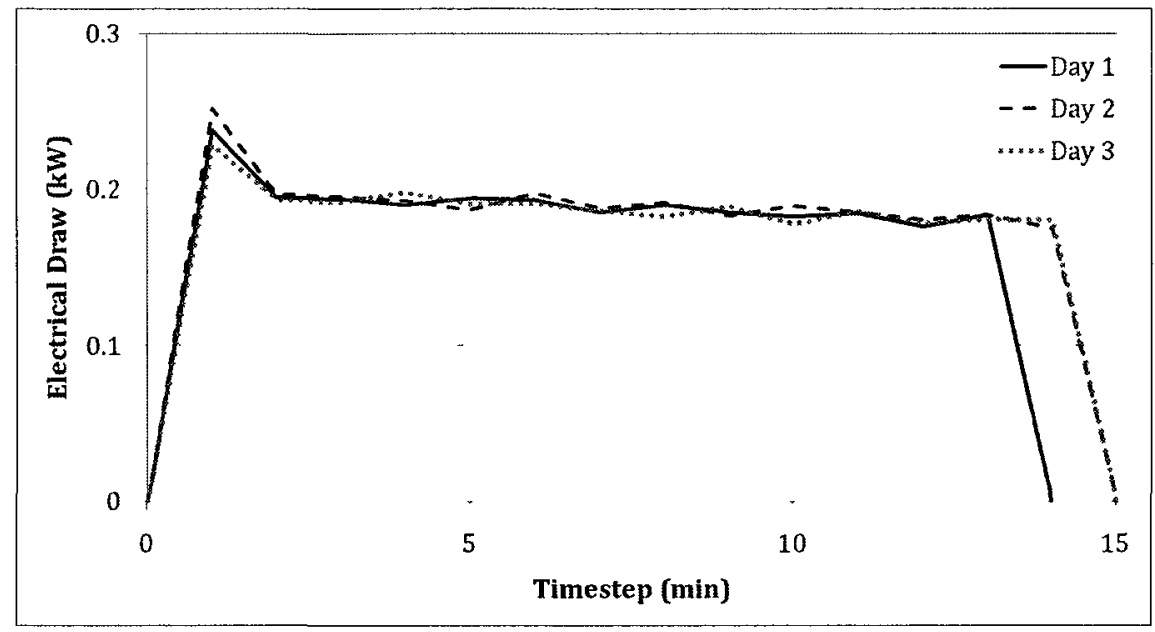

(a) Field measured electricity consumption of the freezer over 3 separate days

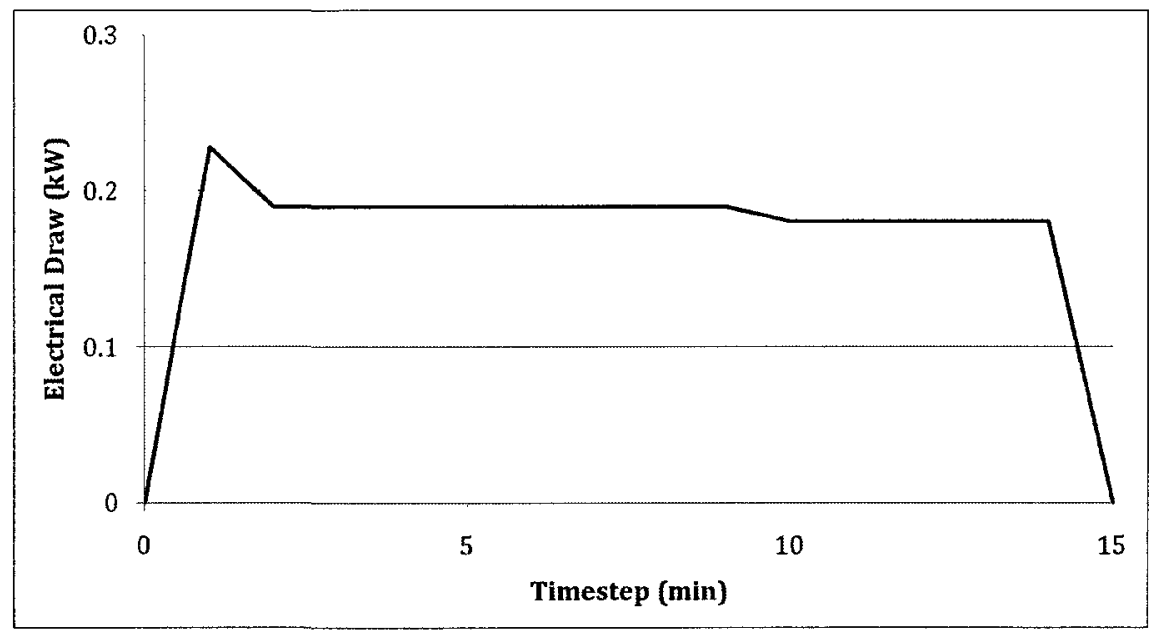

(b) Representative freezer electricity profile

Figure 4.9: Freezer usage from (a) field measured data and (b) the representative profile

\subsubsection{Characterizing Small Appliances and Remaining Plug Loads}

Computer electricity demand was available for 6 days. This showed a constant 0.2 $\mathrm{kW}$ electrical draw between 7:30 am and 4:45 pm, and this profile is used in the representative profile. 
The rest of the household's plug-in items and appliances are estimated to complete the generated profile. These appliances include lighting, electronics both in-use and any phantom loads when off, smaller kitchen appliances etc. Along with the three measured appliances, the Saldanha study included the daily total non-HVAC electricity demand [51]. Over 79 days, each specific measured appliance load is subtracted from the total non-HVAC load at each minute. This gives a daily measurement of the remaining loads in the house. For the representative profile, the electricity draw is averaged for each minute over 79 days. This averaged profile of remaining loads for the representative profile is shown in Figure 1.10.

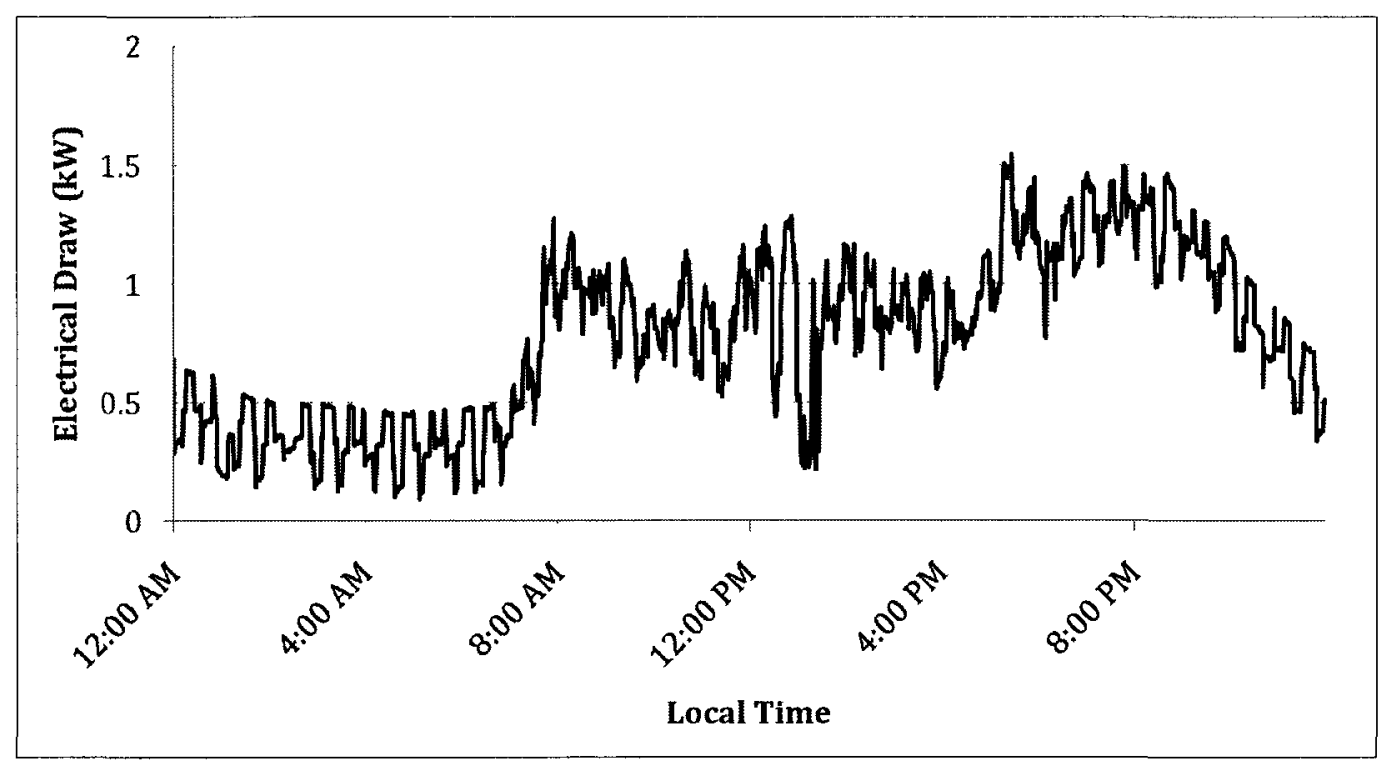

Figure 4.10: Averaged profile of remaining plug loads

\subsubsection{Final Completed Profile}

Each profile listed above is aggregated into one household electricity profile. The overlaid loads are shown in Figure 4.11, which demonstrates the mixture of low electrical draw appliances along the horizontal axis, as well as the peak electrical draws of the clothes dryer and dishwasher. Figure 4.12 shows the aggregated representative profile which is implemented into the ESP-r base case model. Appliances release different amounts of heat into the environment - and this was accounted for in the operations file, as described in Chapter 3. 


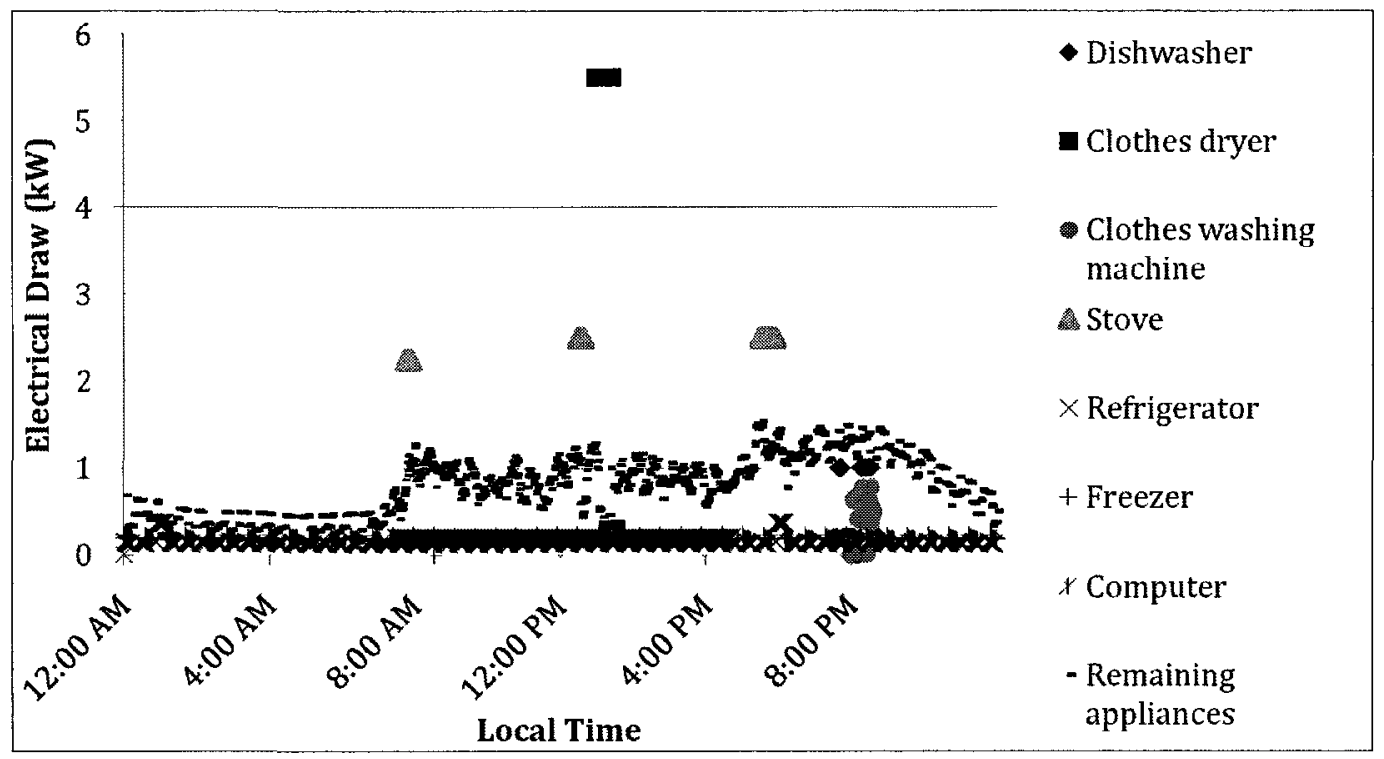

Figure 4.11: Aggregation of appliances in the representative profile

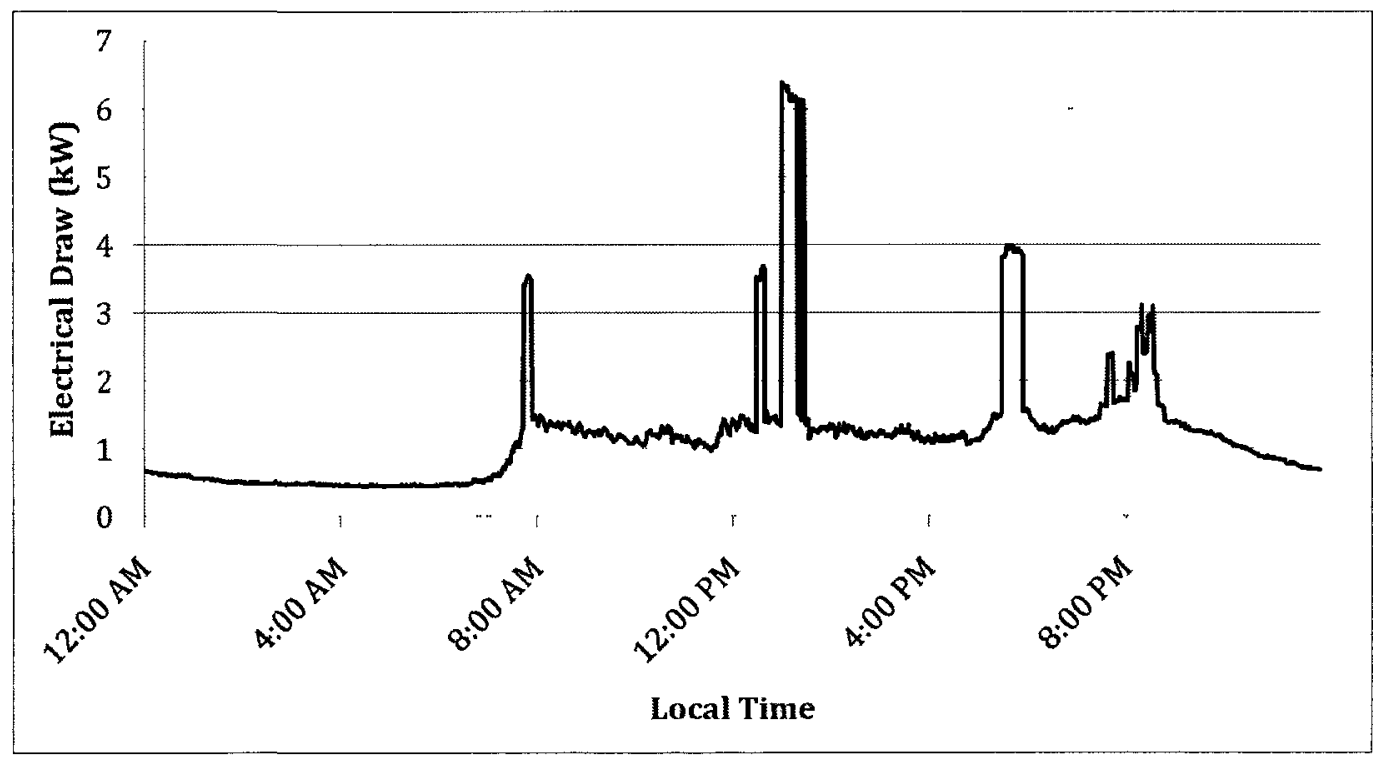

Figure 4.12: Representative profile of the occupant electricity usage

Unlike the representative occupancy profile, the daily HVAC profile depends on the zone's thermal setpoints and is also affected by changes in external solar, thermal 
and wind conditions. The HVAC and non-HVAC profiles, and total electricity consumption in kilojoules over each minute on July 31 are shown in Figure 4.13. July 31 was a hot summer day with a high amount of solar radiation.

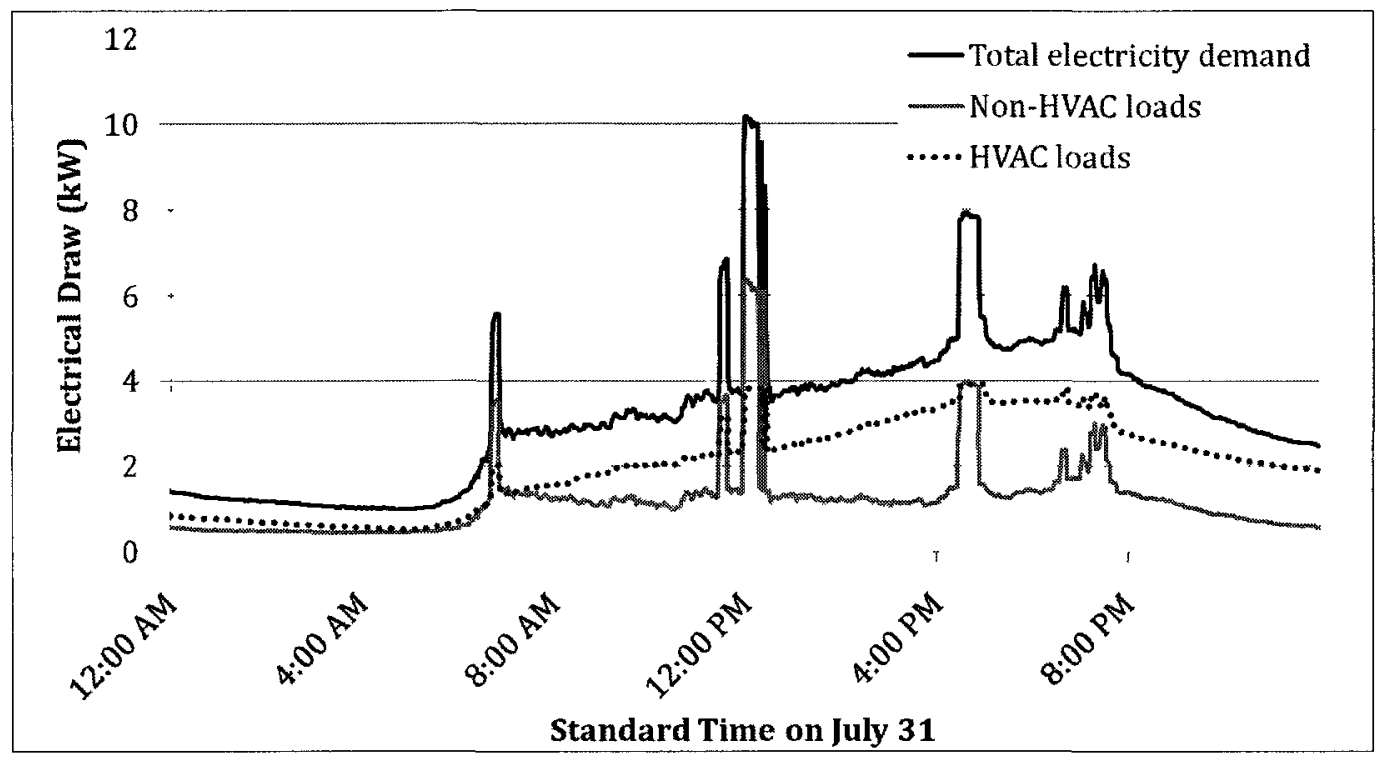

Figure 4.13: HVAC, non-HVAC and total electricity consumption on July 31 


\section{Chapter 5}

\section{Variations on the Base Case with the Potential to Reduce On-Peak Electricity Consumption}

Both varying architectural components and modifying the operation of the house have the potential to reduce the electricity consumption on-peak. There are four categories of techniques that can potentially reduce the on-peak electricity consumption of the base case: varying architectural and design components, technological variations, changes in occupant behaviour, and local generation with or without a storage component. These broad categories encompass specific modifications of the base case. The results of each modification are based on a set of metrics described in Chapter 6. The following chapter describes each variation on the base case and the reason for the choosing the variant to reduce on-peak electricity consumption. Each category includes a large number of options, therefore an initial extreme or highly-unlikely variation is simulated. This is done to give reference to the maximum potential of the category of variation and to determine how effective and worthwhile this variant is for investigation.

\subsection{Variations of Architectural and Design Com- ponents}

Modifying the building envelope is a passive approach to mitigate cooling loads. Variations in this category have the potential to reduce space cooling by shading the opaque and transparent surfaces of the building, reducing the absorption of incoming 
solar radiation, or redistributing the fenestration to reduce the on-peak solar gains.

\subsubsection{Architectural Shading Features}

Building shading is achieved by adding materials to absorb and block the direct solar radiation that would otherwise have penetrated the surfaces of the building. Roof overhangs can block direct solar radiation during on-peak hours when the solar altitude angle is larger. The original building specifications included roof overhangs, however said overhangs were excluded from the base case. Thus, all variations could be compared to this reference, and the effects of external shading features could be properly examined. There are two variations that make use of roof overhangs. The first variant uses the overhangs from the building specifications, which are $0.5 \mathrm{~m}$ deep. The second variant increases the depth of the roof overhangs to $1 \mathrm{~m}$, providing more shade over a longer period of time. Figure 5.1 shows the addition of the original roof overhangs onto the house.

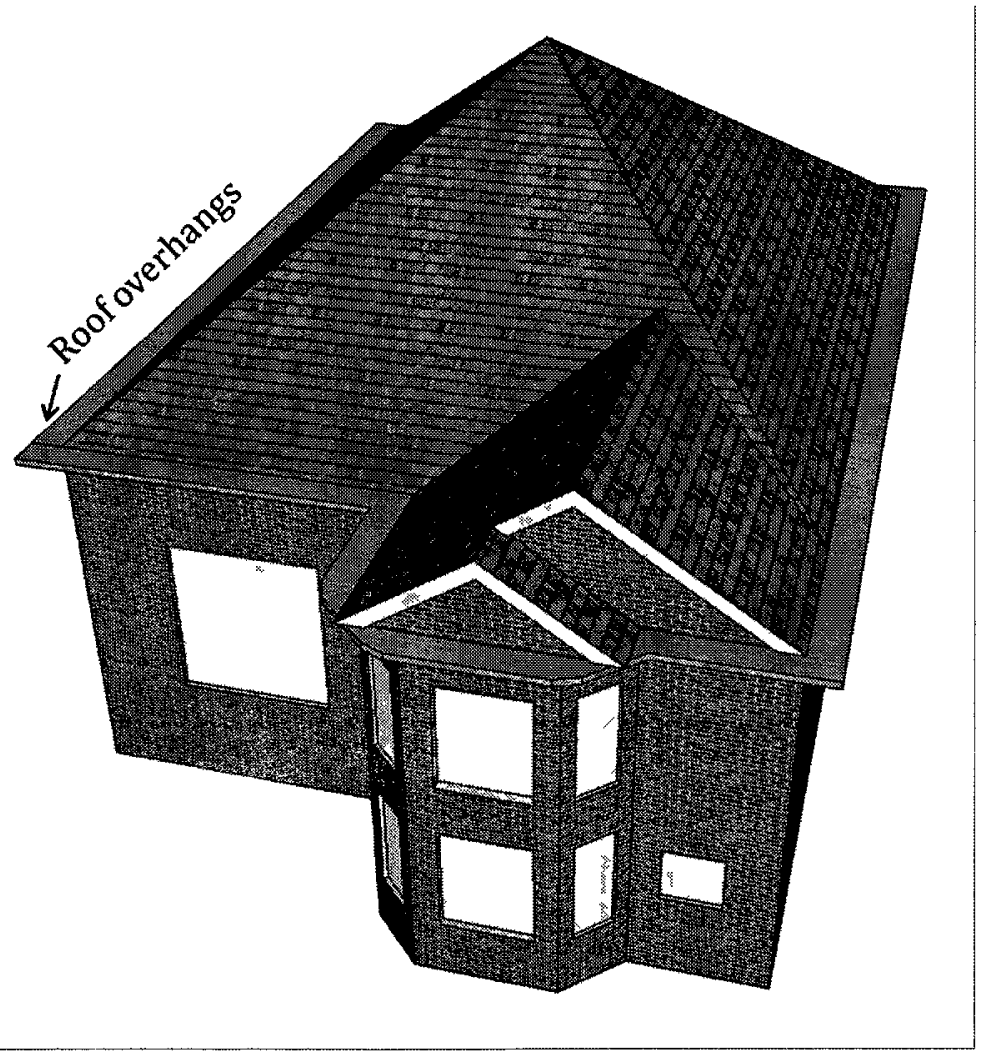

Figure 5.1: $0.5 \mathrm{~m}$ deep roof overhangs 
Window awnings explicitly shade the transparent surfaces from direct solar radiation as they are placed directly above the fenestration of a building. Due to the northern hemispheric location of the building, solar gains are higher on the south face. The base case has a large amount of south-west facing glazing, and window awning variations focus on this face. Window awnings are placed over the south-west fenestration of the building for two variations, one set with a depth of $30 \mathrm{~cm}$ and the second set with a depth of $50 \mathrm{~cm}$. The variation with $30 \mathrm{~cm}$ south-west window awnings are shown in Figure 5.2.

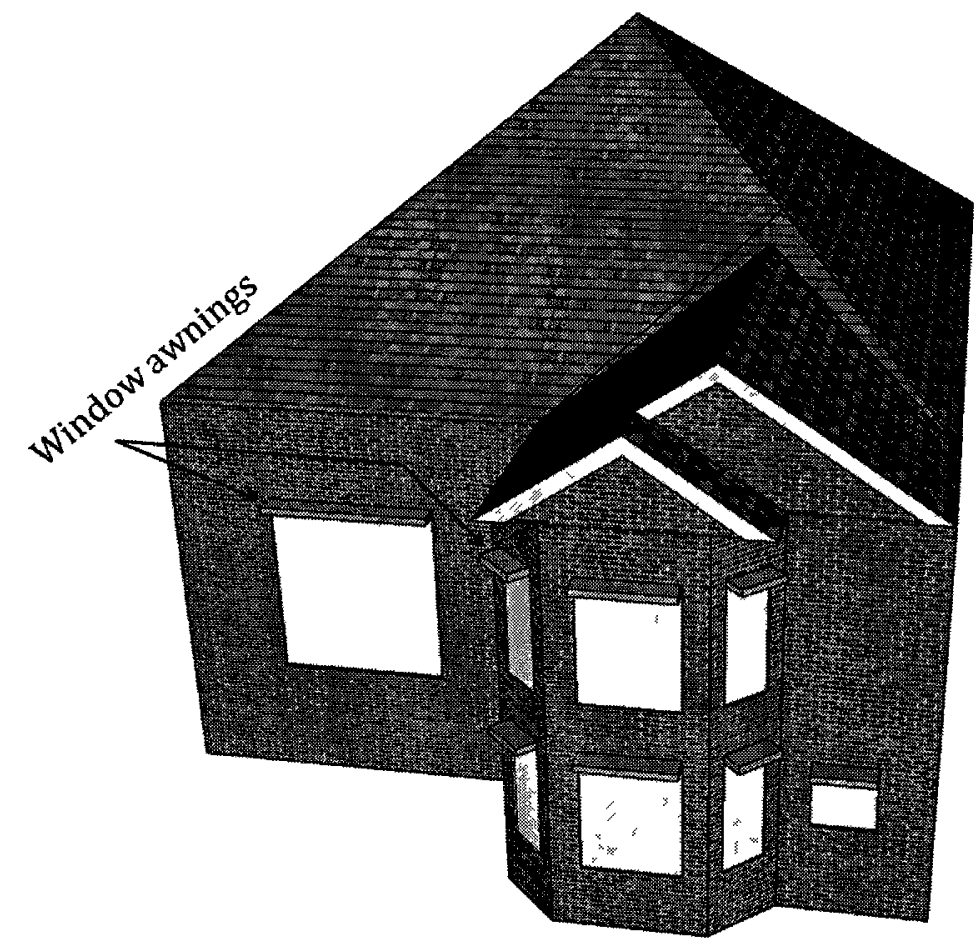

Figure 5.2: $30 \mathrm{~cm}$ window awnings on the south-west building face

\subsubsection{Shading by Vegetation}

Use of vegetation for shading has the potential to mitigate cooling by reducing the solar gains that reach the opaque and transparent surfaces, but the effectiveness shading with vegetation is limited to the size of vegetation. Large trees would be a primary form of shading through vegetation, but take years to reach a size which 


\begin{tabular}{|l|l|}
\hline Architectural Shading Variants & Details \\
\hline \hline Roof overhangs & $\begin{array}{l}\text { a) } 0.5 \mathrm{~m} \text { depth } \\
\text { b) } 1 \mathrm{~m} \text { depth }\end{array}$ \\
\hline South-west face window awnings & a) $30 \mathrm{~cm}$ depth \\
& b) $50 \mathrm{~cm}$ depth \\
\hline Line of trees & Located $8 \mathrm{~m}$ south of the house \\
& $15 \mathrm{~m}$ height \\
& $6 \mathrm{~m}$ wide \\
\hline
\end{tabular}

Table 5.1: Architectural shading variations

provides useful shading. A vegetative shading variation is an extreme strategy and models a solid line of trees along an east-west axis south of the house. The house and tree-line are $8 \mathrm{~m}$ apart, a value chosen as a reasonable distance to allow space around the house but still provide shading on the house. The trees common in a Southern Ontario climate grow between $10 \mathrm{~m}$ and $35 \mathrm{~m}$ tall [53], and a conservative estimate was made for the height of mature trees at $15 \mathrm{~m}$. To ensure an extended period of shading on the south face of the building, the tree line is $6 \mathrm{~m}$ long. The trees are assumed to provide a constant amount of shading over the entire year.

The variants that make use of architectural shading features are concisely listed in Table 5.1.

\subsubsection{Window Design and Properties}

Modifying the thermal or optical characteristics of a window using fill gases, additional glazing layers or varying the glazing properties will change the associated heat transfer and solar gains. Reflective glass on the outer pane reduces the absorbed and transmitted solar radiation by increasing the amount that is reflected. Low-e coatings are placed on the the inner pane of glass facing the gas gap, shown in Figure 5.3, and reduce the radiant heat transfer into the zone. The low-e coating is a thin layer of low-emissivity material, typically a microscopically thin layer of metal, on the glass face. The low-e coating is transparent to visible light, but reduces the transmittance of long-wave radiation into the zone, therefore reducing solar heat gains. Thermal 
windows with multiple panes and gas fills such as argon or krypton are useful in a Canadian climate in the winter. Different gas fills reduce heat loss from a building as they are more resistive to heat flow than air. More focus was placed the reflective and low-e coating options as they have a higher potential to reduce summer electricity consumption, but one window variant models an extreme thermal case with four panes of glass and krypton gas-fill. Use of this window in a Southern Ontario home would be expensive and likely unnecessary. Nonetheless, this variant tests the effect of thermal windows on summer electricity consumption.

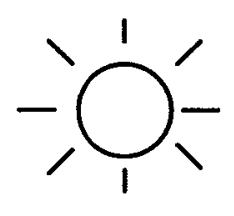

solar 10
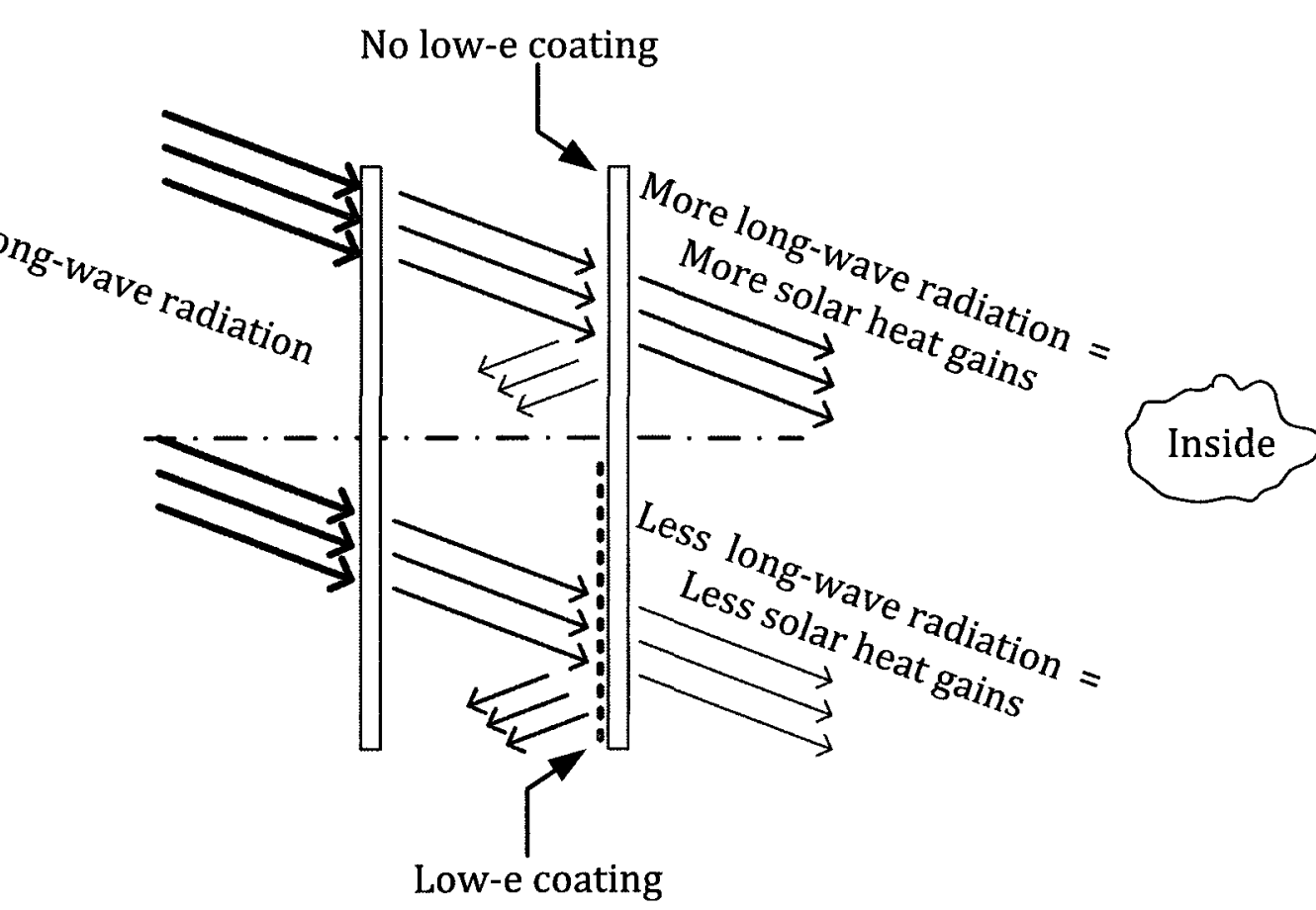

Figure 5.3: Representation of the effect low-e coatings have in reducing entering long-wave solar radiation

Reflective window variants increase the reflectivity of the outer-most pane of glass reflecting more of the incoming solar radiation, therefore reducing the amount of solar radiation that is absorbed or transmitted. The base case windows have a reflectivity value ( $\rho$ value) of 0.072 . Two variants use the same window construction as the base case, but increase the outer pane reflectivity value. The first has a $\rho$ value of 0.117 , and the second with a larger $\rho$ value of 0.217 . 
The reflective glass with a $\rho$ value of 0.117 is also used as the external pane of a triple-pane window and is integrated with low-e coatings on the two inner panes. This combination of reflectivity and low-e coatings reduces both the shortwave and longwave radiation entering the zone. A triple-pane, low-e window construction without the reflective outer coating is also a variant to test the effects of two low-e panes compared to use of the reflective layer, as well as to the base case.

The base case windows have internal horizontal venetian blinds with a slat angle in the open position ( $0^{\circ}$ relative to the horizontal). To test the effectiveness of blinds for shading, space cooling mitigation or shifting space cooling demands, two variants change the slat angle of the blinds for the entire year. These variants are not realistic, but give reference to the potential blinds have in reducing on-peak electricity consumption. The first variant has a slat angle at $45^{\circ}$ relative to the horizontal, and the second variant effectively closes the blinds to a slat angle of $80^{\circ}$ relative to the horizontal. The implementation of venetian blinds in ESP-r sets $80^{\circ}$ as the default angle for a closed blind configuration, and does not allow the actuation angle to be above $89^{\circ}$. Venetian blinds tend to overlap slightly, and cannot reach a $90^{\circ}$ slat angle [54]. Figure 5.4 demonstrates the closed slat angle at $80^{\circ}$.

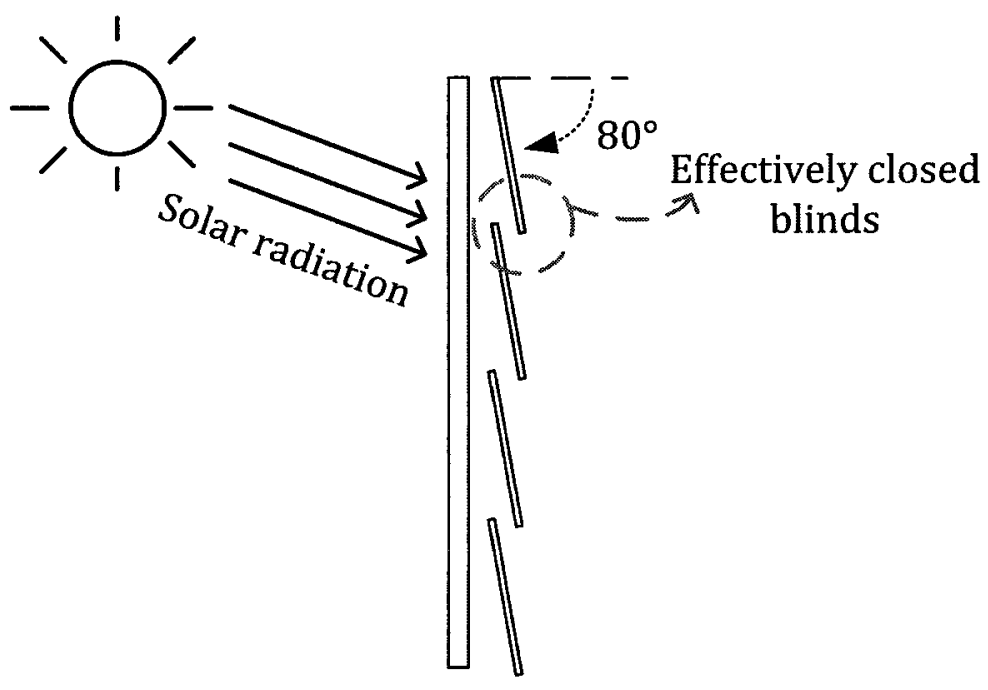

Figure 5.4: Effectively closed venetian blinds at $80^{\circ}$

Table 5.2 concisely lists the variations of window design and properties. 


\begin{tabular}{|l|l|}
\hline Window Variant & Details \\
\hline \hline Extreme thermal windows & Quadruple-pane, krypton gas-fill \\
\hline Reflective outer pane & $\begin{array}{l}\text { a) } \rho=0.217 \\
\text { b) } \rho=0.117\end{array}$ \\
\hline Thermal low-e reflective & $\begin{array}{l}\text { Triple-pane, argon gas-fill } \\
\text { Reflective outer layer } \\
\text { Low-e coating on both inner layers }\end{array}$ \\
\hline Thermal low-e & $\begin{array}{l}\text { Triple-pane, argon gas-fill } \\
\text { Low-e coating on both inner layers }\end{array}$ \\
\hline Blind slat angle, half-closed & Horizontal slat angle of $45^{\circ}$ \\
\hline Blind slat angle, closed & Horizontal slat angle of $80^{\circ}$ \\
\hline
\end{tabular}

Table 5.2: Window and glazing variations

\subsubsection{Fenestration Size and Distribution}

Re-sizing and re-distributing the fenestration can reduce the transmitted solar radiation or shift the times when solar radiation can enter the zone. Re-sizing the fenestration occurs in two variations. The first variant reduces each window and frame area by $10 \%$ relative to the base case. The second variant reduces the glazing and frame areas of each window by $25 \%$ relative to the base case. These values were chosen as feasible options for occupant comfort, without excessively reducing the natural light in the zone.

Re-distributing the fenestration focuses on shifting the south-west fenestration, which has the most glazing, to other faces of the house with less glazing and less intense solar radiation on-peak. For these simulations, both the glazing and framing areas are re-distributed to the other faces. The first fenestration shifting variant moves half of the south-west face fenestration to the north-east and north-west faces. A plan-view of the house is shown in Figure 5.5, demonstrating the two walls with increased fenestration area. The redistributed fenestration increases the area of preexisting windows on other faces. A second fenestration distribution variant shifts half of the south-west fenestration to the three other building faces shown with a 


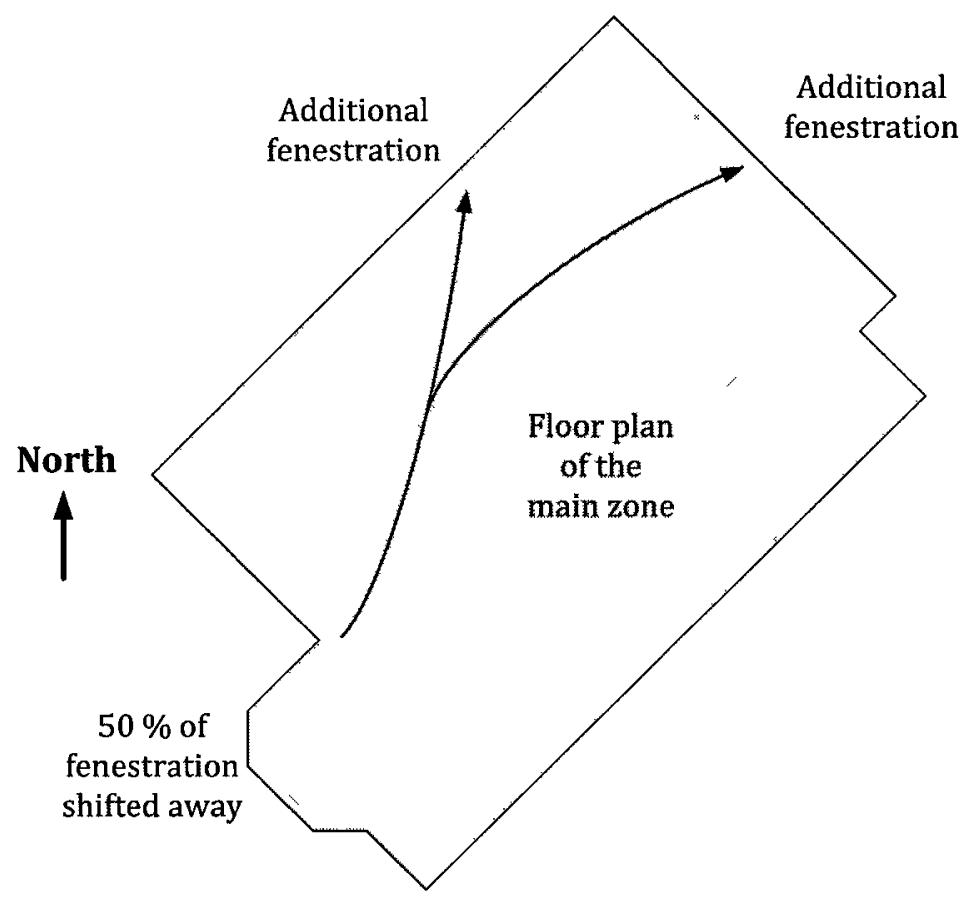

Figure 5.5: Shifting $50 \%$ of the south-west fenestration to the north-west and northeast sides

plan-view in Figure 56. Table 5.3 concisely lists the fenestration variants.

\subsubsection{Modifying Constructions}

Reflective shingles reflect $42 \%$ of the incoming shortwave solar radiation, whereas the base case shingles only reflect $5 \%$. The remaining solar radiation is conducted through the roof layers to convectively transfer heat into the attic space. The reduction in heat transfer to the attic due to reflective shingles reduces the attic temperature, which ultimately reduces the temperature difference between the attic and main zones of the home. This reduction in the temperature difference between the main zone and the attic reduces the heat transfer from the attic to the main zone.

Another construction based design variation is the addition of concrete floors. Concrete surfaces are commonly combined with pre-cooling to take advantage of the thermal mass qualities of concrete. Pre-cooling modifies the thermal setpoint in the zone to a lower temperature in the early morning, so that the temperature of the zone is low at the start of the on-peak period. Thermal mass is characterized by 


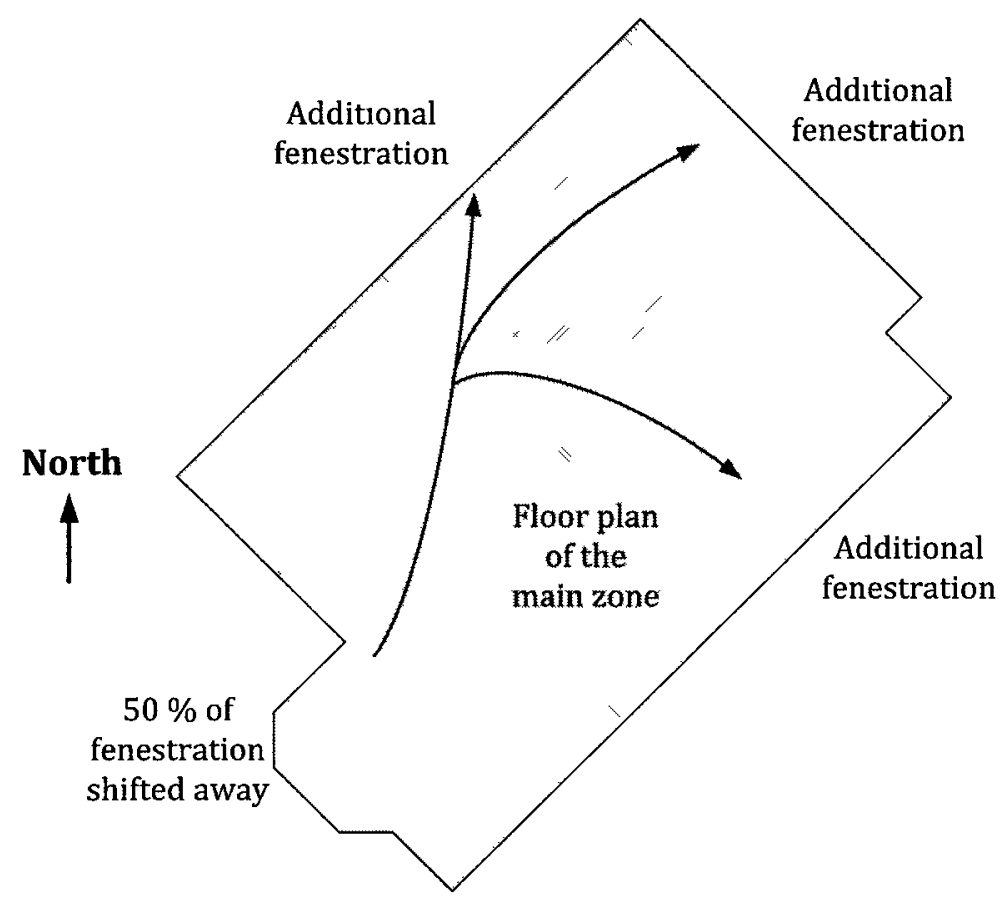

Figure 5.6: Shifting $50 \%$ of the south-west fenestration to the north-west, north-east sides and south-east sides

the heat capacity and density of the material, and affects a material's ability to store thermal energy over time. Storing the thermal energy from the sun during peak hours maintains a cooler air temperature longer, reducing the immediate space cooling demand. The thermal mass will eventually release stored energy back to the air. This release will be shifted in time, resulting in space cooling demand occurring later in the afternoon, potentially outside of the on-peak period. The high heat capacity and density of concrete make it an effective thermal mass material. To characterize the the effectiveness of concrete floors with the current thermal controls, $10 \mathrm{~cm}$ thick concrete floors replace the main zone floor construction for one variant.

\subsection{Technological Modifications with a Building}

Technology based strategies aimed at reducing the on-peak electricity are called active strategies, as opposed to the passive strategies described previously in Section 5.1. These active strategies focus on thermal setpoints, actuating blind position or affecting the air-conditioning usage. 


\begin{tabular}{|l|l|}
\hline Fenestration Variant & Details \\
\hline \hline Reducing fenestration size & $10 \%$ area reduction for all main-zone fenestration \\
\hline Reducing fenestration size & $25 \%$ area reduction for all main-zone fenestration \\
\hline Shifting fenestration & $\begin{array}{l}50 \% \text { area shift of south-west glazing to north-east } \\
\text { and north-west faces }\end{array}$ \\
\hline Shifting fenestration & $\begin{array}{l}50 \% \text { area shift of south-west glazing to north-east, } \\
\text { north-west and south-east faces }\end{array}$ \\
\hline
\end{tabular}

Table 5.3: Variants that shift or reduce the household fenestration

\subsubsection{Thermal Mass and Pre-Cooling Strategies}

Thermal mass in combination with pre-cooling increases the potential for energy absorption of the thermal mass on-peak. Absorption and storage of the thermal energy reduces an immediate effect on the zone temperature, offsetting on-peak space cooling requirements.

Three pre-cooling strategies are combined with the thermal mass case. Pre-cooling strategies chill the zone in the morning, and then allow the zone temperature to rise above typical comfort temperatures until the end of the on-peak period. These precooling strategies heavily rely on thermal mass to absorb thermal energy and keep the zone air cool until a higher setpoint temperature is reached. This higher setpoint period is considered a "float" period, when the house temperature can slowly rise to the new setpoint temperature. Once the main zone temperature reaches a temperature of $27^{\circ} \mathrm{C}$, air-conditioning can be used again to maintain this warmer setpoint until the end of the on-peak period. The three pre-cooling strategies are simulated with the base case, replacing the original control strategy. Thermally massive concrete floor are also simulated with each of the pre-cooling strategies to compare the effects that both pre-cooling and thermal mass have on the zone temperature and space cooling demands.

The pre-cooling strategies shown here are in standard time. Toronto, Ontario uses daylight savings time between March and November. Daylight savings time shifts the local time one hour ahead, and the local time shifts back one hour to standard time in the winter months. Standard time is used in this study, and the standard time on-peak hours are between 10:00 am and 4:00 pm. 


\section{Pre-cooling strategy $1, \mathrm{PC} 1$, in standard time}

$\mathrm{PC} 1$ is shown in Figure 5.7, and chills the house to $21^{\circ} \mathrm{C}$ for an hour between 5:00 and 6:00 am, followed by an hour at a $24^{\circ} \mathrm{C}$ setpoint, and finally has the house float to $27^{\circ} \mathrm{C}$ from 7:00 am to 4:00 pm. This pre-cooling schedule has the longest afternoon float time, and the shortest pre-cooling period. The house is also set to $27^{\circ} \mathrm{C}$ overnight with this strategy, warmer than the base case over night setpoint of $24^{\circ} \mathrm{C}$. This strategy tests the longterm effectiveness of thermal mass and pre-cooling, and is more of an extreme case due to the potential long periods of time with $27^{\circ} \mathrm{C}$ zone temperatures.

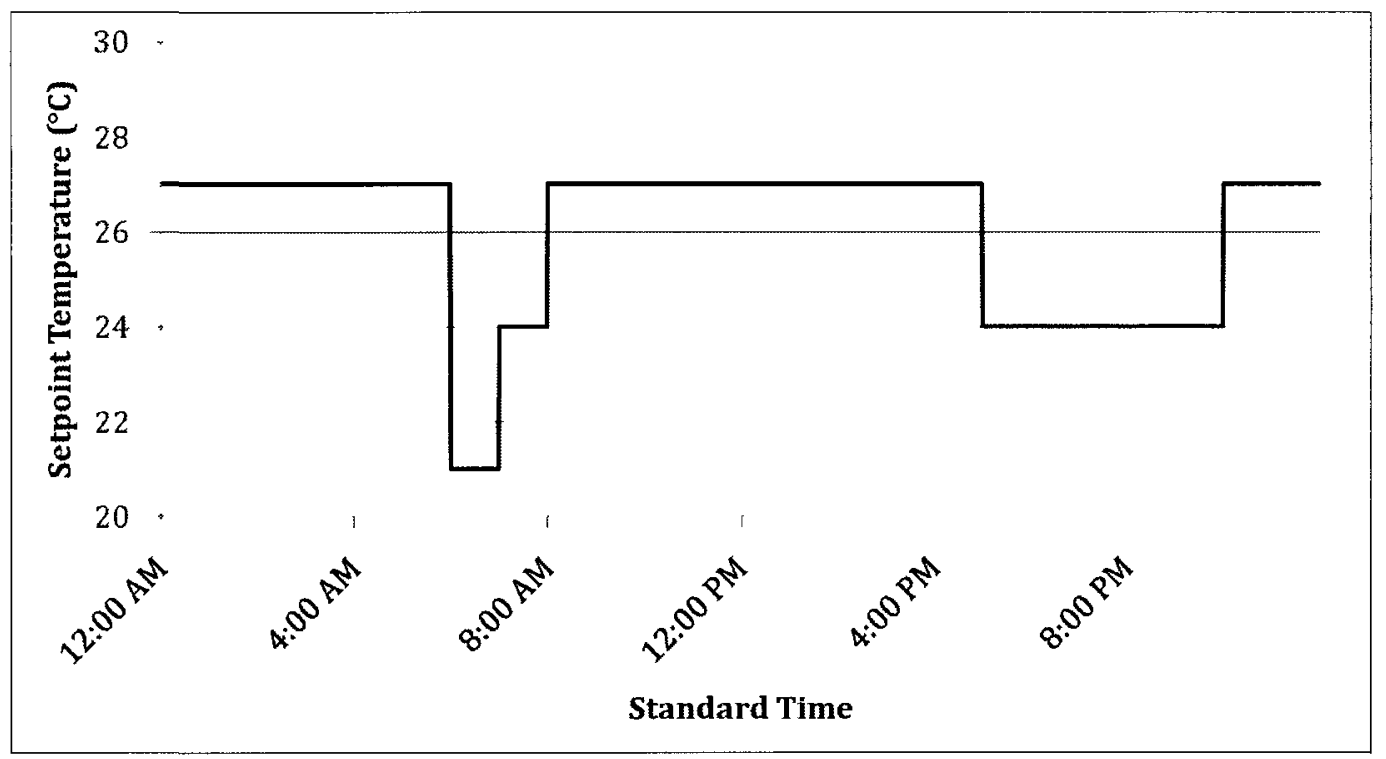

Figure 5.7: Thermal setpoints of the PC1 control strategy

\section{Pre-cooling strategy 2, PC2, in standard time}

PC2 has more variation than PC1 and shortens the afternoon float period. PC2 chills the house to $21^{\circ} \mathrm{C}$ over two separate hours in the morning, the first between 5:00 am and 6:00 am, and the second between 9:00 am and 10:00 am leading up to the on-peak period. The afternoon float with a $27^{\circ} \mathrm{C}$ setpoint occurs between 10:00 am and 4:00 pm. This pre-cooling schedule is shown in Figure 5.8. PC2 also has an overnight setpoint temperature of $27^{\circ} \mathrm{C}$. This strategy is a more realistic implementation of pre-cooling as it focuses the float period during on-peak hours only. 


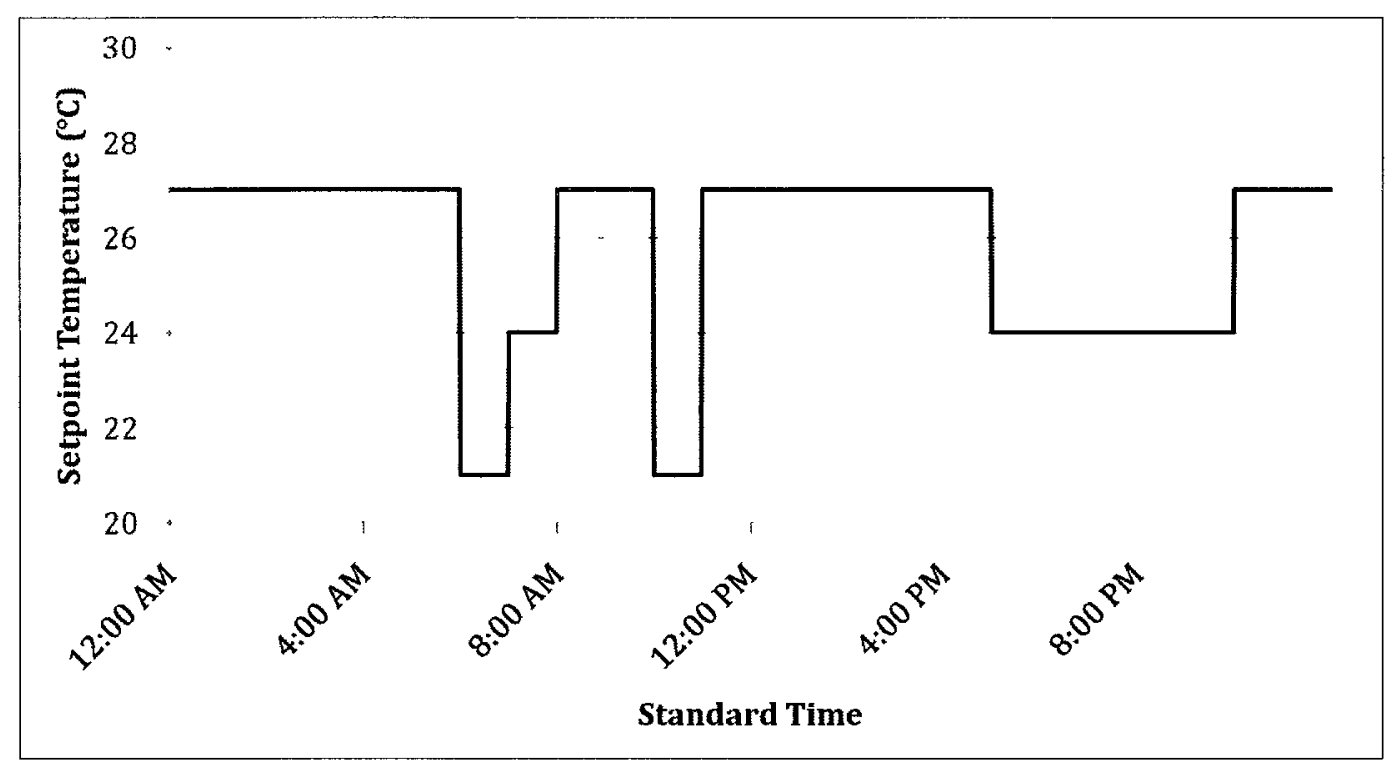

Figure 5.8: Thermal setpoints of the PC2 control strategy

\section{Pre-cooling strategy 3, PC3, in standard time}

PC3 includes a much longer pre-cooling period, from 6:00 am to 10:00 am at $21^{\circ} \mathrm{C}$. The afternoon setpoint is $27^{\circ} \mathrm{C}$ from 10:00 am to 4:00 pm. PC3 also differs from the first two strategies as it allows for cooler overnight temperatures of $24^{\circ} \mathrm{C}$. The PC3 control strategy is shown in Figure 5.9. PC3 has a very long pre-cool period, which can potentially offset the on-peak cooling demand by shifting space cooling use to the morning mid-peak period. The $27^{\circ} \mathrm{C}$ float period is focused on-peak only.

The pre-cooling strategies are listed in Figure 5.2.1 on page 76. 


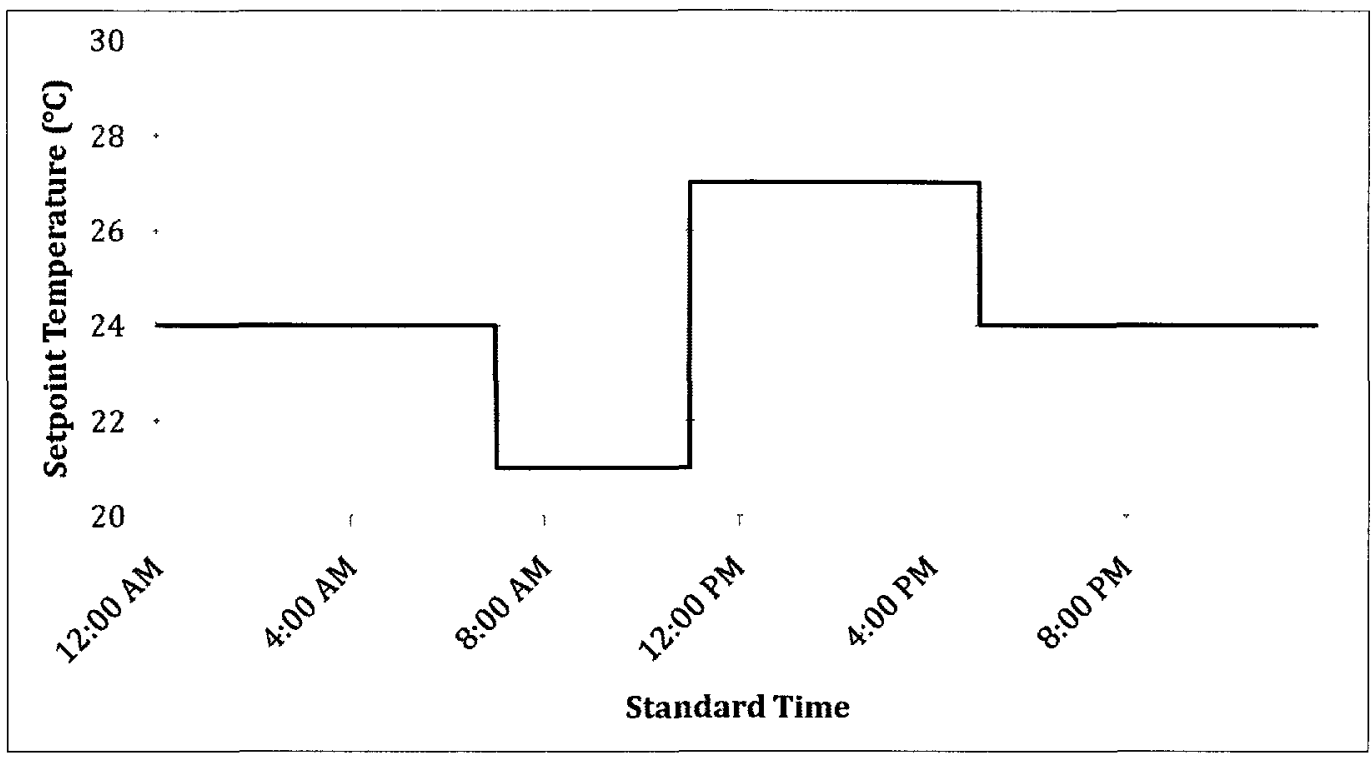

Figure 5.9: Thermal setpoints of the PC3 control strategy

\subsubsection{Blind Actuation to Sensed Conditions}

Technology can be used to actuate the horizontal venetian blinds on the windows based on a sensed condition such as temperature or solar radiation levels. Three sensors are used for blind actuation variants and are combined with both the original base case window construction (internal blinds) as well as a second window construction where the venetian blinds are placed externally. External blinds are beneficial because the convective and radiative heat transfer associated with these blinds does not affect the zone air temperature, instead interacting with the outdoor air. The three controls are based on different sensors that affect the use of space cooling in the zone and are based on previous work by Beausoleil-Morrison, 2009 [45]. The first control senses when the outdoor air temperature, $T_{\text {out }}$, rises above $28^{\circ} \mathrm{C}$ before closing the blinds. The second control senses the main zone temperature, actuating the blinds when the zone temperature, $T_{z o n e}$, rises above $22^{\circ} \mathrm{C}$, reducing immediate solar gains before reaching the cooling setpoint temperature. The third control actuates the blinds when the incident solar radiation, $I_{\text {sol-rad }}$, on the south-west face of the building is above $500 \mathrm{~W} / \mathrm{m}^{2}$. All of the control strategies actuate the blinds to a closed position, which is defined as an $80^{\circ}$ slat angle relative to the horizontal. These 


\begin{tabular}{|l|l|}
\hline $\begin{array}{l}\text { Actuation Strategy } \\
\text { (Internal or External) }\end{array}$ & Environmental Trigger \\
\hline \hline Actuating due to outdoor air temperature & $\begin{array}{l}\text { Blinds close when } T_{\text {out }} \geq 28^{\circ} \mathrm{C} \\
\text { Re-open when } T_{\text {out }} \leq 27^{\circ} \mathrm{C}\end{array}$ \\
\hline Actuating due to zone temperature & $\begin{array}{l}\text { Blinds close when } T_{z o n e} \geq 23^{\circ} \mathrm{C} \\
\text { Re-open when } T_{\text {zone }} \leq 22.5^{\circ} \mathrm{C}\end{array}$ \\
\hline Actuating due to incident solar radiation & $\begin{array}{l}\text { Blinds close when } I_{\text {inc-rad }} \geq 500 \mathrm{~W} / \mathrm{m}^{2} \\
\text { Re-open when } I_{\text {rnc-rad }} \leq 450 \mathrm{~W} / \mathrm{m}^{2}\end{array}$ \\
\hline
\end{tabular}

Table 5.4: Actuating horizontal venetian blinds based on environmental triggers

control strategies are listed in Table 5.4.

\subsubsection{Cycling Air-Conditioning Usage On-Peak}

Air-conditioning cycling reduces the amount of time an air-conditioner is on during a specific period of time. When the air-conditioner is being cycled, it will turn off even if the setpoint temperature has not been met. In Ontario, there are two voluntary programs that cycle residential air-conditioners during peak hours based on specific criteria such as high province-wide electricity demand or high temperatures. The two programs are the Peaksaver program and the Powershift program, described in Chapter 1. Only the Powershift program is used as a variant. The on/off cycling of the air-conditioner in 15 minute intervals occurs when the outdoor temperature rises above $27^{\circ} \mathrm{C}$ or the humidex is above $30^{\circ} \mathrm{C}$. The humidex is an index to describe the sensed temperature that includes both the drybulb temperature and the amount of humidity in the air [55]. The humidex is calculated with the following equations,

$$
e=6.11 \cdot \exp ^{(54177530(1 / 27316)-(1 / \text { dewpont }))}
$$

Where $e$ is the vapour pressure in $\mathrm{hPa}$

dewpornt is the dewpoint temperature in $\mathrm{K}$

5417.7530 is a constant based on the molecular weight of water, latent heat of evaporation, and the universal gas constant 


$$
\text { humidex }=\text { air temperature }+(0.5555)(e-10.0)
$$

Where humidex is the sensed temperature in ${ }^{\circ} \mathrm{C}$

air temperature is outdoor drybulb temperature in ${ }^{\circ} \mathrm{C}$ $e$ is the vapour pressure in $\mathrm{hPa}$

\subsection{Changes in Occupant Behaviour}

With TOU pricing, there is a higher likelihood that occupants will shift the use of their high demand appliances to take advantage of cheaper electricity, reducing on-peak electricity use by an estimated $5 \%$ [13]. Several variations were designed to mimic an occupant's positive response to TOU described below. Changes in occupant behaviour also includes the implementation of energy efficient appliances. All of the occupant behaviour variations are listed in Table 5.5.

Shifting the TOU of appliances comprises two variants shifting either the dryer or the stove use. These two appliances cause a spike in electricity consumption during the peak summer hours of 10:00 am and 4:00 pm (standard time). The base case occupancy schedule, described in Chapter 4, turns the dryer on at 12:00 pm (standard time) for 35 minutes demanding around $5.5 \mathrm{~kW}$. The dryer shift variant moves this usage to 7:30 pm outside of peak hours. A second shifting variant removes the use of the stove at 11:30 am and appends it to the evening stove use at 5:00 pm. This second variant is based on the assumption that on a hot summer day, an occupant will not want to use the stove during seasons of warm weather. Adding the stove use to the evening schedule maintains the same total electrical draw over the course of the day but tests the effect of removing stove use from the on-peak period.

Modifying the energy efficiency of appliances will reduce daily electricity consumption by drawing less electricity for the same amount of usage. 'Energy star' is a government and industry initiative to aid consumers in identifying energy efficient products. An 'energy star' mark requires the product to meet certain levels of energy performance [15]. An 'energy star' rated refrigerator reduces the electricity consumption by one-third compared to the base case refrigerator. One variant uses 
the more energy efficient refrigerator. A second variant uses an 'energy star' rated freezer reducing the freezer electricity consumption by half. A third variant increases the COP of the air-conditioning unit.

The base case air-conditioning unit has a cooling capacity of $10.5 \mathrm{~kW}$ with a COP of 2.64, based on a conservative estimate from similar sized, typical air conditioning units. A high COP value means that the air-conditioner requires less electricity to provide the same amount of cooling. The high efficiency air-conditioner variant has a COP value of 3.81 , which receives an 'energy star' rating [56].

Cool outdoor temperatures can mitigate space cooling loads by opening windows instead of using the air-conditioner when the outdoor temperature drops below $24^{\circ} \mathrm{C}$ (the space cooling setpoint). One variant opens all of the windows in the house to $10 \%$ of their area when the outdoor temperature is lower than the zone temperature, and the zone temperature rises above $23^{\circ} \mathrm{C}$. The value for the opening area is based on the assumptions described in Section 3.3.3. The windows shut when the zone temperature dropped below $20^{\circ} \mathrm{C}$. During the period when the windows are open, there is no space cooling. If the zone temperature rises to $24^{\circ} \mathrm{C}$, space cooling resumes in the zone and the windows are shut.

A similar variant to the open windows uses a ventilative cooling option. Instead of opening the windows, this variant mimics a fan ventilating outdoor air through the zone at $1 \mathrm{ACH}$. Using a fan takes advantage of cool outdoor temperatures without having to open all of the windows. Associated fan power was not accounted for.

\subsection{Local Generation with the Potential for a Stor- age Component}

To effectively make use of local generation or energy storage components, it is important to first reduce on-peak electricity consumption. Once the electrical consumption has been reduced, a PV array and associated battery system can be effectively sized. Initially, sizing is done of a PV system alone to determine if the on-peak power generated with the PV array can meet the on-peak household demand. Combining a PV system with a storage device enables effective use of any energy produced with the PV system during non-peak hours or to store any excess energy once the peak loads have been met. A battery storage device can store this energy for use on days where 


\begin{tabular}{|c|c|}
\hline $\begin{array}{l}\text { Occupant Behaviour } \\
\text { Modifications }\end{array}$ & Details \\
\hline Dryer-use Shifting & $\begin{array}{l}\text { Time-of-use shifted from 12:00 pm to } 7: 30 \mathrm{pm} \\
\text { (standard time) }\end{array}$ \\
\hline Stove-use Shifting & $\begin{array}{l}\text { Time-of-use shifted from 11:30 pm to 5:00 pm } \\
\text { (standard time) }\end{array}$ \\
\hline Energy Efficient Refrigerator & $33 \%$ reduction in refrigerator electricity use \\
\hline Energy Efficient Freezer & $50 \%$ reduction in freezer electricity use \\
\hline Energy Efficient Air-conditioner & COP increase from 2.64 to 3.81 \\
\hline Open Windows & $\begin{array}{l}\text { Opening the windows to } 10 \% \text { of their total } \\
\text { area when } \\
\cdot T_{z o n e}>T_{\text {out }} \\
\cdot T_{\text {zone }}>23^{\circ} \mathrm{C} \\
\end{array}$ \\
\hline Ventilative Cooling & $\begin{array}{l}\text { Ventilating the zone with } 1 \mathrm{ACH} \text { when } \\
\cdot T_{z o n e}>T_{\text {out }} \\
\cdot T_{\text {zone }}>23^{\circ} \mathrm{C}\end{array}$ \\
\hline
\end{tabular}

Table 5.5: Occupant behaviour variations 
the PV system may not produce enough energy to meet the house demand. Details of the sizing process for both the PV and the battery system are described in Chapter 9 .

\subsection{Closing Remarks}

Each variation described in this section is then simulated in ESP-r. The analysis of the results for each simulation is based on a set of metrics outlined in Chapter 6. Simulating each variant separately demonstrates the effect of each variant in comparison to the base case. With these results, effective combinations can then be amalgamated. The simulation results for all of the variants in this chapter are presented in Chapter 7 . 


\begin{tabular}{|c|c|c|}
\hline \multicolumn{2}{|c|}{ PC1 } \\
\hline \hline \multicolumn{2}{|c|}{$\begin{array}{c}\text { Standard } \\
\text { Time }\end{array}$} & $\begin{array}{c}\text { Setpoint } \\
\left({ }^{\circ} \mathbf{C}\right)\end{array}$ \\
\hline \multirow{2}{*}{} & $12-5$ & 27 \\
& $5-6$ & 21 \\
& $6-7$ & 24 \\
\hline \multirow{2}{*}{} & 4 AM - 4PM & 27 \\
\hline & $9-11: 59$ & 24 \\
\hline
\end{tabular}

(a)

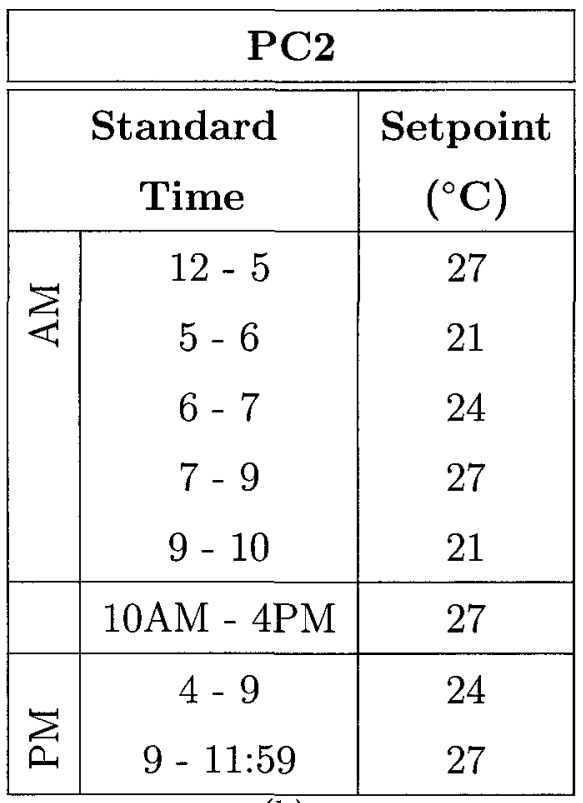

(b)

\begin{tabular}{|c|c|c|}
\hline \multicolumn{3}{|c|}{ PC3 } \\
\hline \hline \multicolumn{2}{|c|}{$\begin{array}{c}\text { Standard } \\
\text { Time }\end{array}$} & $\begin{array}{c}\text { Setpoint } \\
\left({ }^{\circ} \mathrm{C}\right)\end{array}$ \\
\hline$\sum$ & $12-6$ & 24 \\
$6-10$ & 21 \\
\hline$\sum$ & $10 \mathrm{AM}-5 \mathrm{PM}$ & 27 \\
\hline$\sum$ & $5-11: 59$ & 24 \\
\hline
\end{tabular}

(c)

Figure 5.10: Daily temporal variations of three pre-cooling strategies: (a) PC1, (b) PC2 and, (c) PC3 


\section{Chapter 6}

\section{Performance Metrics}

Having defined a base case and variations that have potential to reduce the on-peak electricity consumption, a comprehensive set of metrics needs to be developed to analyse the simulation results. The metrics help to interpret and evaluate the results to determine the performance of the house, and relate to the overall goal of achieving a ZPH. The metrics provide a means to compare, quantitatively, between the base case and variant cases. This chapter outlines the methodologies for selecting meaningful metrics, followed by a description of each performance metric utilized in the study and the basis for each choice in analyzing the current work. Each metric is denoted by an abbreviated symbol used for referencing in the results analysis in Chapter 7 .

\subsection{Considerations When Choosing Metrics for Low Energy Houses}

Metrics are the basis for selecting effective combinations for a final design. A study on the definition and calculation methodologies of zero energy buildings by Marszal, et. al. [17] describes multiple approaches to the analysis of low-energy buildings and the potential of reaching a zero energy house. The Marszal study stresses the importance of how zero energy is defined. Options for the zero energy component include zero primary energy use, zero delivered energy, zero $\mathrm{CO}_{2}$ emissions or zero energy cost. The chosen zero energy component is important for selecting metrics, since the strategies used and the methods of analysis change depending on what is being minimized. The choice of metrics must consider the time-frame to reach a zero value, such as monthly, annually or over the life-span of the building. The choice 
of metrics must reflect the goals of the project to enable accurate results analysis towards achieving a $\mathrm{ZPH}$.

For the current study, the goal is to have zero electricity delivered on-site during summer on-peak hours. Effective variants will reduce the electricity consumption onpeak, when provincial grid demand is high, and may increase electricity consumption mid- and off-peak, when provincial grid demand is low. A secondary goal in this study is to have a low adverse effect on heating energy used in the house by observing the natural gas consumption. The consumption of water and the energy supplied to heat water are not a part of the simulation results and are not considered with any metrics.

\subsection{ZPH Metrics}

The chosen metrics consider electricity and natural gas consumption, compare household electricity consumption to the provincial grid demand, consider the summer on-peak period, and examine the household performance over one day in different weather conditions. Certain metrics focus on the annual results of the simulations, but shorter time periods are also used to offer a more detailed analysis of the results.

\subsubsection{Annual Electricity Consumption}

Electricity consumption in the house is an aggregation of four components that provide household conditioning or represent occupancy. Heating requires natural gas, but electricity powers the furnace circulation fan to circulate the heated air. As well, the air-conditioner and HRV both draw electricity to condition and ventilate the main zone. Finally, occupant driven electricity loads, previously described in the representative occupancy profile in Chapter 4 , is the last component that contributes to electricity consumption. Annual electricity consumption, denoted as $E_{\text {annual }}$, demonstrates the total effect a variant has on electricity consumption as an overview of the variant's potential, but does not consider any on-peak electricity consumption effects.

\subsubsection{Summer Weekday On-Peak Electricity Consumption}

The effectiveness of a variant in reducing on-peak electricity consumption is determined by calculating the total summer weekday on-peak electricity consumption, 
$E_{\text {on peak }}$. This metric verifies the choice of each variant towards the defined ZPH goal, and assists in filtering out variants that may adversely affect the on-peak electricity consumption. The summer season is defined by the local electricity distributer, to occur between May 1 and October 31. The cooling season of the house is shorter, between May 15 and September 30, to meet the majority of cooling demands. The $E_{\text {on peak }}$ variant uses the provincial definition of summer, and calculates the total electricity consumption during on-peak hours (10:00 am to 4:00 pm standard time).

\subsubsection{Annual Natural Gas Consumption}

The annual natural gas consumption, denoted $N G_{\text {annual }}$, demonstrates any adverse effects a variant has on the heating demand. Several variants shade the opaque and transparent surfaces of the house in order to reduce the on-peak solar gains in the summer, but this also reduces the amount of solar gains available in the winter that have potential to offset heating loads. This metric shows the energy shift from electricity consumption to natural gas consumption caused by a variant.

\subsubsection{Summer Weekday and Annual Correlation}

Modifying the temporal distribution of electricity consumption and reducing the household electricity consumption on-peak changes the consumption pattern over the day. The summer on-peak period originates from large provincial grid demand between 11:00 am and 5:00 pm local time, and hours outside of this range are considered mid-peak or off-peak. Household electricity with higher consumption outside of peak hours, and low to zero on-peak helps to average the provincial demand. The metric to analyse and compare the household and provincial daily electricity consumption patterns uses a correlation coefficient. A correlation coefficient determines the similarity in the trend of two data sets by calculating their linear dependence. The correlation coefficient is a comparison of the proportional increase or decrease in value of the data points in one set relative to the other, and is calculated using Equation 6.1, [57]:

$$
r=\frac{\sum_{i=1}^{n}\left(X_{i}-\bar{X}\right)\left(Y_{i}-\bar{Y}\right)}{\sqrt{\sum_{i=1}^{n}\left(X_{i}-\bar{X}\right)^{2}} \sqrt{\sum_{i=1}^{n}\left(Y_{i}-\bar{Y}\right)^{2}}}
$$

where $r$ is the sample correlation coefficient between sets $\mathrm{X}$ and $\mathrm{Y}$ 
$X_{i}$ and $Y_{i}$ are specific values in $\mathrm{X}$ and $\mathrm{Y}$ at the $i^{\text {th }}$ point in the set

$\bar{X}$ and $\bar{Y}$ are the mean values of each set

$n$ is the length or number of values in the each set

When two data sets have a positive correlation value (between 0 and 1 ), they both increase or decrease in a similar manner. A high correlation value between the household electricity demand and the provincial grid electricity demand is disadvantageous as it indicates coincident high demand. A negative correlation value (between 0 and -1) represents two data sets with inverse trends, such that when one increases the other decreases. A negative correlation represents a drop in household electricity demand coincident with an increase in provincial grid demand, which is the goal of this work. Real data sets tend not to have perfectly correlated data, with correlation values that lie between the two extreme values of -1 and 1 . When comparing results from each variant to the base case, variants that shift electricity consumption to off-peak hours should result in a lower correlation coefficient.

Two metrics calculate a correlation coefficient between the household electricity consumption and the provincial grid electricity demand. The first metric determines the annual correlation, denoted Corr $_{\text {annual }}$, and the second determines the correlation over all provincially defined summer weekdays (weekdays between May 1 and October

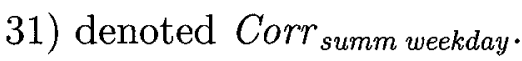

\subsubsection{One Day Household Performance}

A final category of metrics examines a single day of simulation results. A one day snapshot of the performance of the house offers a detailed look at the results of each variant and can provide a better explanation of the simulation results. Four days are used for this metric to represent different temperature or solar conditions. To observe the winter performance, a cold day with a large amount of solar radiation on January 15 can demonstrate the household response to variants that have increased natural gas consumption. Observing the performance in conditions where the outdoor air temperature fluctuates over the day is done on June 16, a day with low overnight temperatures dropping to $13^{\circ} \mathrm{C}$ and higher afternoon temperatures reaching $28.5^{\circ} \mathrm{C}$. To determine household performance on hot days, two days with slightly different weather conditions are used. The first day is July 31, when temperatures reached $33.6^{\circ} \mathrm{C}$ during the on-peak hours and direct solar radiation was high over the day. 
The second day is August 1, the hottest day of 2006 in the Toronto region, with the drybulb temperature reaching $36.4^{\circ} \mathrm{C}$ but with less direct solar radiation. All four days are not necessarily useful to quantify results with all of the variants, and the day $(\mathrm{s})$ observed depends on the variant. The outdoor air temperature over each one day metric is shown in Figure 6.1.

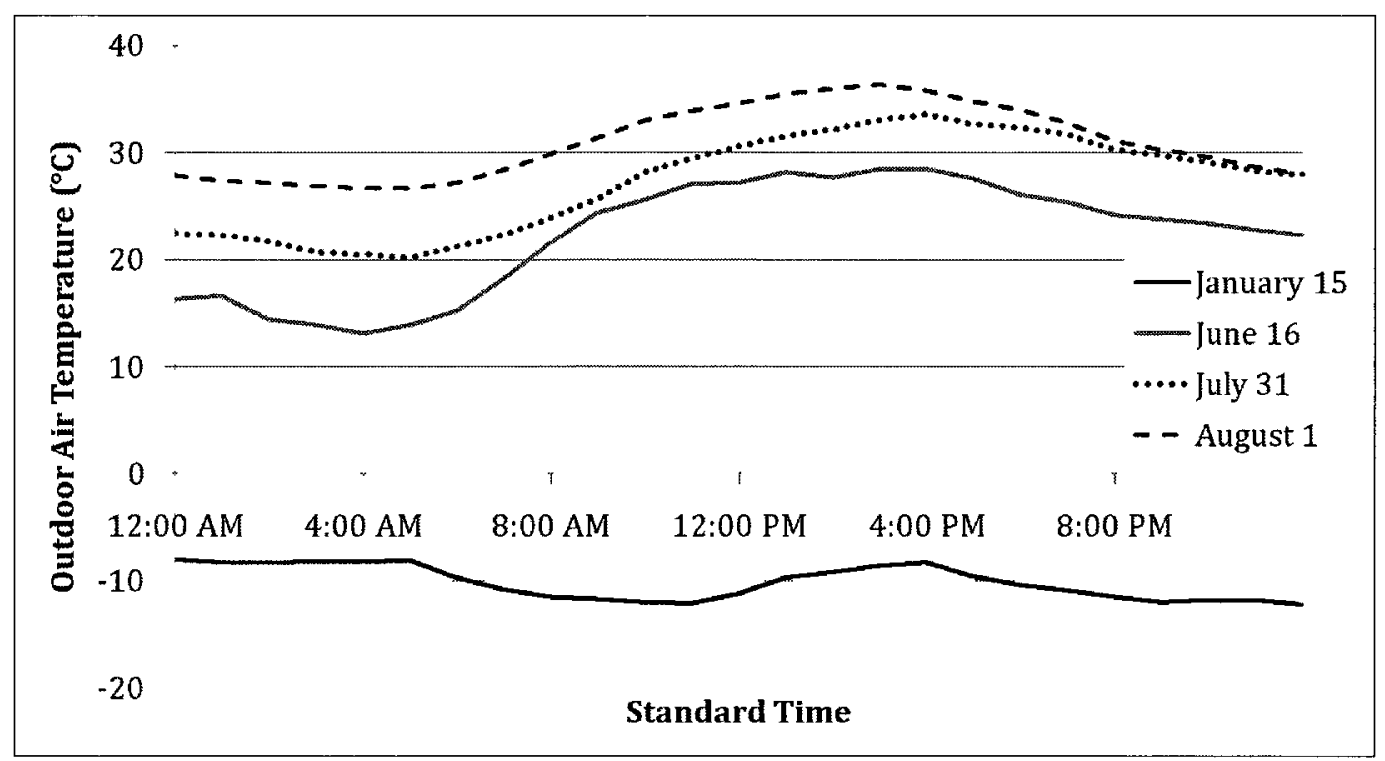

Figure 6.1: Outdoor air drybulb temperature over each one day metric

The one day household performance metric is secondary to the metrics described above, and will provide clarification of the results in electricity or natural gas consumption. The one day snapshot can also indicate the zone temperatures, which determine the feasibility of certain variants that modify thermal setpoints in the zone.

\subsection{Closing Remarks}

The choice of metrics is highly dependent on the project goals, and use of the metrics determines which strategies are most effective in meeting these goals. For the current study, the metrics used to evaluate a $\mathrm{ZPH}$ focus on electricity and natural gas consumption, to analyse different variant cases and gauge any adverse impact on energy required for heating. These metrics are used to describe and compare the simulation 
results in Chapter 7. 


\section{Chapter 7}

\section{Simulation Results of Variations on the Base Case}

The simulation results are presented in sections categorized by variant. Each section includes key results based on the metrics described in Chapter 6 and a bar graph summarizing the total summer weekday on-peak electricity consumption $\left(E_{\text {on peak }}\right)$ in gigajoules, relative to the base case. The sections are concluded with analysis using one or more of the one day household performance metrics, depending on the impact of the variant. The $E_{\text {on peak }}$ metric is shown in this chapter in each variant category, as it is the most representative metric in demonstrating on-peak demand reduction. The remaining metrics are discussed with each variation, but are located in Appendix B.

The results demonstrate the effectiveness of various techniques in mitigating onpeak electricity consumption. Combinations of these effective variants have the potential to further reduce on-peak loads to achieve a low to zero peak house. The combination models and their simulation results are described in Chapter 8.

\subsection{Architectural and Vegetative Shading}

Five variants were simulated to assess the impact of shading on the building. These examined various sized roof overhangs, south-west window awnings, and vegetative shading from a line of trees south of the house. 


\subsubsection{Summary of Key Shading Results}

- $E_{\text {on peak }}$ was affected most with $1 \mathrm{~m}$ roof overhangs resulting in a $5.7 \%$ reduction relative to the base case, shown in Figure 7.1. The remaining shiading variants affixed to the building (not including the line of trees) reduce $E_{\text {on peak }}$ by $2.5 \%$ to $3.4 \%$. The line of trees has the smallest effect on this metric, resulting in a $1.1 \%$ decrease relative to the base case.

- The architectural and vegetative shading $E_{\text {annual }}$ results are similar to $E_{\text {on peak }}$, with the $1 \mathrm{~m}$ roof overhangs causing the largest reduction of $3 \%$ and the line of trees causing the smallest reduction of $0.7 \%$. The remaining architectural and shading $E_{\text {annual }}$ results are shown in Figure B.1 on page 148.

- The largest adverse effect on $N G_{\text {annual }}$ is with $1 \mathrm{~m}$ roof overhangs with an annual increase of $6.7 \%$. Remaining variants increase $N G_{\text {annual }}$ by $3 \%$ to $4.4 \%$ and are shown in Figure B.2 on page 149.

- Architectural and vegetative shading variants have a minor effect on Corr annual

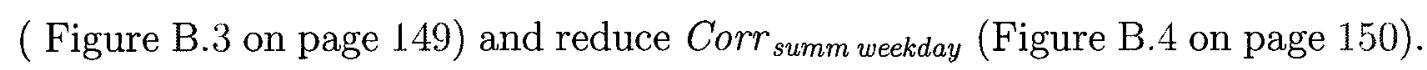

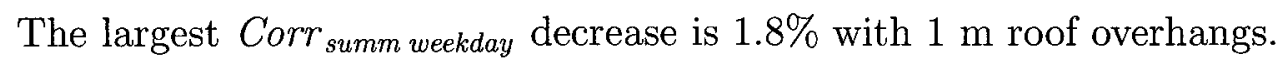




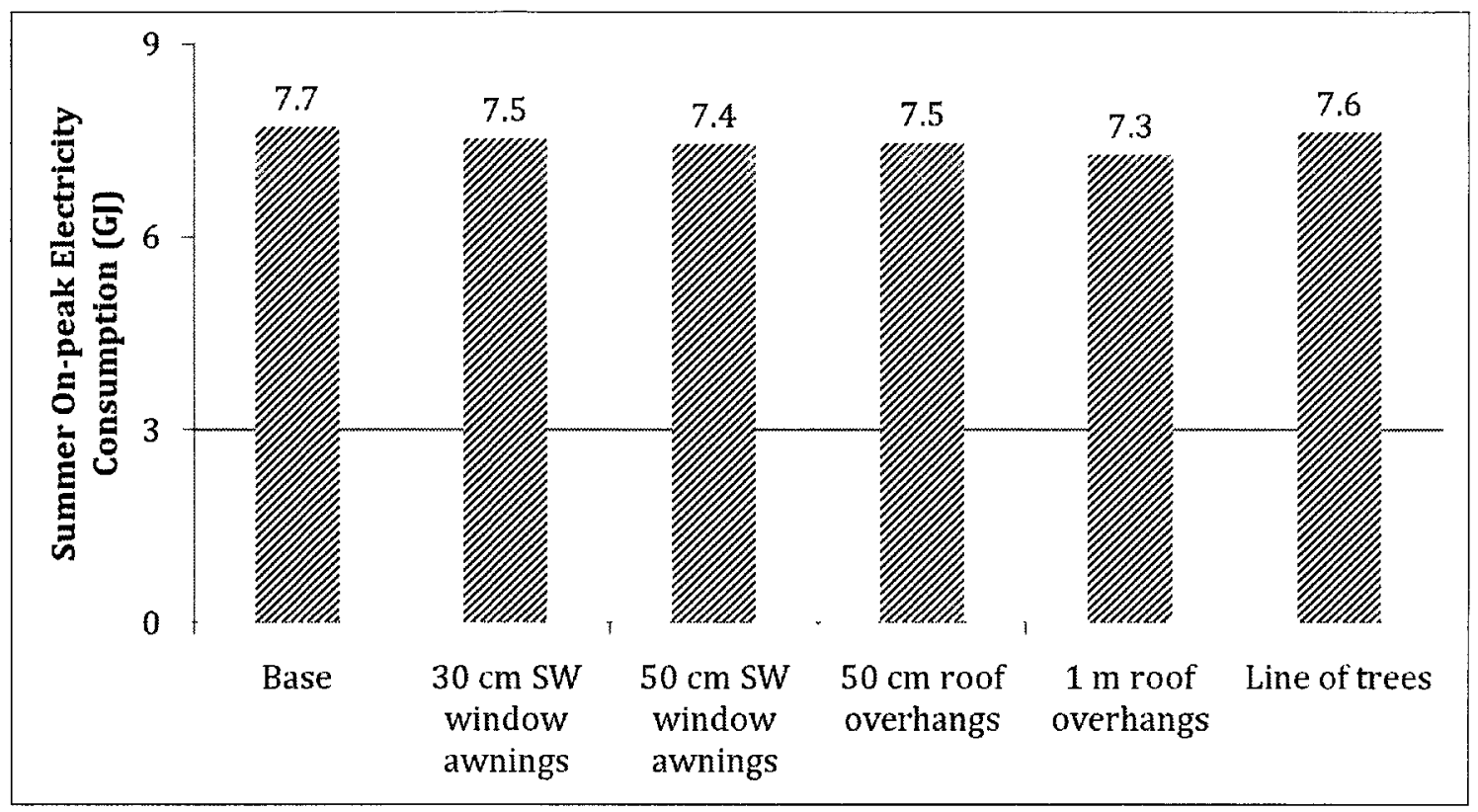

Figure 7.1: Summer weekday on-peak electricity consumption with architectural and vegetative shading variants

\subsubsection{Analysis of Shading Results}

$E_{\text {on peak }}$ is largely affected by $1 \mathrm{~m}$ roof overhangs, followed by the $50 \mathrm{~cm}$ SW window awnings. The solar gains on July 31 demonstrate the difference in shading from these two variants, shown in Figure 7.2. Note the horizontal axis in this figure is in standard time, not local time which is shifted forward one hour with daylight savings. Peak hours in standard time are between 10:00 am and 4:00 pm. 


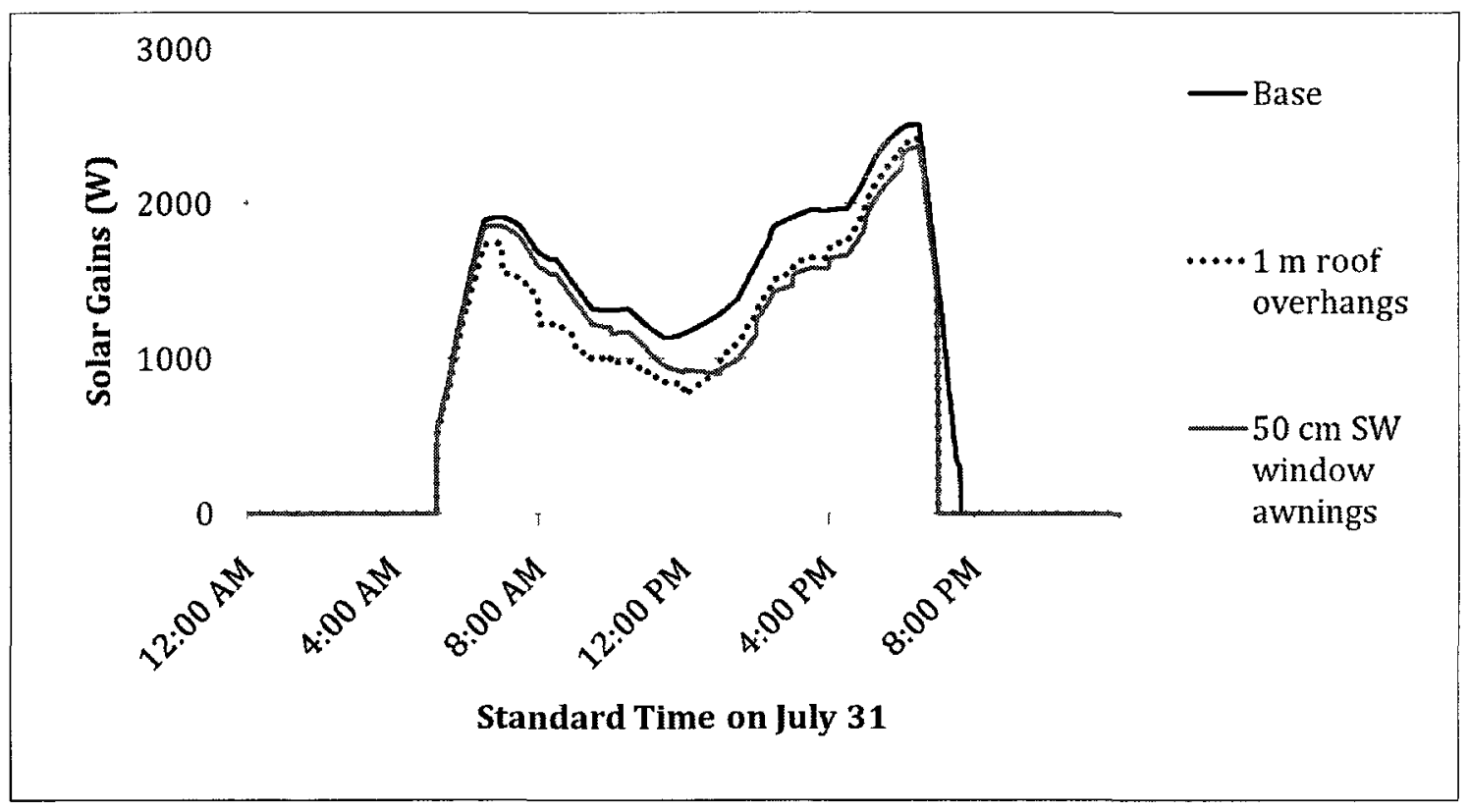

Figure 7.2: Solar gains entering the main zone on July 31, of the base case, $1 \mathrm{~m}$ roof overhangs and $50 \mathrm{~cm}$ SW window awnings

Figure 7.2 shows less solar gains between 6:30 am and 12:15 pm with the $1 \mathrm{~m}$ roof overhangs. In the afternoon, the $50 \mathrm{~cm} \mathrm{SW}$ window awnings are slightly more effective, with the westerly azimuth of the sun. Over the on-peak period, $1 \mathrm{~m}$ roof overhangs offer more shading, resulting in a larger $E_{\text {on peak }}$ reduction.

The $50 \mathrm{~cm}$ SW window awnings and the $50 \mathrm{~cm}$ roof overhangs have the same mitigation effect on $E_{\text {on peak. }}$. The $50 \mathrm{~cm}$ roof overhangs reduce solar gains in the early peak hours while the $50 \mathrm{~cm}$ SW window awnings have a larger effect during the afternoon peak hours, but the net on-peak effect is the same.

In the winter, architectural variants provide less shading with the lower solar angle of the sun. These variants do however reduce some solar gains which increases the $N G_{\text {annual }}$ for all architectural shading variants.

\subsection{Window Design and Properties}

Variations of window design and properties considered both thermal and optical property variations to reduce the solar gains in the main zone of the house. The base case windows have a double pane construction with a low-e coating and an argon gas fill. 
The variations use techniques such as increased outer pane reflectivity, low-e coatings and increased glazing layers to reduce solar gains.

\subsubsection{Summary of Key Window Property Results}

- The variants with reflective properties have the largest effect on $E_{\text {on peak }}$. The largest reduction of $11 \%$ occurs with both the triple pane, reflective, low-e coated window variant and the $\rho=0.217$ reflective outer layer window variant. These results are shown in Figure 7.3.

- $E_{\text {annual }}$ is affected similarly to $E_{\text {on peak }}$ using window design and properties variants. The triple pane, reflective, low-e coated window variant and the $\rho=$ 0.217 reflective outer layer window variant both reduce $E_{\text {annual }}$ by $5 \%$, shown in Figure B.5 on page 151.

- The $N G_{\text {annual }}$ is adversely affected by all of the window design and property variants. The lowest effect is due to the triple pane, low-e coated window variant and the quad pane, krypton gas fill window variant which both cause an increase of $2 \%$ to $3 \%$. The $\rho=0.217$ reflective outer layer window results in a $14 \%$ increase of $N G_{\text {annual }}$ which is at least $6 \%$ higher than the remaining variants, shown in Figure B.6 on page 152.

- The variations of window design and properties do not have a significant effect

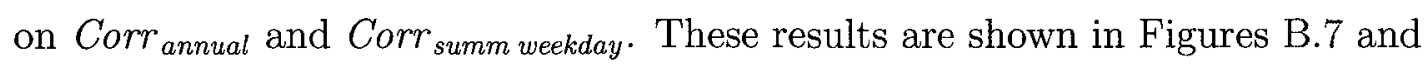
B.8 on pages 152 and 153 respectively. 


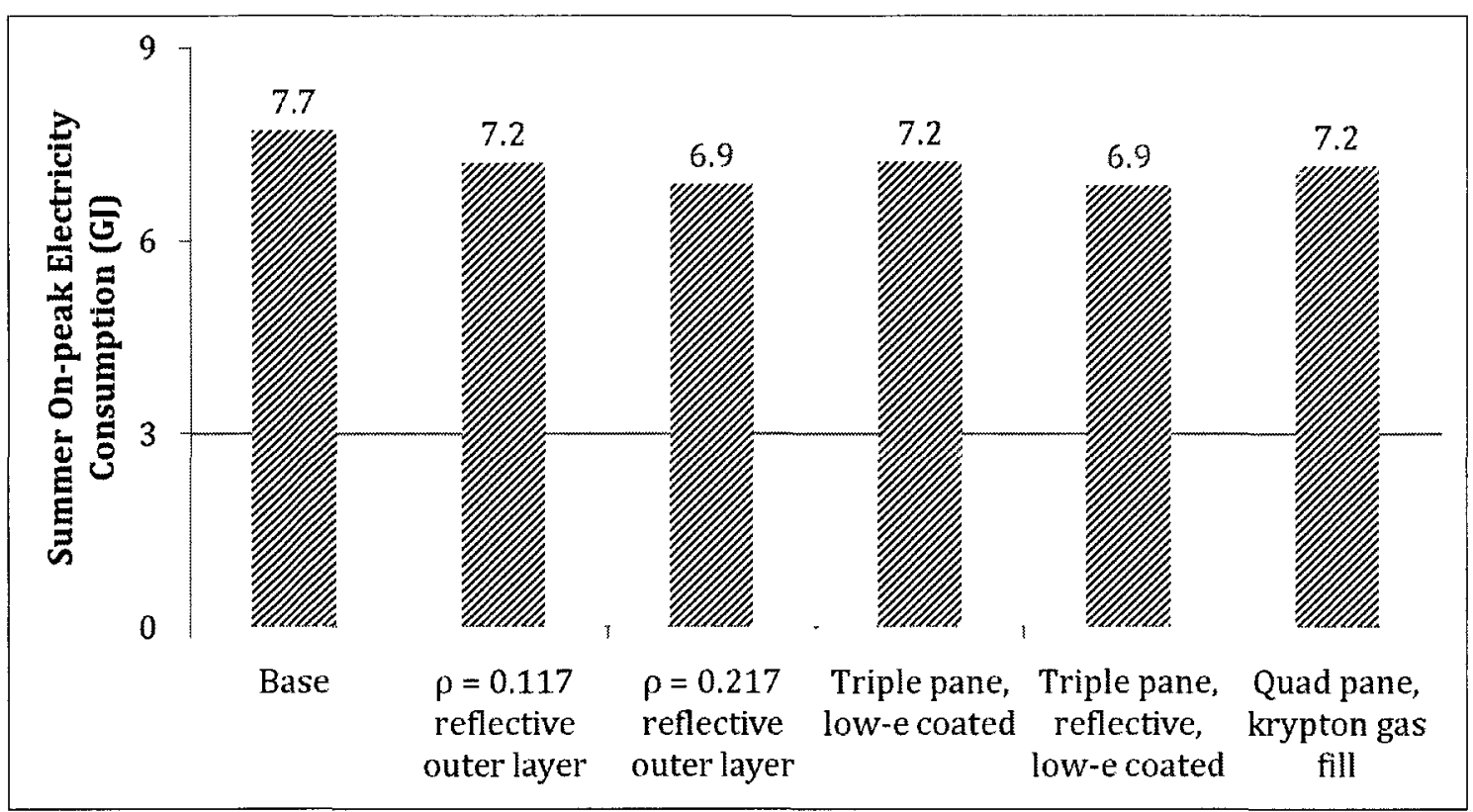

Figure 7.3: Summer weekday on-peak electricity consumption with modified window properties

\subsubsection{Analysis of Window Property Results}

The results of variations in window design and properties are analyzed on January 15 to examine the solar gains in the main zone. Figure 7.4 demonstrates that the main zone in the triple pane, reflective, low-e coated window variant and the $\rho=0.217$ reflective outer layer window variant both receive much less solar gains than the base case on January 15. Over the winter, this significant decrease in solar gains increases use of the furnace, increasing $N G_{\text {annual }}$. 


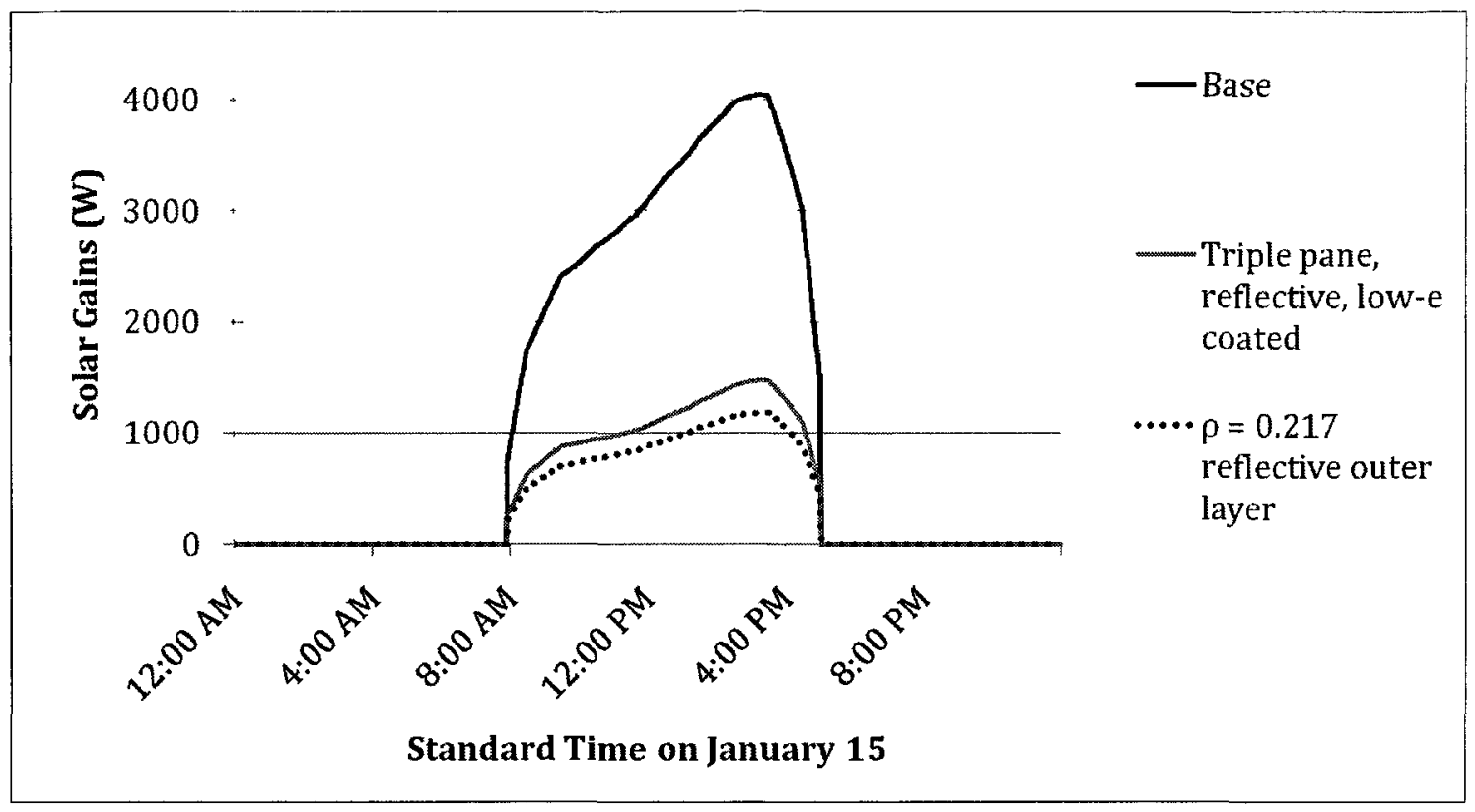

Figure 7.4: Solar gains entering on January 15 with the base case, the triple pane, reflective, low-e coated window variant and the $\rho=0.217$ reflective outer layer window variant

The $\rho=0.217$ reflective outer layer window variant and the triple pane, reflective, low-e coated window variant are both effective in reducing $E_{\text {on peak }}$, as both of these variants have much lower solar gains relative to the base case. Solar gains increase heat in the zone but also provide natural sunlight, and reduced natural light may cause occupants to use electrical lights offsetting the benefits.

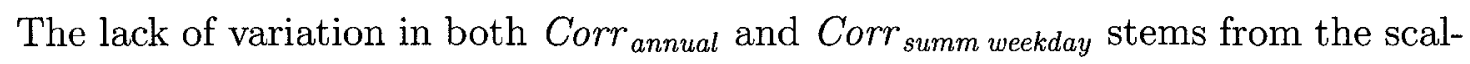
ing effect these variants have on the electricity consumption profile. Since the profile shape remains the same, without any temporal redistribution of demand, the correlation value remains the same.

\subsection{Venetian Blinds}

Two variants simulated different fixed slat angles of venetian blinds annually. The base case has internal venetian blinds with a $0^{\circ}$ slat angle relative to the horizontal. One variation changed the slat angle to a fixed $45^{\circ}$ relative to the horizontal, and the second variation changed the slat angle to $80^{\circ}$, effectively closing the blinds. 


\subsubsection{Summary of Key Venetian Blind Results}

- $E_{\text {on peak }}$ is reduced by $5.1 \%$ with closed blinds and by $2.0 \%$ with $45^{\circ}$ blinds.

- Both variants reduce $E_{\text {annual }}$, with closed blinds causing the largest reduction of $3.1 \%$. These results are shown in Figure B.9 on page 154 .

- $N G_{\text {annual }}$ increases significantly relative to the base case from both variants, shown in Figure B.10 on page 155. The closed blinds variant has a $13.8 \%$ increase of $N G_{\text {annual }}$ and the $45^{\circ}$ blinds cause a $5.8 \%$ increase relative to the base case.

- Both Corr $_{\text {annual }}$ and Corr $_{\text {summ weekday }}$ were minimally affected by the venetian blind variations, as seen in Figures B.11 and B.12 on pages 155 and 156 respectively.

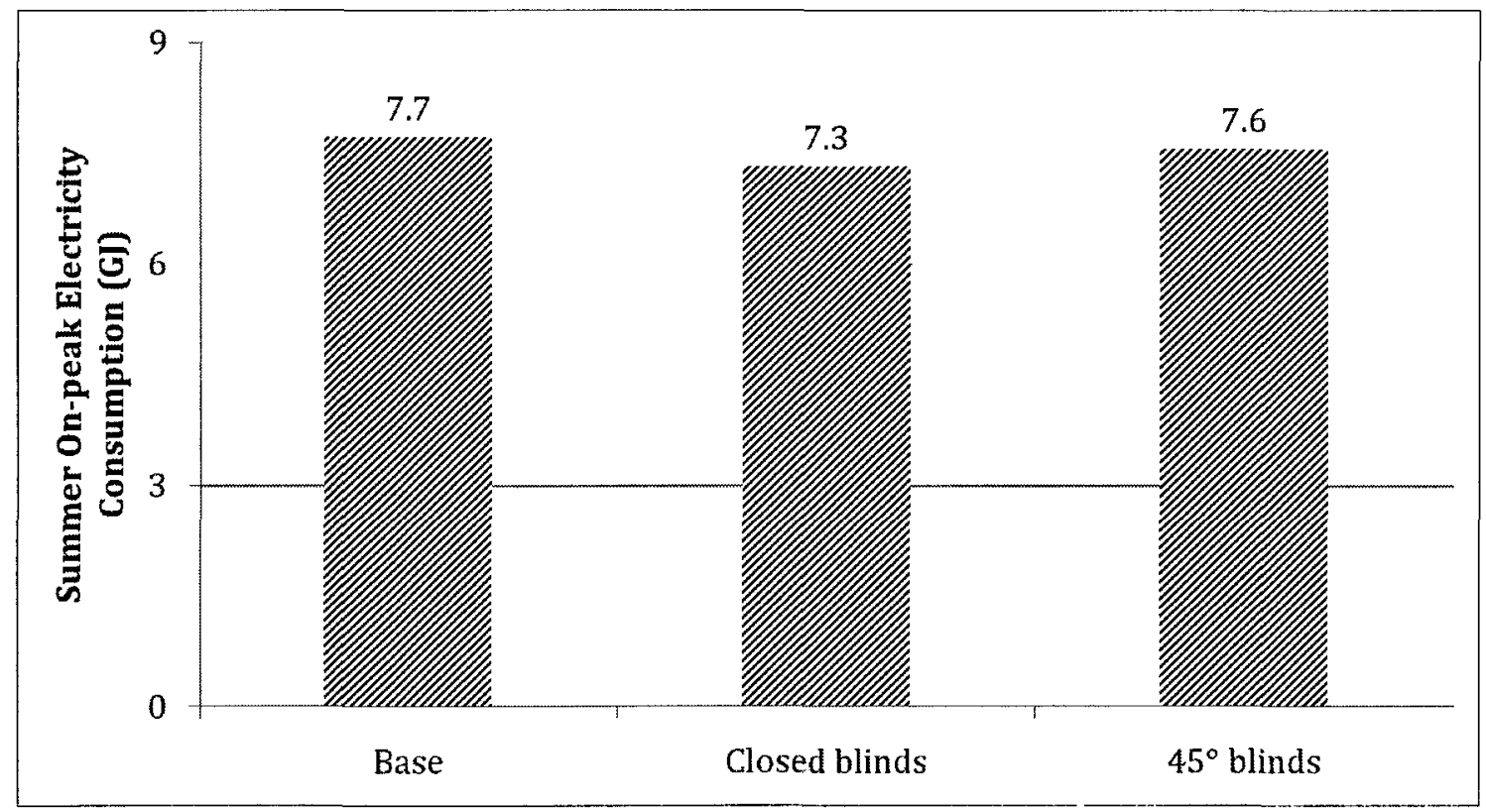

Figure 7.5: Summer weekday on-peak electricity consumption with venetian blind position

\subsubsection{Analysis of Venetian Blind Results}

Solar radiation results with the venetian blinds variants are examined on both January 15 and July 31 . On January 15, solar gains reduce by $94 \%$ relative to the base case 
with closed blinds and $55 \%$ relative to the base case with $45^{\circ}$ blinds. On July 31 , closed blinds receive $90 \%$ less solar gains and $45^{\circ}$ blinds receive $41 \%$ less solar gains than the base case. Less solar gains reduce both $E_{\text {on peak }}$ and $E_{\text {annual }}$, but also cause an increase in $N G_{\text {annual }}$. Less solar gains also reduce the amount of natural sunlight entering the zone, which may trigger occupants to compensate with electrical lights offsetting the benefit of this variant.

Having a fixed slat-angle for the venetian blinds annually scaled the daily profile of both electricity and natural gas consumption without affecting the shape of the consumption pattern when compared to the base case. This scaling effect does not affect the correlation values which compare the pattern of electricity usage to that of the provincial grid demand.

\subsection{Fenestration Area and Distribution}

Using the base case window properties, but varying the area and distribution of the building fenestration comprise four variants. Two of the variants reduce the total fenestration area on the building. The remaining two variants maintain the total fenestration area of the base case, but redistribute the fenestration on each building face.

\subsubsection{Summary of Key Fenestration Results}

- $E_{\text {on peak }}$ results are shown in Figure 7.6 and demonstrate that redistributing the fenestration increases $E_{\text {on peak }}$ by up to $4 \%$ with the variant shifting $50 \%$ of SW window to all other sides. The variant reducing all window areas by $25 \%$ reduces $E_{\text {on peak }}$ by $4.5 \%$.

- The fenestration shifting variants both adversely affect $E_{\text {annual }}$, resulting in a $2.1 \%$ increase with the variant shifting $50 \%$ of SW windows to all other sides and a $1.8 \%$ increase with the variant shifting $50 \%$ of SW windows to NE and NW faces. The variants that reduce the total fenestration area reduce $E_{\text {annual }}$ by up to $2.1 \%$. These results are shown in Figure B.13 on page 157.

- $N G_{\text {annual }}$ experiences the most adverse effect due to the variant shifting $50 \%$ of the SW windows to NE and NW, causing a $0.7 \%$ increase. The variant shifting $50 \%$ of SW windows to all other sides and the variant reducing all window 
areas by $25 \%$ both reduce $N G_{\text {annual }}$ by $0.8 \%$. The remaining variant, reducing all window areas by $10 \%$, has little effect on $N G_{\text {annual }}$. These results are shown in Figure B.14 on page 158.

- Corr ${ }_{\text {annual }}$ results are shown in Figure B.15 on page 158, and Corr $_{\text {summ weekday }}$ results are shown in Figure B.16 on page 159. Both of these metrics are insignificantly affected by the fenestration size and distribution variants.

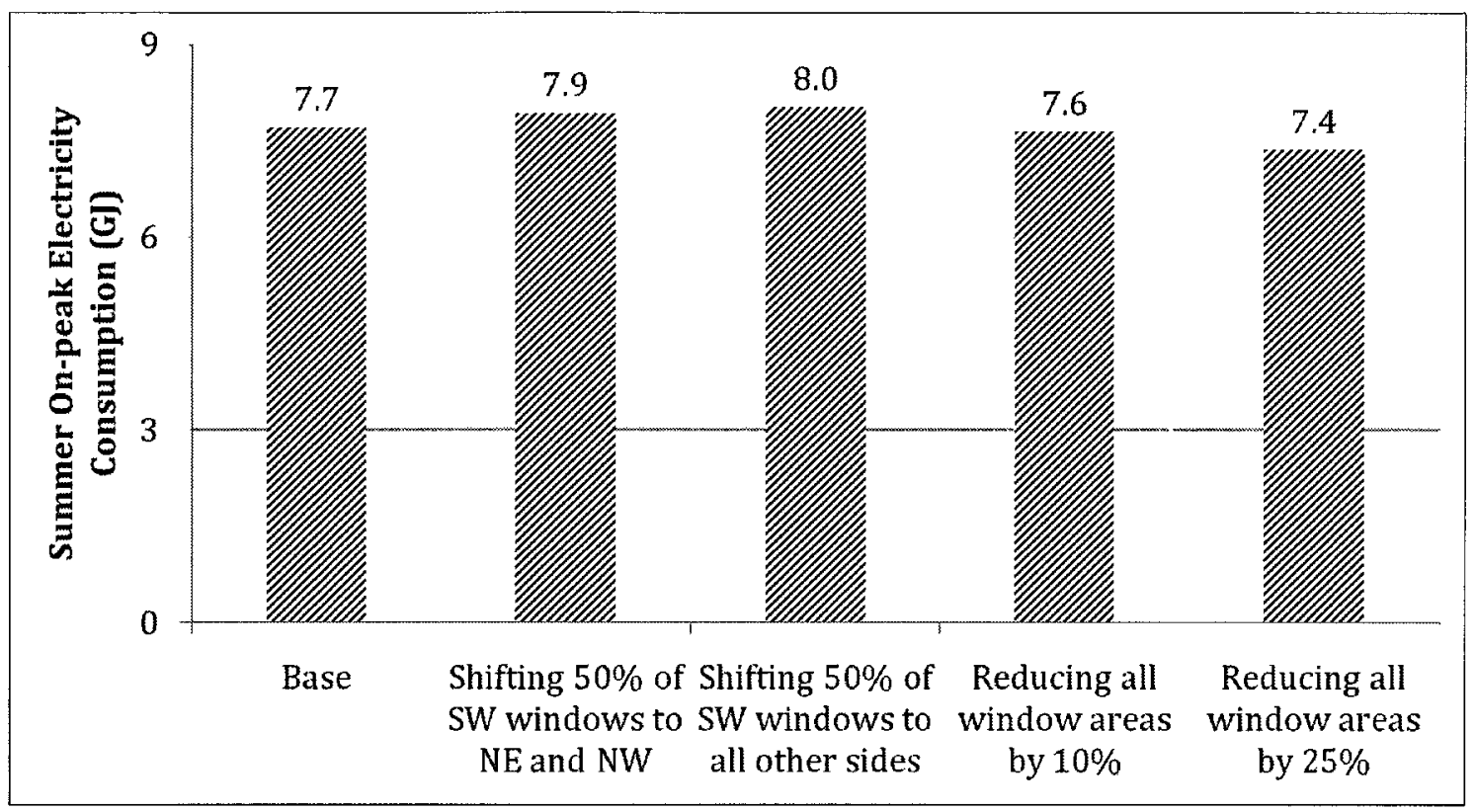

Figure 7.6: Summer weekday on-peak electricity consumption with fenestration area and distribution

\subsubsection{Analysis of Fenestration Area and Distribution Results}

\section{Reducing Fenestration Area}

Reducing the fenestration area on the house decreases the amount of solar radiation entering the zone. On January 15 and July 31, reduced glazing area scales down the profile of solar gains in the zone but maintains the same shape over the day. On January 15, natural gas consumption increases during the day with less solar gains. Overnight on January 15, the variant reducing all window areas by $25 \%$ used less natural gas than the base case. This variant has more insulated exterior walls on the 
building with a higher thermal resistance than the windows, thereby reducing heat loss. The overnight decrease in natural gas consumption with this variant offsets the daytime increase, resulting in an overall reduction of $N G_{\text {anrisal. }}$. On July 31 , both variants that reduce all window areas require less space cooling compared to the base case.

\section{Redistributing Building Fenestration}

Redistributing the building fenestration temporally shifts when solar radiation enters the zone. These variants shift part of the southwest fenestration to the faces of the building that receive more solar radiation outside of the on-peak hours. Temporally shifting the solar gains should similarly shift the space-cooling demand in the house, but the simulation results of these variants proved differently. On July 31, the high noon sun does not provide as much direct solar radiation on the building glazing than in the morning and afternoon when the sun is lower in the sky. Solar gains are increased at the start of the on-peak period with more easterly glazing that faces the morning sun. In July in a Toronto location, the sun sets in the northwest and as such the northwest building face receives large amounts of incident solar radiation in the late afternoon. With more northwest facing glazing, the afternoon solar gains are much higher, shown in Figure 7.7. The increase in solar gains both on- and off-peak increase $E_{\text {on peak }}$ and $E_{\text {annual }}$ with these variants. 


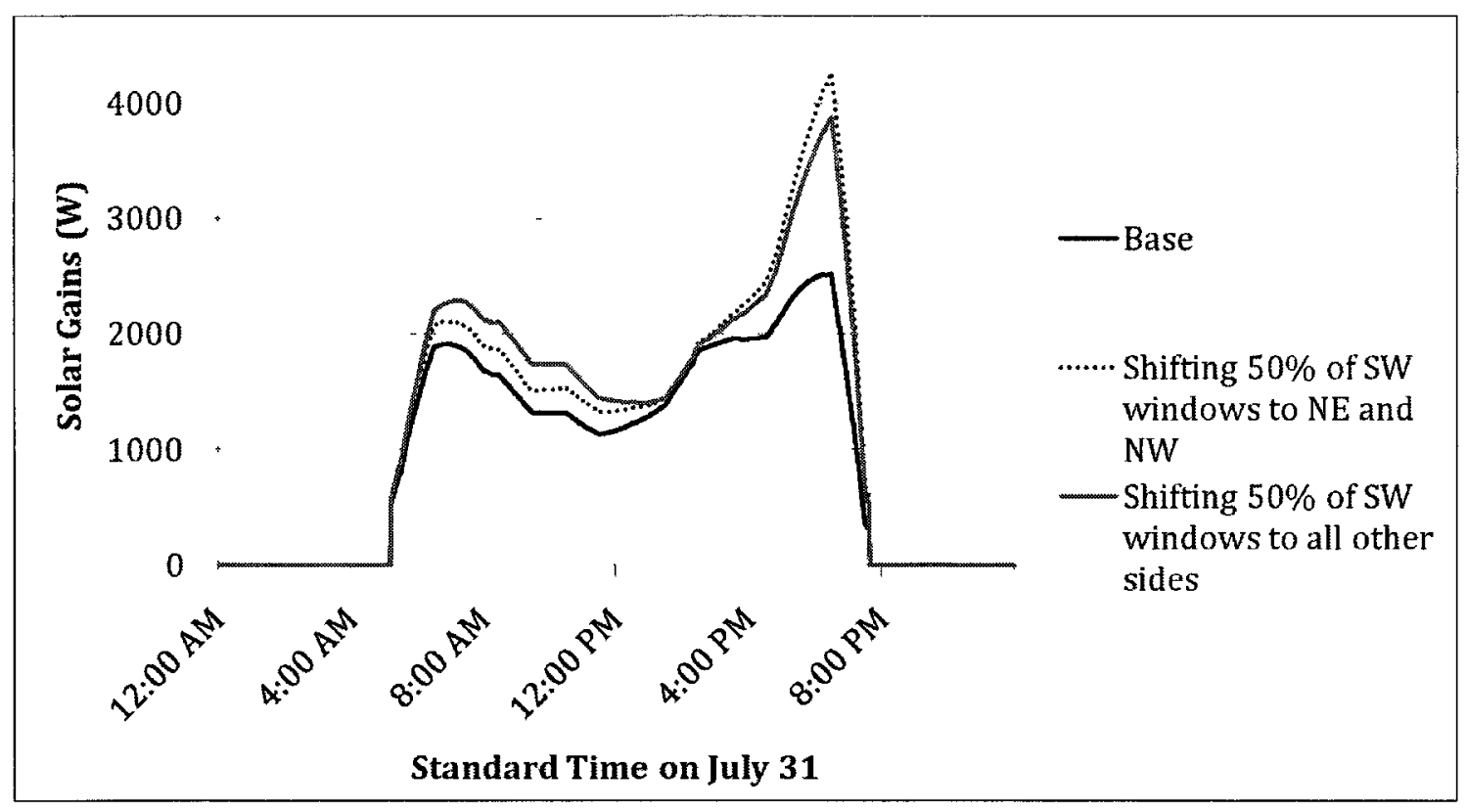

Figure 7.7: Solar gains entering on July 31 in the base case and the variants that shift the fenestration distribution on the building

On January 15, the increase in east facing glazing in the variant shifting $50 \%$ of the SW windows to all other sides results in higher solar gains in the morning and less natural gas consumption. The southwest azimuth of the setting sun in January in Toronto causes a reduction in afternoon solar gains with variants that shift fenestration away from the southwest face. Increased solar gains in the morning offset the adverse afternoon effect on natural gas consumption in the variant shifting $50 \%$ of the SW windows to all other sides. This results in lower $N G_{\text {annual }}$ with this variant. The variant shifting $50 \%$ of the SW windows to NE and NW receives much less afternoon winter solar gains, with no morning compensation, and $N G_{\text {annual }}$ increases.

Even while these variants did affect the amount of incoming solar radiation into the zone, the daily trend of electricity demand followed a similar but slightly shifted pattern to the base case. These small changes have a minimal effect on the correlation values. 


\subsection{Reflective Shingles}

One variant increased the reflectivity of the shingles on the roof of the house. The base case shingles reflect $5 \%$ of the incoming solar radiation, while the variant using reflective shingles reflects $42 \%$ of the incoming solar radiation.

\subsubsection{Summary of Key Reflective Shingle Results}

- The reflective shingles have a negligible effect in all areas of the metrics.

- $E_{\text {on peak }}$ reduces by $0.9 \%$ with reflective shingles, shown in Figure 7.8 .

- $E_{\text {annual }}$ decrease by $0.6 \%$, shown in Figure B.17 on page 160 .

- $N G_{\text {annual }}$ increases by $1.2 \%$ shown in Figure B.18 on page 161 .

- Corr $r_{\text {annual }}$ increases by $0.3 \%$ shown in Figure B.19 on page 161 .

- Corr $_{\text {summ weekday }}$ decreases by $0.5 \%$ shown in Figure B.20 on page 162.

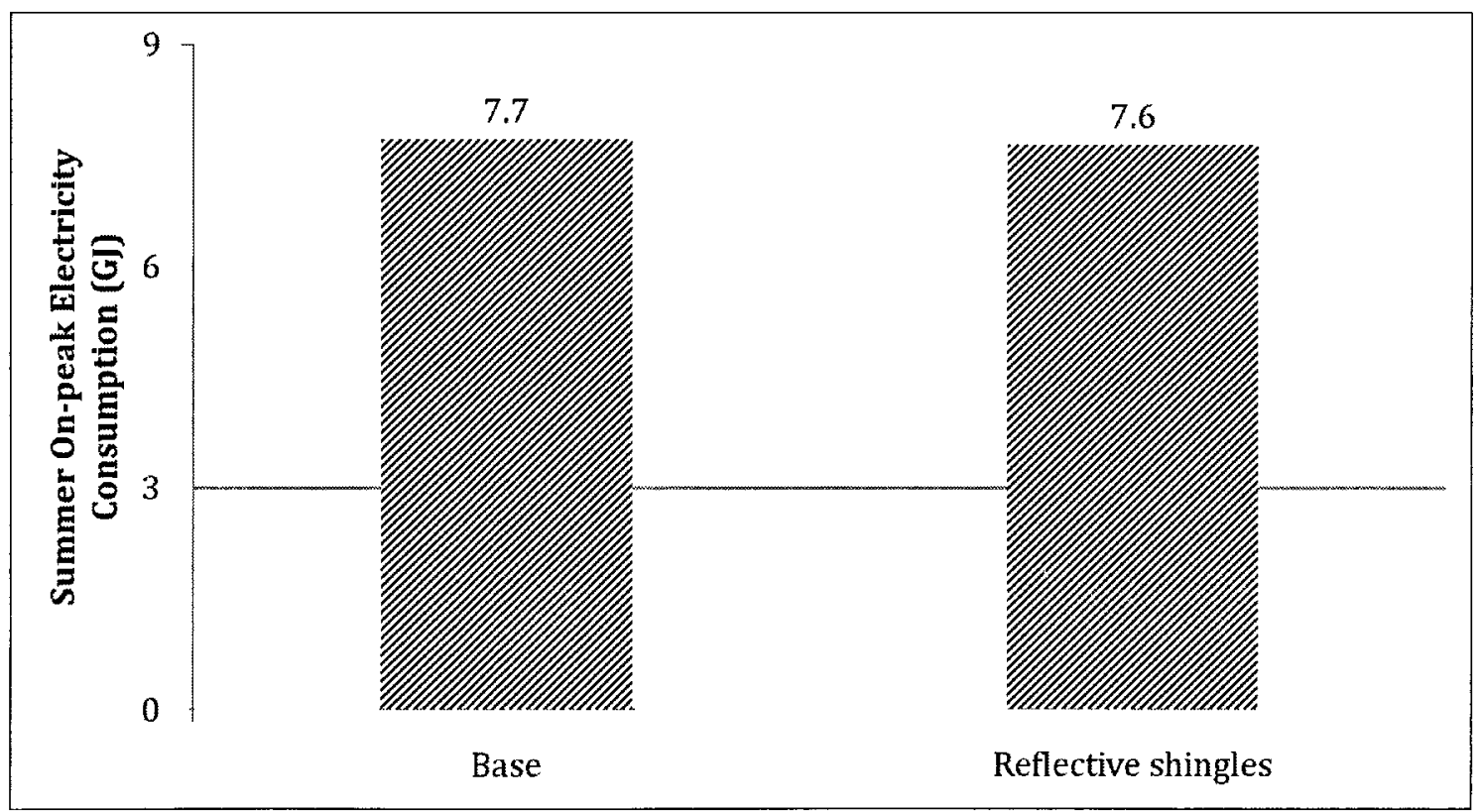

Figure 7.8: Summer weekday on-peak electricity consumption with reflective shingles 


\subsubsection{Analysis of Reflective Shingles Results}

The negligible effect with reflective shingles can be attributed to the large amount of insulation between the attic space and the main zone which reduces any thermal interaction. Reflective shingles reduce the thermal energy absorbed into the attic space by reflecting more solar radiation. The lower attic temperature does not significantly affect the main zone temperature since the zones are separated by RSI $9.0 \mathrm{~m}^{2} \mathrm{~K} / \mathrm{W}$ insulation.

Reflective shingles affect the temperature of the unconditioned attic space compared to the base case. On January 15, the attic space temperature difference between the base case and the reflective shingles reaches a maximum of $4.5^{\circ} \mathrm{C}$ around 2:00 pm. On July 31, the maximum temperature difference between the base case and reflective shingles is $10.5^{\circ} \mathrm{C}$ around $1: 30 \mathrm{pm}$, which can be seen in Figure 7.9. The large temperature differences have little effect on the main zone electricity consumption over the same day and only reduces the electricity consumption on July 31 between the base case and reflective shingles variant by $1 \%$.

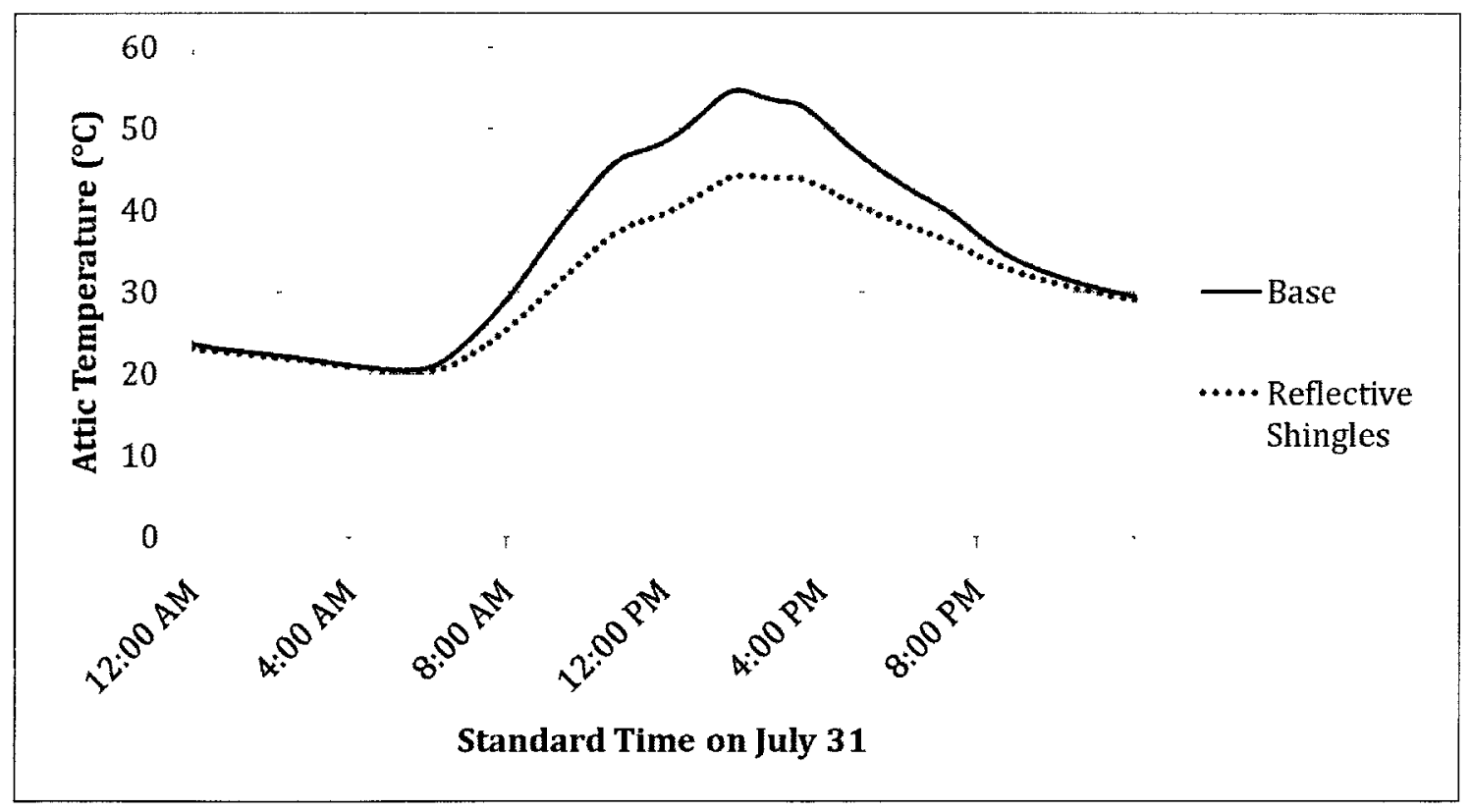

Figure 7.9: Attic temperature on July 31 in the base case and reflective shingles variant 


\subsection{Thermal Mass and Pre-cooling Control Strate- gies}

Thermal mass variants replaced the main floor construction with $10 \mathrm{~cm}$ of concrete. The thermal mass case and the base case were simulated with three different precooling strategies to examine the effects of modifying the thermal setpoints with different constructions. The pre-cooling strategies were described in detail in Section 5.2 of Chapter 5 .

\subsubsection{Summary of Key Thermal Mass and Pre-Cooling Re- sults}

- The PC3 cooling strategy has the largest effect on $E_{\text {on peak }}$, reducing this metric by $26.9 \%$ with the base case floor construction, and $27.3 \%$ with the $10 \mathrm{~cm}$ concrete main floor construction.

- Concrete floors increase $N G_{\text {annual }}$ by $0.4 \%$. The pre-cooling schedules only modify the summer thermal setpoints and when combined with the base case have no effect on $N G_{\text {annual }}$, shown in Figure B.22 on 164.

- The PC1 strategy has the largest reduction in $E_{\text {annual }}$ of $4.5 \%$ with the 'base with $\mathrm{PC1}$ ' variant and $4.7 \%$ with the ' $10 \mathrm{~cm}$ concrete floor with $\mathrm{PC1}$ ' variant. The PC2 variants also reduce $E_{\text {annual }}$ by just over $3 \%$ with both the base and concrete constructions. These results are shown in Figure B.21 on 163.

- Corr annual decreases $12.5 \%$ with ' $10 \mathrm{~cm}$ concrete floor with PC3' relative to the base case, shown in Figure B.23 on page 164. The remaining variants using pre-cooling strategies also reduce Corr $_{\text {annual }}$ between $9 \%$ and $12 \%$.

- The ' $10 \mathrm{~cm}$ concrete floor with PC3' variant results in a $48.9 \%$ reduction in

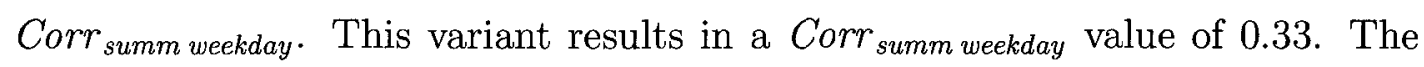
'base with PC3' variant has a decrease of 47.1\%, shown in Figure B.24 on page 164. 


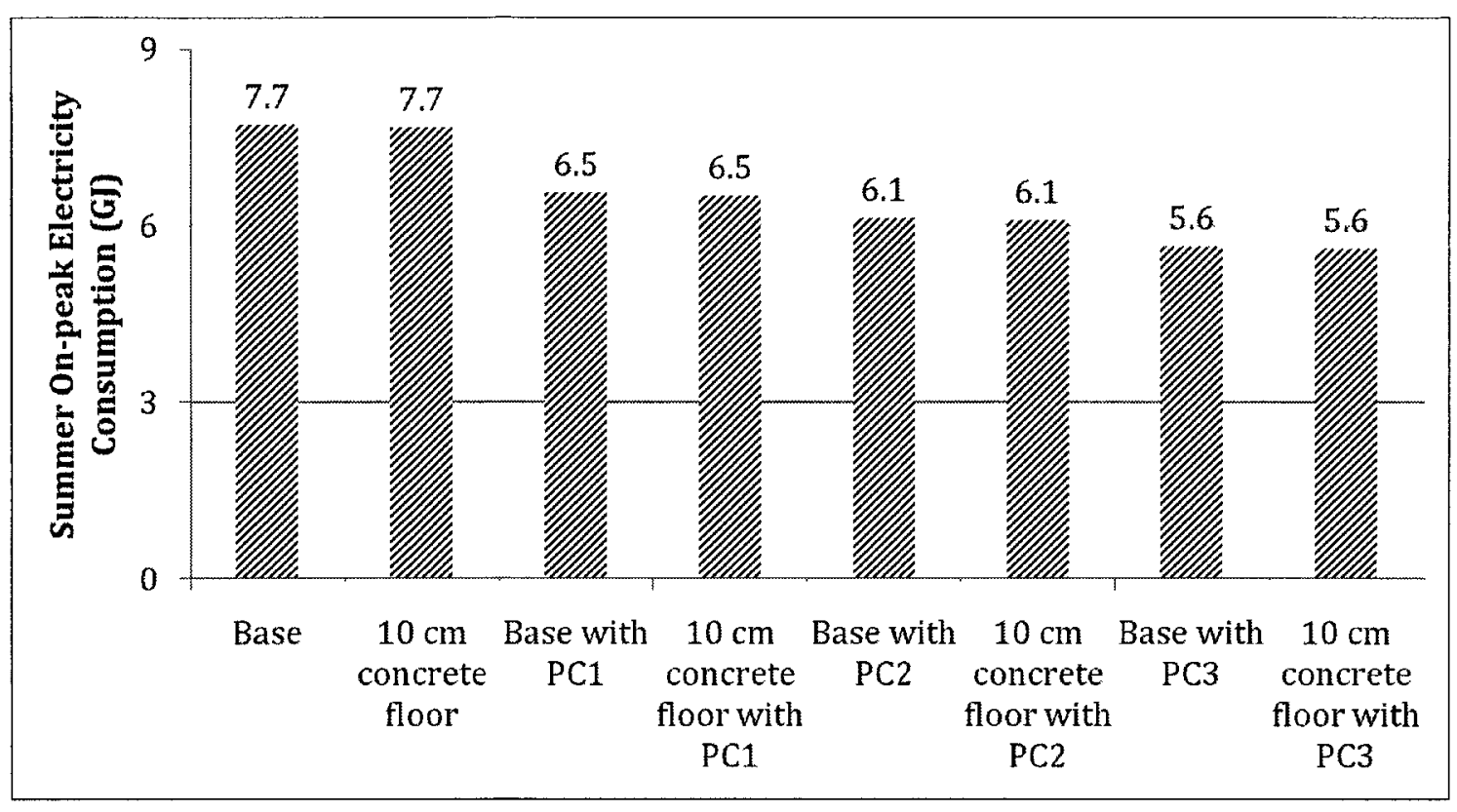

Figure 7.10: Summer weekday on-peak electricity consumption with thermal mass and/or pre-cooling

\subsubsection{Analysis of Concrete and Pre-Cooling Results}

\section{The main zone temperature on July 31}

The three pre-cooling strategies have a $27^{\circ} \mathrm{C}$ setpoint for the on-peak period, with the PC1 strategy extending to the morning as well. The length of the float period, before reaching the $27^{\circ} \mathrm{C}$ setpoint for each pre-cooling variant with $10 \mathrm{~cm}$ concrete floors is shown in Table 7.1. The PC3 strategy, which has a longer pre-cooling period, has the longest float period. This float period, prior to reaching the $27^{\circ} \mathrm{C}$ setpoint, represents the length of time with no space cooling demand during the on-peak period.

The main zone temperatures on July 31 for the three pre-cooling variants with 10 $\mathrm{cm}$ concrete floor, and the base case are shown in Figure 7.11. The main zone temperature of the pre-cooling strategy variants with the base case main floor construction are not shown as there is little difference compared to the concrete floor cases. The main zone temperature for the $\mathrm{PC} 1$ and $\mathrm{PC} 2$ variants are $27^{\circ} \mathrm{C}$ during the on-peak period, as well as overnight. Extended warm temperatures may be uncomfortable for the occupants who may override the pre-cooling setpoints for thermal comfort. 


\begin{tabular}{|l|l|}
\hline Pre-cooling Variant & $\begin{array}{l}\text { Float Period Prior to Reaching } \\
\text { a } \mathbf{2 7 ^ { \circ }} \mathbf{C} \text { setpoint temperature }\end{array}$ \\
\hline \hline $10 \mathrm{~cm}$ concrete floor with PC1 & $\begin{array}{l}25 \text { minutes (float starts } 3 \text { hours before } \\
\text { on-peak period) }\end{array}$ \\
\hline $10 \mathrm{~cm}$ concrete floor with PC2 & 28 minutes (float starts at on-peak period) \\
\hline $10 \mathrm{~cm}$ concrete floor with PC3 & 88 minutes (float starts at on-peak period) \\
\hline
\end{tabular}

Table 7.1: Main zone temperature float period on July 31

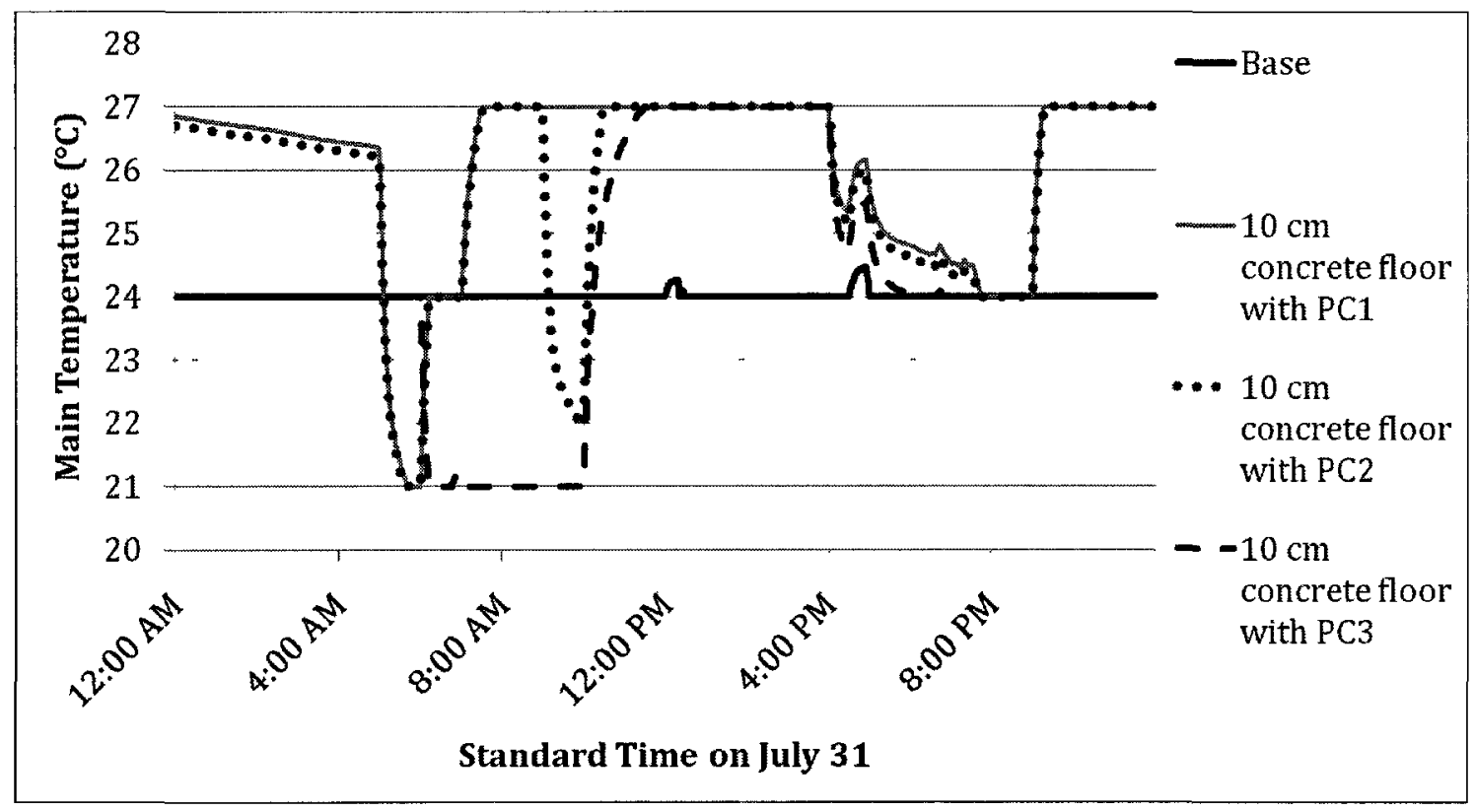

Figure 7.11: Main zone temperature variation from different pre-cooling schedules on July 31

Thermal mass properties of the base case main floor construction compared to the $10 \mathrm{~cm}$ concrete floor

All of the pre-cooling strategies were simulated with both the base case main floor construction and $10 \mathrm{~cm}$ concrete floor construction to examine the effect of various thermal control strategies with different constructions. The results show that there is a much larger effect due to pre-cooling strategies than modifying the main floor 
construction. The product of mass and specific heat of a material is an approximation of its actual thermal capacity, which determines the thermal mass potential of the material. Higher thermal capacity indicates a larger amount of heat is required to change the temperature of the material. A higher thermal capacity indicates more energy can be absorbed before the material reaches the ambient temperature at which point heat will convectively release back into the air. Comparing this thermal capacity approximation for the base case main floor construction and the $10 \mathrm{~cm}$ concrete main floor construction results in a $1.5 \%$ difference in the estimated thermal capacity value. The amount of thermal mass already contained in the base case main floor construction accounts for the similarity in results.

\subsection{Actuating Venetian Blinds}

Six variants actuated venetian blinds located internally or externally between May 15 and September 30, the household cooling period. Blind actuation is based on three sensed conditions: external temperature above $28^{\circ} \mathrm{C}$, main zone temperature above $23^{\circ} \mathrm{C}$ and incident solar radiation on the southwest face of the building above 500 $\mathrm{W} / \mathrm{m}^{2}$.

\subsubsection{Summary of Key Results on Actuating Venetian Blinds}

- The external blind variants have a larger effect on $E_{\text {on peak }}$ than the internal blind variants. Sensing the main zone temperature has the largest effect compared to the other sensors. External blinds actuating to the main zone temperature result in a $15.3 \%$ drop in $E_{\text {on peak }}$ compared to the base case. These results are shown in Figure 7.12.

- External blinds combined with a main zone temperature sensor reduce $E_{\text {annual }}$ by $7.4 \%$. The $E_{\text {annual }}$ results are shown in Figure B.25 on page 166.

- Each external blind variant causes a $9.9 \%$ increase in $N G_{\text {annual }}$ while internal blinds have no effect, shown in Figure B.26 on page 167.

- The Corr ${ }_{\text {annual }}$ effects are negligible with the actuating venetian blind variants, shown in Figure B.27 on page 167. 
- External blinds actuating to main zone temperature reduce Corr $_{\text {summ weekday }}$ by 4.0\%, shown in Figure B.28 on page 168.

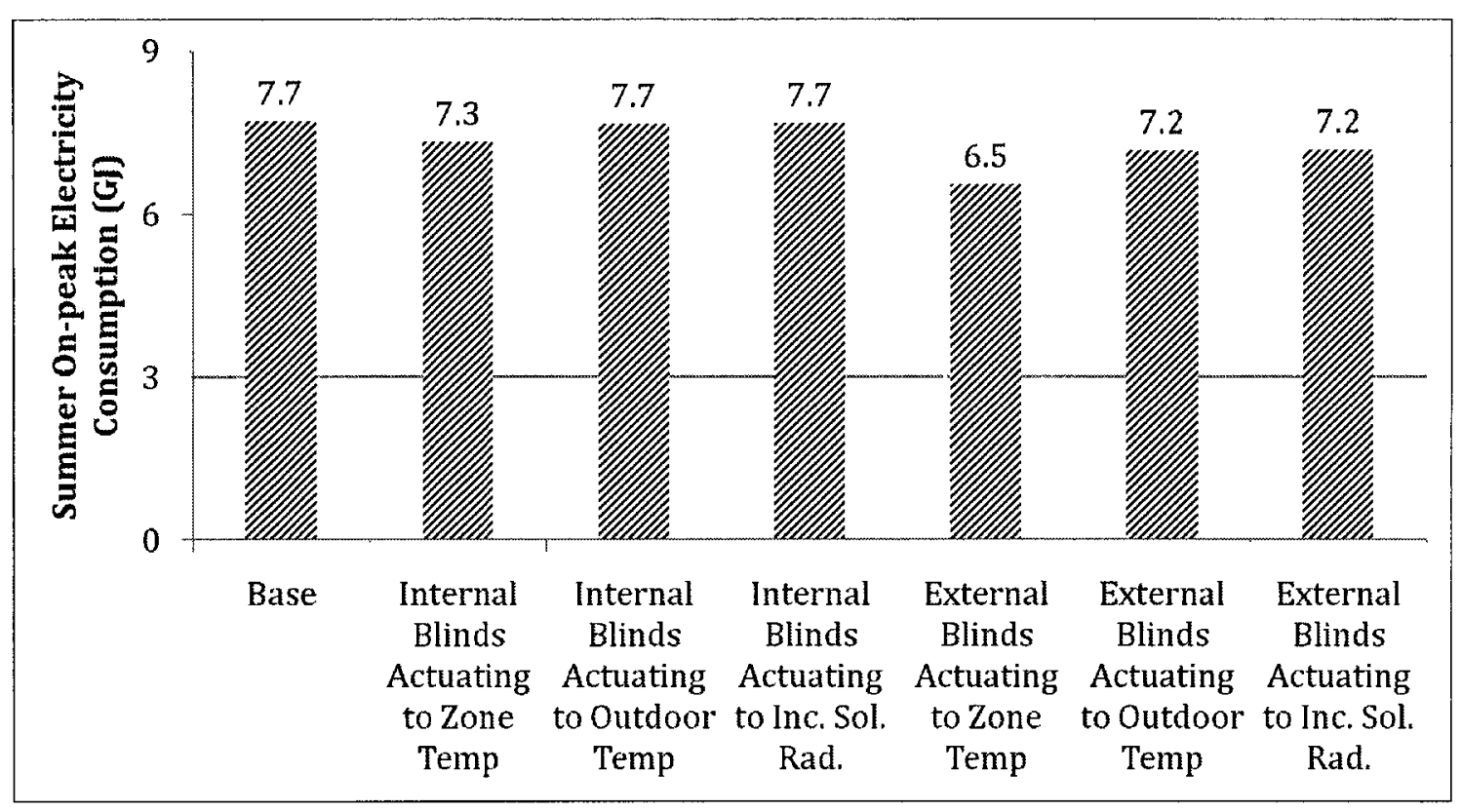

Figure 7.12: Summer weekday on-peak electricity consumption with actuating venetian blinds

\subsubsection{Analysis of Actuating Venetian Blind Results}

The actuating venetian blinds benefit the $E_{\text {on peak }}$ metric by reducing the solar radiation entering the zone. Externally located venetian blinds absorb solar radiation and release the energy convectively and radiatively to the outdoor environment, reducing heat gains in the zone. This mitigates summer space cooling demands with external blinds, but adversely affects the winter heating demand.

The sensors were chosen to coincide with conditions causing large space cooling demands, such as high temperature or solar radiation. Actuating blinds reduce immediate solar gains and the available natural sunlight entering the zone. On July 31, internal and external venetian blinds that actuate when the zone temperature rises above $23^{\circ} \mathrm{C}$ remain closed over the entire day. Internal and external venetian blinds that actuate to an outdoor temperature above $28^{\circ} \mathrm{C}$ close just before $10: 00 \mathrm{am}$, and remain closed for the rest of the day. Internal and external venetian blinds actuating 


\begin{tabular}{|l|c|}
\hline Blind Actuating Variant & $\begin{array}{c}\text { Percent of Time } \\
\text { Blinds Closed }\end{array}$ \\
\hline \hline $\begin{array}{l}\text { External blinds actuating to external } \\
\text { temperature }\end{array}$ & $8 \%$ \\
\hline $\begin{array}{l}\text { Internal blinds actuating to external } \\
\text { temperature }\end{array}$ & $8 \%$ \\
\hline $\begin{array}{l}\text { External blinds actuating to incident solar } \\
\text { radiation on south-west face }\end{array}$ & $6.5 \%$ \\
\hline $\begin{array}{l}\text { Internal blinds actuating to incident solar } \\
\text { radiation on south-west face }\end{array}$ & $6.5 \%$ \\
\hline $\begin{array}{l}\text { External blinds actuating to zone } \\
\text { temperature }\end{array}$ & $81 \%$ \\
\hline $\begin{array}{l}\text { Internal blinds actuating to zone } \\
\text { temperature }\end{array}$ & $85 \%$ \\
\hline
\end{tabular}

Table 7.2: Percentage of time that the blinds are closed with each actuating blind variant

to incident solar radiation on the south-west face above $500 \mathrm{~W} / \mathrm{m}^{2}$ close between 1:00 pm and 5:00 pm.

Table 7.2 shows the percentage of time the blinds are closed for each actuating blind variant during the household summer season. Sensing the zone temperature is the most beneficial sensor to reduce electricity consumption, but this sensor actuates the blinds closed for the majority of the time. Similar to the variant with closed blinds, natural light is impeded with blinds that remain closed over extended periods of time. Occupants may open the blinds or use electrical lights which can offset the benefit of this variant.

\subsection{On-Peak Air-Conditioning Cycling}

Turning off, or cycling, the air-conditioner in 15 minute intervals during the provincial summer period (May 1 to October 31) reduces on-peak electricity consumption. 
This cycling occurs during on-peak hours when the outdoor air temperature is above $27^{\circ} \mathrm{C}$ or when the humidex value, which calculates the sensed temperature with the humidity, rises above $30^{\circ} \mathrm{C}$. The humidex is calculated using Equation 5.2 on page 72 .

\subsubsection{Summary of Key Air-Conditioning Cycling Results}

- $E_{\text {on peak }}$ decreases by $5.6 \%(0.4 \mathrm{GJ})$ with air-conditioner cycling shown in Figure 7.13 .

- $E_{\text {annual }}$ decreases by $0.6 \%(0.3 \mathrm{GJ})$ with air-conditioner cycling shown in Figure B.29 on page 169 .

- $N G_{\text {annual }}$ is not affected by this variant, but can still be referenced in Figure B.30 on page 170 .

- Corr $_{\text {annual }}$ decreases by $2 \%$ shown in Figure B.31 on page 170 and Corr $_{\text {summ weekday }}$ decreases by $1.2 \%$ relative to the base case shown in Figure B.32 on page 171 .

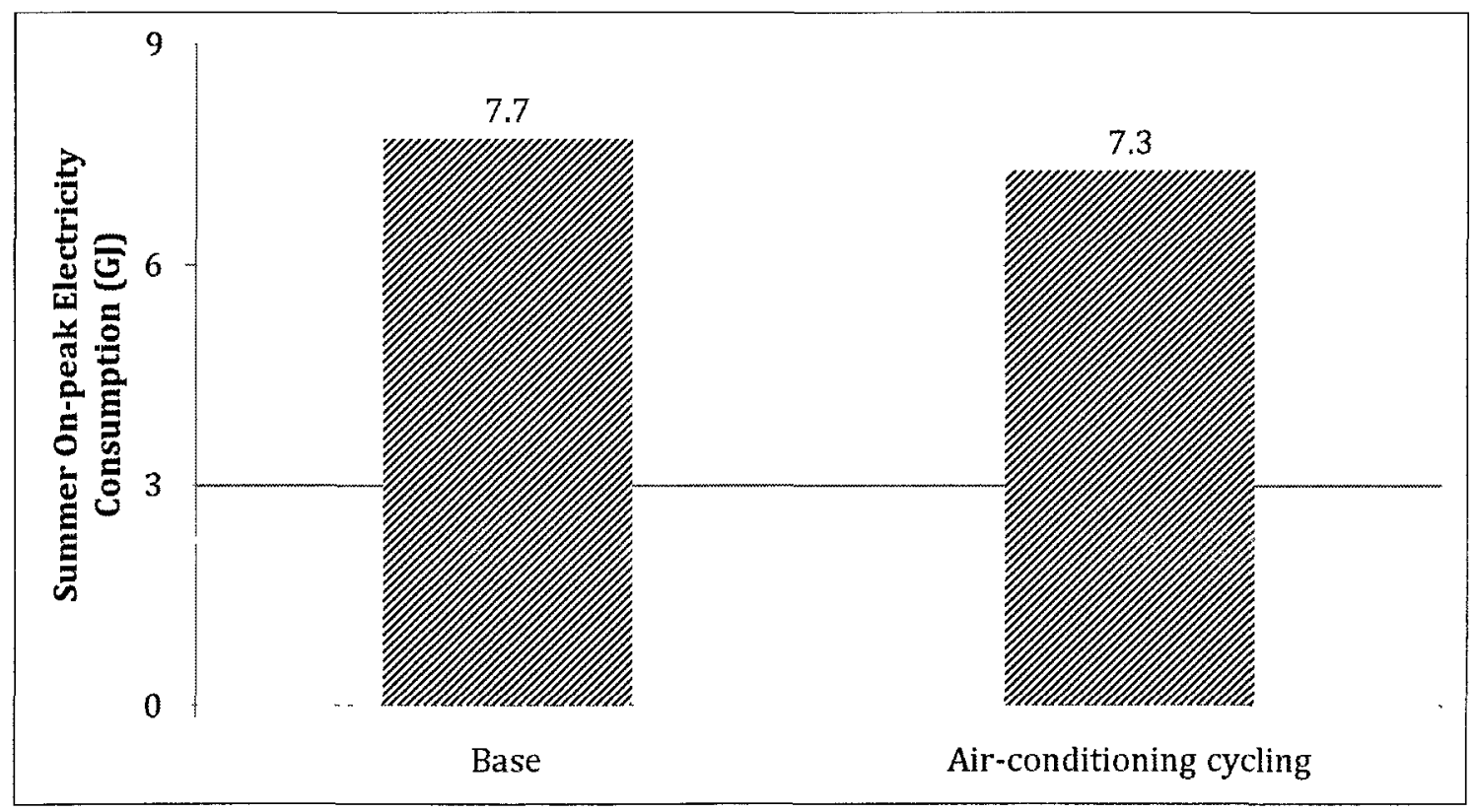

Figure 7.13: Summer-weekday on-peak electricity consumption with airconditioning cycling 


\subsubsection{Analysis of Air-Conditioning Cycling Results}

Air-conditioner cycling is beneficial as it reduces the $E_{\text {on peak }}$ without adversely affecting the $N G_{\text {annual }}$ metric. During times when the air-conditioner is cycled off, the main zone temperature rises above the setpoint temperature. Examining the main zone temperature on July 31 shows that the temperature did not return to the $24^{\circ} \mathrm{C}$ setpoint for 5 cycles and reached a maximum temperature of $28.6^{\circ} \mathrm{C}$ during one of the 15 minute intervals when the air-conditioner was off. These temperature fluctuations are shown in Figure 7.14. The thermostat directly senses and actuates cooling to the air-point node in the simulation, causing near instantaneous temperature changes. The average temperatures in each 15 minute interval on July 31 are lower, with an average high of $27^{\circ} \mathrm{C}$. Over the entire peak period, the main zone temperature averages $25.5^{\circ} \mathrm{C}$.

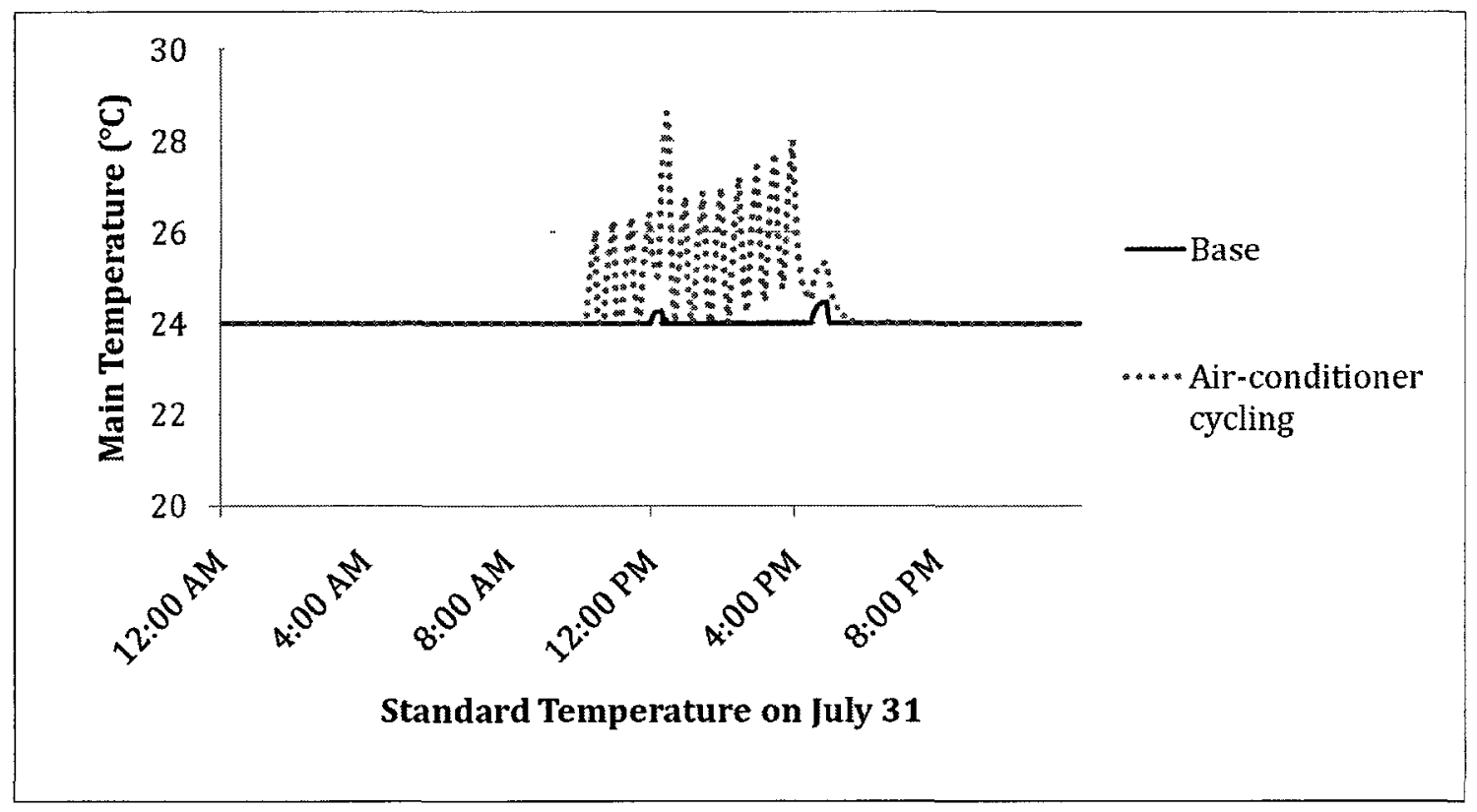

Figure 7.14: Main temperature on July 31 in the base case and the air-conditioner cycling variant

The decrease in $E_{\text {annual }}$ of 0.3 GJ is less than the 0.4 GJ reduction in $E_{\text {on peak }}$, indicating that there is a short period after the peak hours when space-cooling demand increases to return the main zone temperature to the setpoint.

Both Corr $_{\text {annual }}$ and Corr summ weekday reduce with air-conditioner cycling. During off-peak and overnight hours, household electricity consumption follows a similar 
trend to the base case. During on-peak hours, the average trend is similar to the base case but scaled with the reduced electricity consumption.

\subsection{Shifting Use of Appliances and Appliance Ef- ficiency}

Five variants focused on appliance use and efficiency to simulate an occupants response to TOU pricing. Two variants shifted the usage of specific appliances to midor off-peak periods, two variants increased the efficiency of the refrigerator or freezer, and the last variant increased the COP of the air-conditioner.

\subsubsection{Summary of Key Appliance Use and Efficiency Results}

- With the dryer shift variant, $E_{\text {on peak }}$ experiences the largest decrease of $15.0 \%$, followed by the high COP A/C by 10.8\%, shown in Figure 7.15.

- $E_{\text {annual }}$ decreases by $5.9 \%$ with the high COP A/C variant shown in Figure B.33 on page 172. $E_{\text {annual }}$ is unchanged with the dryer shift and stove shift variants from the base case since there is no reduction in electricity consumption over the day, the appliance use is just temporally shifted. The energy efficient freezer reduces $E_{\text {annual }}$ by $2.5 \%$, and the energy efficient fridge causes a $1.5 \%$ decrease in this metric.

- The $N G_{\text {annual }}$ metric is not significantly affected with these variants. The dryer shift variant reduces $N G_{\text {annual }}$ by $0.4 \%$, while the stove shift has no effect. The energy efficient freezer and fridge variants slightly increase $N G_{\text {annual }}$ by $1.1 \%$ and $0.7 \%$ respectively.

- Corr $_{\text {annual }}$ decreases by $3.2 \%$ with the dryer shift variant, while Corr summ weekday $_{\text {sum }}$ decreases by $5.1 \%$. The effect of the remaining variants with these metrics is lower. The Corr annual results are shown in Figure B.35 on page 173 and the Corr $_{\text {summ weekday }}$ results are shown in Figure B.36 on page 174. 


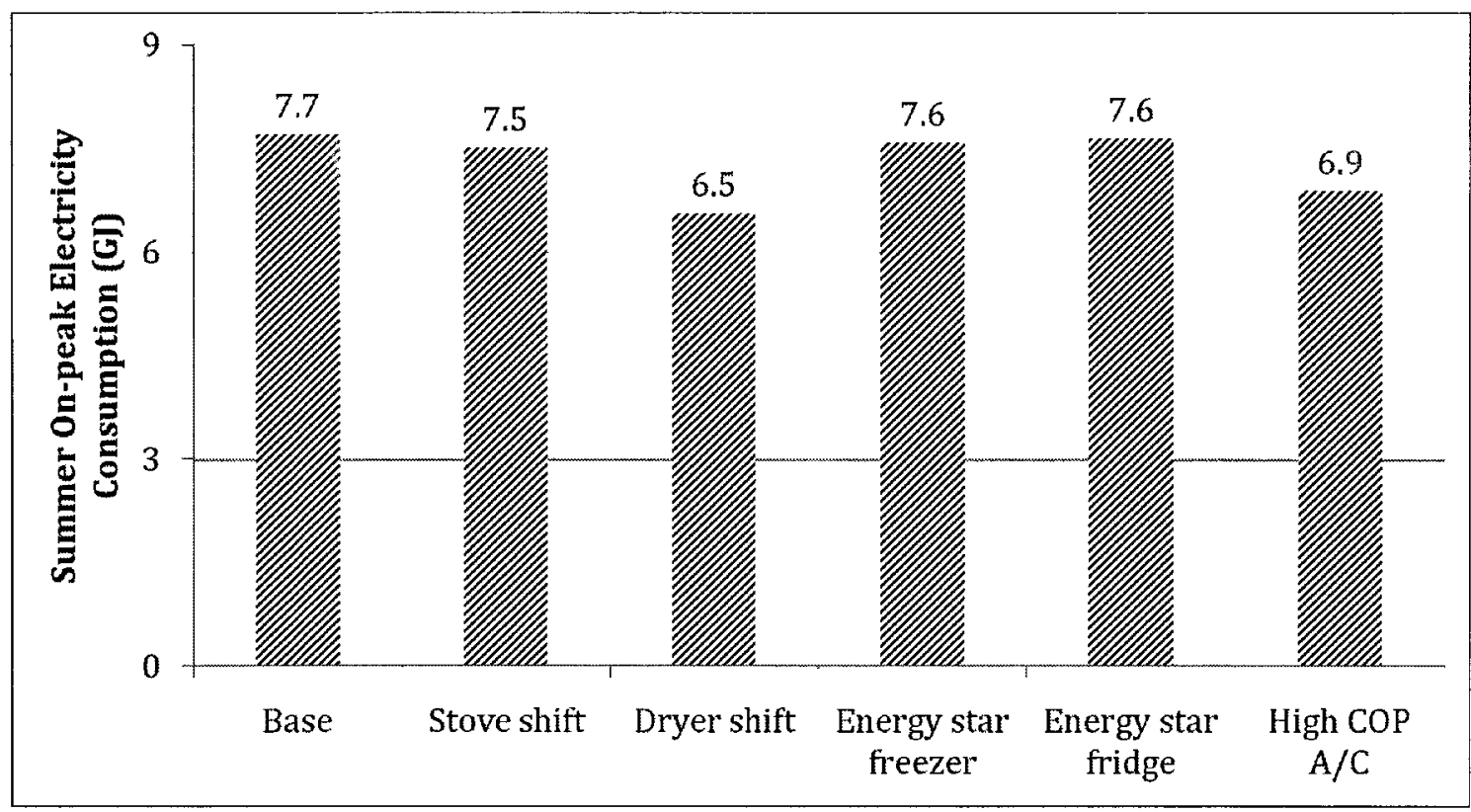

Figure 7.15: Summer weekday on-peak electricity consumption with changes to occupant behaviour

\subsubsection{Analysis of Shifting Use of Appliances and Appliance Efficiency}

Temporally shifting the use of the dryer has a significant effect on the on-peak electricity consumption since the dryer draws $5.5 \mathrm{~kW}$ of electricity when in use.

The energy efficient fridge and freezer have a minimal effect over one day, but cumulatively reduce the overall on-peak and annual electricity consumption since these appliances regularly draw electricity over the entire day.

The increase in $N G_{\text {annual }}$ from energy efficient variants stems from the reduction in associated internal gains from these appliances.

The Corr ${ }_{\text {annual }}$ and Corr $_{\text {summ weekday }}$ metrics have the largest effect the dryer shift variant. This metric modifies the temporal distribution of electricity over the day modifying the daily pattern of household electricity consumption to a pattern that is less similar to the provincial grid demand. 


\subsection{Outdoor Air Ventilation by Opening Win- dows or Using Ventilative Cooling}

Two variants simulated the use of outdoor air to supplement space cooling in the zone. The first opened all of the windows to $10 \%$ of their area at times when the zone temperature is above $23^{\circ} \mathrm{C}$ and the outdoor air temperature is below the zone air temperature. The second variant used the same sensed conditions, but the zone ventilated at $1 \mathrm{ACH}$ representative of a fan ventilating the zone. An estimated fan power was not included in the ventilative cooling variant.

\subsubsection{Summary of Key Outdoor Air Ventilation Results}

- Both outdoor air ventilating variants reduce $E_{\text {on peak }}$, with a $7.0 \%$ (0.5 GJ) decrease with summer open windows, and a $3.2 \%$ (0.2 GJ) decrease with ventilative cooling, shown in Figure 7.16.

- Both variants reduce $E_{\text {annual }}$. Summer open windows affects this metric with a $3.6 \%(1.9 \mathrm{GJ})$ reduction, and ventilative cooling causes a $2.0 \%$ (1.0 GJ) reduction, shown in Figure B.37 on page 175.

- The effect on $N G_{\text {annual }}$ is insignificant as can be seen in Figure B.38 on page 176.

- Corr ${ }_{\text {annual }}$ increased with both of these variants shown in Figure B.39 on 176.

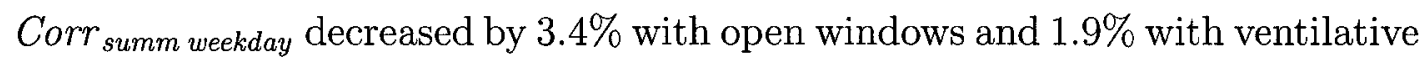
cooling shown in Figure B.40 on page 177. 


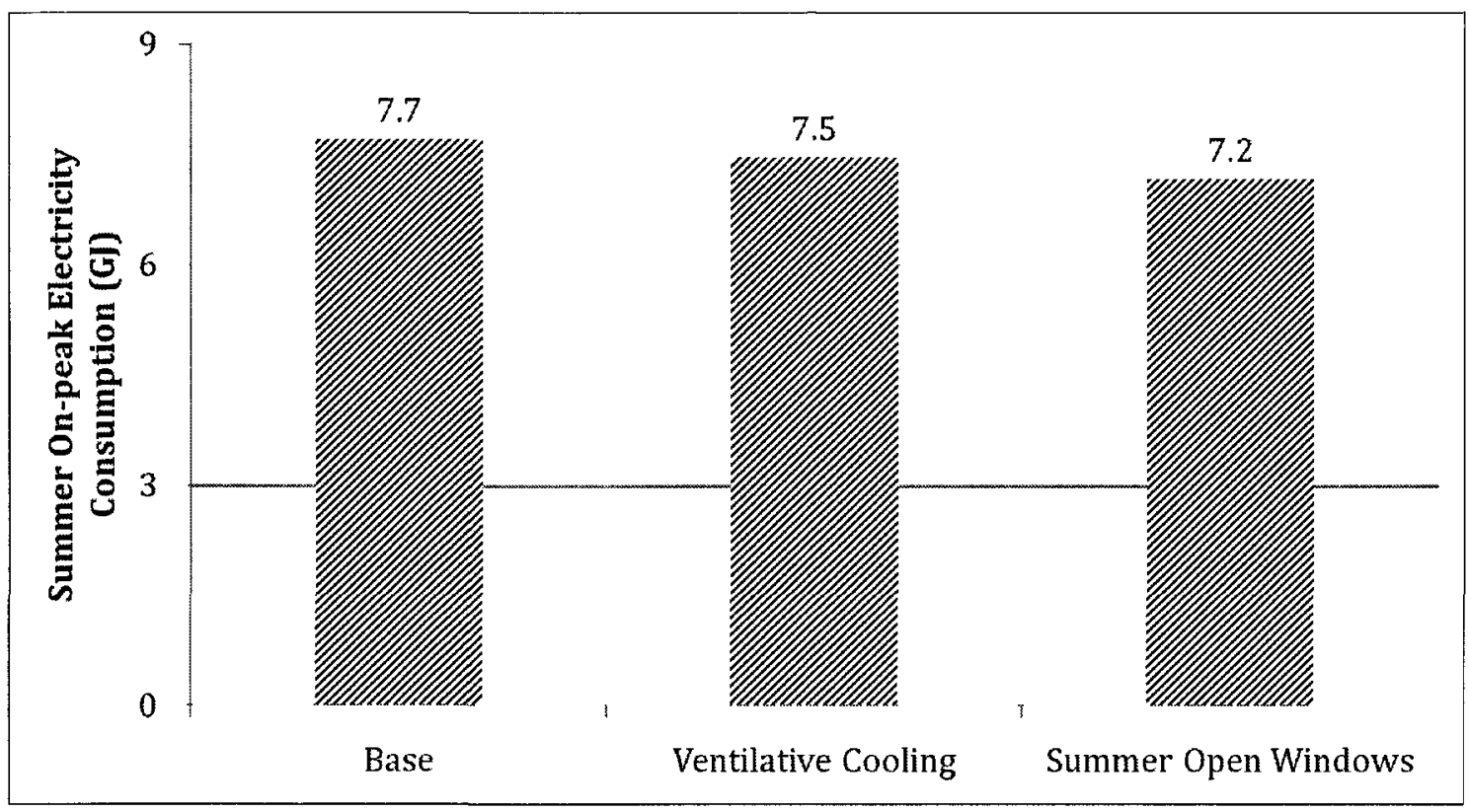

Figure 7.16: Summer weekday on-peak electricity consumption with use of outdoor air

\subsubsection{Analysis of Outdoor Air Ventilation}

Ventilating the main zone with outdoor air is beneficial on days in the summer when the overnight temperatures drop below the temperature in the house. Open windows or ventilative cooling have no effect on hot days, or days when the overnight temperatures remain high which tend to coincide with days of high demand.

On June 16, low overnight and morning temperatures pre-cool the zone before the on-peak period, which offsets some on-peak space cooling demand shown in Figure 7.17. It should be noted that the vertical axis in Figure 7.17 is in kilojoules over each minute. In the morning, ventilation has the largest reduction in electricity consumption compared to the base case. These variants, specifically the opening of the windows, have the potential to reduce on-peak electricity consumption on similar days to June 16 , but not on extremely hot days. 


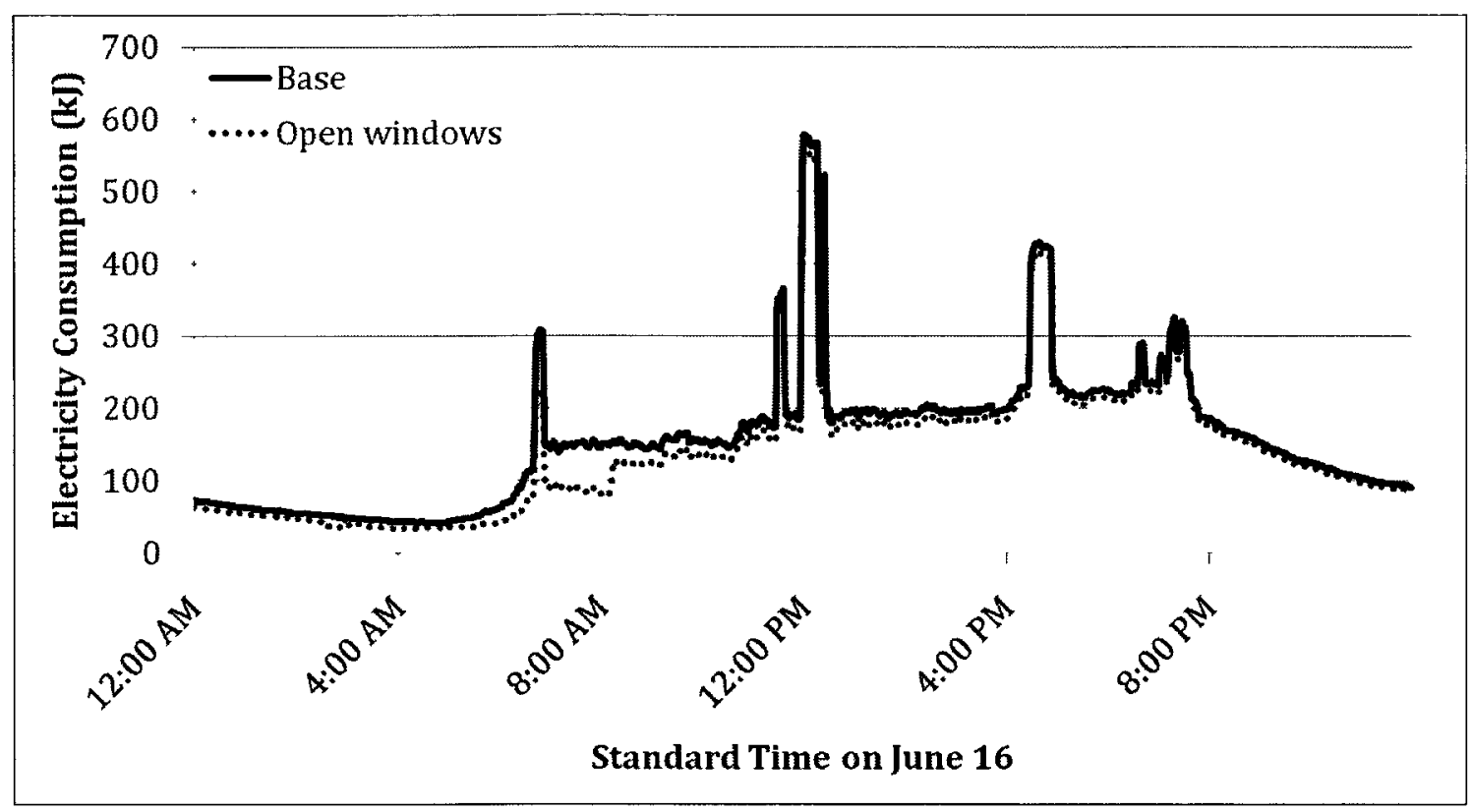

Figure 7.17: Electricity consumption on June 16 of the base case and open windows variant

\subsection{Comparing the Use of a Representative Pro- file to Real House Electricity Demand Data}

Chapter 4 detailed the process of creating a representative electricity profile to imitate occupancy in the house. To validate the use of a single day profile, non-HVAC data from three houses in the Ottawa study by Saldanha [51], replaced the representative profile, and were simulated with the base case. The non-HVAC data represents real occupancy and is non-repeating and random, unlike the representative profile. The three houses simulated with the base case; denoted $\mathrm{H} 1, \mathrm{H} 10$ and $\mathrm{H} 12$, represent different categories of annual energy consumption. H1 has low annual consumption while H10 and H12 are medium to high houses. The results of simulating real occupancy profiles are analyzed with the same set of metrics used for the variants in this work. 


\subsubsection{Summary of Key Results in Comparing the Represen- tative Profile to Real Occupancy Profiles}

- $E_{\text {on peak }}$ of the representative profile is higher than $E_{\text {on peak }}$ for all of the real occupancy profiles, shown in Figure 7.18.

- $E_{\text {annual }}$ of the representative profile is larger than two of the real occupancy profiles. H12 has the largest $E_{\text {annual }}$ of $54.7 \mathrm{GJ}, 5 \%$ higher than the representative profile. The results for $E_{\text {annual }}$ are shown in Figure B.41 on page 178

- The $N G_{\text {annual }}$ of the representative profile is within the range of the real occupancy profiles, and is surpassed by both $\mathrm{H} 1$ and H12, shown in figure B.42 on page 179

- Corr ${ }_{\text {annual }}$ is highest with the representative profile, shown in Figure B.43on page 179 .

- Corr $_{\text {summ weekday }}$ is highest with the representative profile. H12 has a similar Corr $_{\text {summ weekday }}$ value, $1.8 \%$ lower than the representative profile, shown in Figure B.44 on page 180.

\subsubsection{Analysis of Comparing the Representative Profile to Real Occupancy Profiles}

\section{A comparison of $E_{\text {on peak }}$}

The representative profile has the highest $E_{\text {on peak }}$, a result of the daily use of the dryer. The closest real occupancy profile is H12, whose $E_{\text {on peak }}$ is $80 \%$ of that of the representative profile. Comparing the on-peak consumption gives a clear indication that the use of a daily repeating profile represents a house with little concern for energy efficiency or electricity consumption during on-peak hours, and may not accurately represent single-family houses.

The $E_{\text {on peak }}$ results for each real occupancy profile simulation are quite varied, and $\mathrm{H} 1$ has the smallest $E_{\text {on peak }}$ consuming $43 \%$ of that of the representative profile. This significantly low value demonstrates the low on-peak electricity consumption of existing households with potential to become a $\mathrm{ZPH}$ with either local generation or storage strategies. 


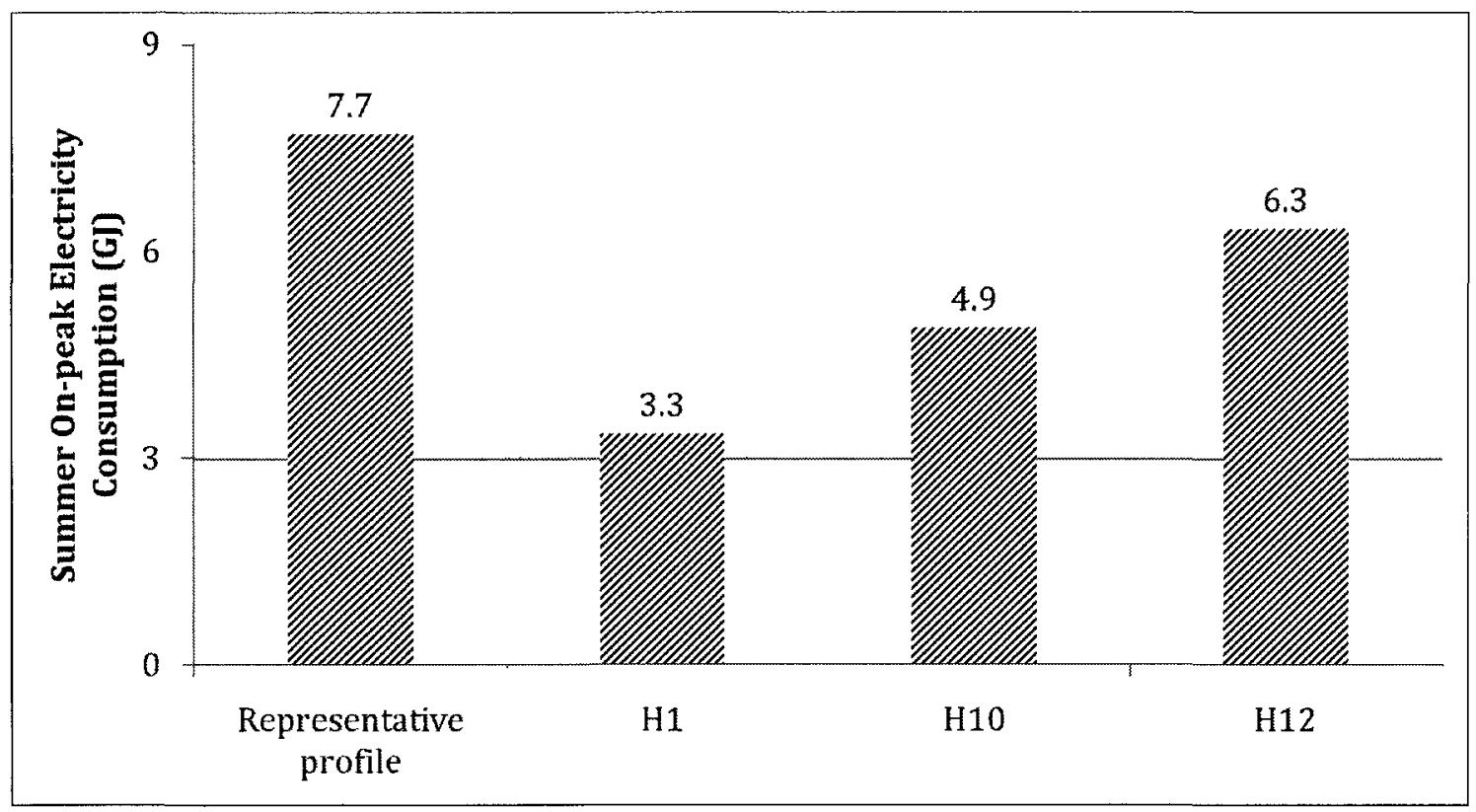

Figure 7.18: Summer weekday on-peak electricity consumption of the base case with the representative profile compared to real occupancy profiles from three Ottawa area houses

\section{Comparing $E_{\text {annual }}$ results}

The largest $E_{\text {annual }}$ is from $\mathrm{H} 12$, which uses $5 \%$ more electricity annually than the representative profile. The representative profile fits in the range of real results, but does have a high value of $E_{\text {annual }}$ making it a high-use house along with H12.

$\mathrm{H} 1$ has the lowest $E_{\text {annual }}$ using $46 \%$ less than that of the representative profile. H10 uses 48 GJ annually, $8 \%$ less than the representative profile.

This broad range of consumption levels validates the representative profile annually, as it fits within the real occupancy results.

\section{Comparing $N G_{\text {annual }}$ results}

The $\mathrm{H} 1$ and $\mathrm{H} 12$ have larger heating demands, using $20.6 \%$ (H1) and 3.7\% (H10) more $N G_{\text {annual }}$ than the representative profile.

The higher value of $N G_{\text {annual }}$ with $\mathrm{H} 1$ stems from $\mathrm{H} 1$ 's low electricity consumption. Less internal gains from appliance use in the winter time require more natural gas to maintain the thermal setpoint. 
Comparing Corr ${ }_{\text {annual }}$ and Corr $_{\text {summ weekday }}$ results

Both Corr $_{\text {annual }}$ and Corr $_{\text {summ weekday }}$ are lower for all of the real occupancy profiles. Corr $_{\text {summ weekday }}$ for $\mathrm{H} 12$ is only $1.8 \%$ less than the representative profile. The high correlation values of the representative profile relate to the consistency in the repeating daily pattern of the profile, similar to that of the provincial grid demand. Real occupancy profiles have much more variation, and include days where the occupants may be gone for long periods of time and electricity consumption is low.

Comparing the real occupancy profiles' metrics for Corr $_{\text {summ weekday }}$ and Corr annual $_{\text {an }}$ demonstrate a clear difference. Of the three real occupancy profiles, H12 has the

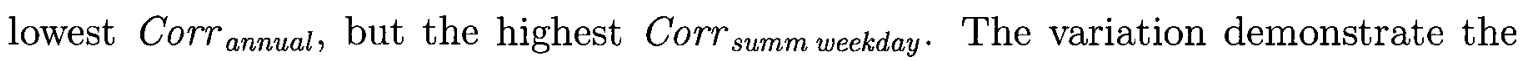
daily and seasonal changes in occupant behaviours.

\section{Overall comparison of the representative profile to real occupancy profiles}

Simulations with real occupancy profiles are intended to compare and validate the representative profile used to represent occupancy in the base case and each variant. Within each set of metrics, the representative profile compared differently to the real occupancy profiles. On-peak electricity consumption is over-estimated in the representative profile, due mainly to the daily use of the dryer. The annual electricity and natural gas consumption metrics show the representative profile within the range of values of real occupancy profiles. The correlation metrics find the representative profile to be higher than the real occupancy profiles.

The real occupancy profiles also present interesting results on the variety of electricity consumption patterns both on-peak and annually. The low house, H1, demonstrates low on-peak consumption in existing houses and the potential of achieving $\mathrm{ZPHs}$ in real communities.

\subsection{Synthesis Summary of Results}

This section presented the simulation results from each set of variants, as well as validating the use of the representative profile with these simulations. Table 7.3 briefly summarizes all of the variations and their effectiveness towards the goal of this project. 


\begin{tabular}{|c|c|c|c|}
\hline Category & Variant & Effective & Ineffective \\
\hline \multirow{18}{*}{ 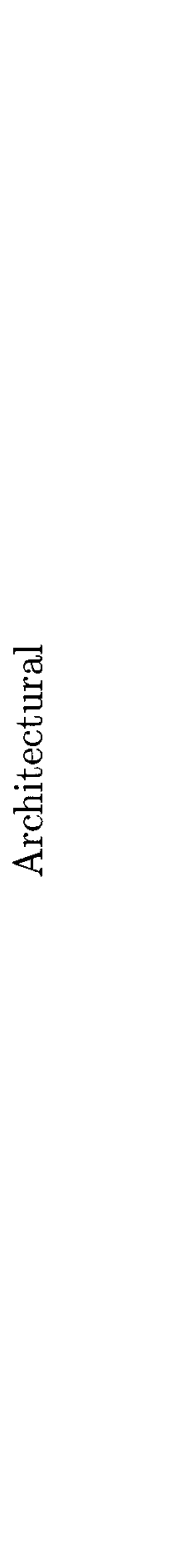 } & $30 \mathrm{~cm} \mathrm{SW}$ window awnings & $\mathrm{X}$ & \\
\hline & $50 \mathrm{~cm}$ SW window awnings & $\mathrm{X}$ & \\
\hline & $50 \mathrm{~cm}$ roof overhangs & $\mathrm{X}$ & \\
\hline & $1 \mathrm{~m}$ roof overhangs & $\mathrm{X}$ & \\
\hline & Line of trees & $\mathrm{X}$ & \\
\hline & $\rho=0.117$ reflective outer layer & & $\mathrm{X}$ \\
\hline & $\rho=0.217$ reflective outer layer & & $\mathrm{X}$ \\
\hline & Triple pane, low-e coated & $\mathrm{X}$ & \\
\hline & Triple pane, reflective, low-e coated & & $\mathrm{X}$ \\
\hline & Quad pane, krypton gas fill & $\mathrm{X}$ & \\
\hline & Closed blinds & & $\mathrm{X}$ \\
\hline & $45^{\circ}$ blinds & & $\mathrm{X}$ \\
\hline & Shifting $50 \%$ of SW windows to NE and NW & & $\mathrm{X}$ \\
\hline & Shifting $50 \%$ of SW windows to all other sides & & $\mathrm{X}$ \\
\hline & Reducing all window areas by $10 \%$ & $\mathrm{X}$ & \\
\hline & Reducing all window areas by $25 \%$ & $\mathrm{X}$ & \\
\hline & Reflective shingles & & $\mathrm{X}$ \\
\hline & $10 \mathrm{~cm}$ concrete main floor & & $\mathrm{X}$ \\
\hline \multirow{4}{*}{ 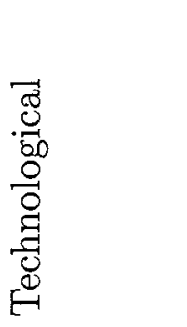 } & Pre-cooling strategy 1 & $\mathrm{X}$ & \\
\hline & Pre-cooling strategy 2 & $\mathrm{X}$ & \\
\hline & Pre-cooling strategy 3 & $\mathrm{X}$ & \\
\hline & Actuating venetian blinds to zone & $\mathrm{X}$ & \\
\hline
\end{tabular}




\begin{tabular}{|c|c|c|c|}
\hline Category & Variant & Effective & Ineffective \\
\hline & temperature & & \\
\hline & $\begin{array}{l}\text { Actuating venetian blinds to outdoor } \\
\text { temperature }\end{array}$ & $\mathrm{X}$ & \\
\hline & $\begin{array}{l}\text { Actuating venetian blinds to incident } \\
\text { solar radiation }\end{array}$ & $\mathrm{X}$ & \\
\hline & A/C on/off cycling & $\mathrm{X}$ & \\
\hline \multirow{6}{*}{ 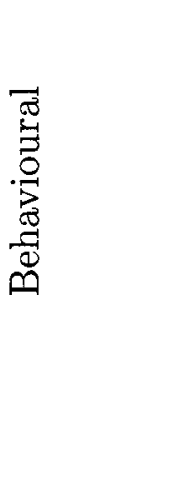 } & Shifting TOU of dryer & $\mathrm{X}$ & \\
\hline & Shifting TOU of dryer & $\mathrm{X}$ & \\
\hline & Energy efficient appliances & $\mathrm{X}$ & \\
\hline & High COP A/C & $\mathrm{X}$ & \\
\hline & Open windows & $\mathrm{X}$ & \\
\hline & Ventilative cooling & $\mathrm{X}$ & \\
\hline
\end{tabular}

Table 7.3: Synthesis summary of variant results

\subsection{Closing Remarks}

The most effective variants for on-peak electricity consumption reduced incoming solar radiation, modified thermal setpoints, altered the TOU of appliances, and ventilated the zone with cooler outdoor temperatures when applicable. Modifying constructions with reflective shingles or thermal mass had a minimal impact on the metrics.

The $E_{\text {on peak }}$ metric was the best indication of each variant's potential towards to goal of a ZPH, while the correlation metrics $\left(\right.$ Corr $_{\text {annual }}$ and Corr $\left._{\text {summ weekday }}\right)$ were the least supportive.

Substituting real occupancy profiles in the base case demonstrated the total summer-weekday on-peak consumption of the representative profile is much higher 
than with real house occupancy. This is due to the one-day repeating nature of the representative profile. Conversely, annual electricity and natural gas consumption from the representative profile and real occupancy profiles are much closer in value. The real occupancy profiles demonstrate the complexity of real occupant behaviour. The variety of results indicates the representative profile, while overestimating the onpeak electricity consumption, is a relatively accurate interpretation of real occupancy within a house.

The most effective results from this chapter are combined to form several combinations to establish a low on-peak house, described in Chapter 8 , followed by the sizing and implementation of local generation and storage to achieve zero on-peak electricity demand in Chapter 9. 


\section{Chapter 8}

\section{Combinations of Effective Variants}

Results from each variant were presented and analyzed in Chapter 7. Analysis of these results using a set of defined metrics demonstrated that the most effective variants were ones that reduced incoming solar radiation, modified thermal setpoints, altered the time-of-use of appliances, and ventilated the zone with cooler outdoor temperatures when applicable. Combining these variants takes advantage of multiple strategies to mitigate space cooling demand. Combinations of effective variants have potential to significantly reduce the on-peak electricity consumption such that a ZPH is achievable with the implementation of local generation with or without an energy storage component, discussed in Chapter 9. Effective variants that mitigate on-peak electricity consumption in a similar fashion are compared using different combinations. The combinations use two techniques to reduce solar gains, two techniques to modify HVAC settings, and test the effects of outdoor air ventilation. All of the combinations incorporate occupant behaviour modifications based on TOU pricing and appliance efficiencies.

There are six different combinations of effective variants. These are summarized in Table 8.1. The methods employed to form each of these six combinations are described in the next section.

\subsection{Effective Variants Used in Combinations}

\section{Reducing solar gains}

Two effective methods of reducing solar gains in the zone are used in combination models. The first uses architectural and vegetative shading features. These features 
are chosen for the combinations as they can be used in conjunction to shade the transparent and opaque surfaces of the building, and are a relatively easy addition to a house. The second strategy to reduce solar gains uses external blinds actuating to a sensor. The most effective sensor is to a main zone temperature above $23^{\circ} \mathrm{C}$. This strategy, which alone reduced $E_{\text {on peak }}$ by $15.3 \%$, has even more potential when combined with other effective variants.

If should be noted that even though modified window properties reduced solar gains, they impede natural light in the zone and cannot be overridden by the occupants. As such they were not incorporated into the combinations.

\section{Modifying HVAC settings}

Two methods of modifying the base case HVAC settings are used in combination models. The first is the PC3 pre-cooling strategy, which pre-cools the zone for four hour before the on-peak period to $21^{\circ} \mathrm{C}$ and increases the on-peak setpoint to $27^{\circ} \mathrm{C}$. This variant is chosen because it reduced $E_{\text {on peak }}$ by $26.9 \%$ relative to the base case. The second method incorporates automatic air conditioner cycling during on-peak hours when the drybulb temperature is above $27^{\circ} \mathrm{C}$ or a calculated humidex value is above $30^{\circ} \mathrm{C}$ (see Equation 5.2 on page 72). Automatically reducing the available space cooling on high temperature days reduced $E_{\text {on peak }}$ by $5.6 \%$. Combining this variant with open windows on days with cool overnight temperatures has potential to reduce space cooling demands over the entire summer season.

\section{Shifting use of appliances and appliance efficiency}

All of the variants that shift the time-of-use of appliances or increase the appliance efficiency reduced $E_{\text {on peak }}$, and are compatible with other variants. The six combination models incorporate the shifting of stove and dryer use to outside of on-peak hours, the energy efficient refrigerator and freezer, and the high COP air-conditioner.

\section{Open windows}

Opening windows is a useful variant on days with low overnight temperatures and warm afternoon temperatures. Outdoor air ventilation was most effective when all of the windows were opened to $10 \%$ of their area, reducing $E_{\text {on peak }}$ by $7.0 \%$. This variant is only incorporated with the cycling air conditioner, examining an alternative method 
of pre-cooling. A similar combination model without open windows examines the effect of outdoor air ventilation, as well as scenarios when occupants do not respond to cooler outdoor temperatures by opening their windows.

All of the combinations opened the windows in the winter when the zone temperature rose above $25^{\circ}$, to prevent overheating from solar gains.

\subsection{Summary of Key Combination Results}

- All of the combination variants have a significant effect in reducing $E_{\text {on peak }}$. All combinations reduce $E_{\text {on peak }}$ by at least $40 \%$ relative to the base case. Combos 1 and 4, which both use a pre-cooling control strategy, have the largest effect with a $51.2 \%$ decrease relative to the base case. Combos 2 and 5, with open windows and air-conditioner cycling reduce $E_{\text {on peak }}$ by $45.2 \%$ with combo 2 and $44.4 \%$ with combo 4 . Combos 3 and 6 were least effective, with a $42.5 \%$ decrease with combo 3 and a $40.5 \%$ decrease with combo $6 . E_{\text {on peak }}$ results are shown below in Figure 8.1.

- All of the combination variants reduce $E_{\text {annual }}$ by between $14 \%$ and $17 \%$. Combos 2 and 5 are most effective, while combos 3 and 6 are least effective shown in Figure B.45 on page 181.

- $N G_{\text {annual }}$ increases with all of the combinations. External blind combos cause a $12 \%$ increase, and external fixed shading combos cause a $13 \%$ increase. These results can be seen in Figure B.46 on page 182.

- Corr $_{\text {annual }}$ reduces for all the combinations, as shown in Figure B.47 on 182. Corr $_{\text {annual }}$ decreases the most with combos 1 and 4 , by approximately $14 \%$, which both use the pre-cooling control strategy.

- The Corr $r_{\text {summ weekday }}$ results are also reduced for all the combinations. Corr $_{\text {summ weekday }}$ decreases the most with combos 1 and 4 with a reduction of $23 \%$ and $25 \%$ respectively. Combos 2 and 5 also have significant reductions in their Corr $_{\text {summ weekday }}$ values, both causing a $18 \%$ drop relative to the base case. Corr $_{\text {summ weekday }}$ results are shown in Figure B.48 on page 183. 


\begin{tabular}{|l|c|c|c|c|c|c|}
\hline & \multicolumn{2}{|c|}{ Shading } & \multicolumn{2}{c|}{ HVAC Controls } & & \\
& $\begin{array}{c}\text { Actuating external } \\
\text { venetians blinds }\end{array}$ & $\begin{array}{c}\text { External fixed } \\
\text { shading objects }\end{array}$ & $\begin{array}{c}\text { PC3 } \\
\text { strategy }\end{array}$ & $\begin{array}{c}\text { Air-conditioner } \\
\text { cycling }\end{array}$ & $\begin{array}{c}\text { Efficient } \\
\text { Appliances }\end{array}$ & Open Windows \\
\hline \hline Combo 1 & $\mathrm{X}$ & & $\mathrm{X}$ & & $\mathrm{X}$ & \\
\hline Combo 2 & $\mathrm{X}$ & & & $\mathrm{X}$ & $\mathrm{X}$ & $\mathrm{X}$ \\
\hline Combo 3 & $\mathrm{X}$ & & & $\mathrm{X}$ & $\mathrm{X}$ & \\
\hline Combo 4 & & $\mathrm{X}$ & $\mathrm{X}$ & & $\mathrm{X}$ & \\
\hline Combo 5 & & $\mathrm{X}$ & & $\mathrm{X}$ & $\mathrm{X}$ & $\mathrm{X}$ \\
\hline Combo 6 & & $\mathrm{X}$ & & $\mathrm{X}$ & $\mathrm{X}$ & \\
\hline
\end{tabular}

Table 8.1: Six combination models 


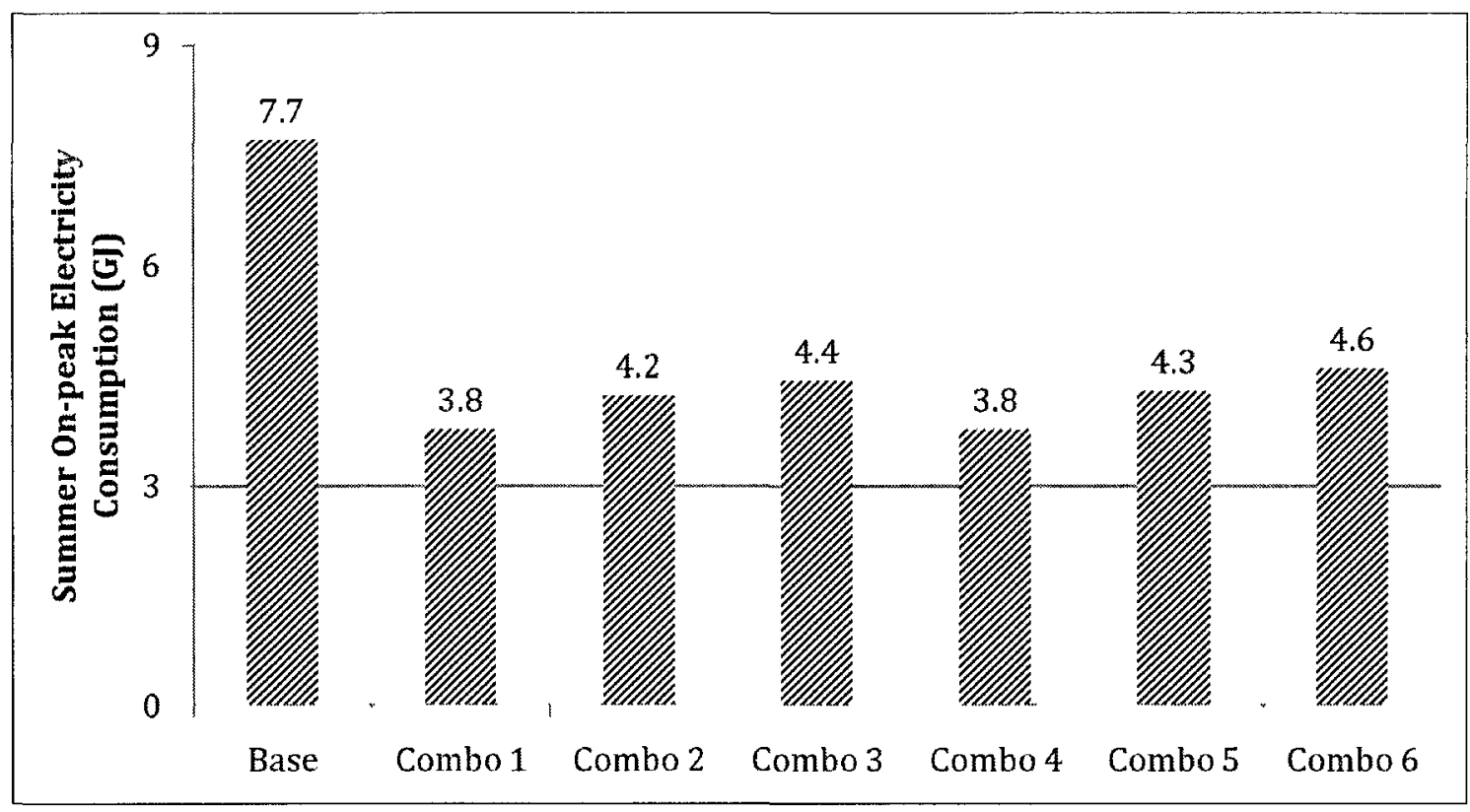

Figure 8.1: Summer weekday on-peak electricity consumption with a combination of effective variants

\subsection{Analysis of Combination Variants}

Combos 1 to 3 , and combos 4 to 6 use different methods to reduce the incoming solar radiation. The combination pairs that use the same HVAC setting but different shading techniques have similar results. This implies that direct control of space cooling and thermal setpoints have more of an effect on reducing $E_{\text {on peak }}$ than shading techniques.

\section{Combination Results Analysis with on July 31}

The electricity consumption in kilojoules over each minute on July 31 is shown in Figure 8.2 for combos 1 to 3 . Due to appliance shifting and modified HVAC controls, there is a large difference in electricity consumption during the on-peak period. The base case is significantly higher, especially when the dryer is used at 12:30 pm standard time. Combo 1 has a constant low electricity draw on-peak with the higher temperature setpoint from PC3. Both combos 2 and 3 have fluctuating electricity consumption on-peak from the cycling air-conditioner. The daily electricity consumption is very similar between combinations with different shading techniques but 
the same HVAC strategy i.e. combo 1 with external actuating blinds and combo 4 with architectural and vegetative shading, both use the PC3 pre-cooling strategy. The electricity consumption on July 31 from combos 4 to 6 are shown in Figure B.49 on page 183.

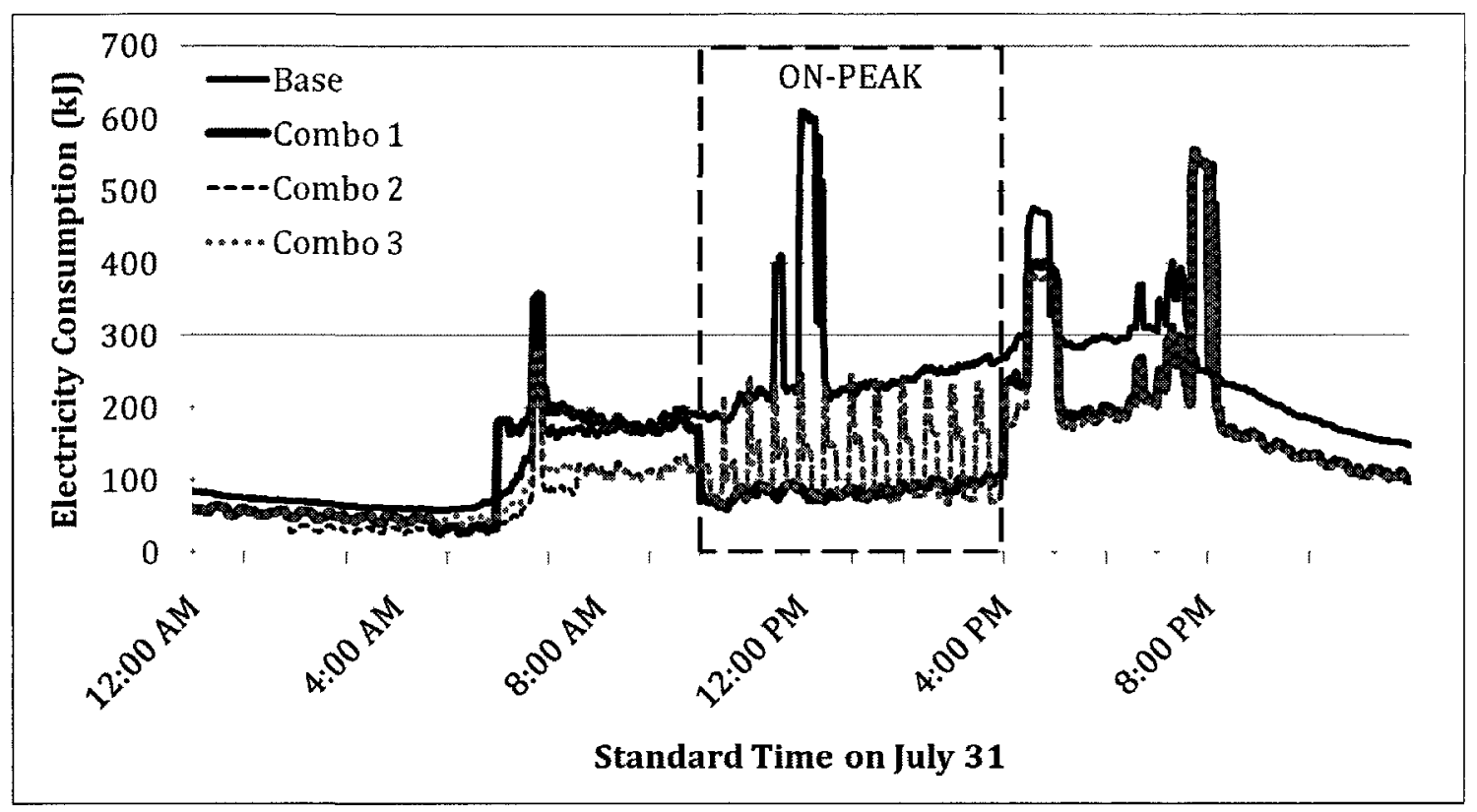

Figure 8.2: Electricity consumption on July 31 for Combinations 1,2 and, 3 compared to the base

HVAC controls allow a warmer zone temperature than the base case setpoint of $24^{\circ} \mathrm{C}$, either by raising the setpoint temperature or reducing the availability of space cooling. During the on-peak hours on July 31 , the main zone temperature in all of the combinations increased above $24^{\circ} \mathrm{C}$. The main zone temperatures of the base case and combos 1 through 3 are shown in Figure 8.3. Combo 1 uses pre-cooling during the four hours before the on-peak period. On-peak, the main zone temperature in combo 1 reaches the $27^{\circ} \mathrm{C}$ setpoint in 84 minutes and remained there until the end of on-peak period. Combo 4, which also uses the PC3 strategy, reaches $27^{\circ} \mathrm{C}$ in 105 minutes. The combinations that cycle the air-conditioner have fluctuating temperatures over the on-peak period. On July 31, the size of each temperature fluctuation increases over the course of the on-peak period. Initially the fluctuations are between $24^{\circ} \mathrm{C}$ and $26^{\circ} \mathrm{C}$, and end the on-peak period with fluctuations between $24^{\circ} \mathrm{C}$ and $27^{\circ} \mathrm{C}$.

The main zone temperature in combo 2 dropped below the cooling setpoint of $24^{\circ} \mathrm{C}$ 
in the morning on July 31 , which opens the windows allowing outdoor air ventilation, shown in Figure 8.3. When the windows are open, there is no space cooling demand. The main zone temperature in combo 5 did not drop below $24^{\circ} \mathrm{C}$, and the windows did not open, shown in Figure B.50 on page 184.

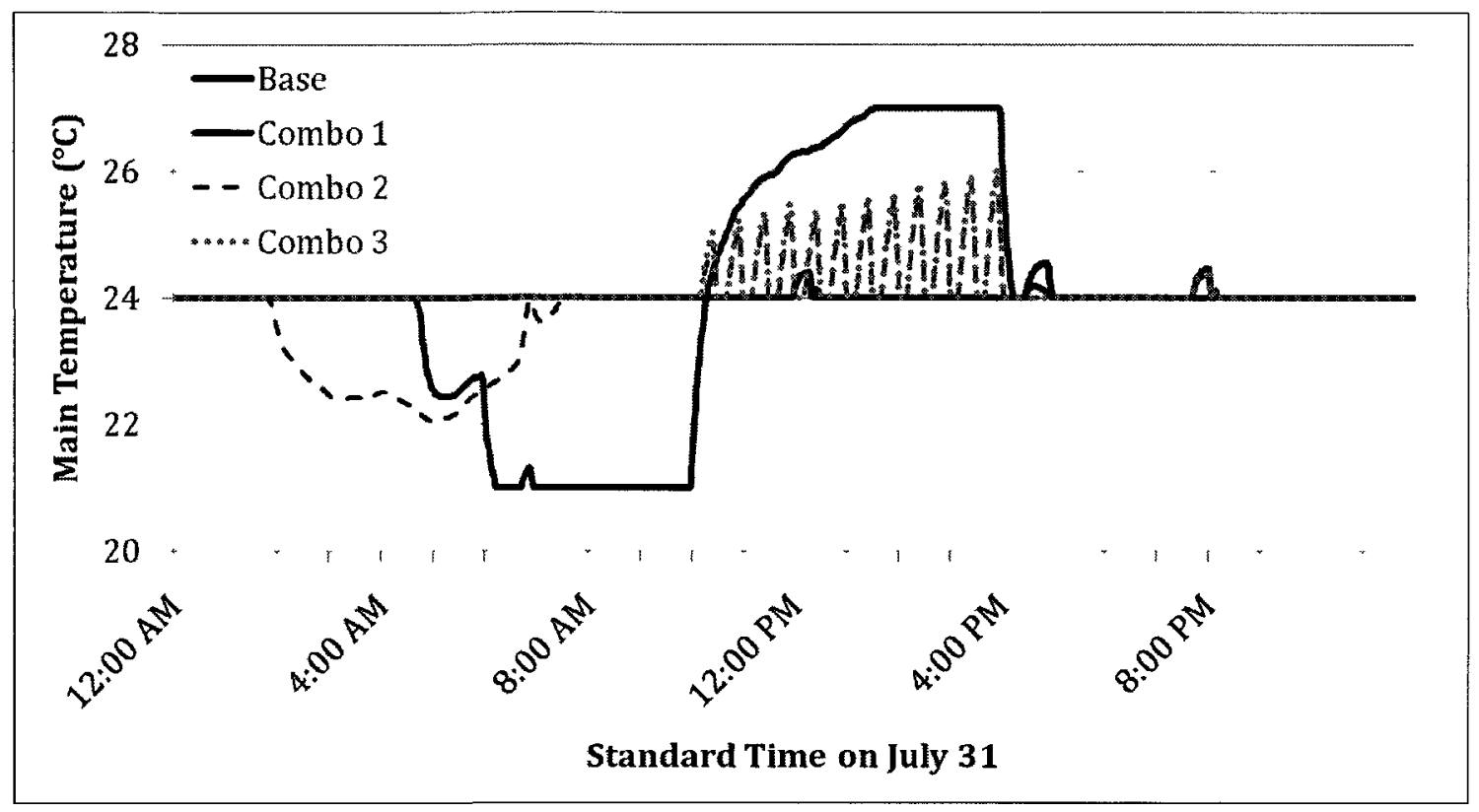

Figure 8.3: The main zone temperature on July 31 for Combinations 1,2 and, 3 compared to the base

\section{Combination Results Analysis on August 1}

August 1 was the hottest day in 2006, and the day when the provincial grid experienced record high demand. The household electricity demand in kilojoules over each minute on August 1, for the base case and combos 1 to 3, is shown in Figure 8.4. The electricity consumption on August 1 is scaled up slightly from July 31 with increased cooling demands. The combinations are still effective on this extremely hot day, and reduce on-peak electricity consumption by approximately half. 


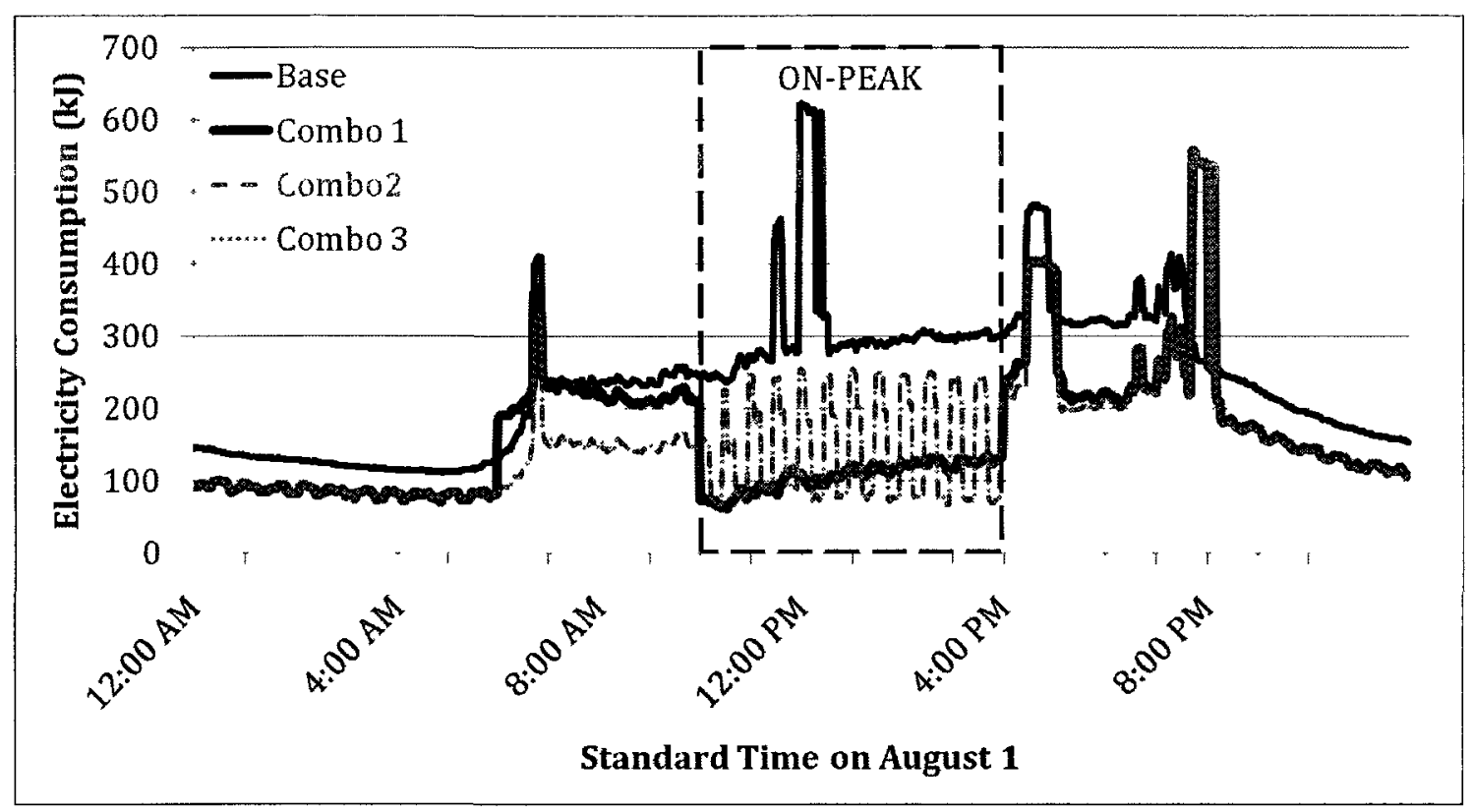

Figure 8.4: Electricity consumption on August 1 for Combinations 1, 2 and, 3 compared to the base

\section{Incoming solar radiation}

The first set of combinations actuate the external blinds to a closed position when the indoor temperature rises above $23^{\circ} \mathrm{C}$. On hot days, the zone temperature is often above $23^{\circ} \mathrm{C}$ resulting in extended periods of time with closed blinds. Closed blinds reduces natural light in the zone which may cause occupants to use electrical lighting instead, reducing the benefits these combinations. Over the household cooling season, combo 1 has closed blinds for $41 \%$ of the time, combo 2 has closed blinds for $60 \%$ of the time and combo 3 has closed blinds for $93 \%$ of the time. Combo 2 utilizes open windows to ventilate the zone with outdoor air, while combo 3 does not. The difference in the amount of time the blinds were closed with these two variants demonstrates the value of utilizing cooler outdoor air temperatures.

\section{Adverse effect on winter heating}

The venetian blinds in combos 1,2 and 3 do not actuate during the winter season, but the external placement of the blinds reduces the amount of heat transfer to the zone from the blinds in the winter months. Combos 4,5 and 6 maintained the 
internal venetian blinds in the open slat position, and incorporated external shading with window awnings, roof overhangs and a line of trees to reduce solar gains, which increase natural gas consumption in the winter time.

\subsection{Closing Remarks}

Combinations of variants can effectively mitigate large amounts of on-peak electricity consumption in the summer. Modifying occupant behaviour to shift the use of large appliances off-peak is essential. Reducing space cooling is more effective with HVAC settings than shading techniques. Overall, combined variants can reduce the on-peak electricity consumption by 50\%. Temporally redistributing the electricity demands away from the on-peak period was done such that the appliances were placed at staggered hours mid-peak and off-peak. This ensures that the entire household peak was evenly redistributed, and not shifted which would not alleviate the problems associated with residential electricity consumption. Chapter 9 uses combo 1 , which has the lowest on-peak demand, in conjunction with local generation and storage to achieve a $\mathrm{ZPH}$. 


\section{Chapter 9}

\section{Local Generation and Storage Using a Photovoltaic and/or Battery System to Achieve a Zero-Peak Electricity Demand}

Combination models significantly reduce on-peak electricity consumption, but the household demand cannot reach zero as there are still appliances that draw electricity over the whole day. Achieving a $\mathrm{ZPH}$ is only possible with the use of local energy generation to meet the remaining on-peak demands. This local generation can be combined with an energy storage system to compensate for days when the energy generated is not enough to meet the household demand. Energy generation to meet the reduced on-peak demand of a combination model is done using a PV system, with the potential for energy storage using a battery.

This chapter presents the results of sizing both a PV system, and a combination PV and battery system, to meet the on-peak demands from combo 1, as it had the lowest on-peak electricity consumption. Sizing of the PV system is initially done to attempt to meet all of the on-peak demands without any battery storage. A PV and battery system are then sized to collectively meet the on-peak electricity demand. Finally, sizing of a PV and battery system is done to meet the demand on the 10 hottest days in the summer. All of the systems are sized to meet the on-peak demands over either the household summer season (May 15 to September 30) or the provincial summer season (May 1 to October 31). This sizing requirement means that the systems will be oversized for some days. If the PV system cannot meet the house demands at a given time, electricity is imported from the grid. If the PV system is generating more than the house demand at a given time, the leftover electricity is stored in the battery if one is being used, following which any excess is exported to 
the grid.

\subsection{Photovoltaic and Battery System Specifica- tions}

The choice of PV panel is based on the work of Rowlands, et. al. [58], that used a SUNTECH STP200-18/Ub-1 $200 \mathrm{~W}$ solar panel in an Ontario climate. Implementing this PV system incorporates an inverter efficiency factor to account for losses from converting the direct-current output from the PV system to alternating-current electricity power used in the house. A $94.3 \%$ inverter efficiency is used, based on the size of typical PV systems and averaged real inverter efficiencies [59].

Simulations of thirteen azimuths ( $15^{\circ}$ increments from east to west) and ten tilt angles (increments from horizontal to vertical) were previously completed by Kemery, 2011 [59], using the Suntech panel in a Toronto, 2006 climate. These data are used to determine a concise range of azimuths and tilt angles for the PV system to match the on-peak electricity demand of combo 1. The results from Kemery, 2011 [59] show that the PV production is most beneficial to the electricity demands of combo 1 with either a due-south or south $15^{\circ}$ west azimuth, and a tilt angle of $30^{\circ}$ relative to the horizontal. The due-south azimuth has slightly higher power production, and is used for the PV simulations.

The battery storage system is assumed to have a $90 \%$ round-trip efficiency, the amount of electricity available out of the battery from the amount stored. This value is based on typical efficiency values of both lead-acid and lithium-ion batteries, which are both considered conventional storage batteries [60]. The flowchart in Figure 9.1 demonstrates the storage process of the battery system.

\subsection{Utilizing On-Peak PV Production to Meet On- Peak Household Demand}

Using only local generation determines if the on-peak electricity demands can be met solely with PV. A $50 \mathrm{~m}^{2}, 6.8 \mathrm{~kW}$ system, facing due-south, meets $97.1 \%$ of the onpeak household electricity demands during the provincial summer season. Considering 


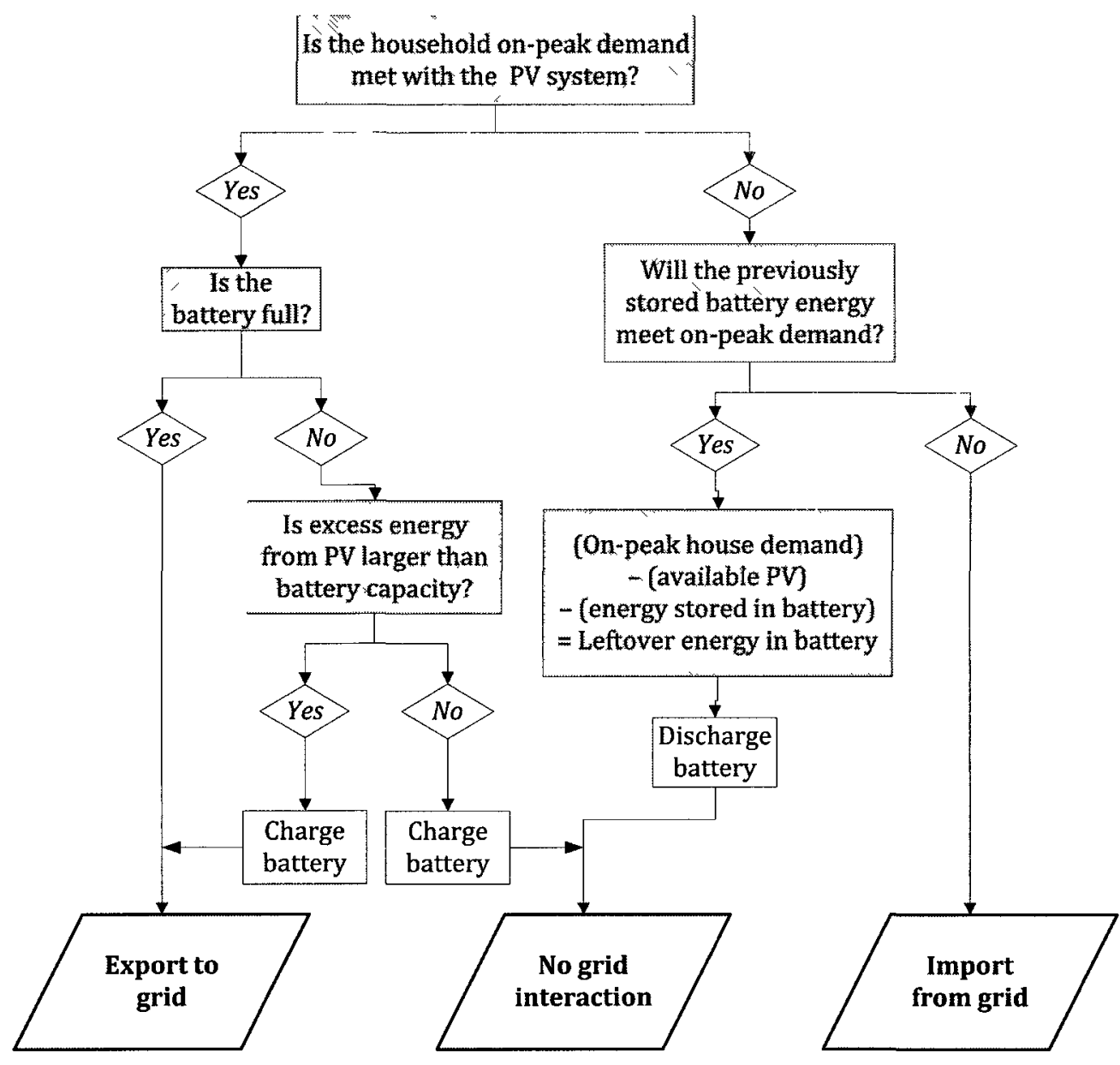

Figure 9.1: Battery storage process

the household summer season, the $50 \mathrm{~m}^{2}$ system would meet $98.8 \%$ of the on-peak household electricity demand. The size of PV system is set to an arbitrary maximum of $50 \mathrm{~m}^{2}$, a very large system for a house. Reducing the size of the PV to a 25 $\mathrm{m}^{2}, 3.4 \mathrm{~kW}$ system, the on-peak electricity demands during the provincial summer season are met $87.3 \%$ of the time. With a $25 \mathrm{~m}^{2}$ system, the on-peak electricity demands are met $90.0 \%$ of the time during the household summer season. With a $10 \mathrm{~m}^{2}, 1.4 \mathrm{~kW}$ system, the electricity produced from the PV system can only meet the household electricity demands $49.9 \%$ of the time during the provincial summer season, and $51.3 \%$ of the time during the household summer season. 


\subsection{Combining PV Production with Battery Stor- age to Meet On-Peak Household Demand}

Making use of locally generated power and energy storage to meet on-peak demands makes use of power generated outside of the on-peak hours, and can make up for reduced power generation on cloudy days. Sizing of the combined PV and battery system is done in three parts.

1. A battery is sized to the day of largest electricity demand from the house, which occurs on August 1 with an electricity demand of $61 \mathrm{kWh}$, to determine the smallest PV system required to meet all on-peak electricity demands.

2. A $50 \mathrm{~m}^{2}, 6.8 \mathrm{~kW} \mathrm{PV}$ system is used to determine the smallest battery system required to meet all on-peak electricity demands.

3. Both the battery and PV system are simultaneously sized to determine the smallest combined system to meet all on-peak electricity demands.

With a $61 \mathrm{kWh}$ battery system, a $19.1 \mathrm{~m}^{2}, 2.6 \mathrm{~kW}$ PV system meets all on-peak electricity demands from the house during the provincial summer season. During the household summer season, a $14.7 \mathrm{~m}^{2}, 2 \mathrm{~kW}$ PV system, with a $61 \mathrm{kWh}$ battery meets the on-peak electricity demands.

Using a $50 \mathrm{~m}^{2}, 6.8 \mathrm{~kW}$ PV system concurrently with an $6.5 \mathrm{kWh}$ battery system, all on-peak electricity demands during the provincial summer season are met. During the household summer season, $0.3 \mathrm{kWh}$ of battery storage is required with the $50 \mathrm{~m}^{2}$, $6.8 \mathrm{~kW}$ PV system to meet all on-peak electricity demands.

The sizing difference between the provincial and household summer periods is due to the decline in solar availability in October. PV production decreases, especially near the end of October, and larger system sizes are required to meet the on-peak electricity demands.

Focusing on the household cooling season, combining a $32.3 \mathrm{~m}^{2}, 4.4 \mathrm{~kW} \mathrm{PV}$ system with a $5 \mathrm{kWh}$ battery system would meet all the on-peak demands.

The house demand of combo 1 compared to the PV electricity production from a $32.3 \mathrm{~m}^{2}, 4.4 \mathrm{~kW}$ PV system on July 31 is shown in Figure 9.2. Enough electricity is produced using PV on-peak to meet the on-peak electricity demands, and use of the 


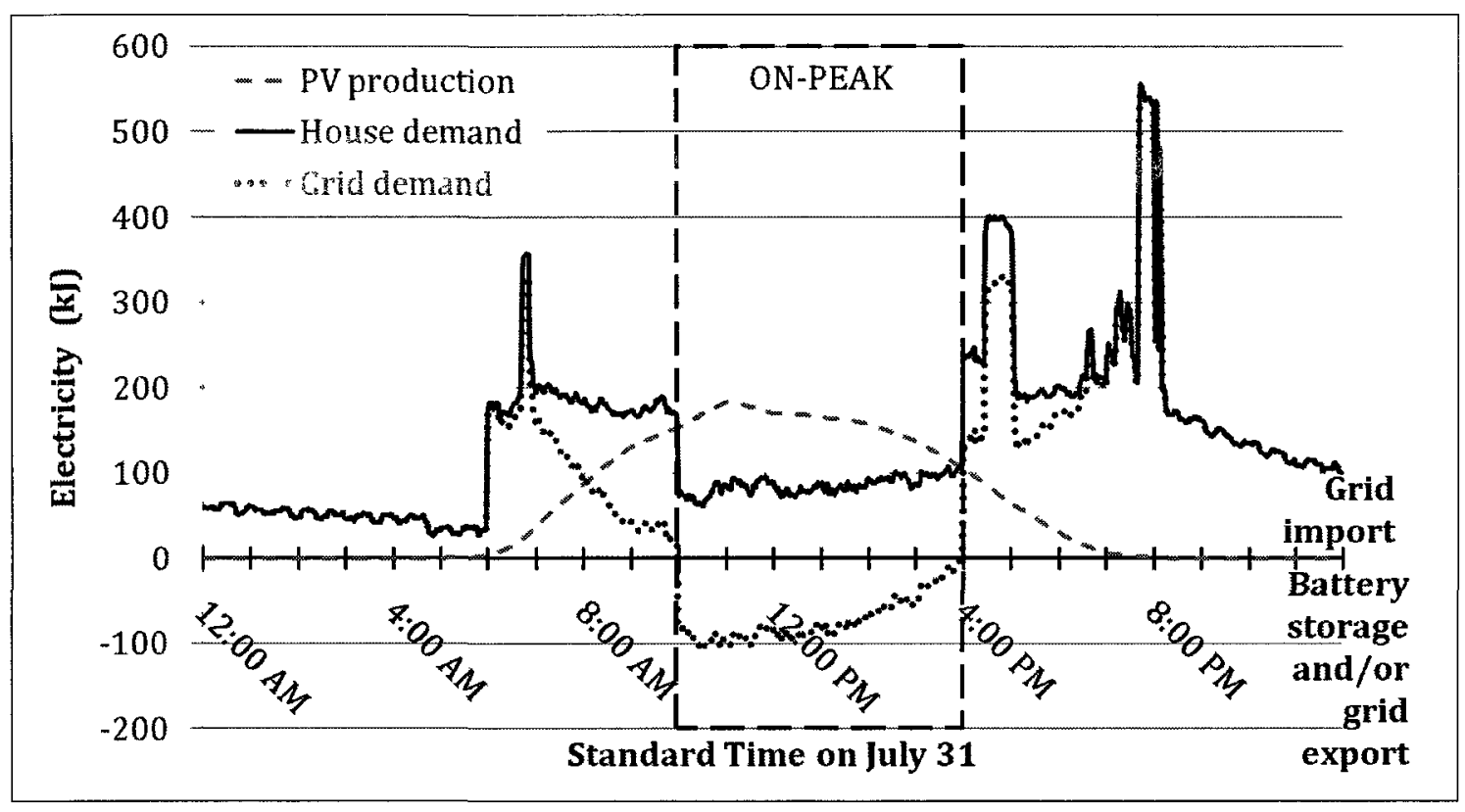

Figure 9.2: PV production and household electricity demand on July 31

stored energy is not needed. The battery is fully charged on this day as well, so the excess PV production is exported to the grid.

Sizing a PV and battery system solely to meet the demands of the 10 hottest summer days by using battery storage only for these hot days would require an 11.8 $\mathrm{m}^{2}, 1.6 \mathrm{~kW}$ PV system with a $3.8 \mathrm{kWh}$ battery system. Once again, this is sized to the requirements of combo 1, with PV panels facing due south at a $30^{\circ}$ tilt angle. If this size system is used for the whole summer, $55 \%$ of the days in the provincial summer season would achieve zero on-peak electricity demand. Over the household summer season, this system would result in $62 \%$ of the days reaching a zero on-peak electricity demand.

\subsection{Sizing Feasibility}

Due to the orientation of the house along a NE axis, it is difficult to fit south facing PV panels on the roof of the house. The south-east roof has a total area of $39.1 \mathrm{~m}^{2}$, while the south-west roof is slightly shaded by the bay window roof and has a smaller total area of $20.9 \mathrm{~m}^{2}$. It should be noted as well, that these roof areas are partially triangular and the available area for rectangular PV panels is lower. There is the 
potential to split the PV panels across both SE and SW faces where both sets are aligned facing due-south. In this case, shading must be considered. If the house were rotated to align along an east-west axis, a laiger roof area would be available for PV panels but a realigned house would have different simulation results.

\subsection{Closing Remarks}

Use of local generation with PV panels combined with battery storage, can reduce the on-peak electricity consumption in the house to zero. PV panels alone cannot meet all on-peak electricity demand, even when using a large $50.0 \mathrm{~m}^{2}, 6.8 \mathrm{~kW}$ system. A $4.4 \mathrm{~kW}$ PV system with a $5 \mathrm{kWh}$ battery meets all on-peak electricity demands between May 15 and September 30.

The sizing in this chapter is an estimate of the local generation and battery storage needs, but was done using an energy balance to sum the total PV generation available compared to the total on-peak household electricity demand. This means that on an hourly basis, some household demands may not be met while other hours have a excess of PV production. The battery is then used to store and provide energy when the PV supply and household demands are mismatched.

Excess energy is exported back to the grid when there is excess PV production and the battery is fully charged. The Ontario Power Authority's feed-in-tariff program that pays 7.5 times the on-peak electricity price per $\mathrm{kWh}$ for electricity exported back to the grid with rooftop PV panels. Electricity from ground-mounted PV panels receive 6 times the on-peak electricity price per $\mathrm{kWh} \mathrm{[16].} \mathrm{This} \mathrm{program} \mathrm{is} \mathrm{incentive}$ for occupants to incorporate PV systems into their houses, but can reduce incentive towards a $\mathrm{ZPH}$, as there is no monetary rebate for battery use. 


\section{Chapter 10}

\section{Conclusions and Recommendations}

The residential sector has a large impact on electricity demands in a Southern Ontario climate. Mitigating these residential demands during the summer on-peak hours, when the grid is experiencing large province-wide demand, reduces GHG emissions and grid strain. This research focused on reducing electricity consumption in a single family detached house, as this house type accounts for the majority of the residential stock in Canada.

\subsection{Conclusions of the Work Completed}

The research objectives were to determine a combination of design, technology and behavioural solutions, with local generation and storage, to achieve a single family house with no electricity demand during the summer on-peak period. A house meeting these conditions is called a zero-peak house. The objectives have been met using building performance simulation to simulate variations of a conventional house design base case with the potential to reduce on-peak electricity, and combining the most effective variants with local energy generation using PV and battery storage.

\section{Base case design and choice of variants}

Initially, a base case single family house was modelled in the software program ESP-r using specifications from a local building company [36],[37]. This base case comprised a conditioned main zone representing a first and second floor, as well as an unconditioned attic space and basement. Occupancy in the house was modelled using a single day profile and repeated each day of the simulation. The repeating nature of this profile was a worst-case representation of appliance use, specifically the clothes washing 
machine and dryer, which are not typically used daily. This representative profile was created using real occupancy data from houses in Ottawa, Ontario [51],[52], and was an aggregation of specific house appliances such as the clothes dryer and stove. Having an aggregate profile allows for variants that shift the time-of-use of appliances with large electricity demand outside of on-peak hours.

Chosen variants focused on modifications with potential to reduce the magnitude or reshape the temporal distribution of electrical loads. The variants were grouped into three categories: architecture, technology and behavioural solutions. A total of thirty eight variations of the base case were chosen.

\section{Simulation metrics}

The results analysis was based on a set of metrics to compare each variant's potential towards achieving a ZPH relative to the base case. The chosen metrics were to examine annual electricity consumption, $E_{\text {annual }}$; summer weekday on-peak electricity consumption, $E_{\text {on peak }}$; the correlation between the household electricity consumption and the provincial grid demand on an annual basis , Corr ${ }_{\text {annual }}$, and over all summer weekdays, Corr summ weekday; and annual natural gas consumption, $N G_{\text {annual }}$. The natural gas metric is secondary to on-peak electricity reduction, but examines adverse effects variants have on winter heating demand. Detailed analysis of results was achieved by examining the one day household performance on days with different weather conditions.

It was found that the most beneficial metric in determining the potential of a variant towards the goal of this work was $E_{\text {on peak }}$, as it gave an immediate impression of the variant's on-peak effect. The correlation metrics were the least beneficial, as they did not provide any indication of effective variants that solely reduced the magnitude of the electrical loads. The correlation metrics were somewhat effective in examining the metrics that reshape the electrical load profile, but were still not a clear indication of the on-peak consumption.

\section{Effective variants}

Effective architectural variants shaded the opaque and transparent surfaces from solar radiation. Architectural components for shading reduced $E_{\text {on peak }}$ by up to $5.7 \%$ with $1 \mathrm{~m}$ roof overhangs, but adversely affected the $N G_{\text {annual }}$ by up to $6.7 \%$. Reflective windows mitigated $E_{\text {on peak }}$ by $11 \%$, but increased $N G_{\text {annual }}$ of $14 \%$. 
All technology variants were effective in reducing $E_{\text {on peak }}$. A four hour pre-cooling period in conjunction with an on-peak setpoint of $27^{\circ} \mathrm{C}$, decreased $E_{\text {on peak }}$ by $26.9 \%$ relative to the base case. The variant actuating external blinds when the zone temperature rose above $23^{\circ} \mathrm{C}$ reduced $E_{\text {on peak }}$ by $15.3 \%$. Reducing available space-cooling by cycling (turning off) the air-conditioner in 15 minute intervals when the outdoor temperature rose above $27^{\circ} \mathrm{C}$, or the sensed temperature with humidity (humidex) rose above $30^{\circ} \mathrm{C}$, reduced $E_{\text {on peak }}$ by $5.6 \%$.

Of all the occupant behaviour variants, shifting the time-of-use of the dryer reduced $E_{\text {on peak }}$ the most by $15.0 \%$. This is due to the large electricity demand of the dryer when in use $(5.5 \mathrm{~kW})$. Increasing the COP of the air-conditioner was also an effective variant, reducing $E_{\text {on peak }}$ by $10.8 \%$. Opening the windows to $10 \%$ of their area when the zone temperature rose above $23^{\circ} \mathrm{C}$, and the outdoor air temperature was below the zone temperature reduced $E_{\text {on peak }}$ by $7.0 \%$.

\section{Ineffective variants}

The variants which redistributed half of the fenestration from the south-west face evenly among other faces had an adverse effect on $E_{\text {on peak }}$, causing an increase of up to $4 \%$. A larger $E_{\text {on peak }}$ value was due in part to the increase in glazing on the south-east face, which receives more sun in the early on-peak period with an easterly rising sun, as well as increased glazing on the north-west face, which receives more evening sun. These fenestration shifting variants were modelled because they shifted fenestration away from the heavily glazed south-west face, which accounts for the majority of on-peak solar gains.

Reflective shingles reduced $E_{\text {on peak }}$ by $0.9 \%$, and had a minimal effect on remaining metrics. The reflective shingles reduce the heat transfer into the attic space, but heavy insulation (RSI $9.0 \mathrm{~m}^{2} \mathrm{~K} / \mathrm{W}$ ) between the main zone and the attic prevents any significant effect on the main zone temperature.

The use of concrete as thermal mass for a main floor construction had little additional benefit with pre-cooling strategies compared to the base case main floor construction. Upon inspection, the thermal mass potential of both constructions were very similar. 


\section{Validating the representative profile}

To validate the use of the representative profile, annual real non-HVAC profiles from the Ottawa based study by Saldanha [51] were simulated with the base case. This is the same study that was used in part to create the representative profile. Simulating real occupancy allowed a comparison of real occupancy behaviour to the base case with the representative profile. Three non-HVAC electricity profiles were used with different levels of electricity consumption. $E_{\text {on peak }}$ of the base case was at least $18 \%$ higher than the real houses' on-peak electricity demands. This results stems from the daily use of the dryer. The remaining metrics placed the results of the representative profile amid those of the real houses. These results proved that even though the onpeak consumption of a daily repeating profile is above the typical range, annually the profile demonstrated similar results to real houses and is representative of a medium to high energy consumption house.

\section{Effective variant combinations}

Effective variants were modelled in six different combinations. These combinations used external fixed shading or actuating external venetian blinds to reduce solar gains, modified the HVAC settings with either a pre-cooling strategy or cycling the air-conditioner, and modified occupant behaviour with appliance shifting, increased appliance efficiency and opened windows. The combinations reduced the $E_{\text {on peak }}$ between $40.5 \%$ and $51.2 \%$. Combinations that used different methods to reduce solar gains but the same HVAC control had similar results. This demonstrated that direct control of space cooling and thermal setpoints have a larger effect on the on-peak electricity consumption than reducing solar gains. Combo 1 was the most beneficial combination, and included actuating external blinds based on a zone temperature above $23^{\circ} \mathrm{C}$ combined with a four hour pre-cooling strategy at $21^{\circ} \mathrm{C}$ with an on-peak setpoint temperature of $27^{\circ} \mathrm{C}$. This effective combination also shifted the time-of-use of the stove and clothes dryer, used an energy efficient refrigerator and freezer, and received space cooling from a high COP air conditioner.

\section{Incorporating a PV and battery system}

Sizing of the PV and battery were done to meet the loads of combo 1, the most effective combination in reducing on-peak electricity consumption. The PV panels 
were placed at a constant azimuth facing due-south and tilt angle of $30^{\circ}$ relative to the horizontal, based on the location and climate in Toronto, 2006. Initially, PV panels were simulated alone to meet on-peak demands. PV sizing was increased up to a maximum of $50 \mathrm{~m}^{2}, 6.8 \mathrm{~kW}$. The electricity produced on-peak from PV panels alone, with the maximum size system, reduced the on-peak electricity grid demands in the house by $97.1 \%$ during the summer season defined by the provincial electricity distributer as May 1 to October 31. During the household cooling season, between May 15 and September 30, on-peak PV production met $98.8 \%$ of the household onpeak electricity demands.

A PV and battery system were combined in three configurations aimed to achieve either the smallest PV system, the smallest battery system or the smallest combination system to meet all of the household on-peak electricity demands during both the provincial and household cooling seasons. The household cooling season required smaller PV and battery sizes than the provincial cooling season. The longer provincial cooling season extends into October, which receives less solar radiation producing less PV power to meet household demands. The following results for PV and battery sizes met household cooling season demands. A $61 \mathrm{kWh}$ battery, sized to meet the largest one day demand of the house, met all on-peak electricity demands with the smallest PV system sized at $14.7 \mathrm{~m}^{2}$ or $2 \mathrm{~kW}$. To achieve the smallest battery size, a $50 \mathrm{~m}^{2}, 6.8 \mathrm{~kW}$ system was used and required a $0.3 \mathrm{kWh}$ battery. The smallest combined PV and battery system required a $32.3 \mathrm{~m}^{2}, 4.4 \mathrm{~kW}$ PV system with a 5 $\mathrm{kWh}$ battery system to achieve a ZPH.

A PV and battery system were also sized to meet electricity demand on the 10 hottest days of the summer only, allowing the PV panels to fully charge the battery leading up the high demand days. To meet the 10 days of demand completely, an $11.8 \mathrm{~m}^{2}, 1.6 \mathrm{~kW}$ PV system was combined with a $3.8 \mathrm{kWh}$ battery system.

\subsection{Recommendations for Future Work}

The objectives of this work were met in the design of an zero on-peak electricity consumption house, but the feasibility of the design was not fully tested. The option of air-conditioning cycling is currently available in Toronto, Ontario, and widespread adoption of this type of program would reduce the on-peak consumption on a residential level. External shading techniques are also a feasible addition to most houses. 
Experimental testing of the combination results would help validate the conclusions of this work, as well as further testing occupant comfort levels such as the humidity in the zone (not considered in this work).

The biggest issue with the research of a low or zero peak electricity house stems from the assumptions made on occupancy. Generalizing the behaviour of occupants does not accurately represent all houses, and as such, the results of this work would not have the same effect in some houses. The simulated occupancy patterns in this project were based on a study completed in Ottawa, Ontario on 12 houses [35]. This detailed information was extremely useful, and larger scale projects of this type would allow for more accurate predictions of residential energy consumption.

The results of this work are based on building performance simulation. Experimentally testing specific effective variants, and the low-energy combinations to validate their effectiveness would be a beneficial addition to this work. 


\section{References}

[1] "Hourly Generator Output for August 1, 2006," tech. rep., Independent Electricity System Operator, 2006.

[2] G. R. Newsham, "Average Hourly Electricity Use from a Sample of up to 1300 Houses in Southern Ontario." Personal communication, National Research Council, 2011.

[3] "Electricity Demand in Ontario - Submitted to the Ontario Energy Board regarding RP-2003-0144," tech. rep., Hydro One, 2002.

[4] "Survey of Household Energy Use, Summary Report," tech. rep., Natural Resources Canada, 2007. Available online http://oee.nrcan.gc.ca/publications/statistics/sheu-summary07/.

[5] "Ontario Demand and Market Prices," tech. rep., Independent Electricity System Operator, 2011. Accessible online at http://www.ieso.ca/imoweb/siteShared/demand\%5Fprice.asp.

[6] Canadian Broadcasting Corporation, "Ontario Hits Record High for Power Use," CBC News, 2006.

[7] G. R. Newsham, "Zero-Peak Demand Housing, The 'Power Nap' project," 2009. Personal communication.

[8] C. Buntine, "Zero peak homes: Designing for zero electric peak demand in new single family residential buildings sited in California climate zone 10," Master's thesis, University of Southern California, December 2007.

[9] "Energy Efficiency Trends in Canada, 1990 to 2005," tech. rep., Natural Resources Canada, 2009. Accessible online at http://oee.nrcan.gc.ca/publications/statistics/trends07/. 
[10] Statistics Canada, "Electric Power Generation,Transmission and Distribution," tech. rep., 2007. Accessible online at http://www.statcan.gc.ca/pub/57-202x/57-202-x:2007000-eng.pdf.

[11] "Smart Meters and Time of Use Rates," tech. rep., Independent Electricity Systems Operator, 2010. Accessible online at http://www.ieso.ca/imoweb/siteShared/smart\%5Fmeters.asp.

[12] Toronto Hydro Electric System, "peaksaver," 2010. Accessible online at http://www.torontohydro.com/peaksaver.

[13] G. R. Newsham and B. G. Bowker, "The effect of utility time-varying pricing and load control strategies on residential summer peak electricity use: A review," Energy Policy, vol. 38, no. 7, pp. 3289 - 3296, 2010.

[14] Canada Green Building Council, "LEED Canada for Homes," 2011. Accessible online at http://www.cagbc.org/homes.

[15] Natural Resources Canada, "ENERGY STAR, EnerGuide and R-2000," 2011. Accessible online at http://oee.nrcan.gc.ca/residential/energystar-energuider2000.cfm.

[16] Ontario Power Authority, "MicroFIT," 2011. Accessible online at http://microfit.powerauthority.on.ca/.

[17] A. Marszal, P. Heiselberg, J. Bourrelle, E. Musall, K. Voss, I. Sartori, and A. Napolitano, "Zero energy building - a review of definitions and calculation methodologies," Energy and Buildings, vol. 43, no. 4, pp. 971 - 979, 2011.

[18] Canadian Mortgage and Housing Corporation, "The EQuilibrium Sustainable Housing Demonstration Initiative," 2010. Accessible online at http://www.cmhc.ca/en/inpr/su/eqho/.

[19] J. Christian, L. Pratsch, and T. Blasing, "Zero Peak Communities Electric Utility Benefits," in Proceedings of the 2010 Building XI Conference, 2010. Accessible online at http://www.ornl.gov/sci/buildings/2010/Session

[20] Florida Solar Energy Center, "ZEH: Lakeland, Florida," 2007. Accessible online at http://www.fsec.ucf.edu/en/research/buildings/zero\%5Fenergy/lakeland/. 
[21] Building and Construction Authority, Singapore, "Singapores First Zero Energy Building Launched at the Inaugural Singapore Green Building Week," tech. rep, 2009 Accessible online at http://www.bca.gov.sg/Newsroom/others/SGBWb\%5FZEB\%5FMedia\%5Frelease\%5Fnon.

[22] Building Research Establishment, "Passivhaus," 2011. Accessible online at http://www.passivhaus.org.uk/.

[23] BioRegional, "BedZED," 2011. Accessible online at http://www.bioregional.com/what-we-do/our-work/bedzed/.

[24] "Inspiration - The Minto Ecohome," 2010. Accessible online at http://www.minto.com/.

[25] "CWEEDS files and CWEC files updated user's manual," tech. rep., Environment Canada - Atmospheric Environment Service, 2008.

[26] "Ontario Energy Board Smart Price Pilot Final Report," tech. rep., Ontario Energy Board, 2007. Accessible online at http://www.oeb.gov.on.ca/documents/cases/EB-20040205/smartpricepilot/OSPP\%20Final\%20Report\%20-\%20Final070726.pdf.

[27] G. Palomino, J. Wiles, J. Stevens, and F. Goodman, "Performance of Grid Connected Residential Photovoltaic System with Energy Storage," in Proceedings of the 26th IEEE Photovoltanc Specialzsts Conference, Sandia National Laboratories, 1997.

[28] United Stated Department of Energy, "Building Energy Software tools directory," 2011. Accessible online at http://apps1.eere.energy.gov/buildings/tools\%5Fdirectory/.

[29] P. Strachan, "ESP-r: Summary of validation studies," tech. rep., Energy Simulation Research Unit - University of Strathclyde, Glasgow, 2000. Accessible online at http://www.esru.strath.ac.uk/Documents/validation.pdf.

[30] J. A. Clarke, Energy Simulatıon in Buıldıng Desıgn. Butterworth-Heinemann, 2nd ed., 2001. 
[31] M. Evans and N. Kelly, "Modelling Active Building Elements with Special Materials," tech. rep., Energy Simulation Research Unit - University of Strathclyde, Glasgow, 1996.

[32] Lawrence Berkeley National Laboratory, "WINDOW5 Software," 2011. Accessible online at http://windows.lbl.gov/software/window/window.html.

[33] B. Lomanowski, "Implementation of Window Shading Models into Dynamic Whole-Building Simulation," Master's thesis, University of Waterloo, Waterloo, Ontario, 2008.

[34] J. G. Purdy and I. Beausoleil-Morrison, "The Significant Factors in Modelling Residential Buildings: Part 2," in Proceedings of the 2001 eSIM Conference, (Ottawa, Ontario), 2001. CANMET Energy Technology Centre, Natural Resources Canada.

[35] N. Saldanha, "Towards the Assessment of a Residential Electric Storage System: Analysis of Canadian Residential Electricity Use and the Development of a Lithium-Ion Battery Model," Master's thesis, Carleton University, Ottawa, Ontario, 2010.

[36] Urbandale Construction, "Single Family Home R-2000 Specifications," June 2009 .

[37] Urbandale Construction, "Palermo Details," June 2007.

[38] J. G. Purdy and I. Beausoleil-Morrison, "The Significant Factors in Modelling Residential Buildings," in Proceedings of the 2001 International IBPSA Conference, 2001. CANMET Energy Technology Centre, Natural Resources Canada, Ottawa, Canada.

[39] National Research Council, "Model National Energy Code of Canada for Housing," tech. rep., National Research Council of Canada, Ottawa, 1997.

[40] I. Beausoleil-Morrison, "BASESIMP Configurations," 1999. Natural Resources Canada.

[41] W. Bahnfleth and C. Pederson, "A Three-Dimensional Study of Slab-on-Grade Heat Transfer," ASHRAE Transactions, vol. 96, no. 2, pp. 61-72, 1990. 
[42] I. Beausoleil-Morrison, "Modelling Non-Rectangular Foundations and 'Attachments' in BASECALC and BASESIMP," 1998.

[43] K. Haddad, "Modeling HVAC Systems in HOT3000," tech. rep., Natural Resources Canada, Ottawa, Ontario, 2002. Edited by J. Purdy, 2003.

[44] J. G. Purdy and K. Haddad, "The Development and Validation of a Furnace Model for ESP-r/HOT3000," in Proceedıngs of the 2002 eSIM Conference, (Ottawa, Ontario), 2002. CANMET Energy Technology Centre, Natural Resources Canada.

[45] I. Beausoleil-Morrison, "On Predicting the Magnitude and Temporal Variation of Cooling Loads in Detached Residential Buildings," in Proceedings of the 2009 Eleventh IBPSA Conference, (Glasgow, Scotland), 2009.

[46] L. Swan, Residential Sector Energy and GHG Emıssions Model for the Assessment of New Technologies. PhD thesis, Dalhousie University, Halifax, Nova Scotia, 2010.

[47] "Hourly Demands for August 19th, 2009 in MW," tech. rep., Independent Electricity Service Operator, 2009. Accessible online at http://www.ieso.ca/imoweb/marketdata/marketData.asp.

[48] N. Isaacs, M. Camilleri, L. French, A. Pollard, K. Savill-Smith, R. Fraser, P. Rossouw, and J. Jowett, "Energy use in New Zealand households - HEEP year 10 report," tech. rep., BRANZ Group, New Zealand, 2006. Accessible online at http://www.branz.co.nz/.

[49] D. Parker, "Research highlights from a large scale residential monitoring study in a hot climate, FSEC-PF369-02," tech. rep., Florida Solar Energy Center, Cocoa, Florida, 2002. Accessible online at http://www.fsec.ucf.edu/en/publications/html/FSEC-PF-369-02/.

[50] I. Knight, N. Kreutzer, M. Manning, M. Swinton, and H. Ribberink, "European and Canadian non-HVAC electric and dhw load profiles for use in simulating the performance of residential cogeneration systems," tech. rep., Subtask A of FC+COGEN-SIM The Simulation of Building-Integrated Fuel Cell and Other Cogenearation Systems. Annex 42 of the International Energy Agency Energy Conservation in Buildings and Community Systems Programme, 2007. 
[51] N. Saldanha, "Electrical measurement project." email correspondance, Department of Mechanical and Aerospace Engineering, Carleton University, 2010.

[52] I. Beausoleil-Morrison, "Electrical measurement project." email correspondance, Department of Mechanical and Aerospace Engineering, Carleton University, 2010.

[53] Ministry of Natural Resources, "Ontario Tree Atlas," June 2011. Accessible online at http://www.mnr.gov.on.ca/en/Business/ClimateChange/2ColumnSubPage/267027.html.

[54] B. Lomanowski, "Complex Fenestration Constructions." email correspondance, Natural Resources Canada, 2011.

[55] Environment Canada, "Weatheroffice - Frequently Asked Qeustions, Humidex," June 2011. Accessible online at http://www.weatheroffice.gc.ca/mainmenu/faq\%5Fe.html.

[56] Natural Resources Canada, "Energy Efficiency Ratings," July 2010. Accessible online at http://oee.nrcan.gc.ca/residential/personal/new-coolingventilation.cfm.

[57] J. L. Devore, Probability and Statistıcs. Brooks/Cole, 6th ed., 2004.

[58] I. H. Rowlands, B. P. Kemery, and I. Beausoleil-Morrison, "Optimal Solar-PV Tilt Angle and Azimuth: An Ontario (Canada) Case-Study," Energy Policy, vol. 39, pp. 1397-1409, March 2011.

[59] B. Kemery, "Suntech PV Summary Data for Toronto 2006." email correspondance, Department of Mechanical and Aerospace Engineering, Carleton University, 2011.

[60] I. Hadjipaschalis, A. Poullikkas, and V. Efthimiou, "Overview of Current and Future Energy Storage Technologies for Electric Power Applications," Renewable Sustannable Energy Reviews, vol. 13, no. 6, pp. 1513-1522, 2009. 
Appendix A

Base Case Materials and Constructions 


\begin{tabular}{|l|l|l|}
\hline Material & $\begin{array}{l}\text { Thickness } \\
(\mathbf{m m})\end{array}$ & $\begin{array}{l}\text { RSI } \\
\left(\mathbf{m}^{2} \mathbf{K} / \mathbf{W}\right)\end{array}$ \\
\hline \multicolumn{2}{|c|}{ EXTERIOR } \\
\hline Brick & 102.5 & 0.11 \\
Air gap & 25.4 & 0.17 \\
Plywood & 11.1 & 0.07 \\
Fiberglass insulation & 139.4 & 3.24 \\
Gypsum board & 12.5 & 0.08 \\
\hline \multicolumn{2}{|c|}{ MAIN ZONE } \\
\hline
\end{tabular}

Table A.1: Exterior wall materials and constructions

\begin{tabular}{|l|l|l|}
\hline Material & $\begin{array}{l}\text { Thickness } \\
(\mathbf{m m})\end{array}$ & $\begin{array}{l}\text { RSI } \\
\left(\mathbf{m}^{2} \mathbf{K} / \mathbf{W}\right)\end{array}$ \\
\hline \multicolumn{3}{|c|}{ MAIN ZONE } \\
\hline Flooring & 38.1 & 0.27 \\
Chipboard & 15.9 & 0.11 \\
Air gap & 254 & 0.17 \\
Chipboard & 15.9 & 0.11 \\
\hline \multicolumn{3}{|c|}{ BASEMENT ZONE } \\
\hline
\end{tabular}

Table A.2: Main floor / basement ceiling materials and constructions

\begin{tabular}{|l|l|l|}
\hline Material & $\begin{array}{l}\text { Thickness } \\
(\mathbf{m m})\end{array}$ & $\begin{array}{l}\text { RSI } \\
\left(\mathbf{m}^{2} \mathbf{K} / \mathbf{W}\right)\end{array}$ \\
\hline \multicolumn{3}{|c|}{ ATTIC ZONE } \\
\hline $\begin{array}{l}\text { Fiberglass insulation } \\
\text { Gypsum board }\end{array}$ & 234 & 9.0 \\
\hline \multicolumn{3}{|c|}{ MAIN ZONE } \\
\hline
\end{tabular}

Table A.3: Main ceiling materials and constructions 


\begin{tabular}{|l|l|l|}
\hline Material & $\begin{array}{l}\text { Thickness } \\
\text { (nnm) }\end{array}$ & $\begin{array}{l}\text { RSI } \\
\left(\mathrm{m}^{2} \mathrm{~K} / \mathrm{W}\right)\end{array}$ \\
\hline \multicolumn{3}{|c|}{ BELOW GRADE } \\
\hline Concrete & 76.2 & 0.2 \\
\hline \multicolumn{3}{|c|}{ BASEMENT ZONE } \\
\hline
\end{tabular}

Table A.4: Basement floor materials and constructions

\begin{tabular}{|l|l|l|}
\hline Material & $\begin{array}{l}\text { Thickness } \\
(\mathbf{m m})\end{array}$ & $\begin{array}{l}\text { RSI } \\
\left(\mathbf{m}^{2} \mathbf{K} / \mathbf{W}\right)\end{array}$ \\
\hline \multicolumn{2}{|c|}{ BELOW GRADE } \\
\hline Insulated drainage board & 203.2 & 0.55 \\
Concrete & 3.52 \\
Fiberglass insulation (20 cm from floor) & \\
Note: thickness of insulation not required in BASESIMP input \\
\hline \multicolumn{2}{|c|}{ BASEMENT ZONE } \\
\hline
\end{tabular}

Table A.5: Basement wall materials and constructions

\begin{tabular}{|l|l|l|}
\hline Material & $\begin{array}{l}\text { Thickness } \\
(\mathbf{m m})\end{array}$ & $\begin{array}{l}\text { RSI } \\
\left(\mathbf{m}^{2} \mathbf{K} / \mathbf{W}\right)\end{array}$ \\
\hline \multicolumn{3}{|c|}{ EXTERIOR } \\
\hline Asphalt shingles & 6.0 & $4.7 \mathrm{E}-3$ \\
Felt sheathing & 11.1 & 0.06 \\
Particle board underlay & 12.7 & 0.12 \\
\hline \multicolumn{3}{|c|}{ ATTIC ZONE } \\
\hline
\end{tabular}

Table A.6: Roof materials and constructions 


\begin{tabular}{|l|l|l|}
\hline Material & $\begin{array}{l}\text { Thickness } \\
(\mathbf{m m})\end{array}$ & $\begin{array}{l}\text { RSI } \\
\left(\mathbf{m}^{2} \mathbf{K} / \mathbf{W}\right)\end{array}$ \\
\hline \multicolumn{3}{|c|}{ EXTERIOR } \\
\hline PVC framing & 290.9 & 0.36 \\
\hline \multicolumn{3}{|c|}{ MAIN ZONE } \\
\hline
\end{tabular}

Table A.7: Window frame materials and constructions 


\begin{tabular}{|l|l|l|l|l|}
\hline Material & $\begin{array}{l}\text { Thickness } \\
(\mathbf{m m})\end{array}$ & $\begin{array}{l}\text { Exterior facing } \\
\text { reflectivity }\end{array}$ & Transmissivity & $\begin{array}{l}\text { Exterior facing } \\
\text { emissivity }\end{array}$ \\
\hline \multicolumn{5}{|c|}{ EXTERIOR } \\
\hline Glass pane & 5.9 & 0.072 & 0.783 & 0.84 \\
Argon gas fill & 12.7 & & 0.662 & 0.157 \\
Low-e glass pane & 5.9 & 0.113 & 0.85 \\
Air gap & 12.7 & & & \\
Aluminum venetian blinds & 12.7 & MAIN ZONE \\
\hline \multicolumn{5}{|c|}{} \\
\hline
\end{tabular}

Table A.8: Window materials and constructions 


\section{Appendix B}

\section{Detailed Results}

\section{B.1 Shading Results Metrics Compared to the Base Case}

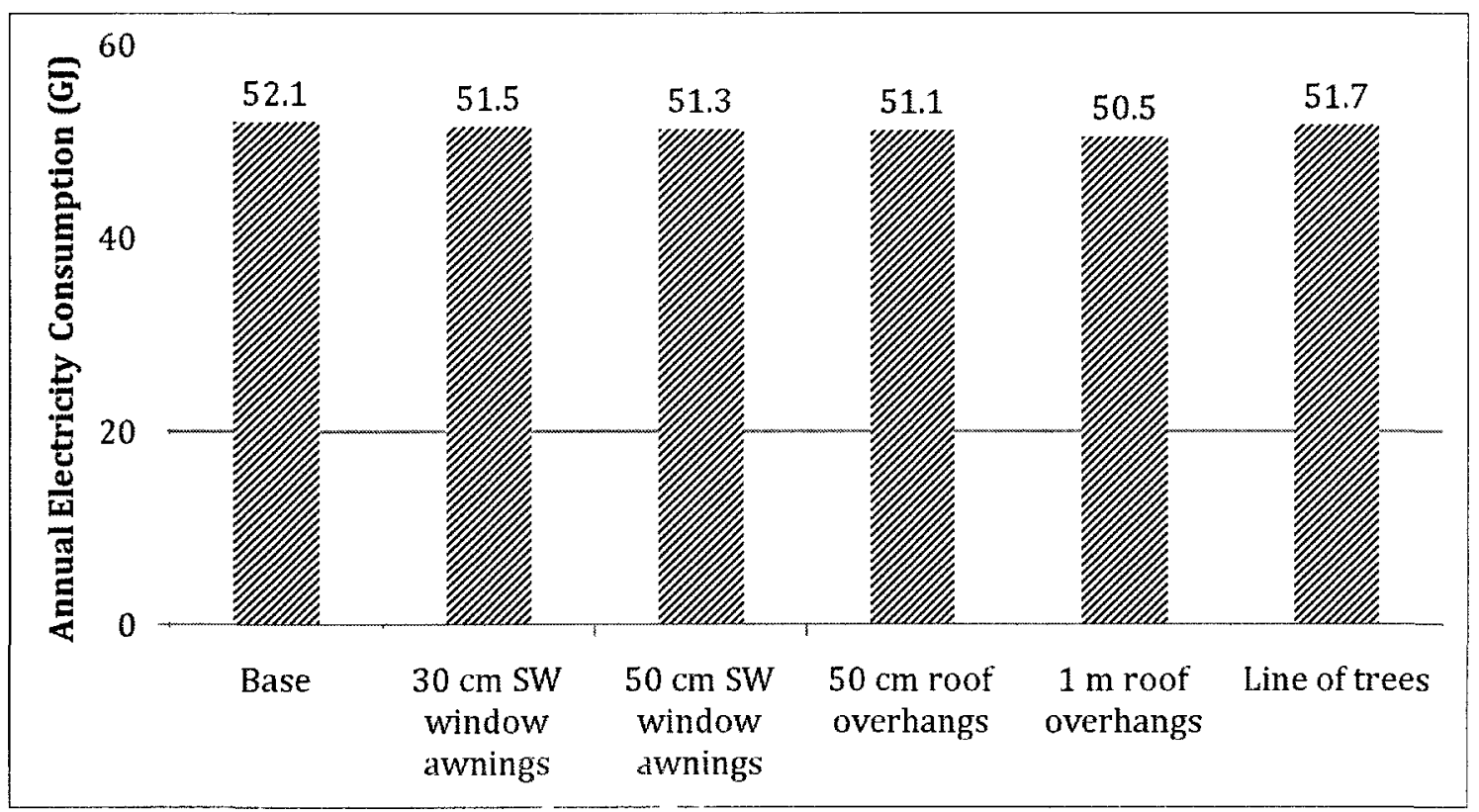

Figure B.1: Annual electricity consumption in GJ with various shading techniques 


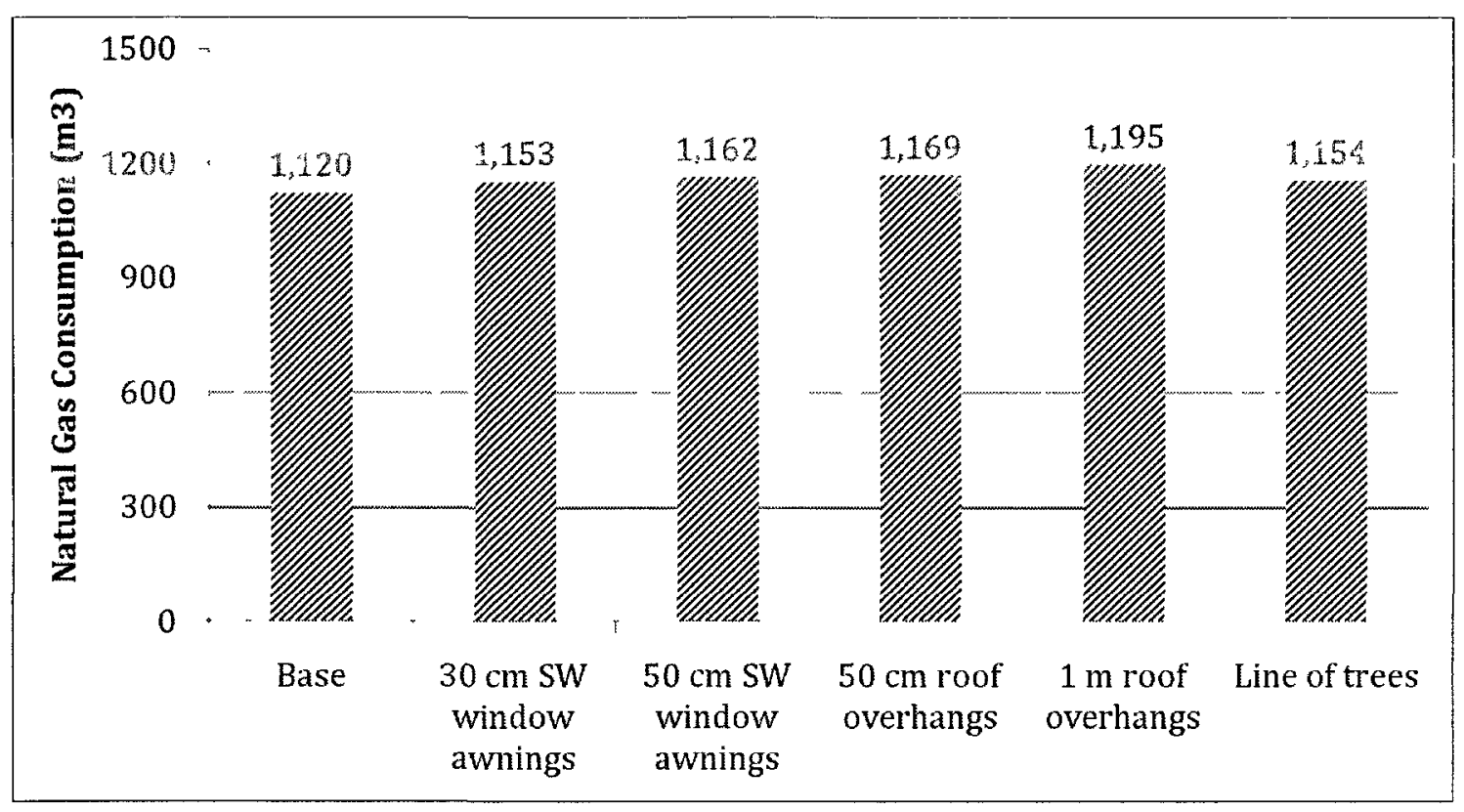

Figure B.2: Annual natural gas consumption with various shading techniques

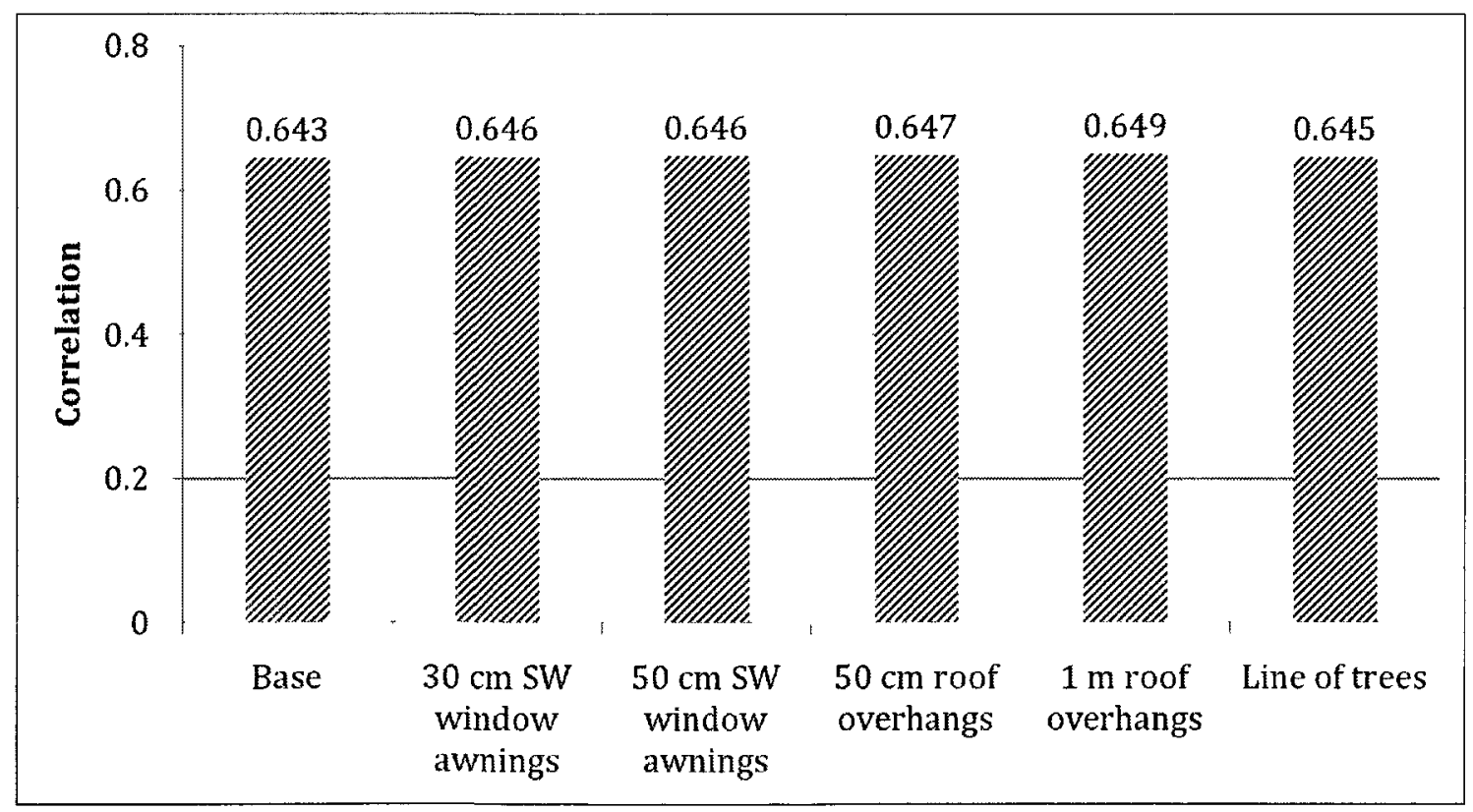

Figure B.3: Annual correlation between the residential consumption and provincial distribution 


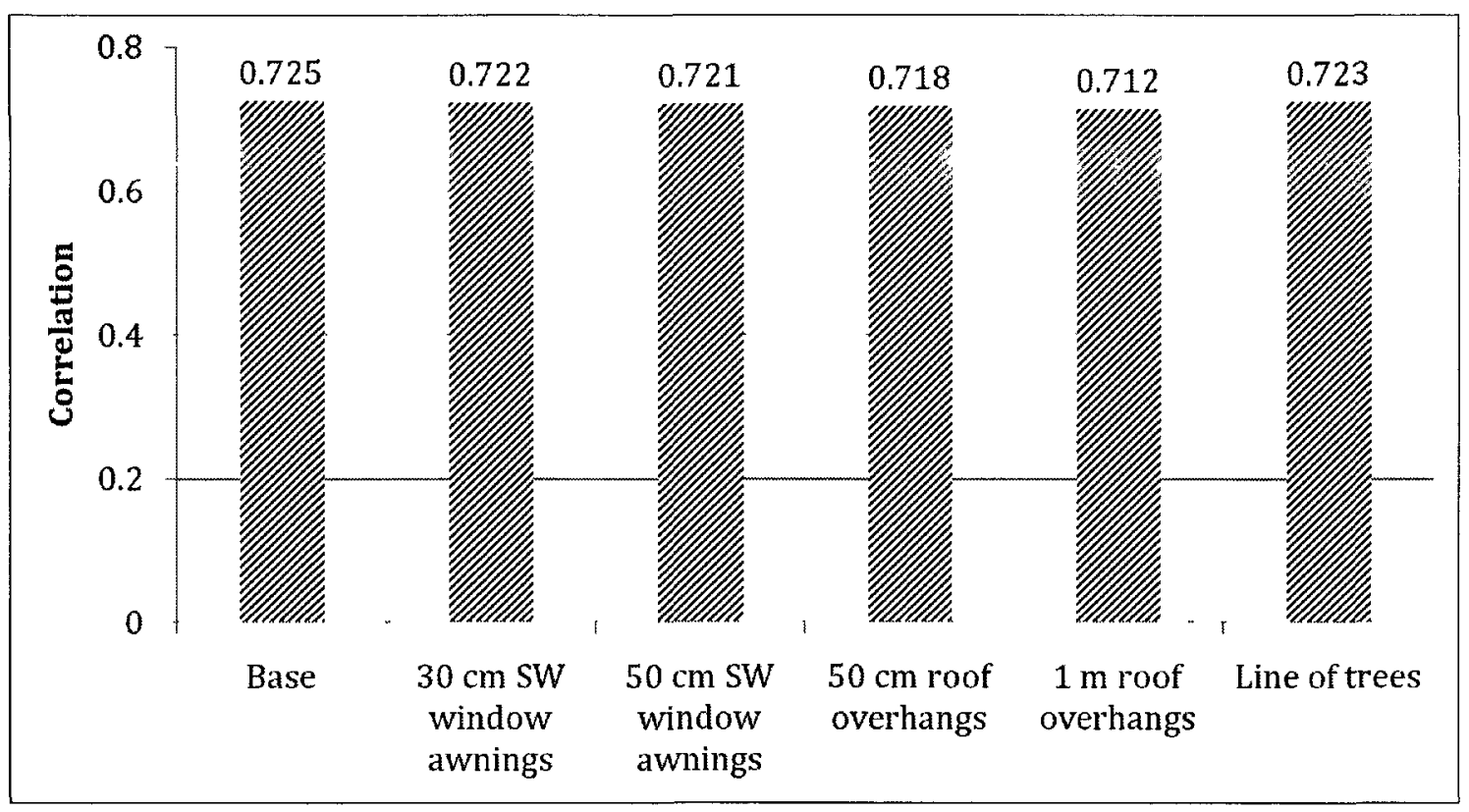

Figure B.4: Summer weekday correlation between the residential consumption and provincial distribution 


\section{B.2 Window Property Results Metrics Compared to the Base Case}

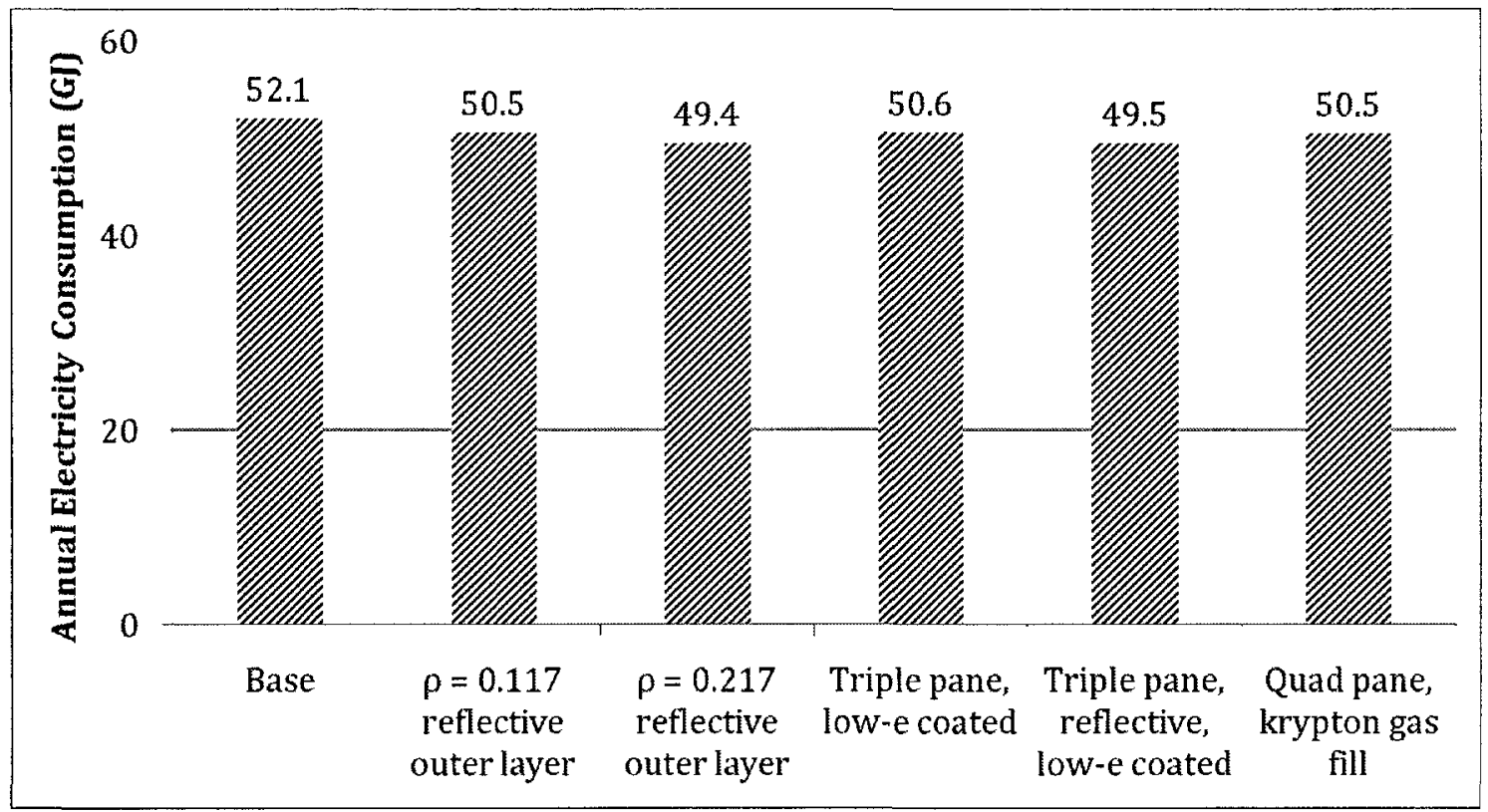

Figure B.5: Annual electricity consumption in GJ with modified window properties 


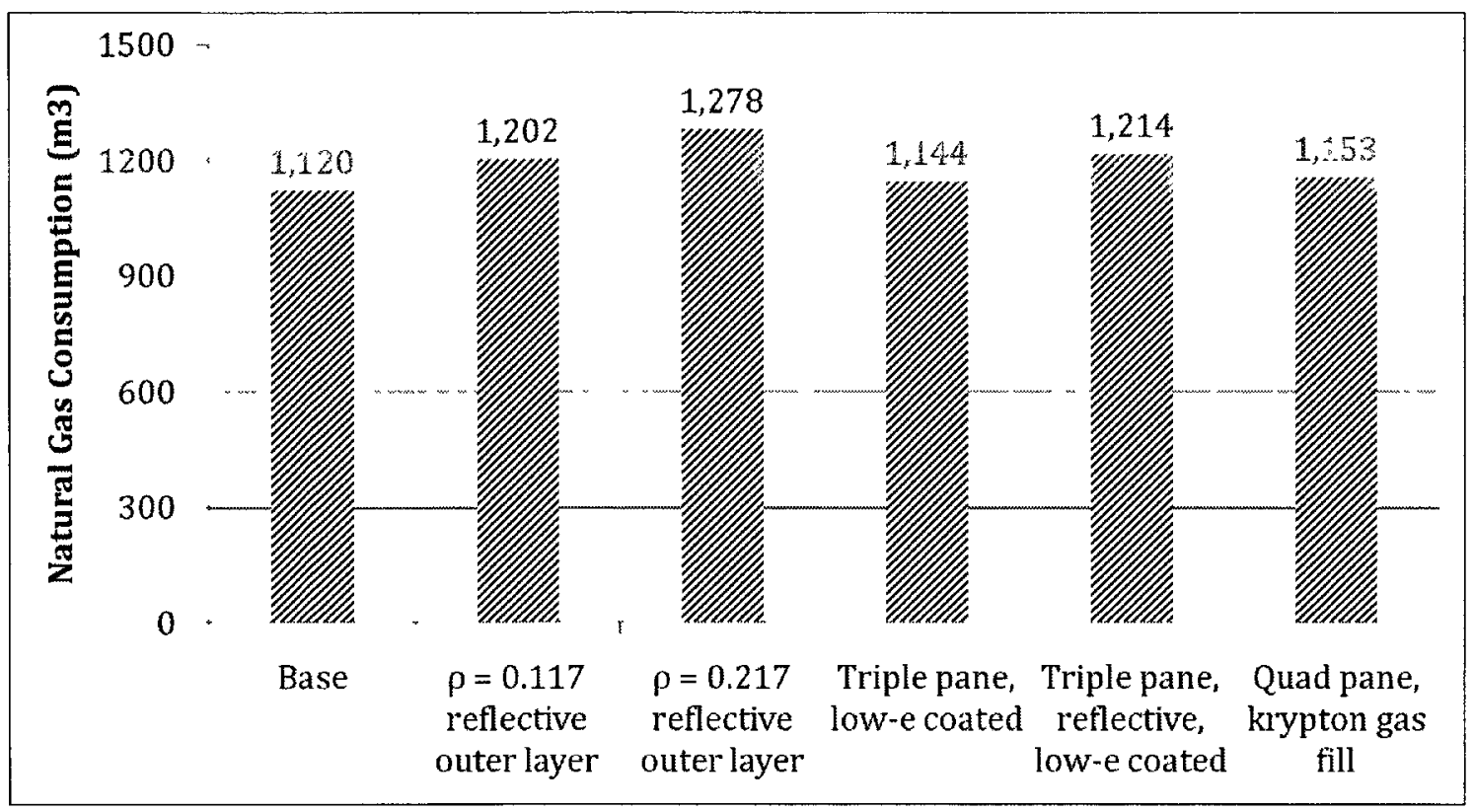

Figure B.6: Annual natural gas consumption with modified window properties

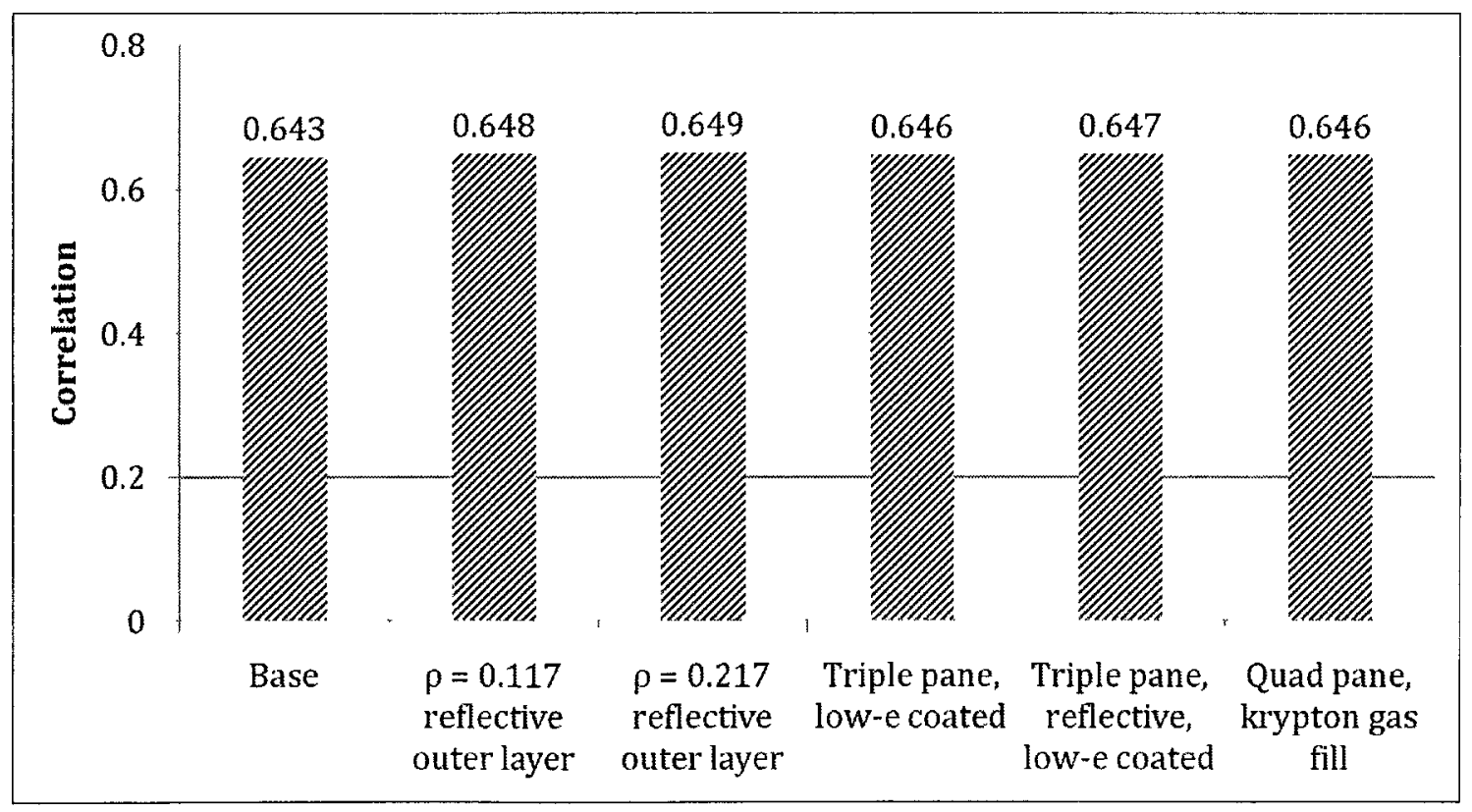

Figure B.7: Annual correlation between the residential consumption and provincial distribution with modified window properties 


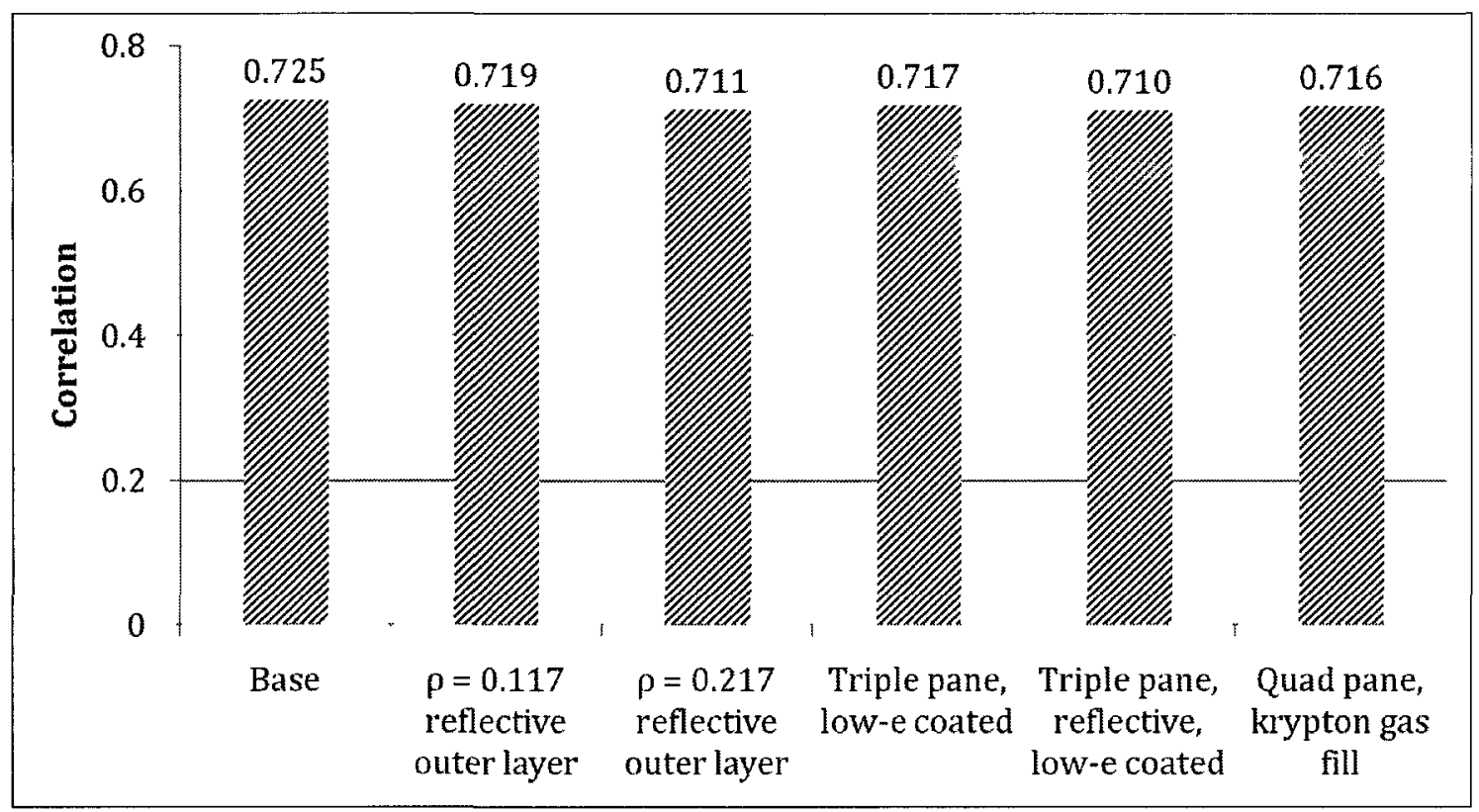

Figure B.8: Summer weekday correlation between the residential consumption and provincial distribution with modified window properties 


\section{B.3 Venetian Blind Results Metrics Compared to the Base Case}

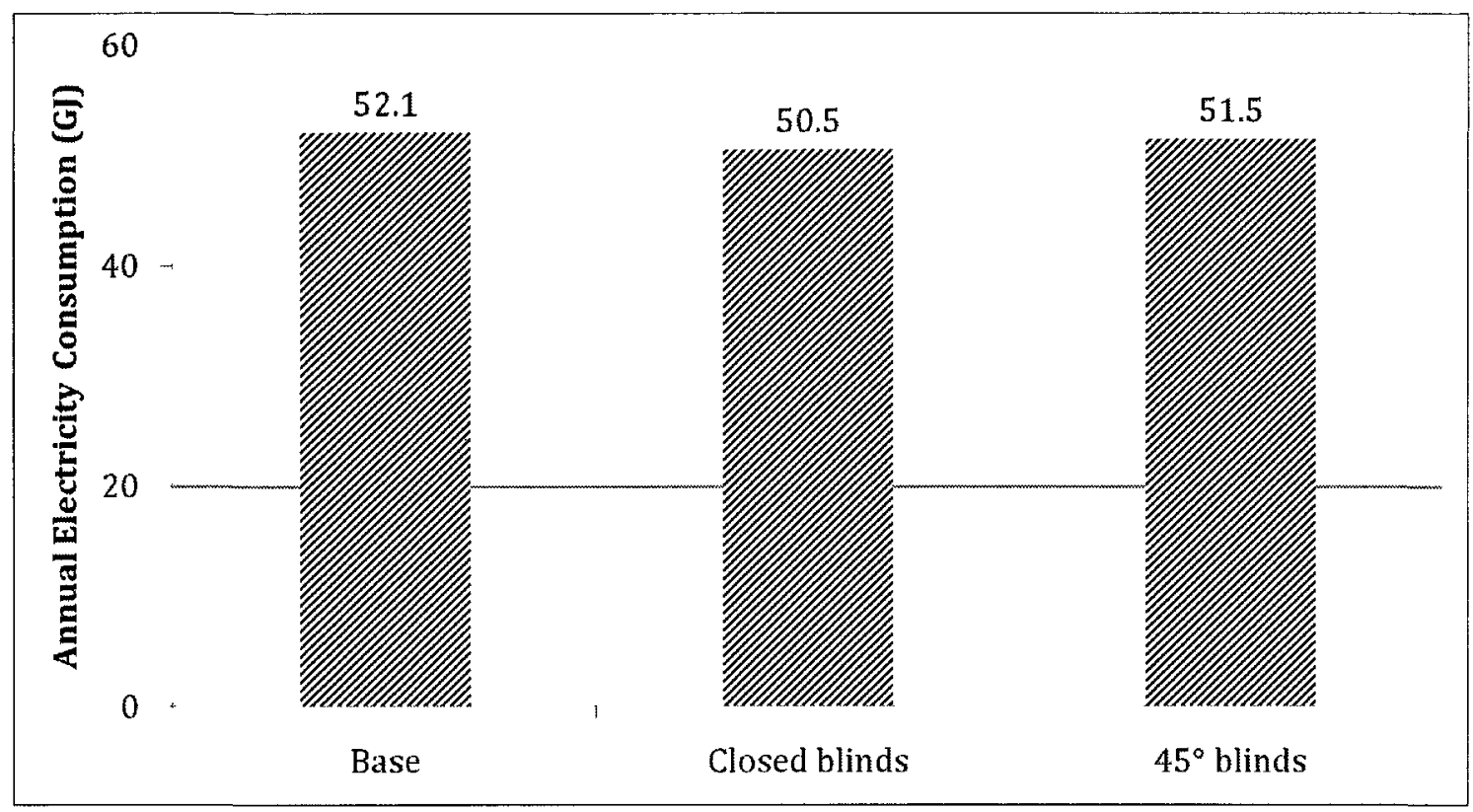

Figure B.9: Annual electricity consumption in GJ with venetian blind position 


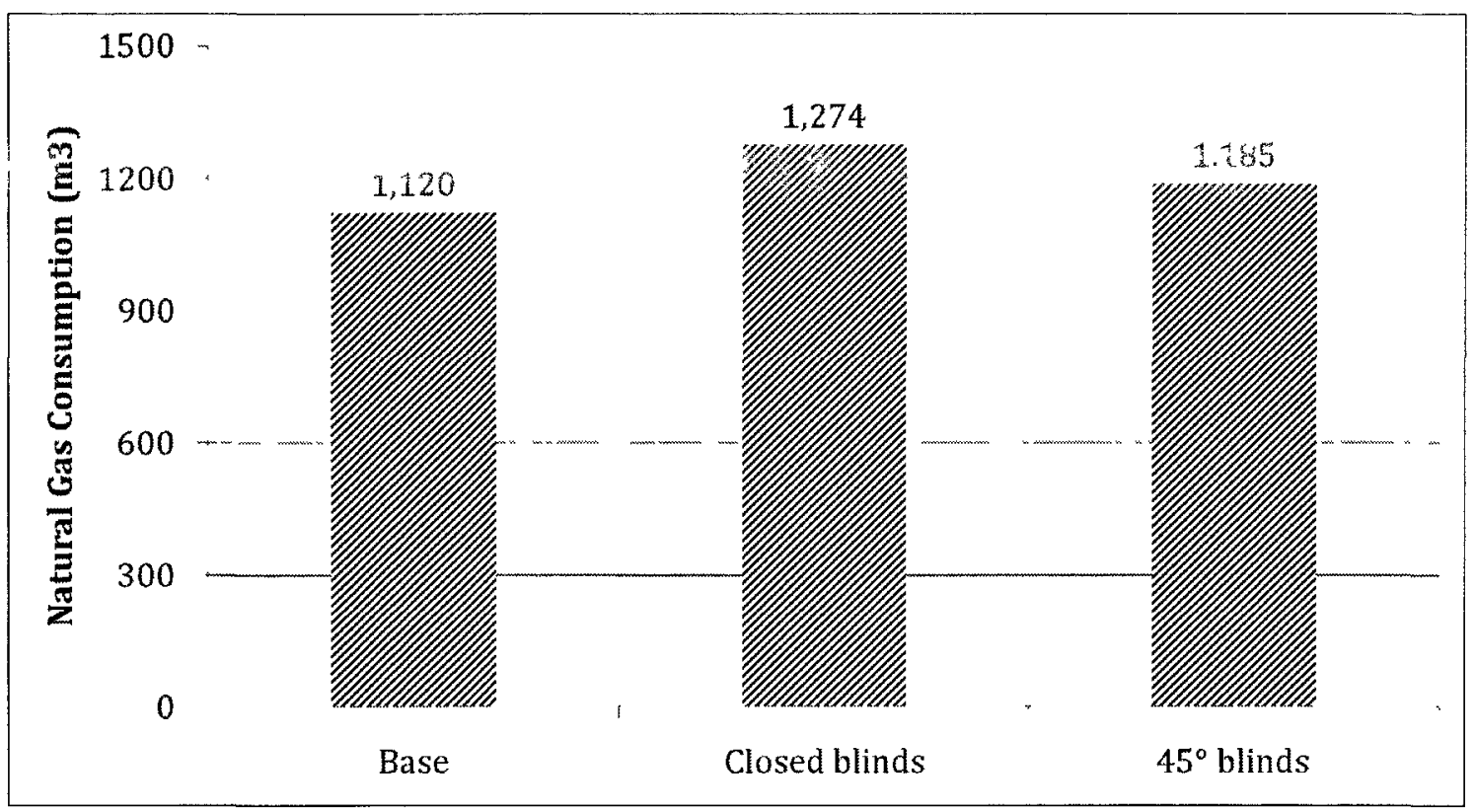

Figure B.10: Annual natural gas consumption with venetian blind position

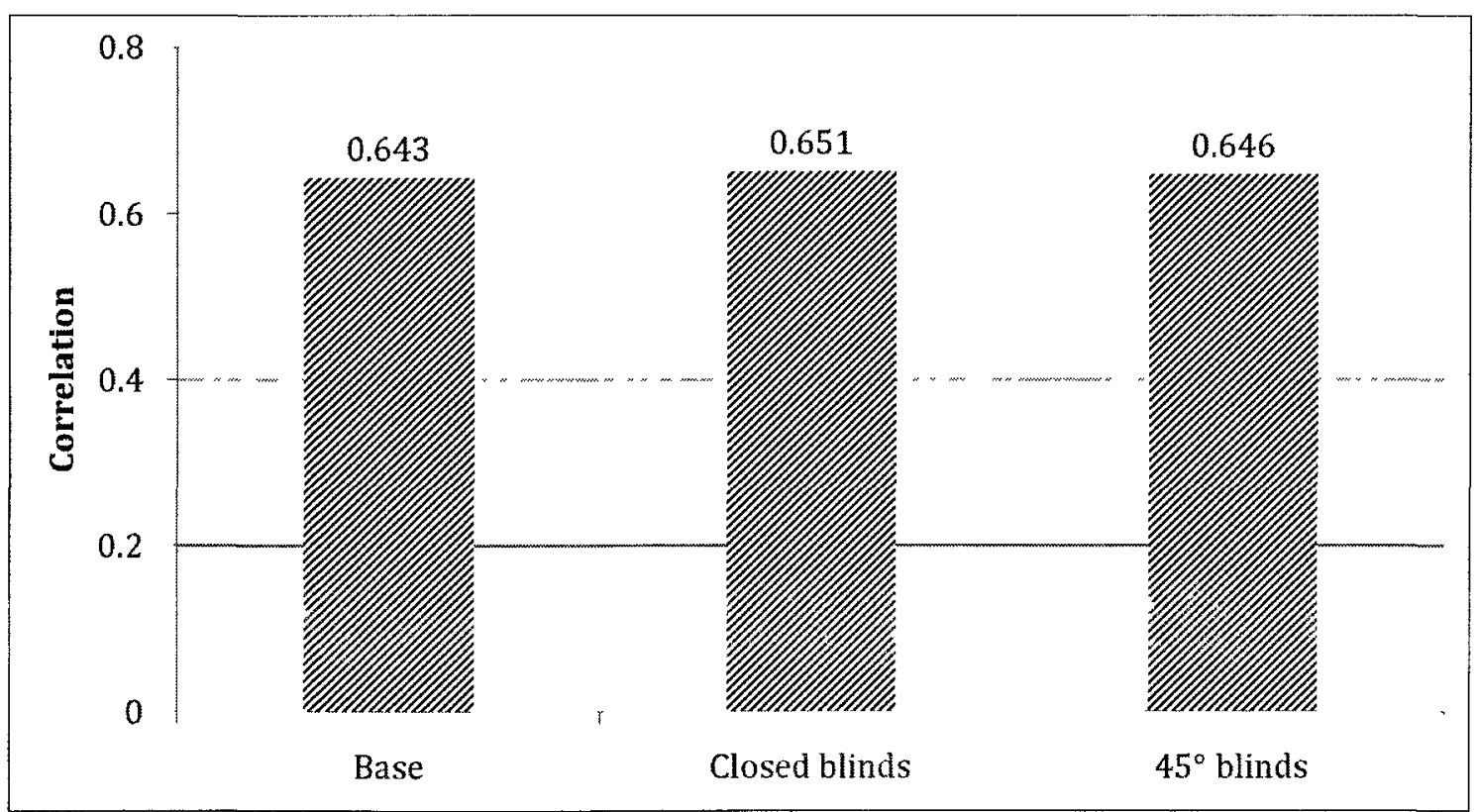

Figure B.11: Annual correlation between the residential consumption and provincial distribution with venetian blind position 


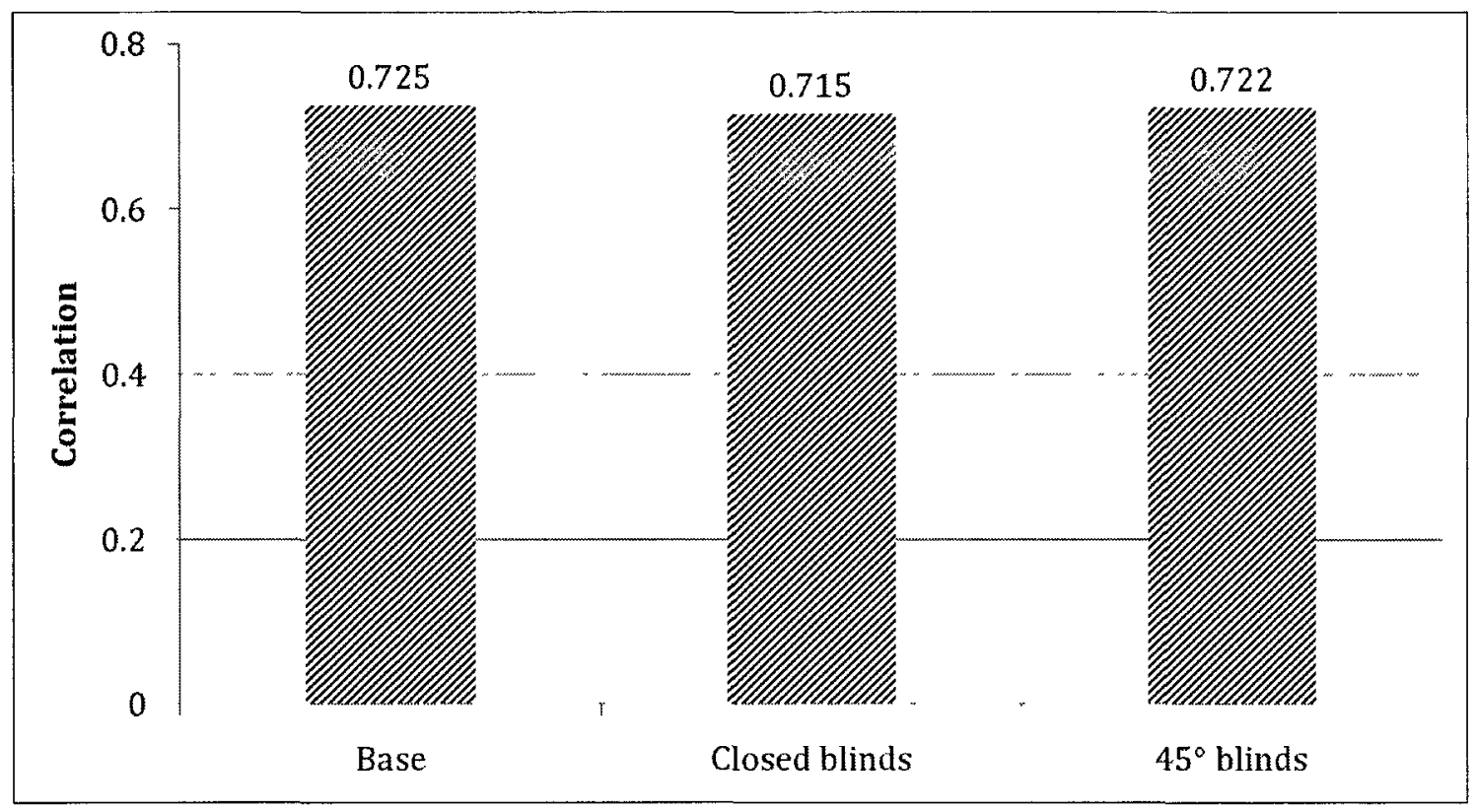

Figure B.12: Summer weekday correlation between the residential consumption and provincial distribution with venetian blind position 


\section{B.4 Fenestration Results Metrics Compared to the Base Case}

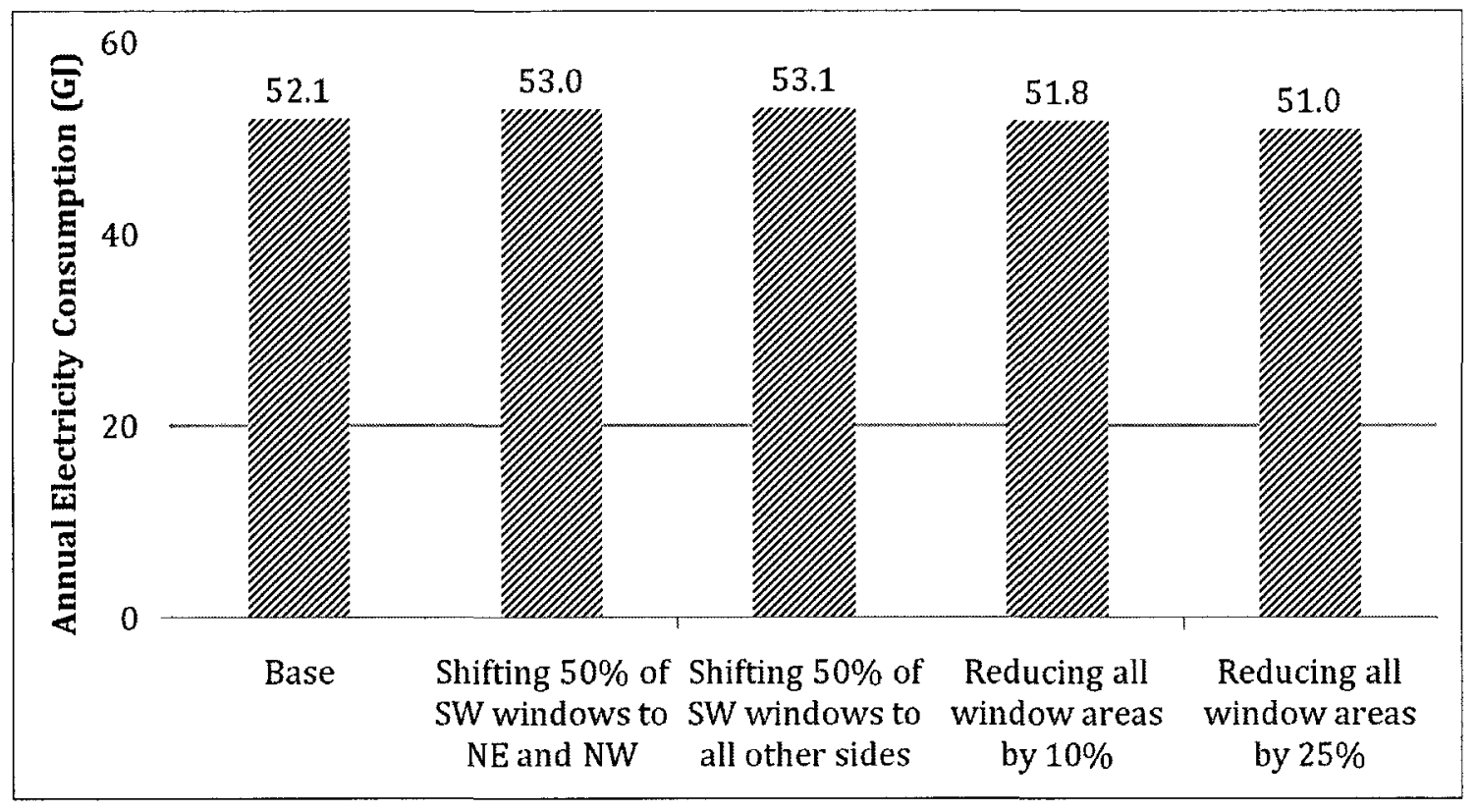

Figure B.13: Annual electricity consumption in GJ with fenestration size and distribution 


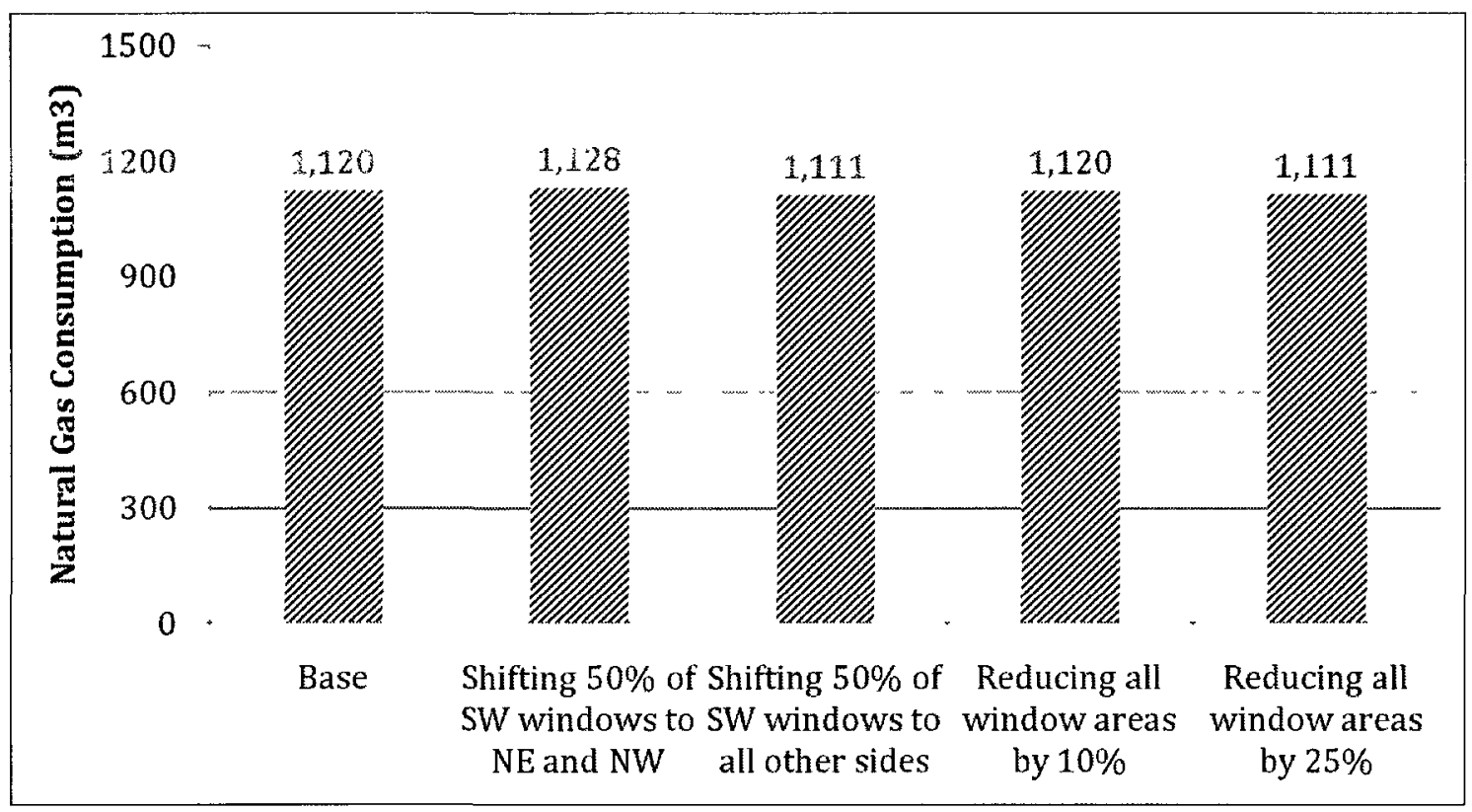

Figure B.14: Annual natural gas consumption with fenestration size and distribution

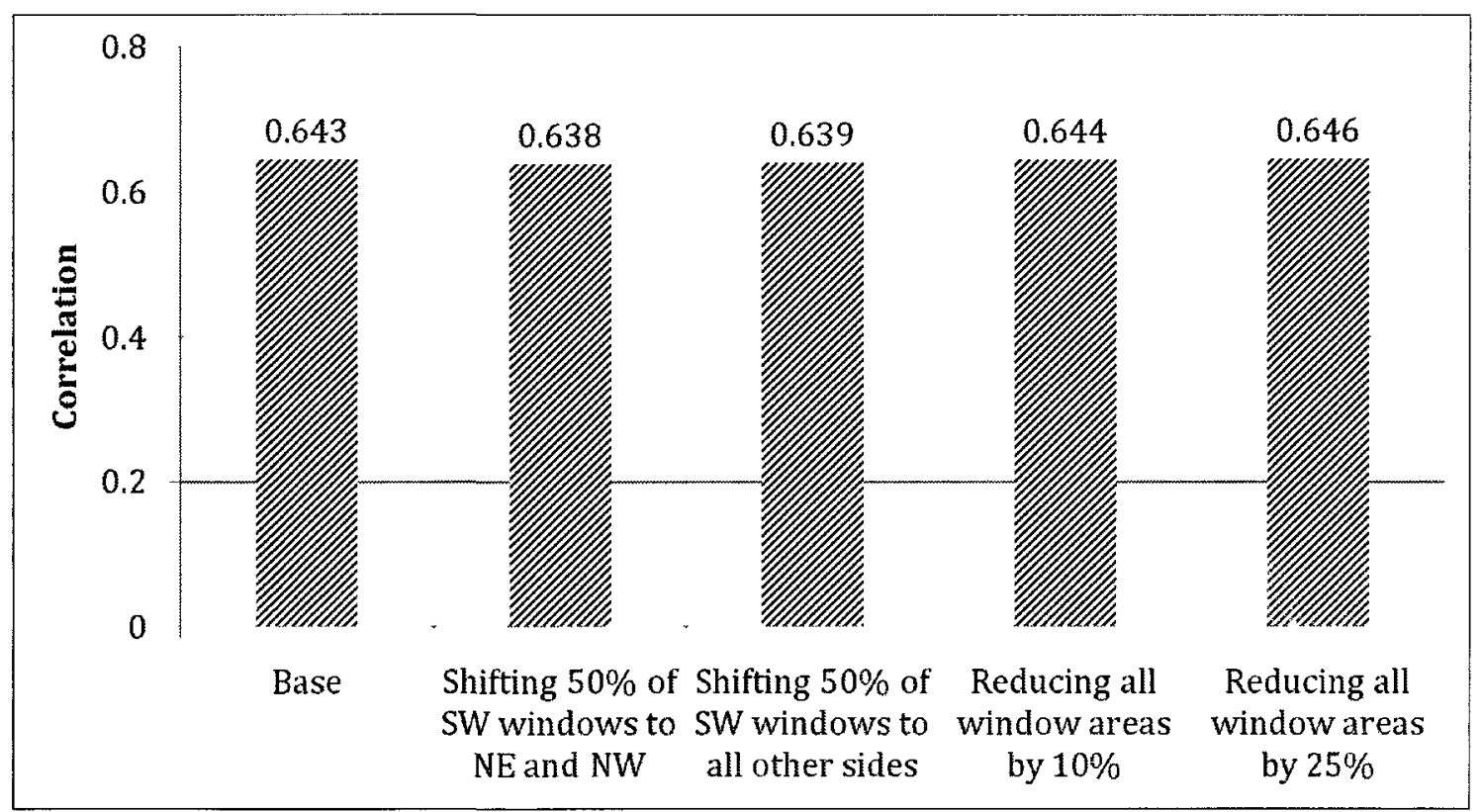

Figure B.15: Annual correlation between the residential consumption and provincial distribution with fenestration size and distribution 


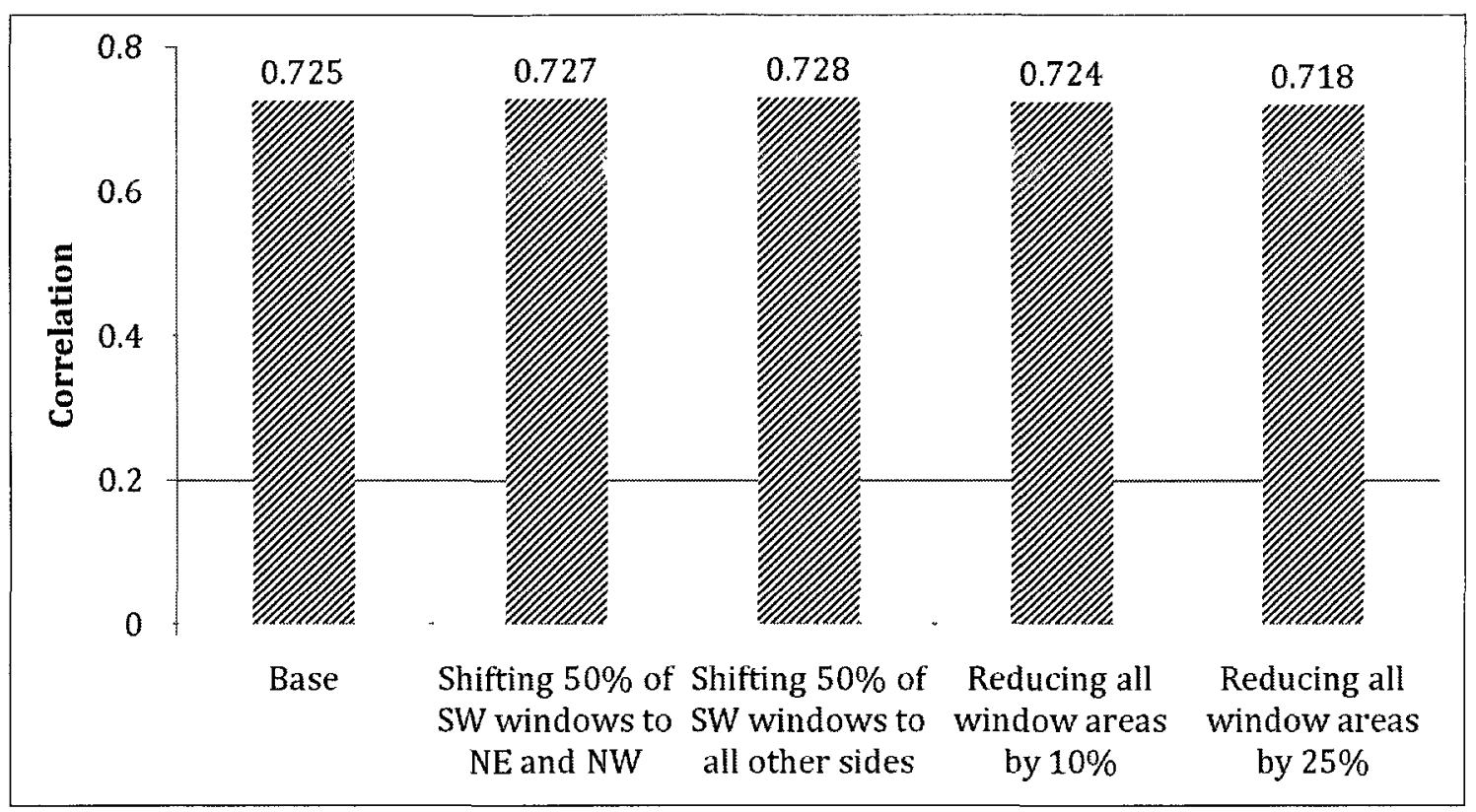

Figure B.16: Summer weekday correlation between the residential consumption and provincial distribution with fenestration size and distribution 


\section{B.5 Reflective Shingles Results Metrics Compared to the Base Case}

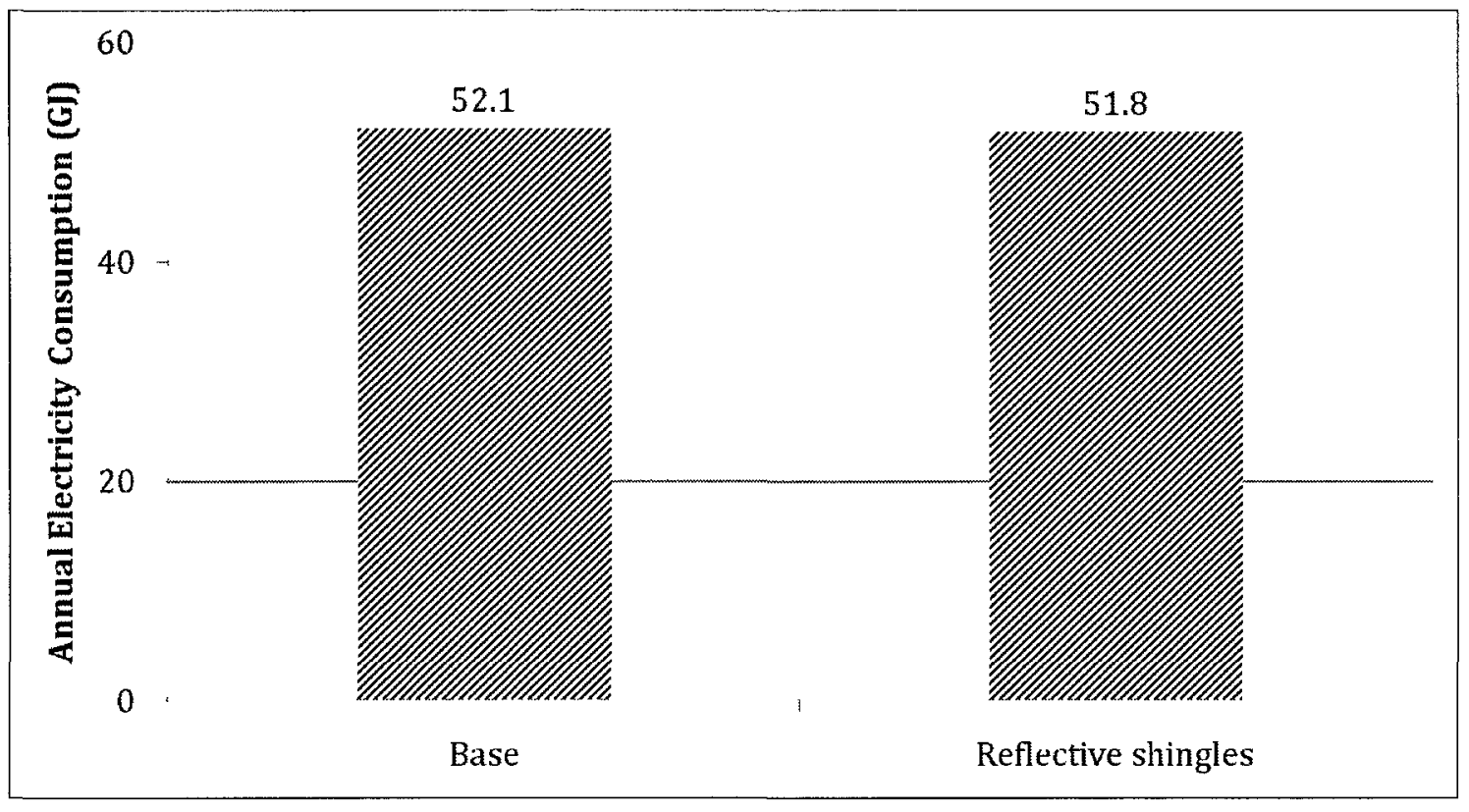

Figure B.17: Annual electricity consumption in GJ with reflective shingles 


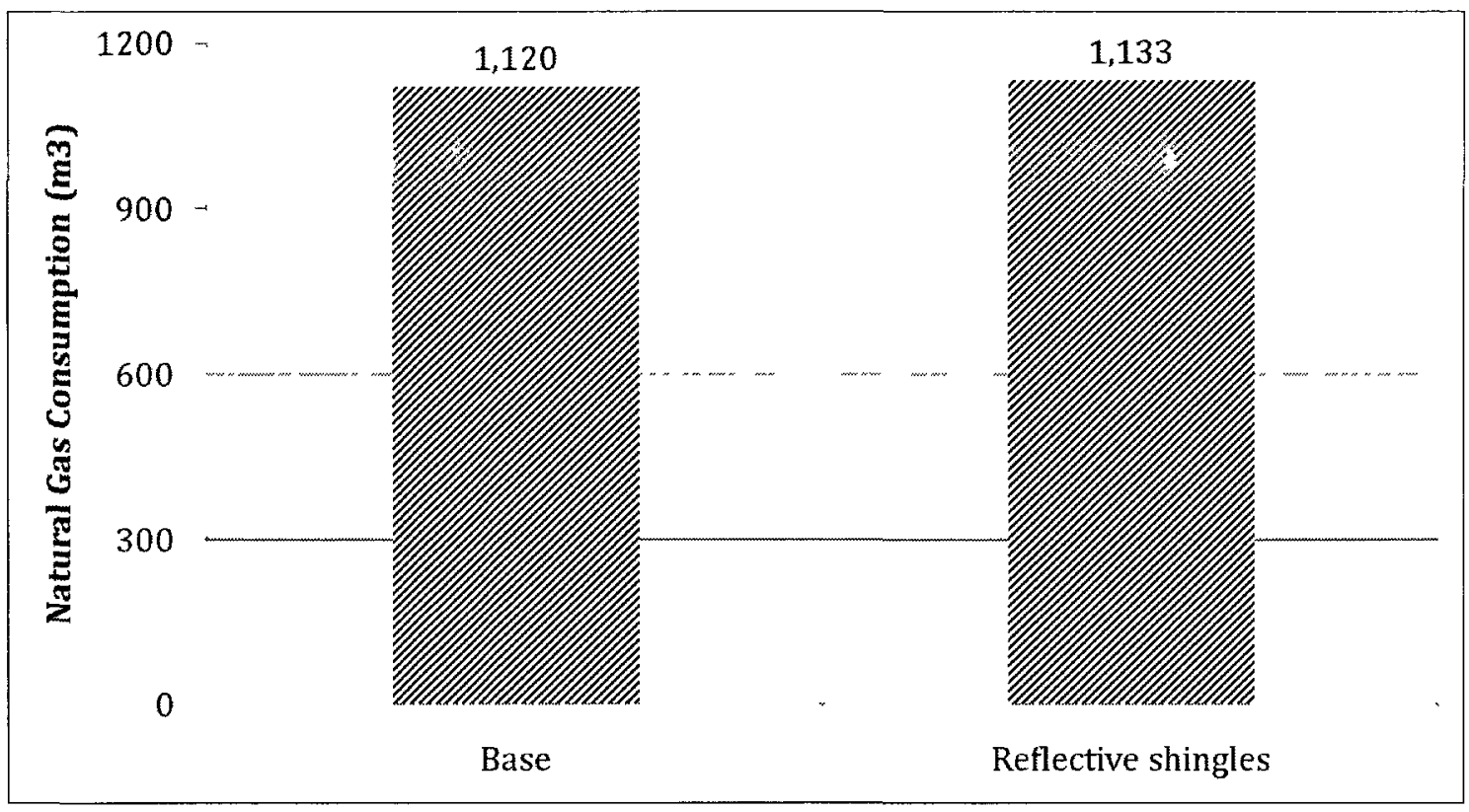

Figure B.18: Annual natural gas consumption with reflective shingles

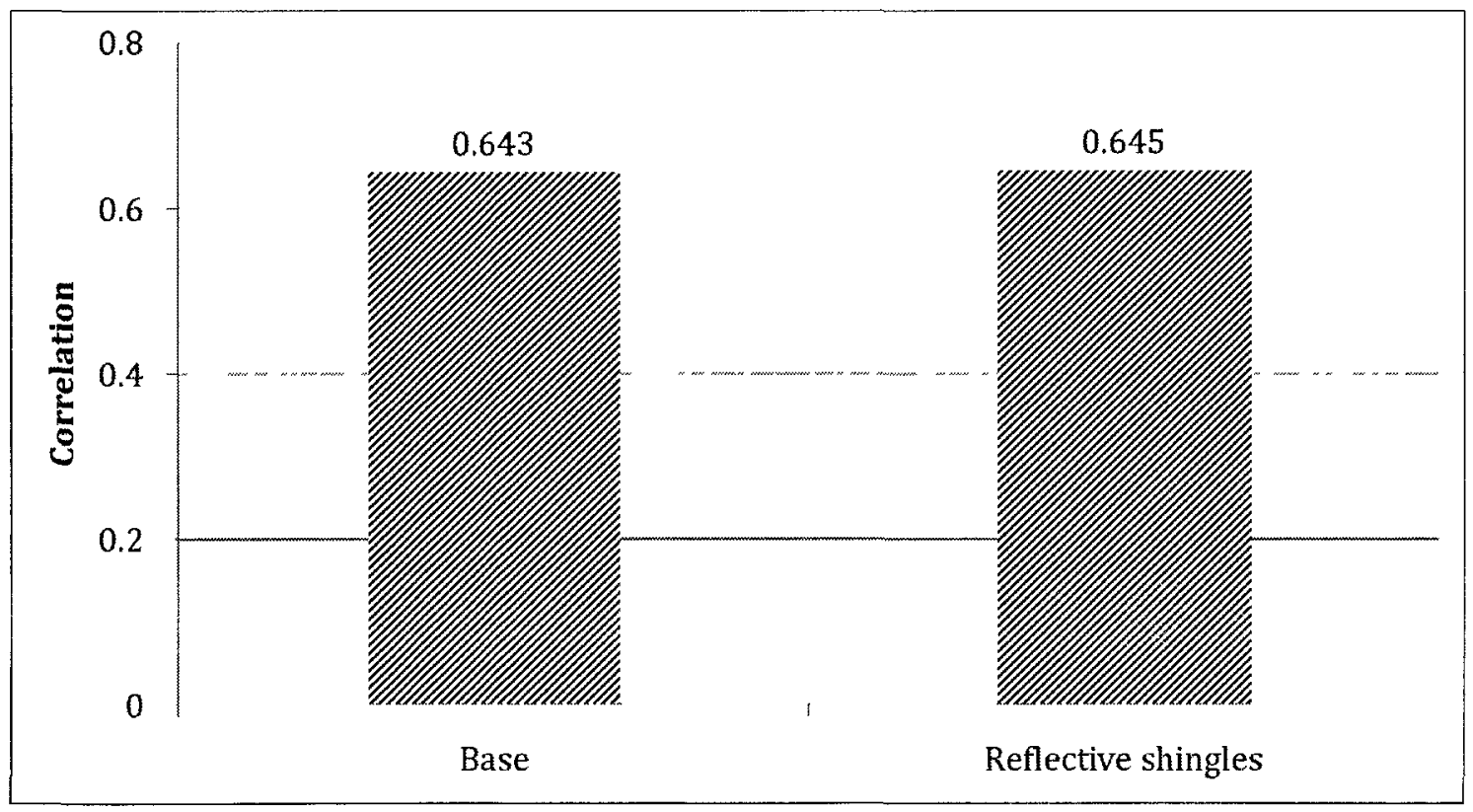

Figure B.19: Annual correlation between the residential consumption and provincial distribution with reflective shingles 


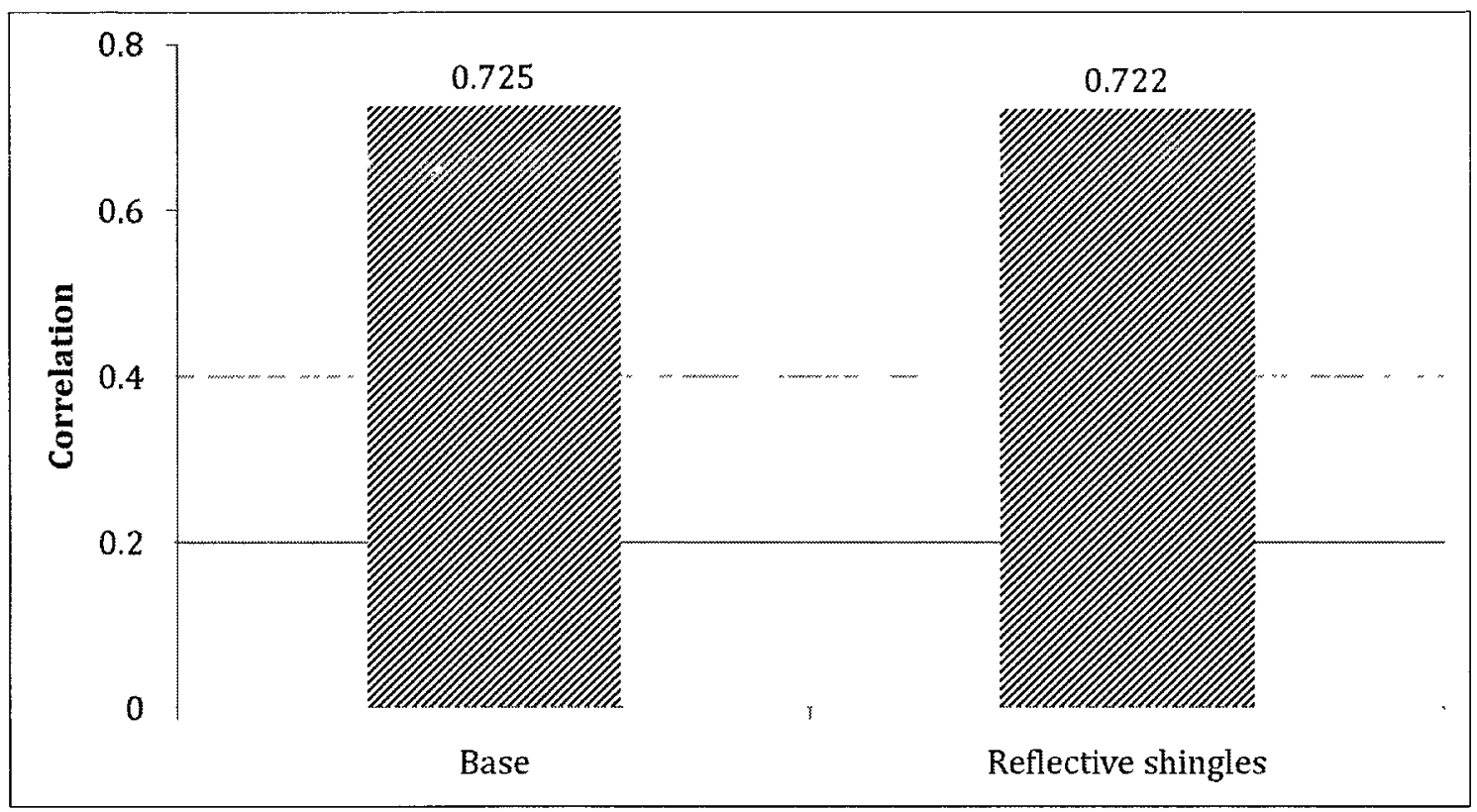

Figure B.20: Summer weekday correlation between the residential consumption and provincial distribution with reflective shingles 


\section{B.6 Thermal Mass and Pre-Cooling Results Met- rics Compared to the Base Case}

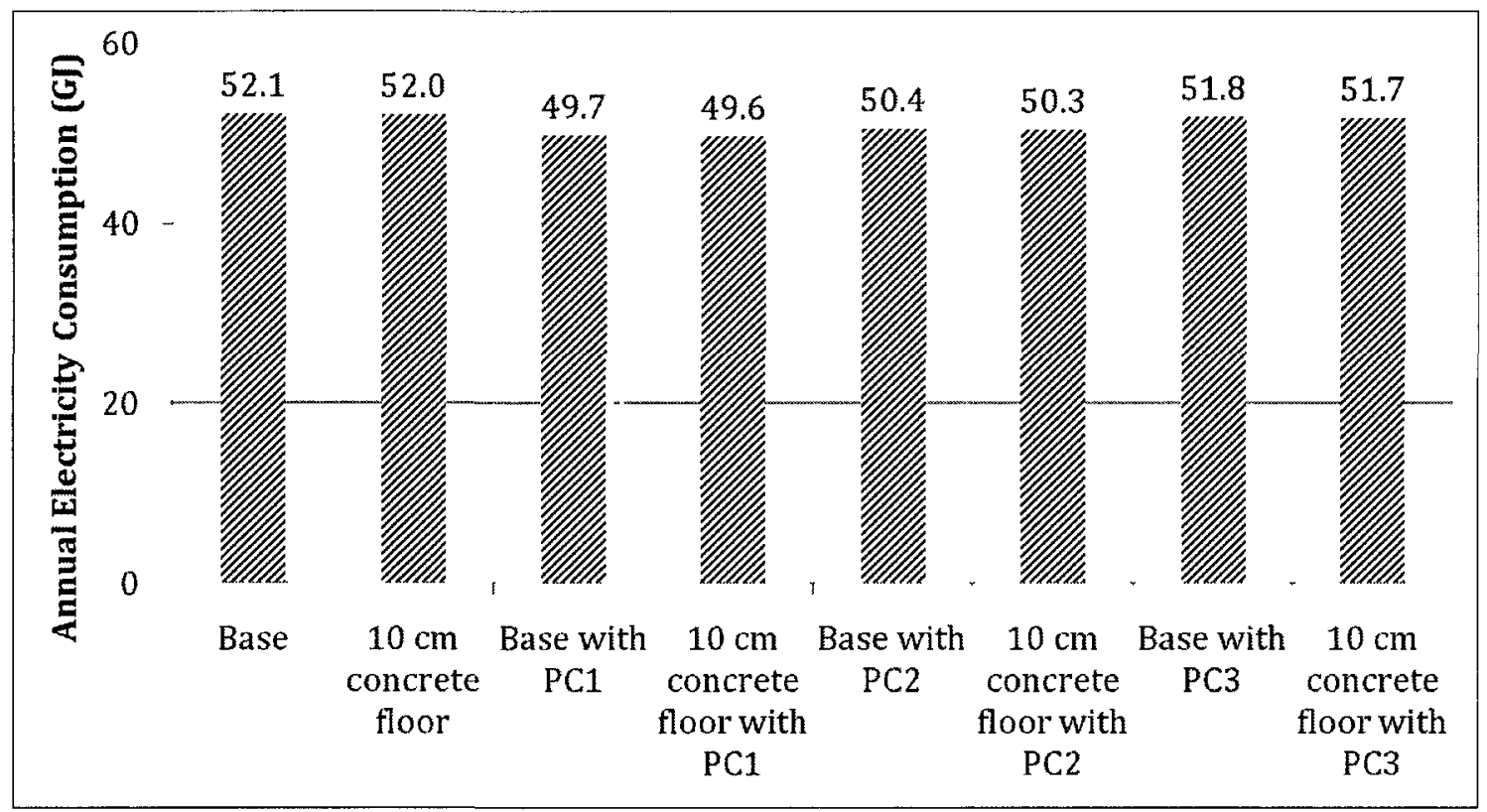

Figure B.21: Annual electricity consumption in GJ with thermal mass and/or precooling 


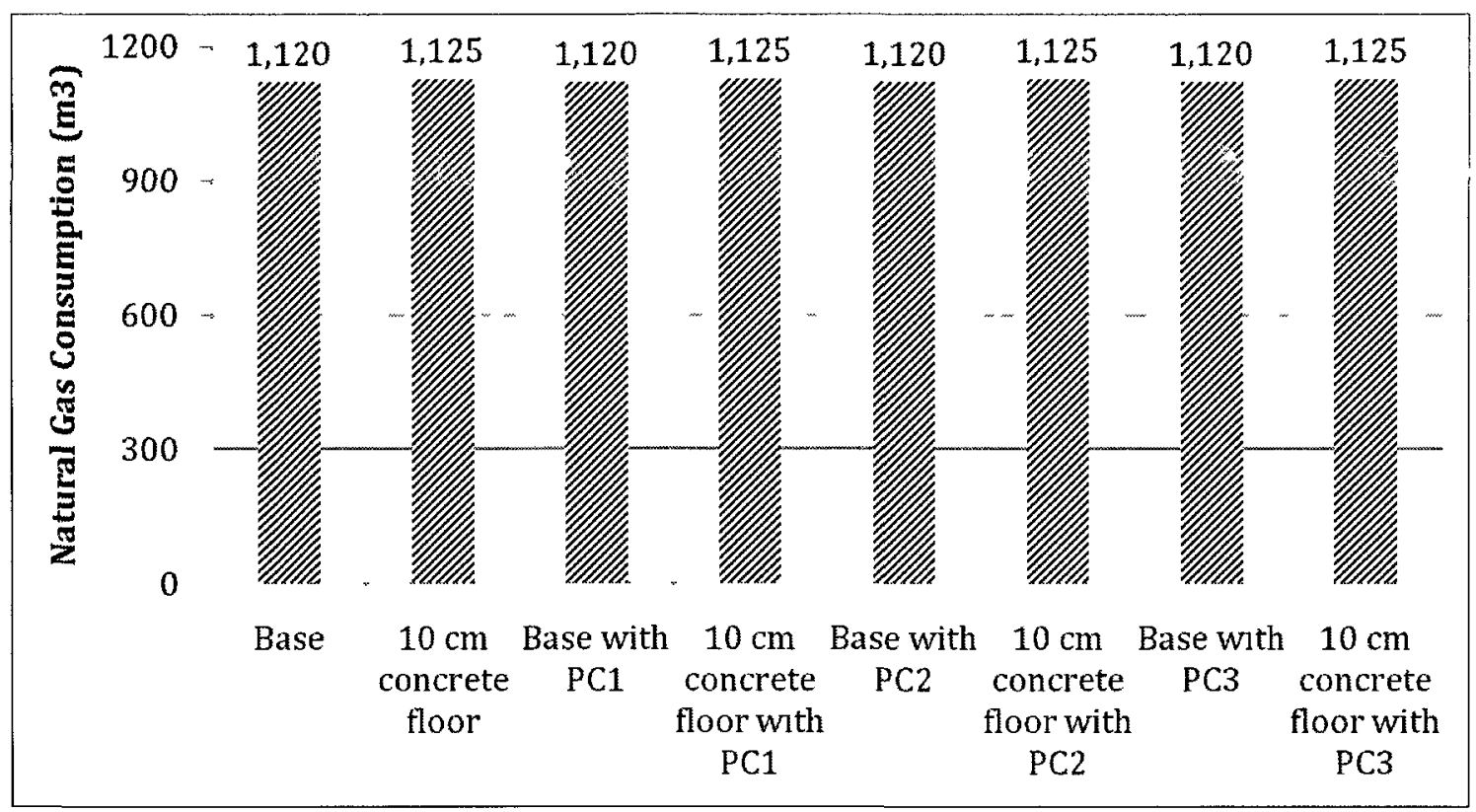

Figure B.22: Annual natural gas consumption with thermal mass and/or pre-cooling

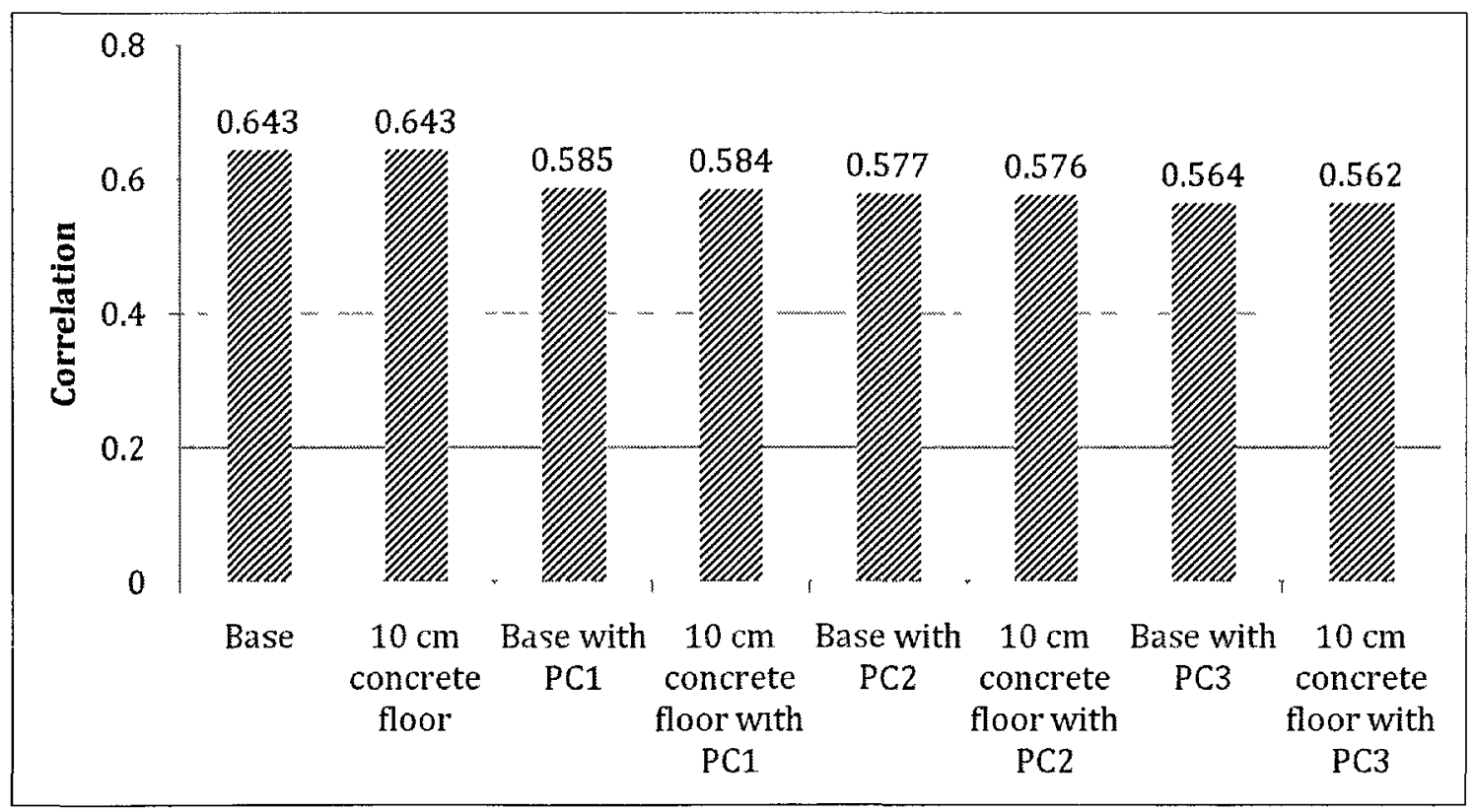

Figure B.23: Annual correlation between the residential consumption and provincial distribution with thermal mass and/or pre-cooling 


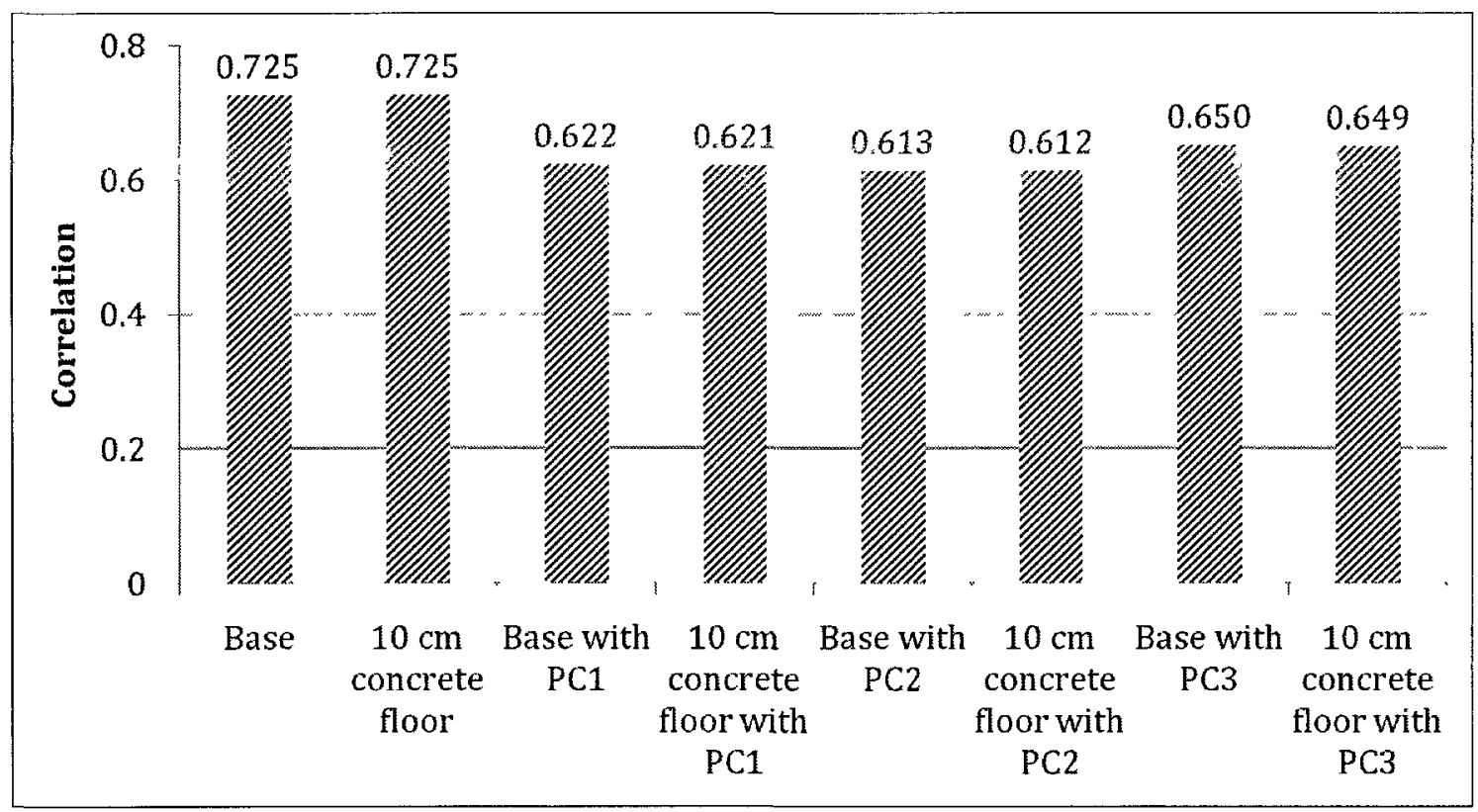

Figure B.24: Summer weekday correlation between the residential consumption and provincial distribution with thermal mass and/or pre-cooling 


\section{B.7 Actuating Venetian Blind Results Metrics Compared to the Base Case}

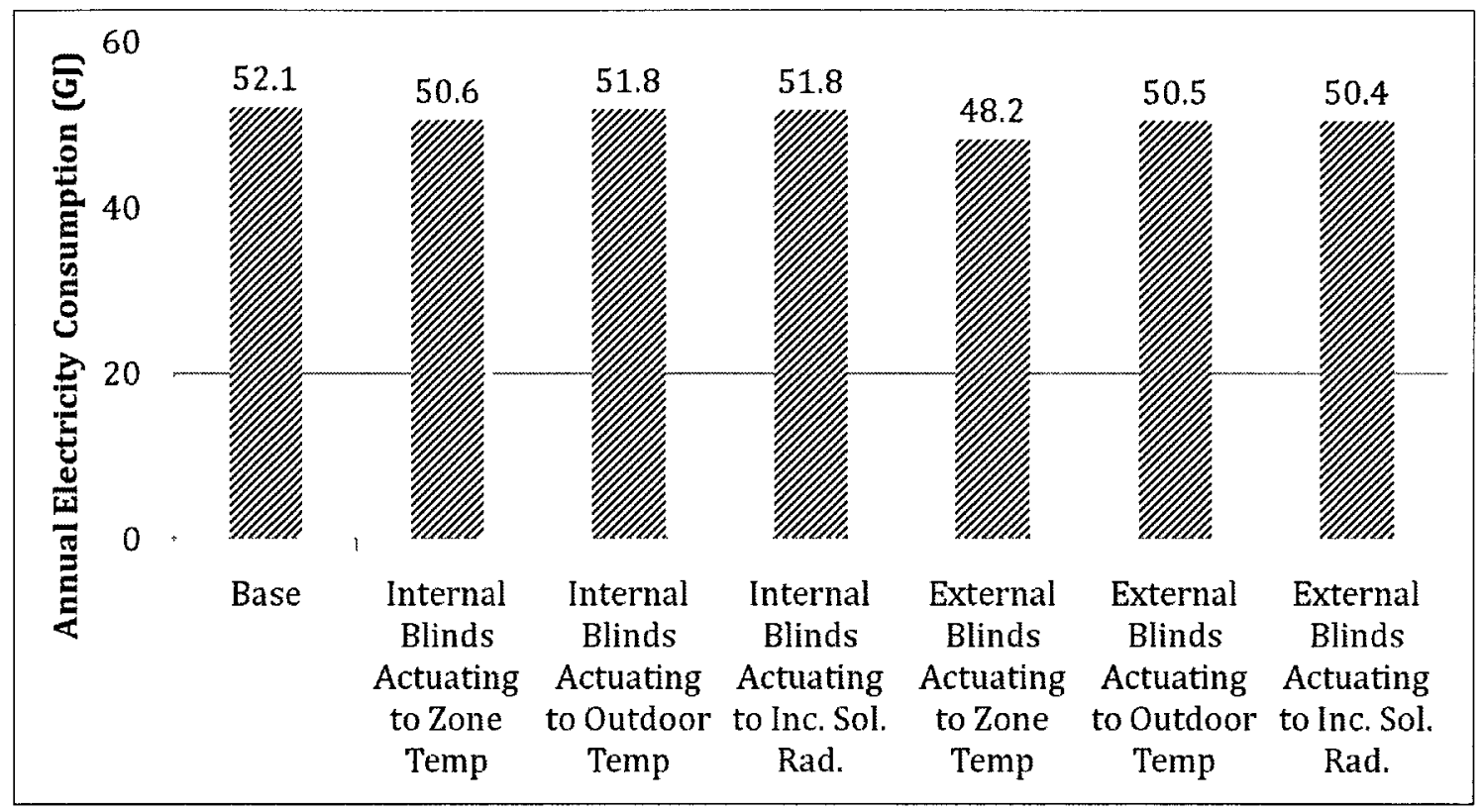

Figure B.25: Annual electricity consumption in GJ with actuating venetian blinds 


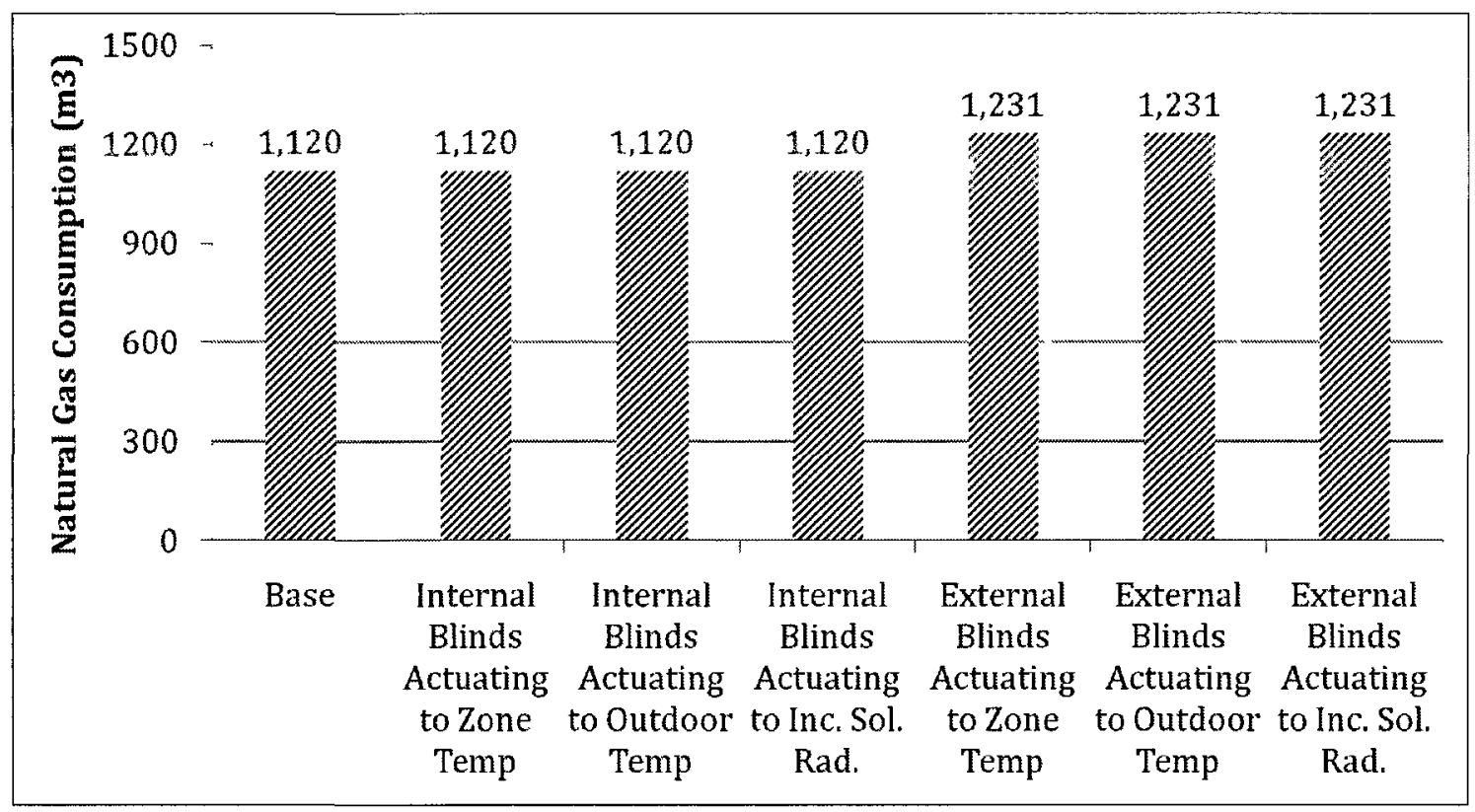

Figure B.26: Annual natural gas consumption with actuating venetian blinds

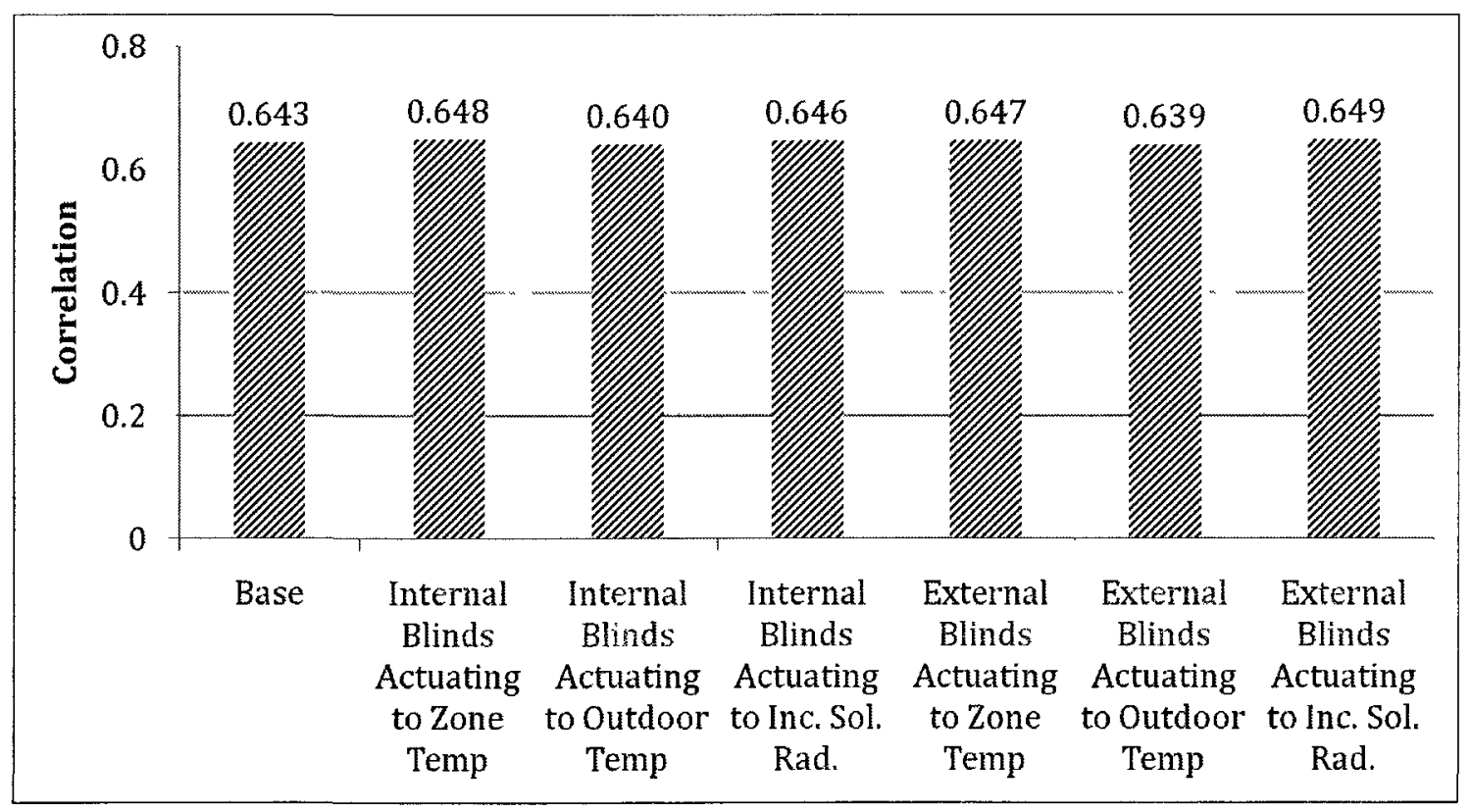

Figure B.27: Annual correlation between the residential consumption and provincial distribution with actuating venetian blinds 


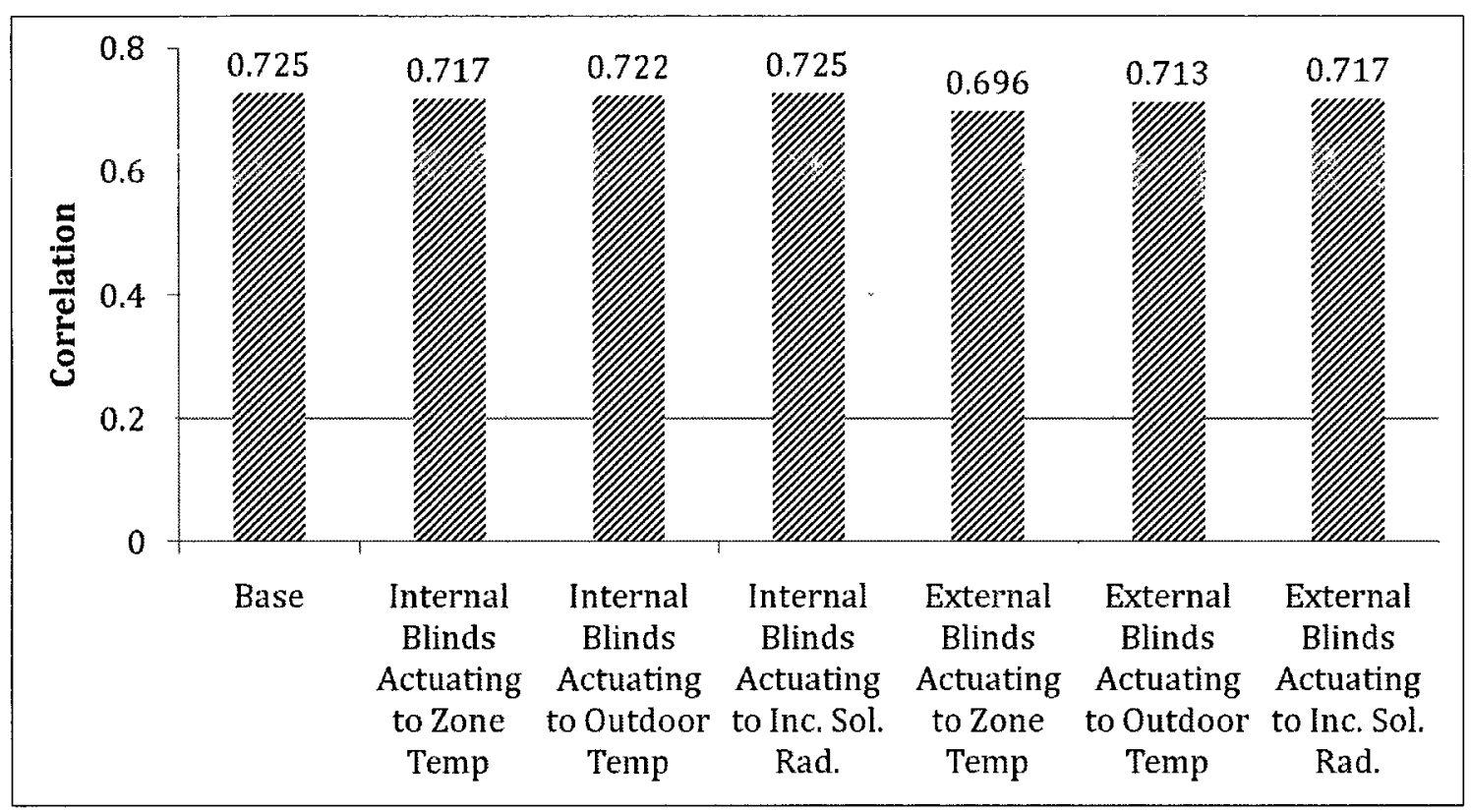

Figure B.28: Summer weekday correlation between the residential consumption and provincial distribution with actuating venetian blinds 


\section{B.8 Air-Conditioning Cycling Results Metrics Compared to the Base Case}

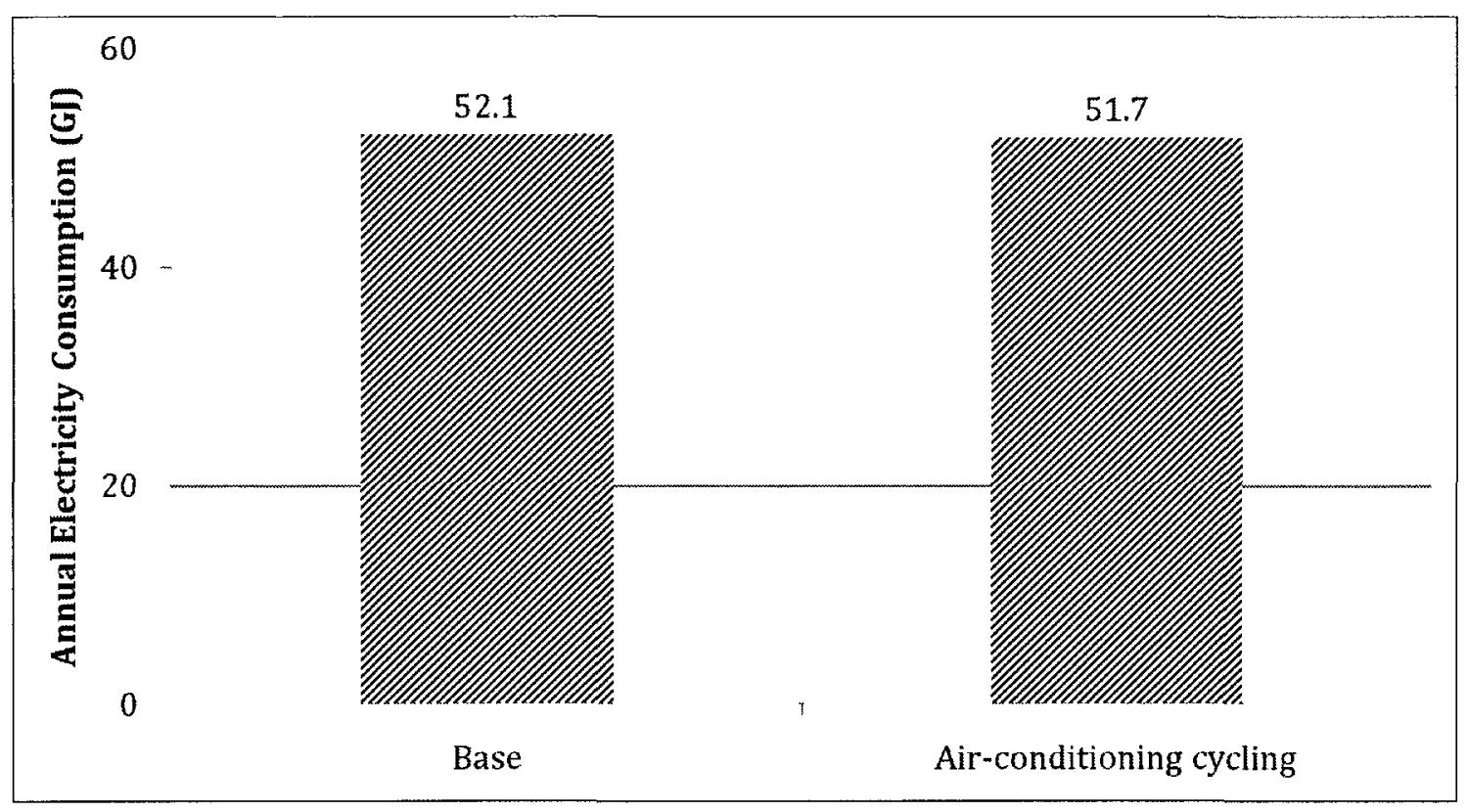

Figure B.29: Annual electricity consumption in GJ with air-conditioning cycling 


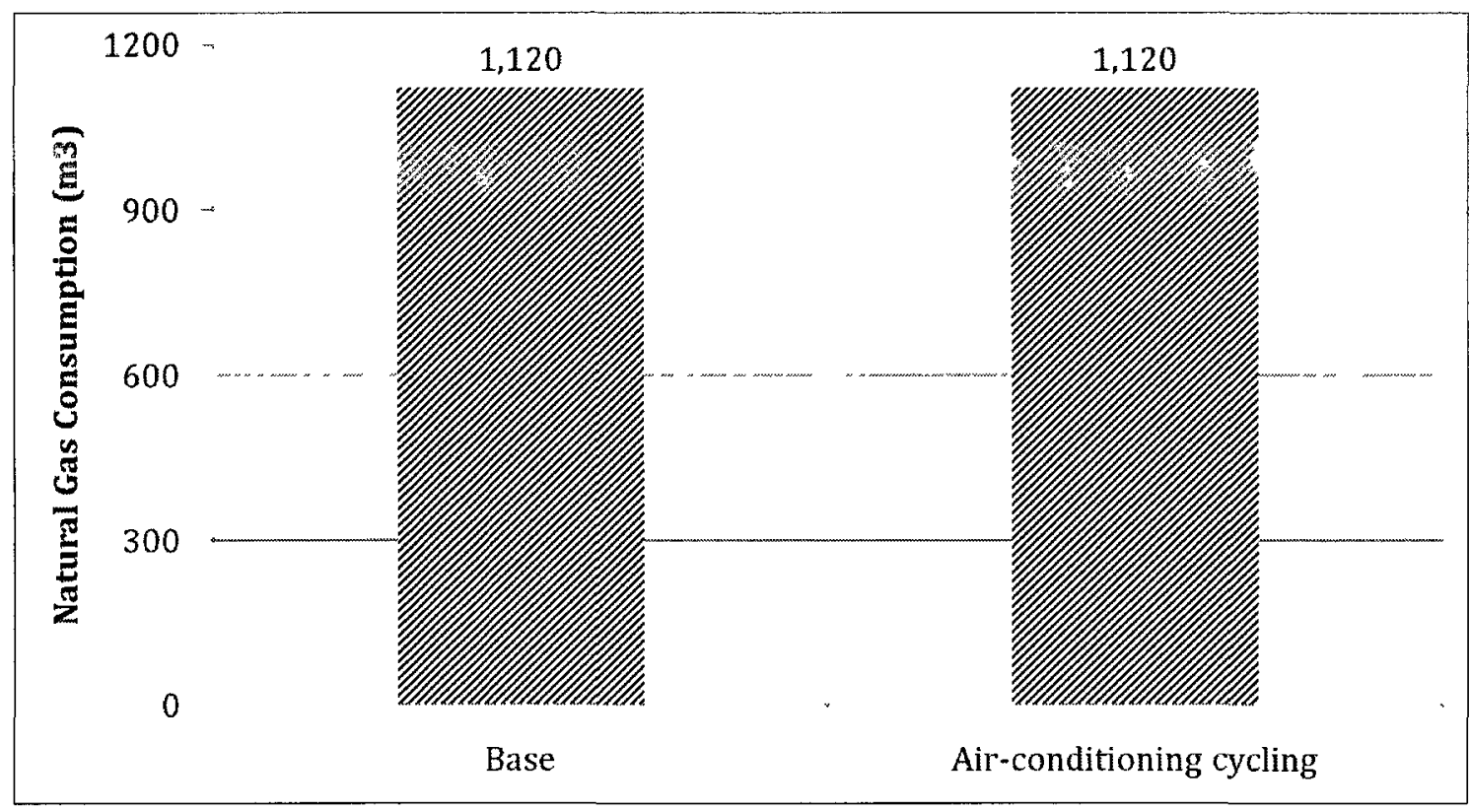

Figure B.30: Annual natural gas consumption with air-conditioning cycling

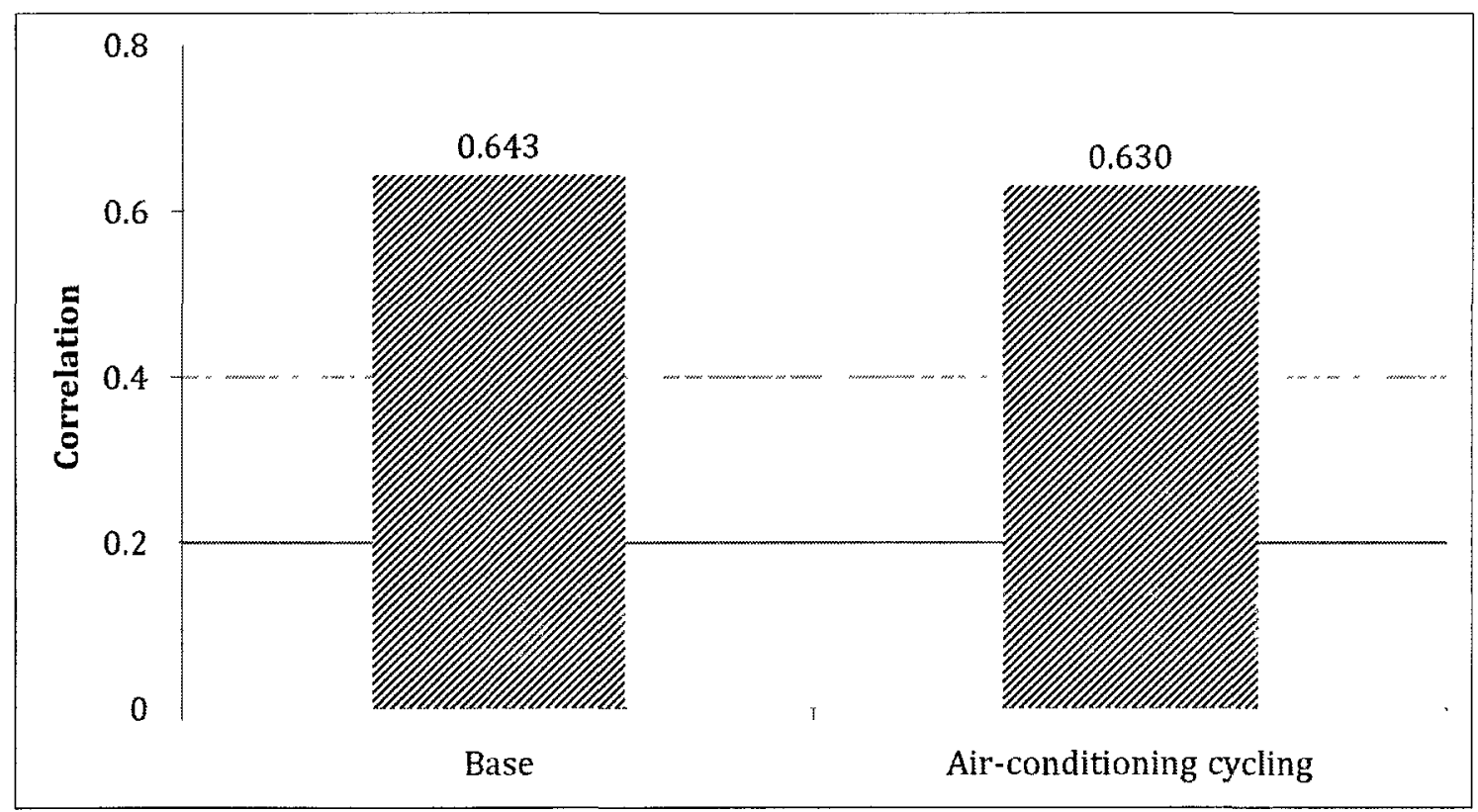

Figure B.31: Annual correlation between the residential consumption and provincial distribution with air-conditioning cycling 


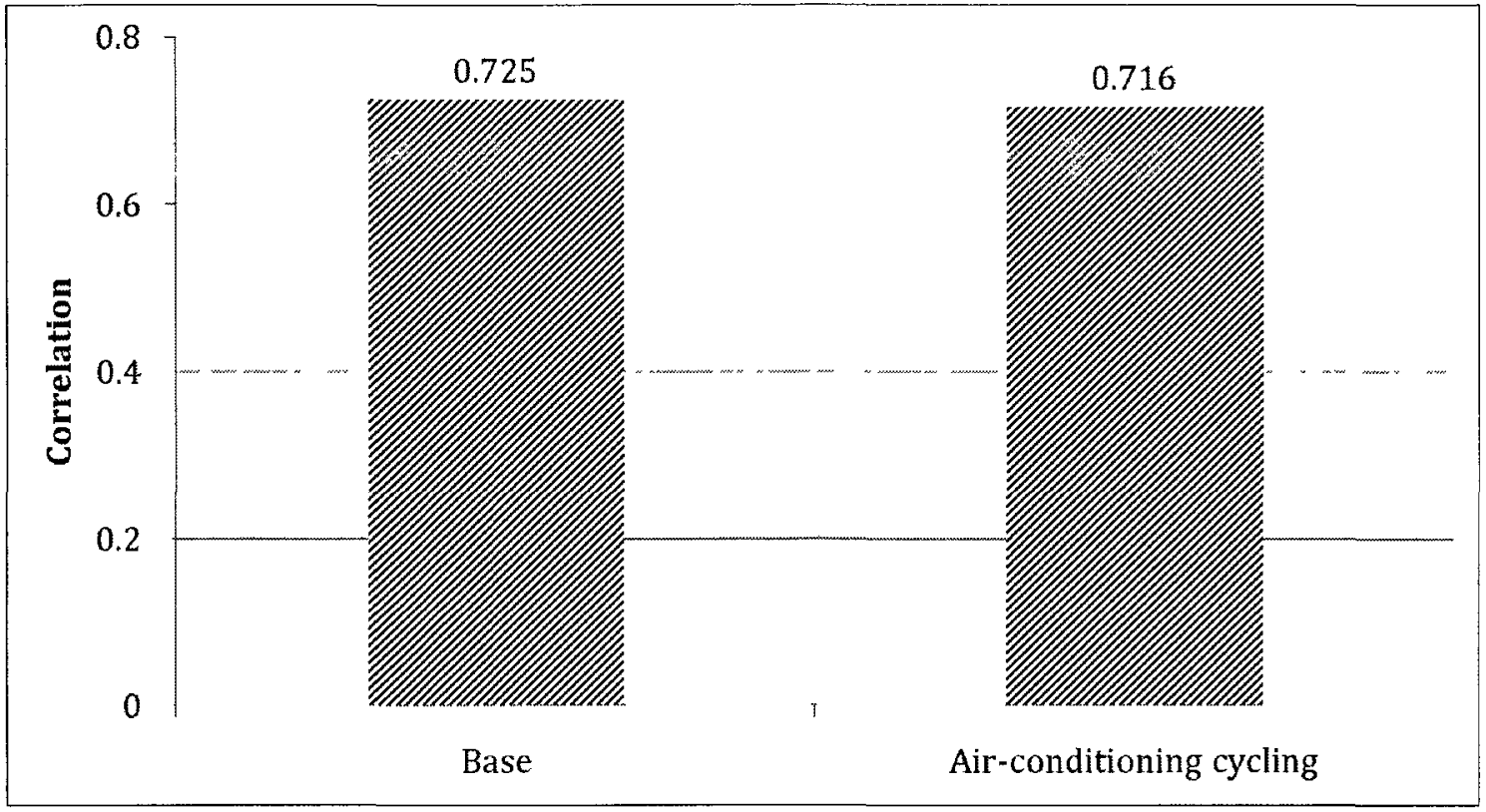

Figure B.32: Summer weekday correlation between the residential consumption and provincial distribution with air-conditioning cycling 


\section{B.9 Shifting Use of Appliances and Appliance Effi- ciency Results Metrics Compared to the Base Case}

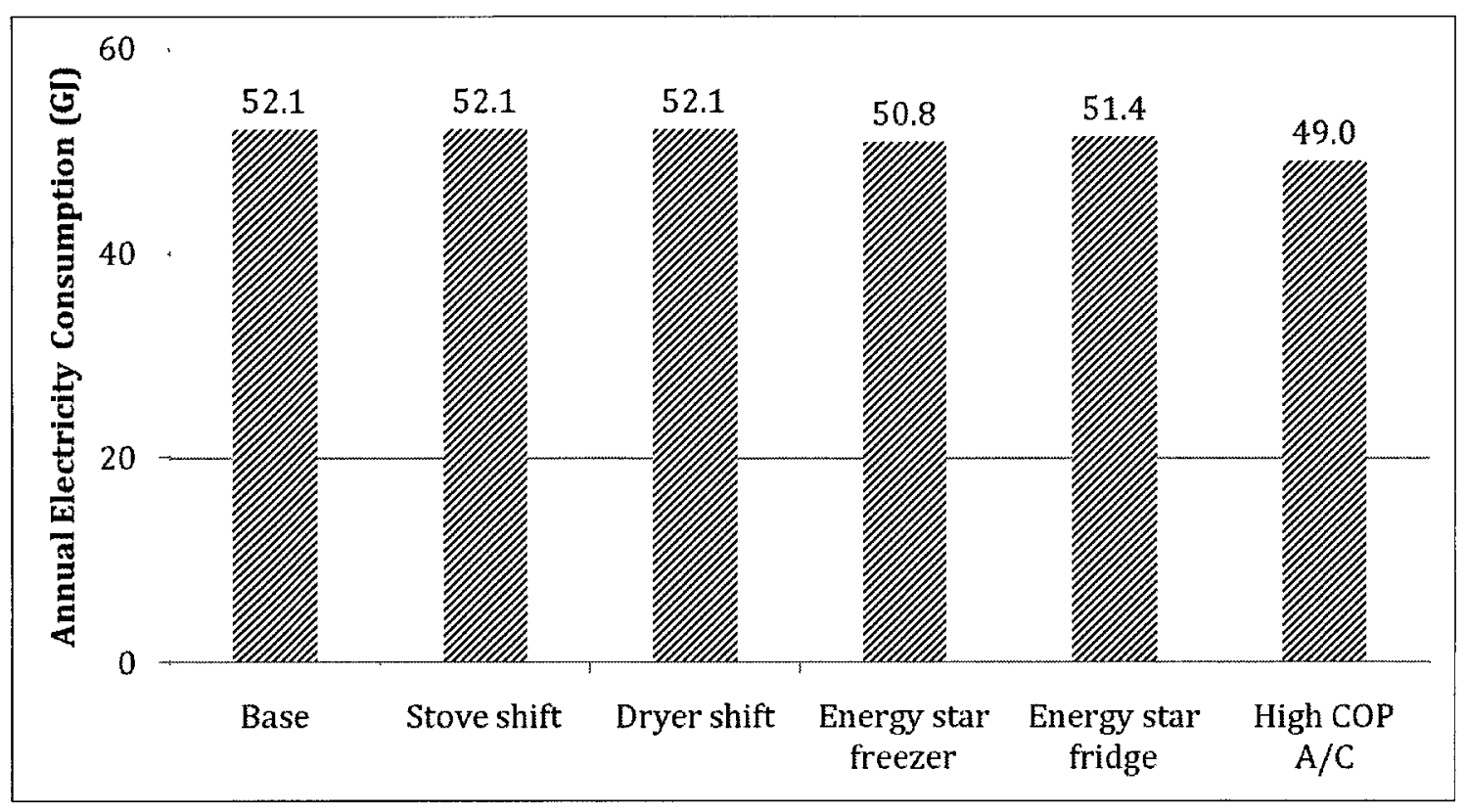

Figure B.33: Annual electricity consumption in GJ with changes to occupant behaviour 


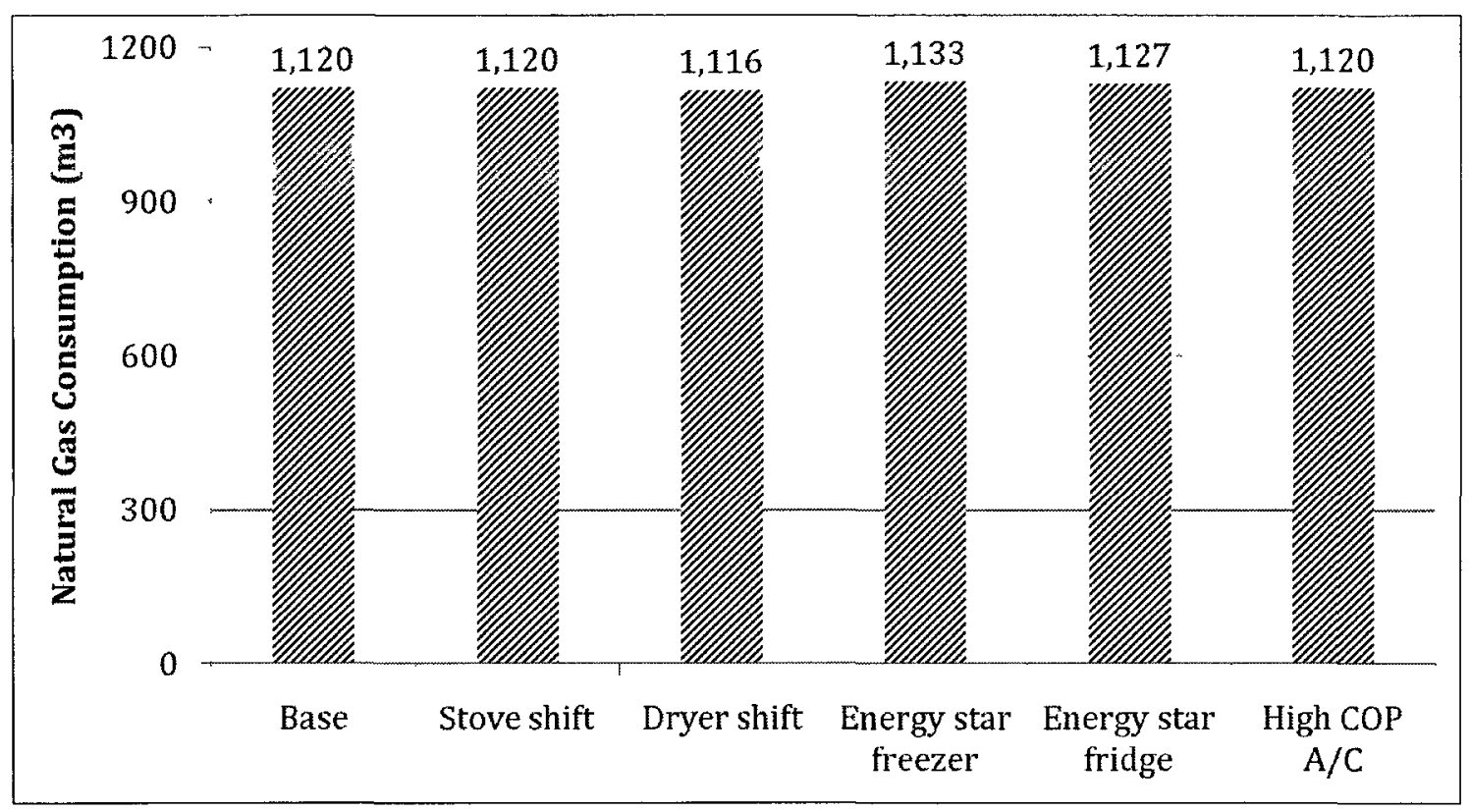

Figure B.34: Annual natural gas consumption with changes to occupant behaviour

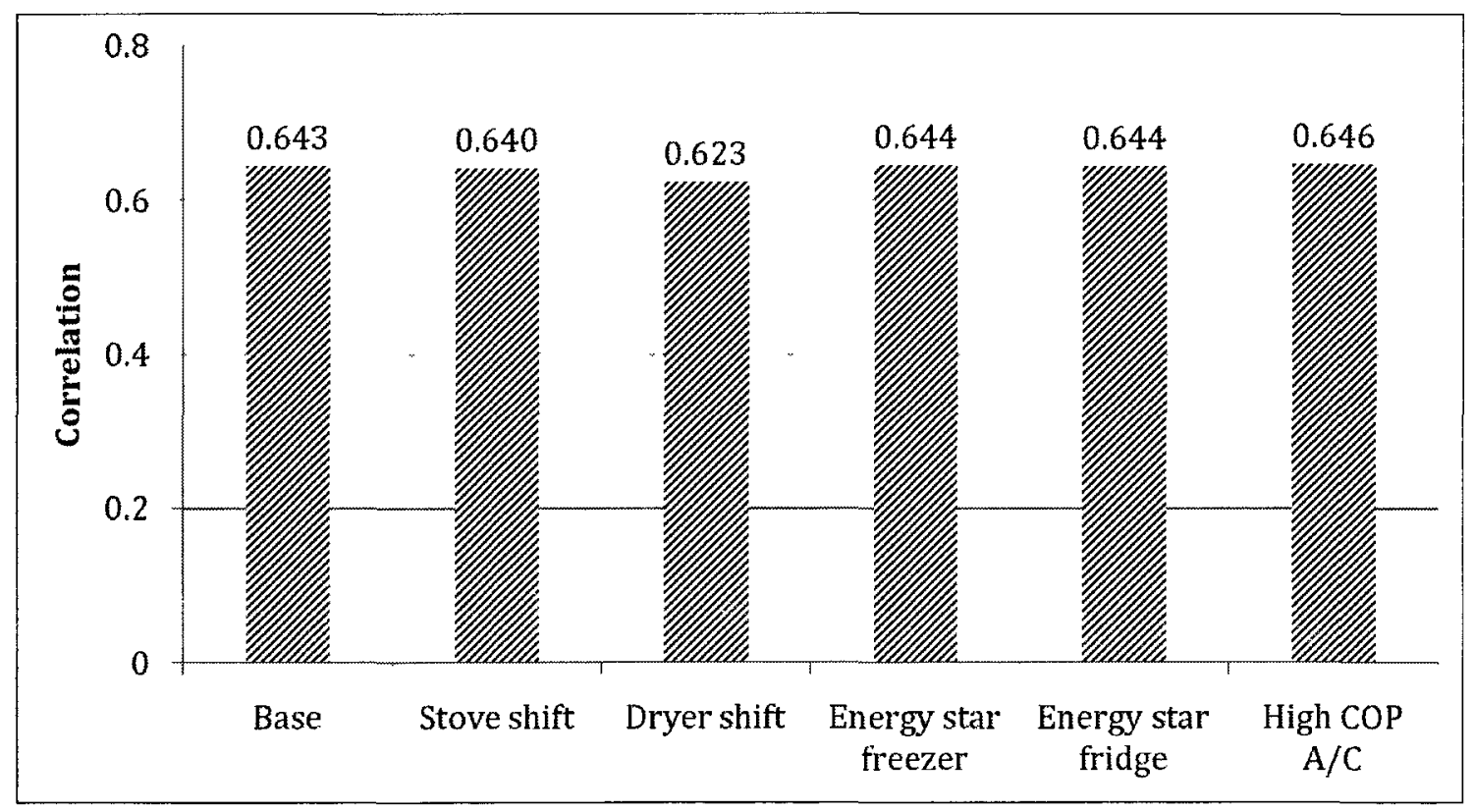

Figure B.35: Annual correlation between the residential consumption and provincial distribution with changes to occupant behaviour 


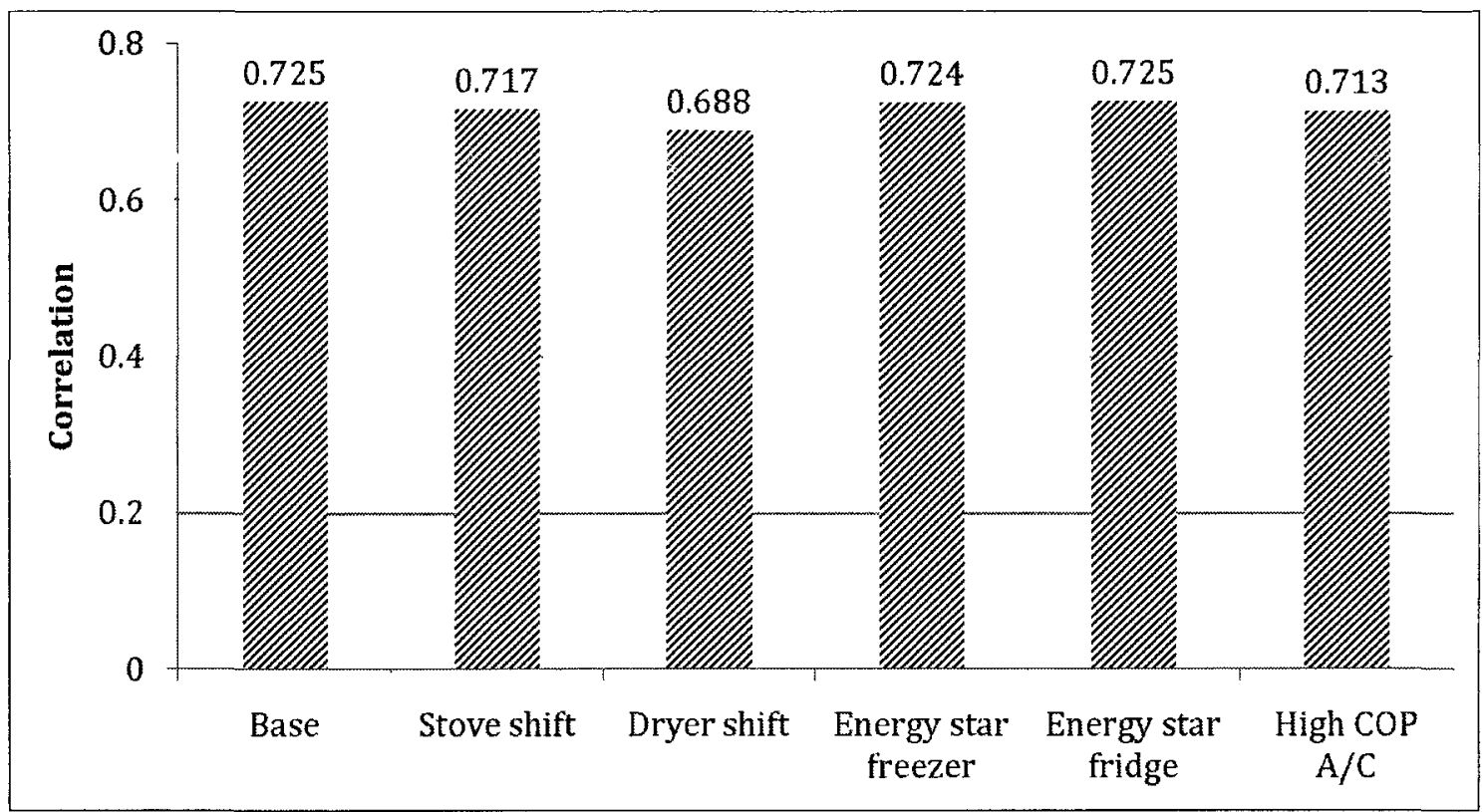

Figure B.36: Summer weekday correlation between the residential consumption and provincial distribution with changes to occupant behaviour 


\section{B.10 Outdoor Air Ventilation - Windows and Ven- tilative Cooling Results Metrics Compared to the Base Case}

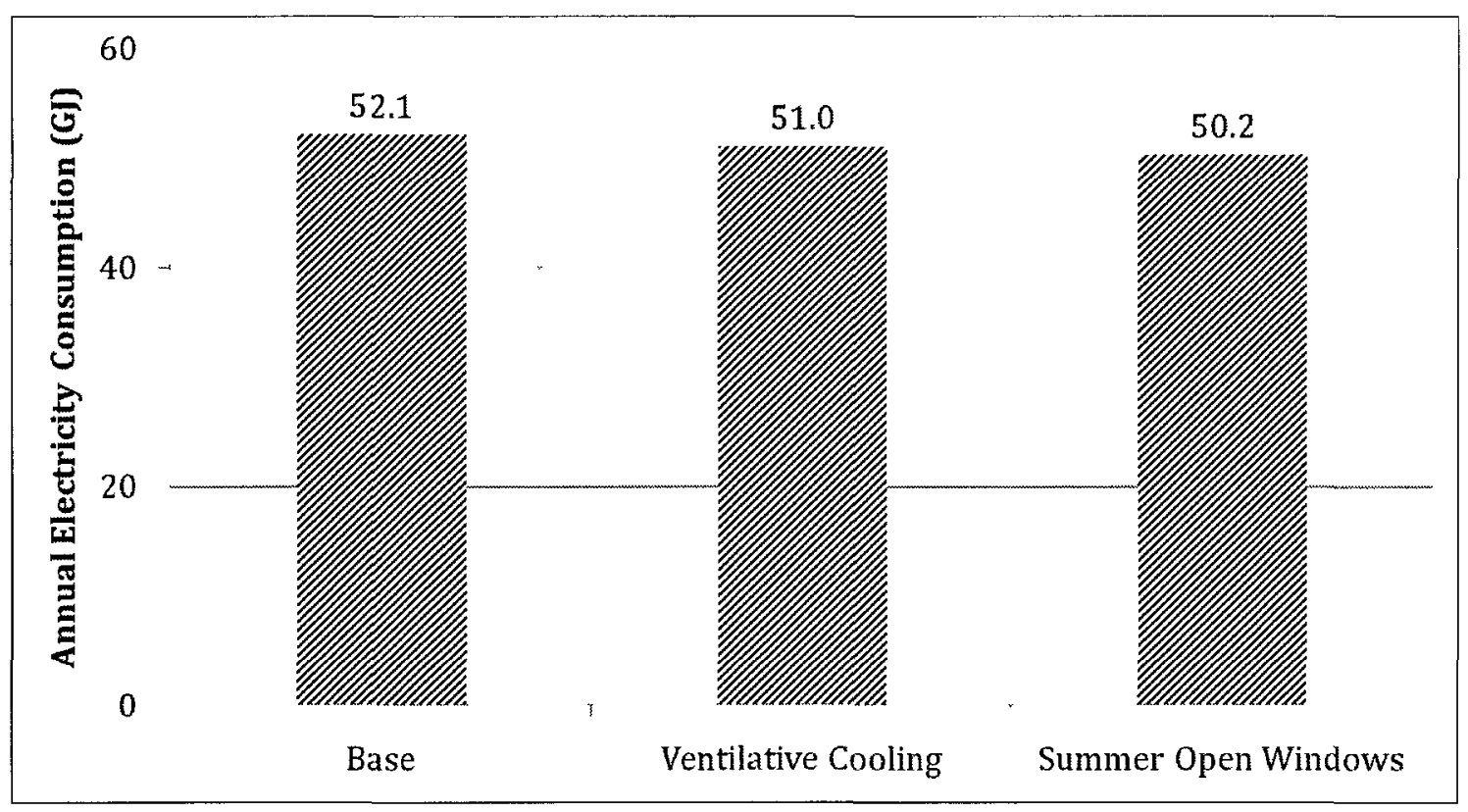

Figure B.37: Annual electricity consumption in GJ with use of outdoor air 


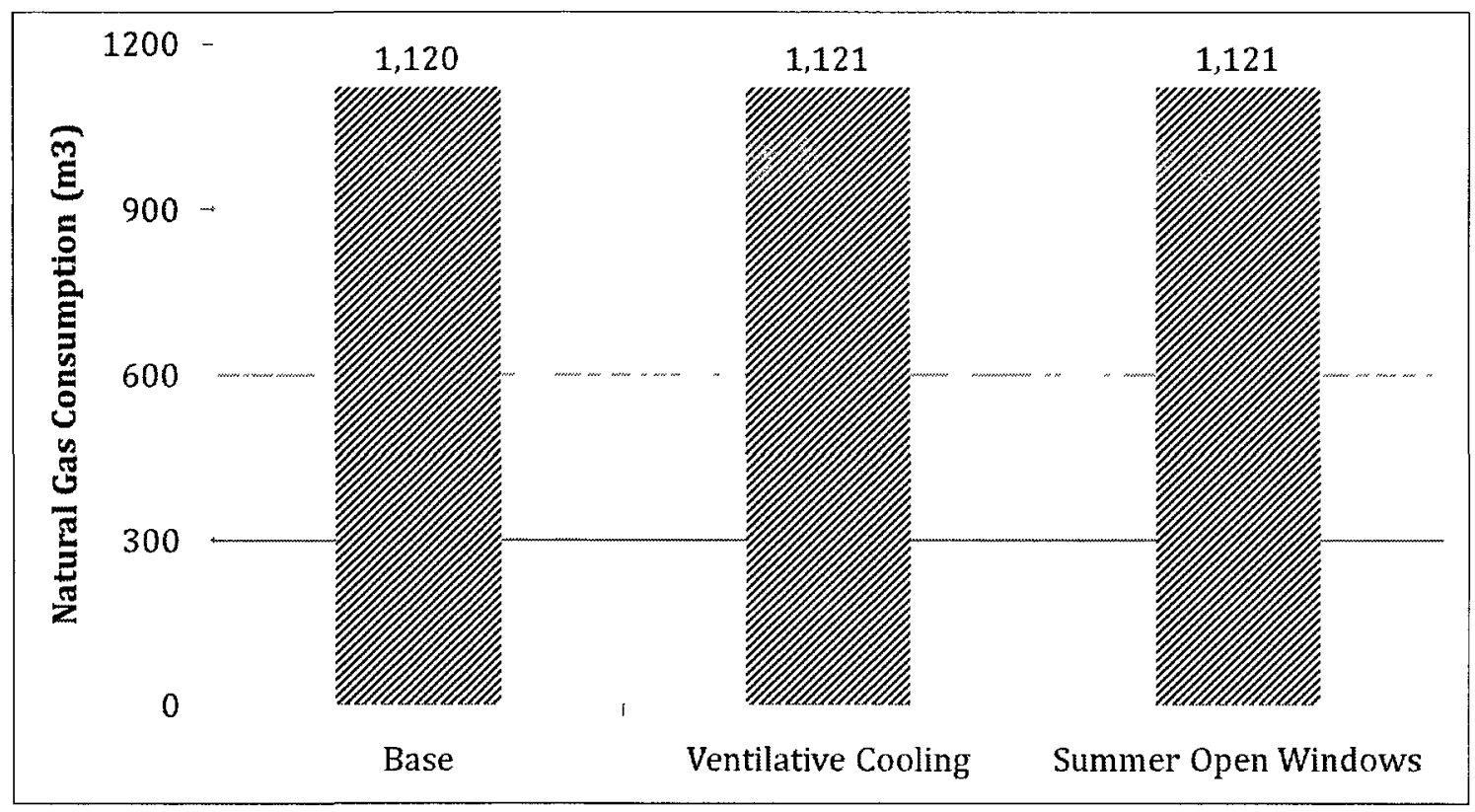

Figure B.38: Annual natural gas consumption with use of outdoor air

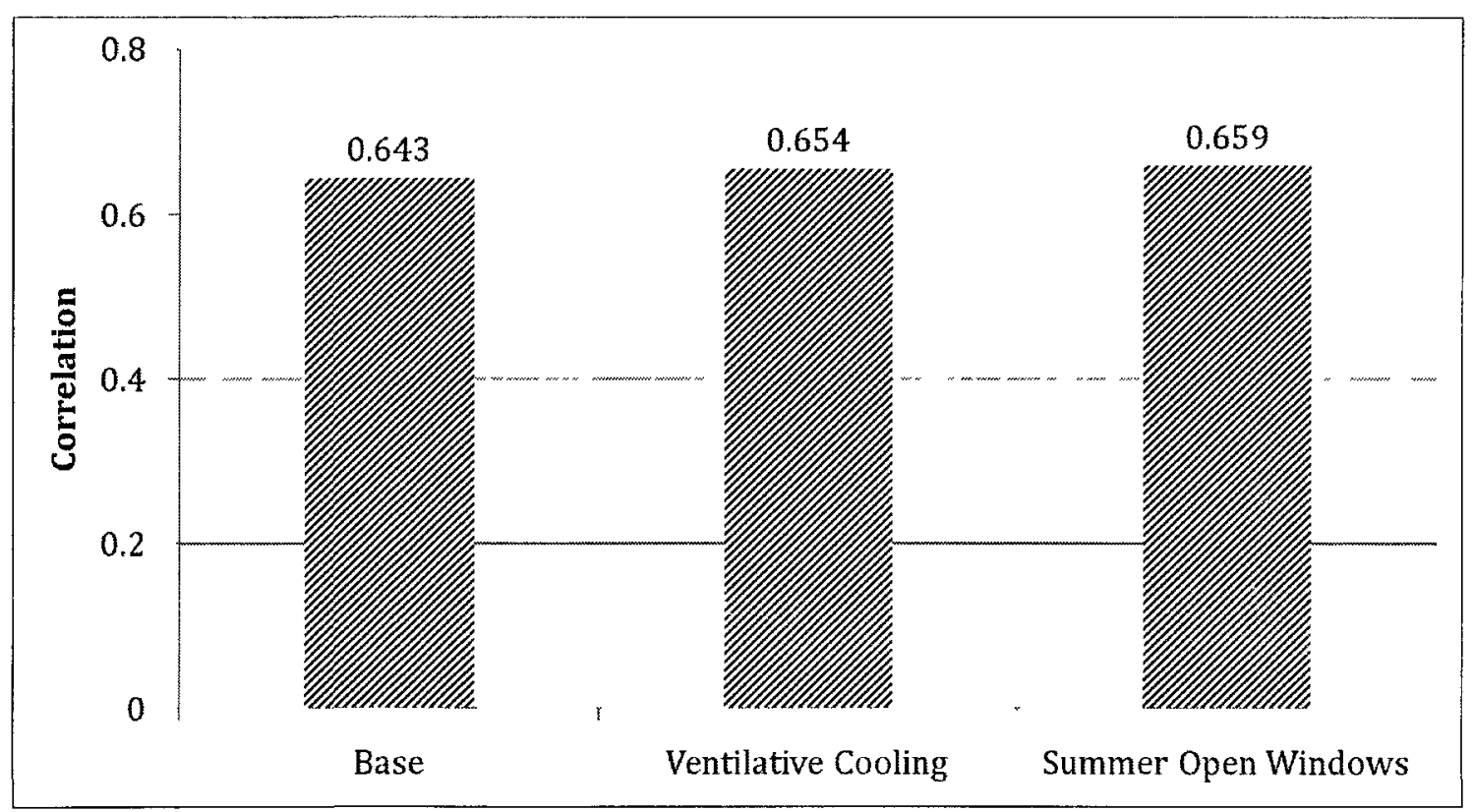

Figure B.39: Annual correlation between the residential consumption and provincial distribution with use of outdoor air 


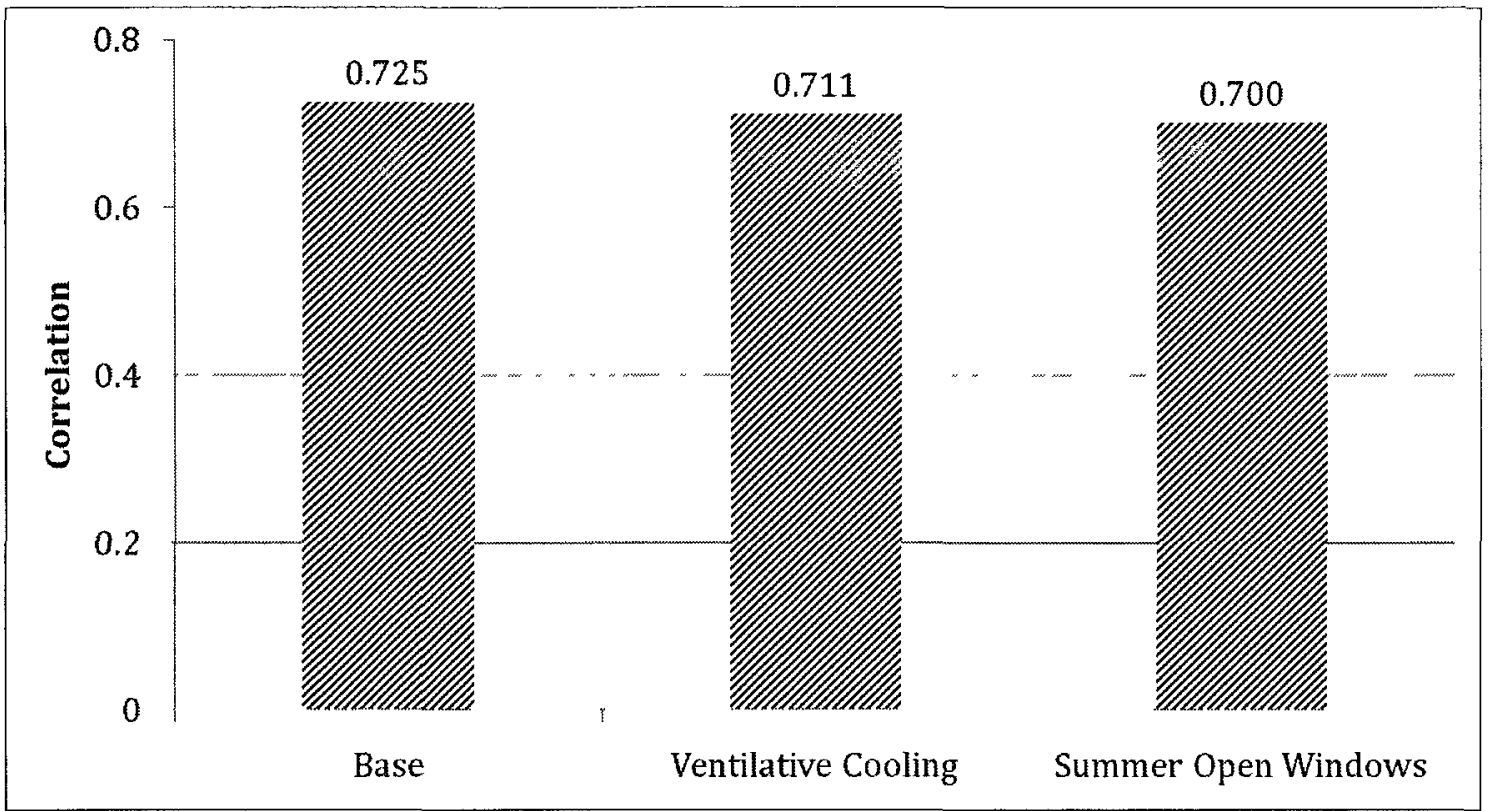

Figure B.40: Summer weekday correlation between the residential consumption and provincial distribution with use of outdoor air 


\section{B.11 Testing the effect of different occupancy schedule}

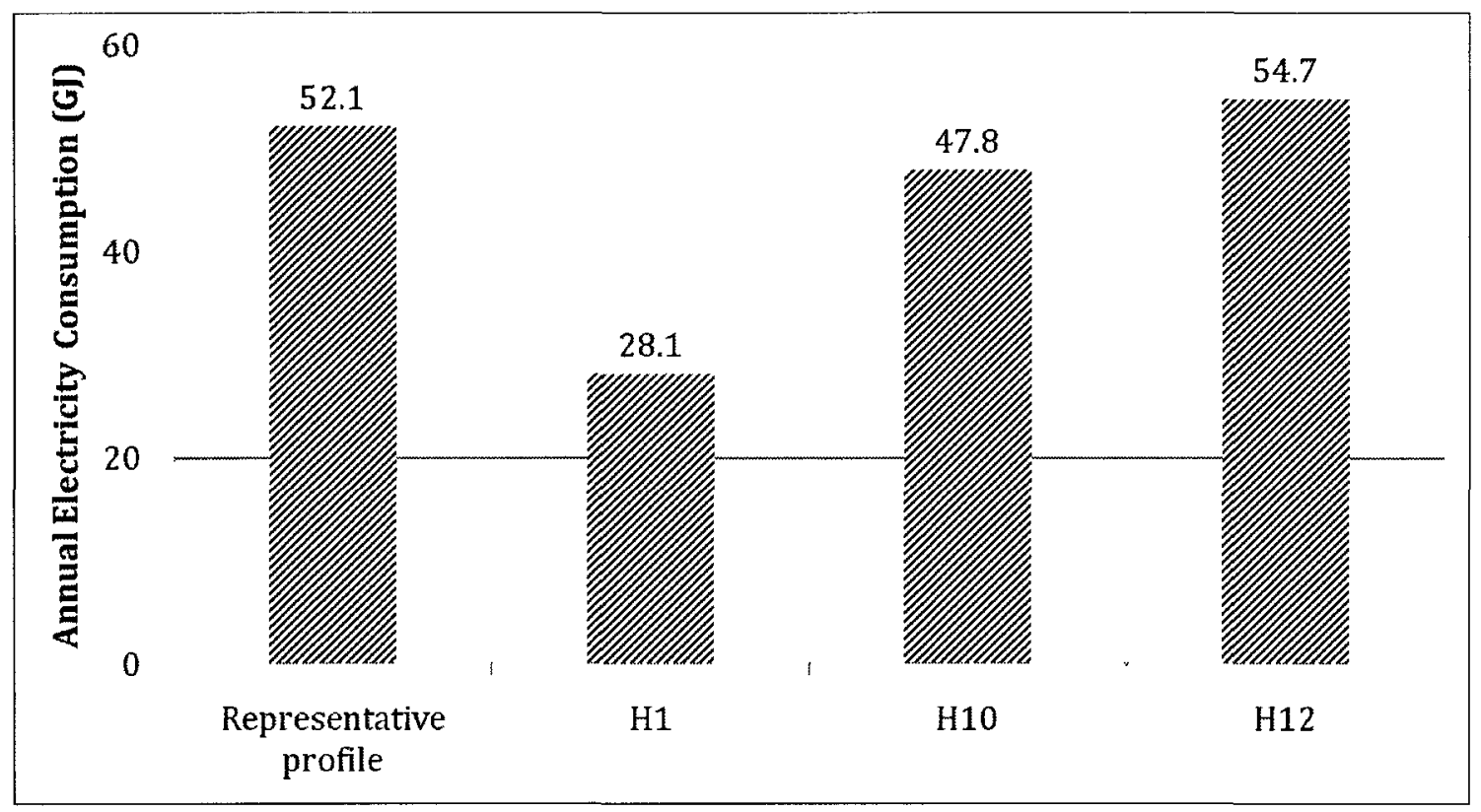

Figure B.41: Annual electricity consumption in GJ with real occupancy schedules 


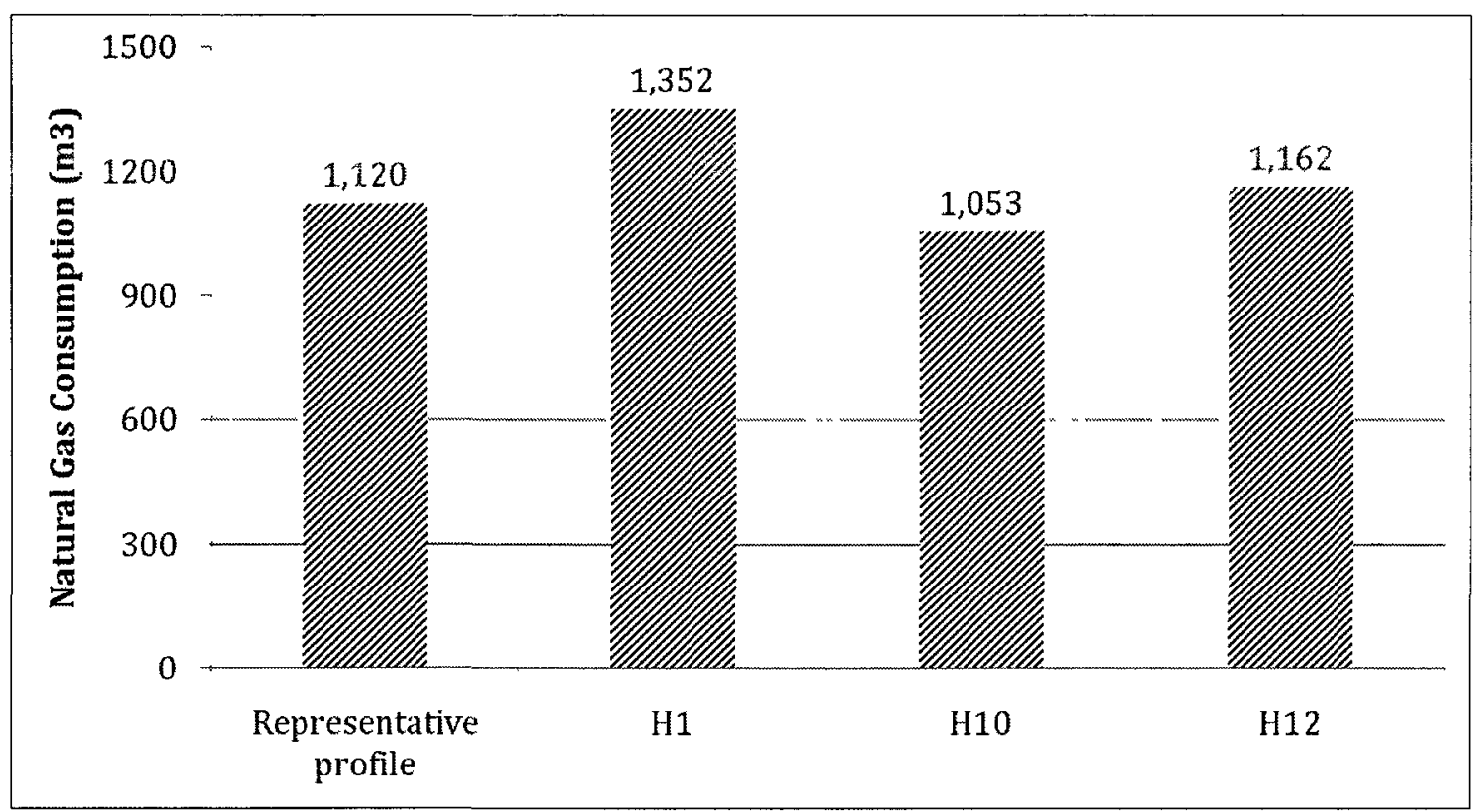

Figure B.42: Annual natural gas consumption with real occupancy schedules

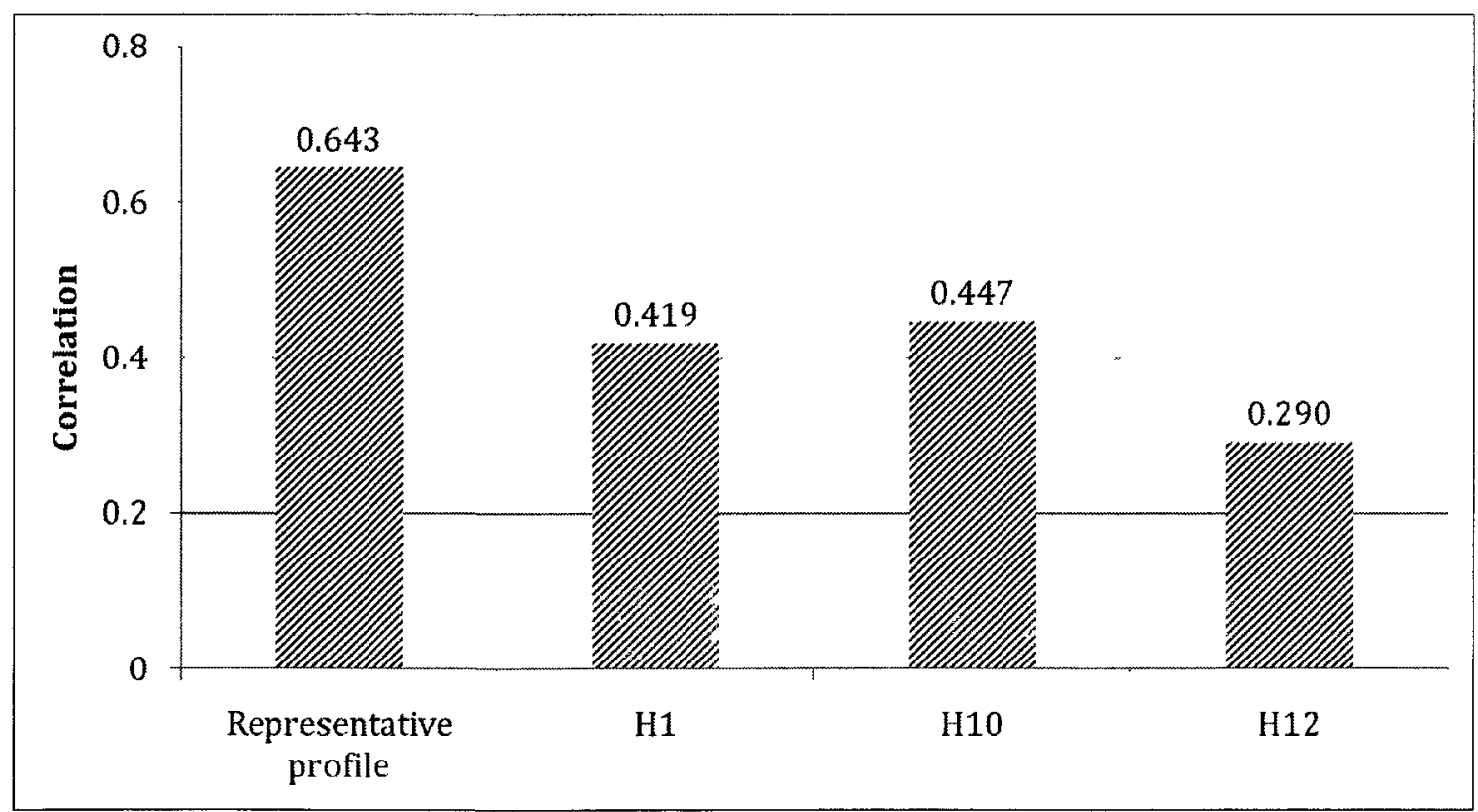

Figure B.43: Annual correlation between the residential consumption and provincial distribution with real occupancy schedules 


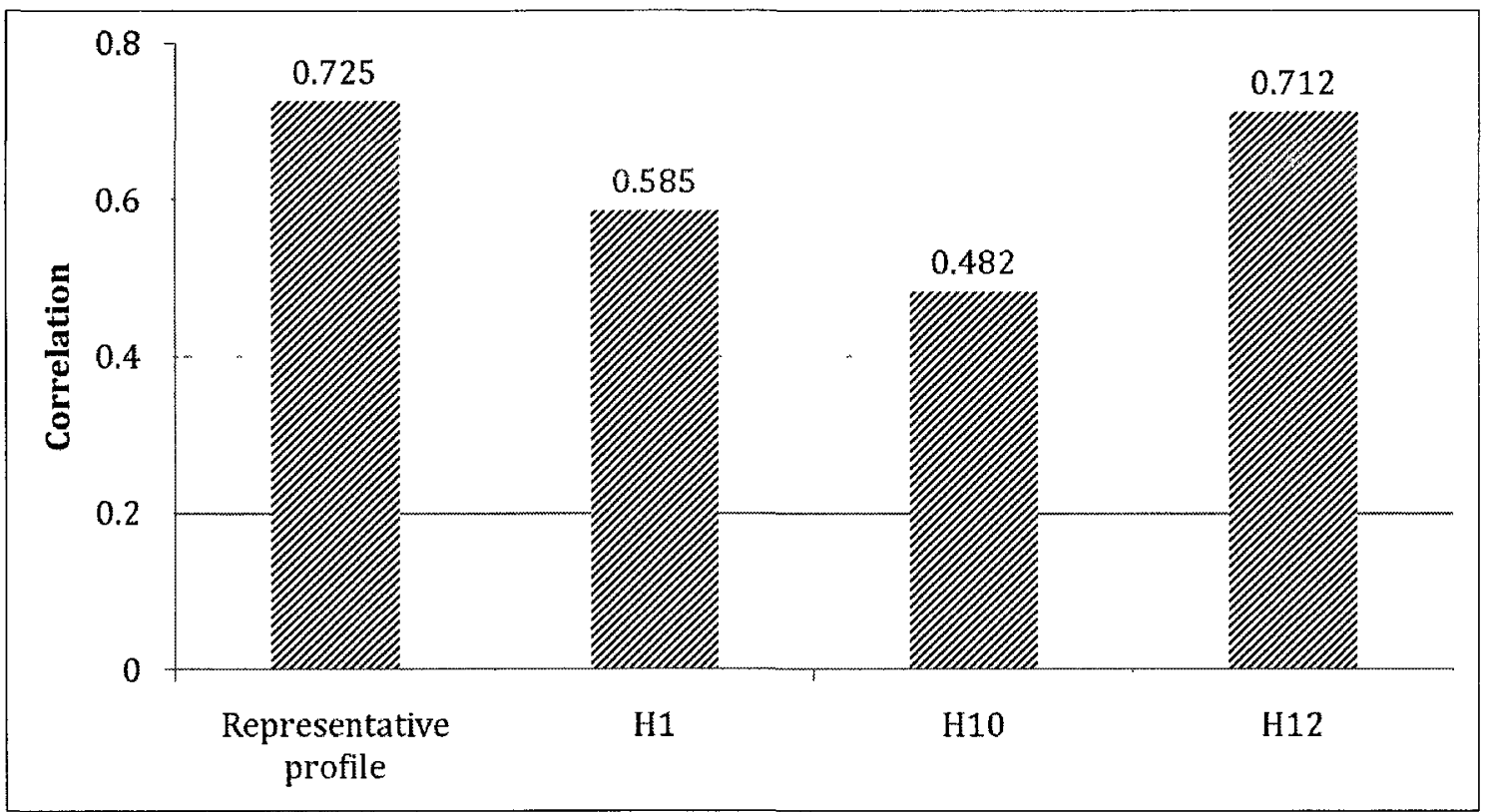

Figure B.44: Summer weekday correlation between the residential consumption and provincial distribution with real occupancy schedules 


\section{B.12 Effective Variant Combination Results Met- rics Compared to the Base Case}

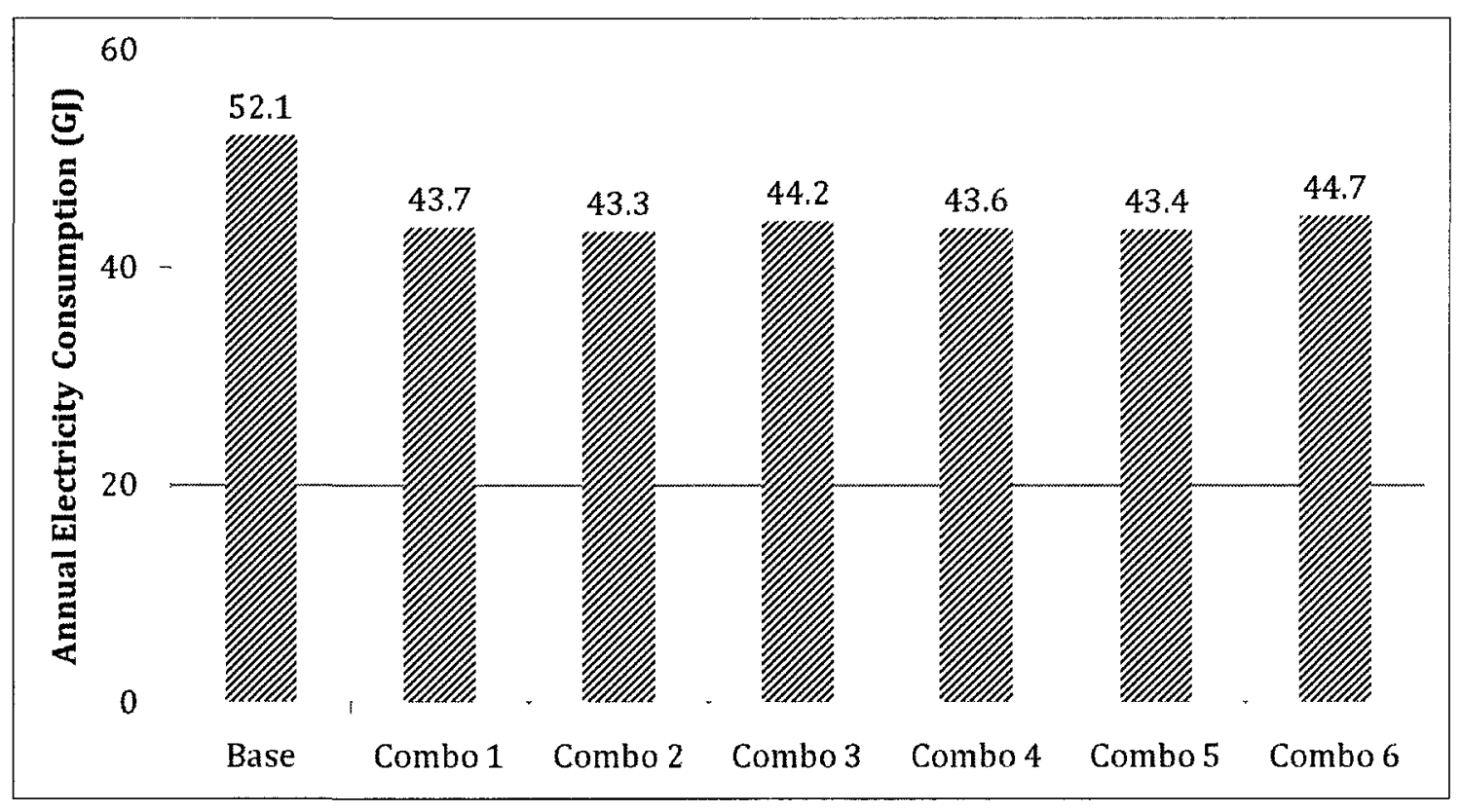

Figure B.45: Annual electricity consumption in GJ with a combination of variants 


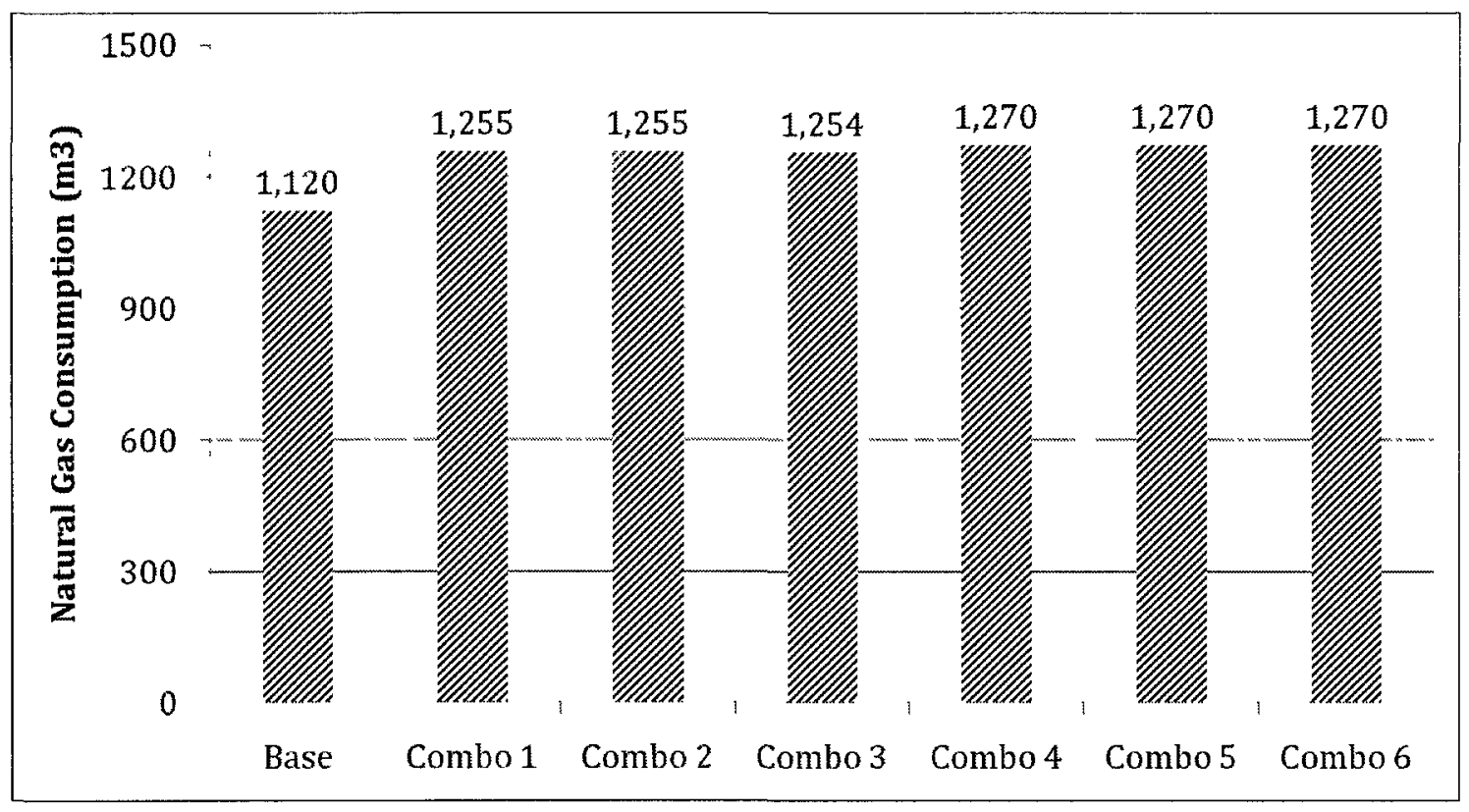

Figure B.46: Annual natural gas consumption with a combination of variants

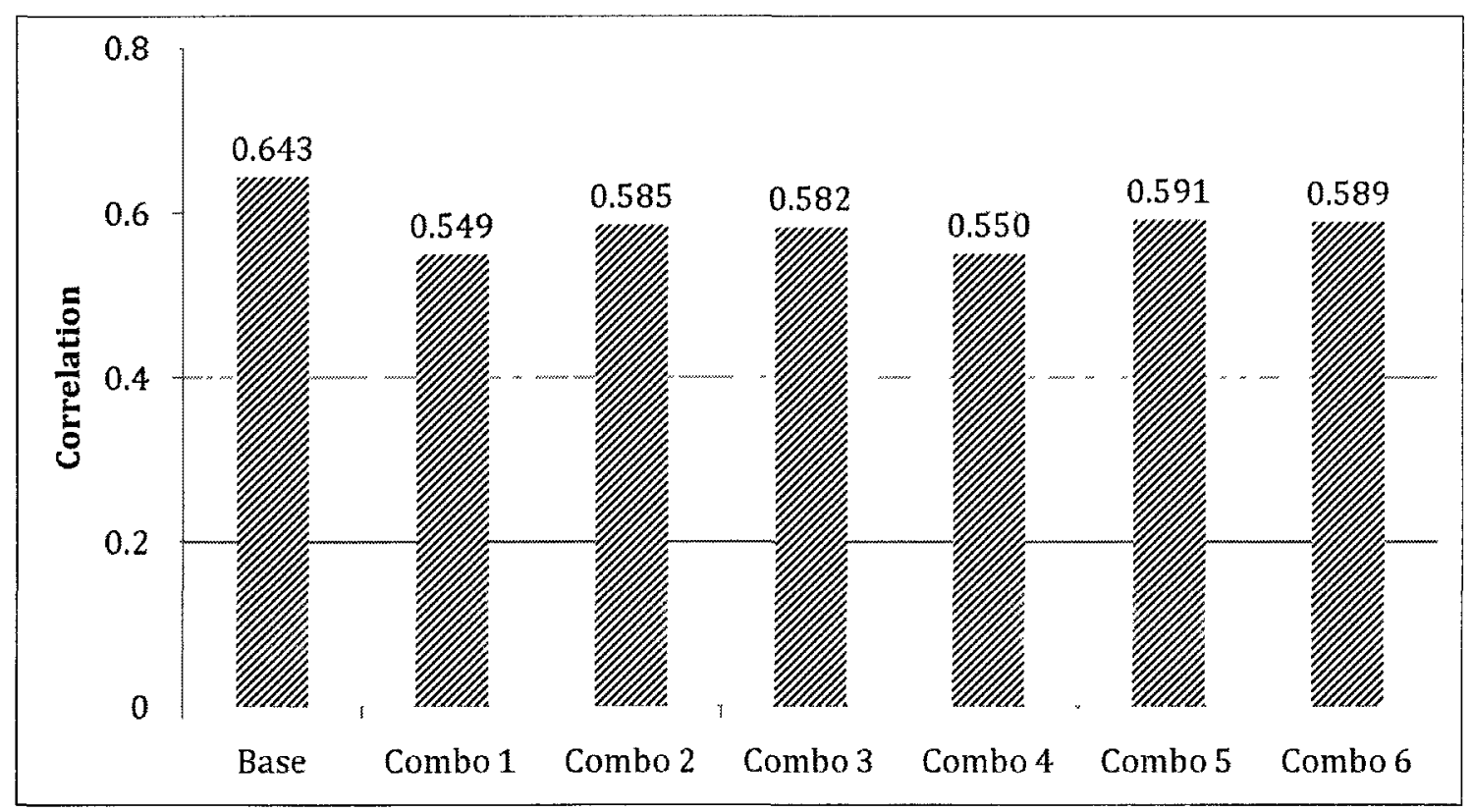

Figure B.47: Annual correlation between the residential consumption and provincial distribution with a combination of variants 


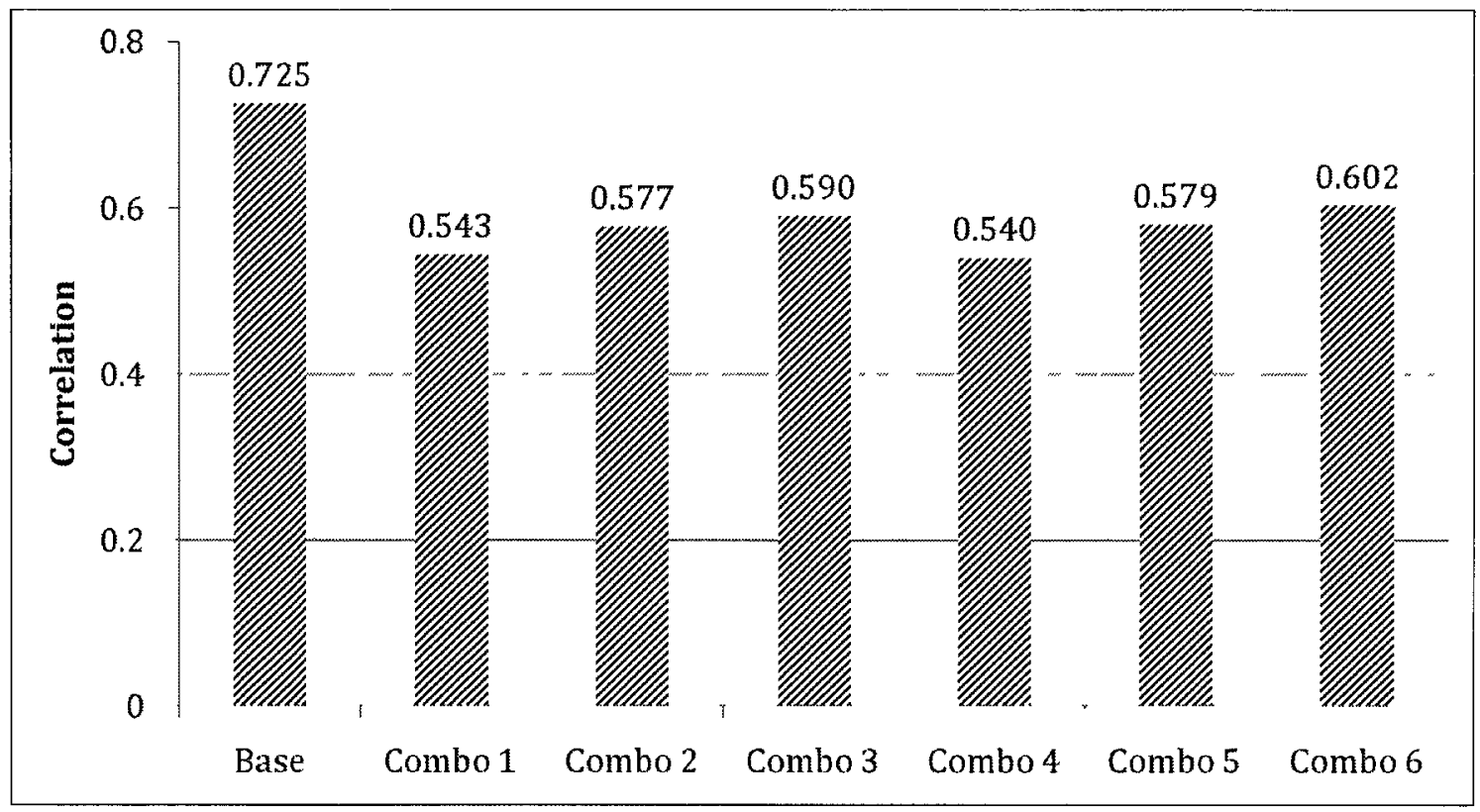

Figure B.48: Summer weekday correlation between the residential consumption and provincial distribution with a combination of variants

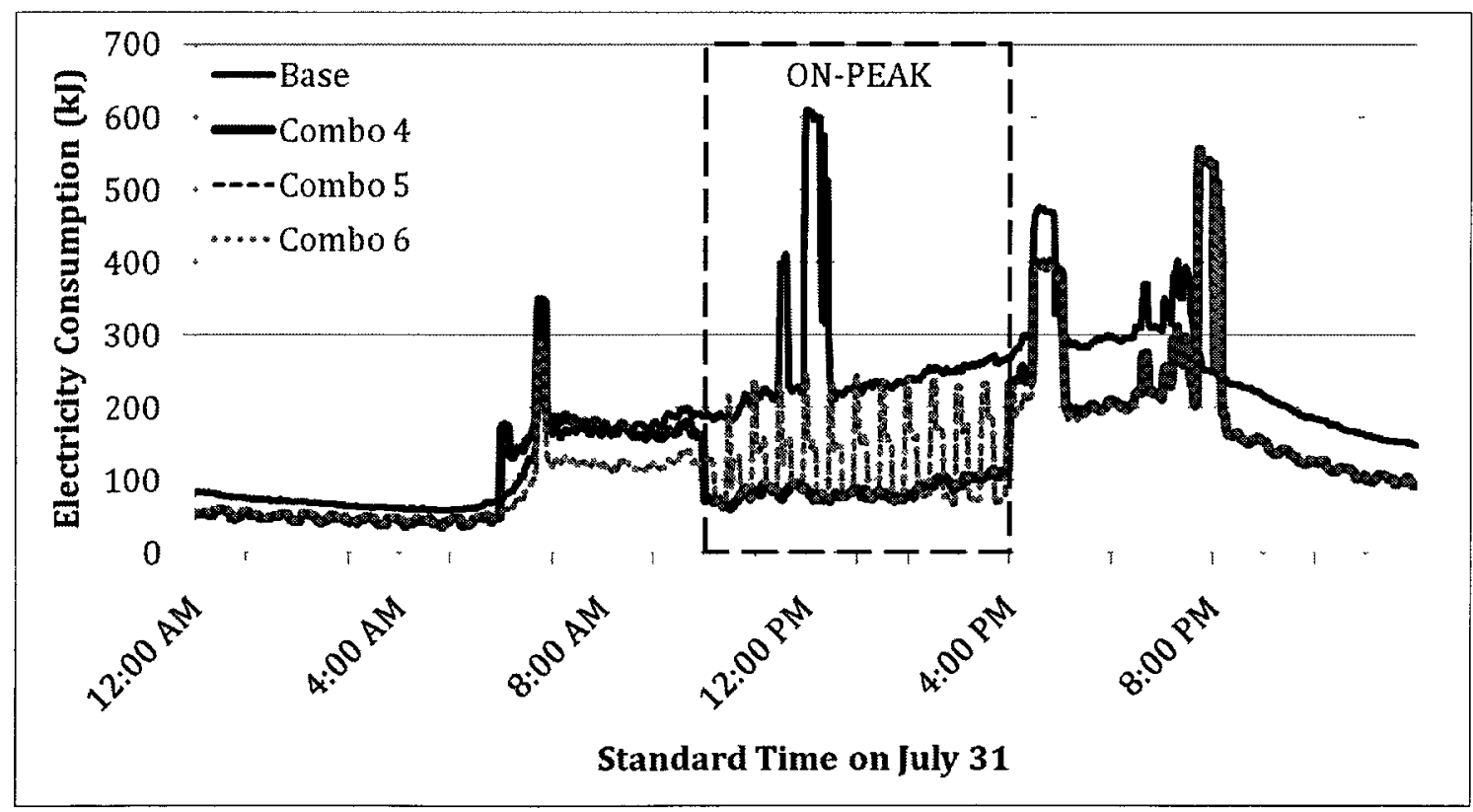

Figure B.49: Electricity consumption on July 31 for Combinations 4, 5 and, 6 compared to the base in kilojoules over each minute 


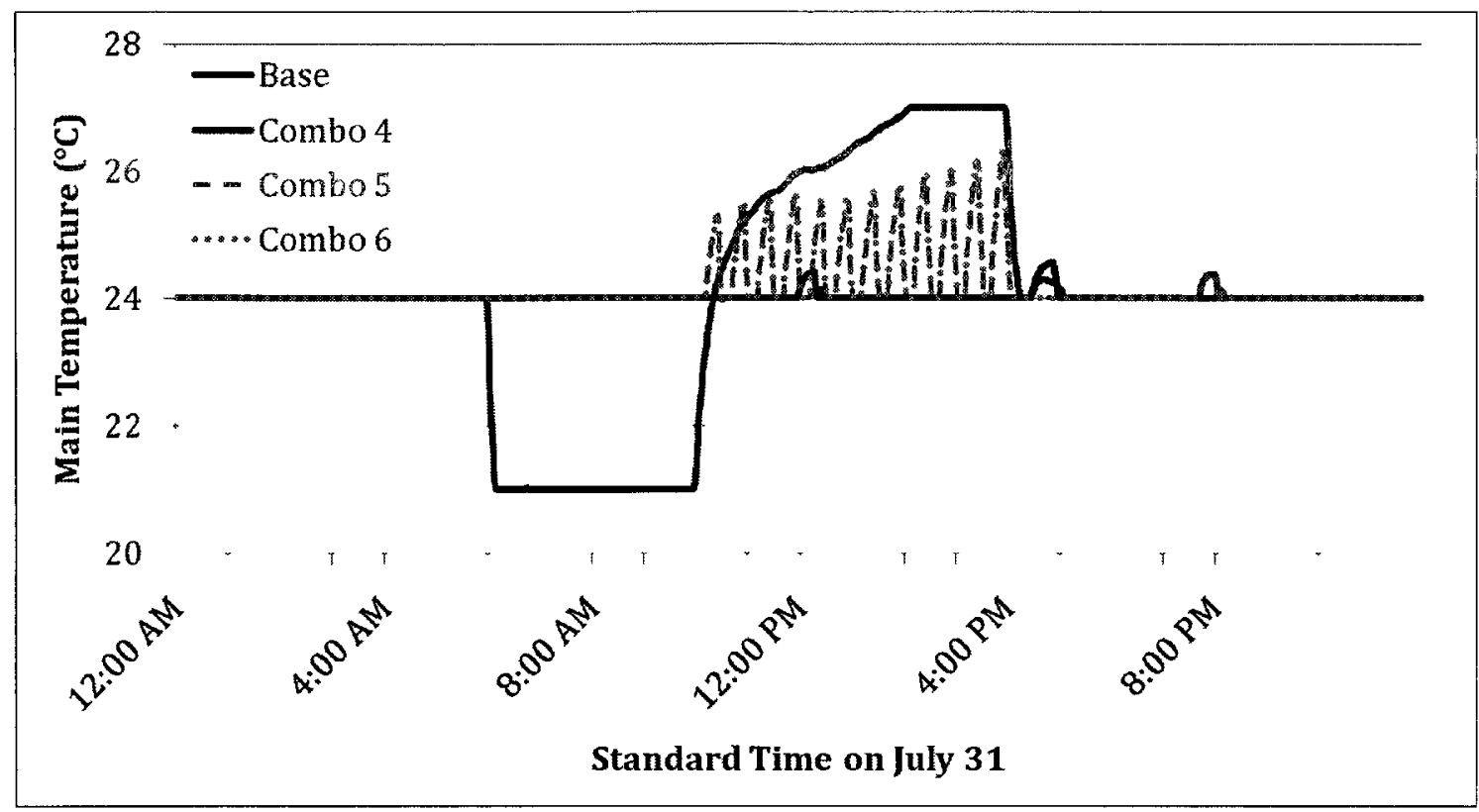

Figure B.50: The main zone temperature on July 31 for Combinations 4, 5 and, 6 compared to the base

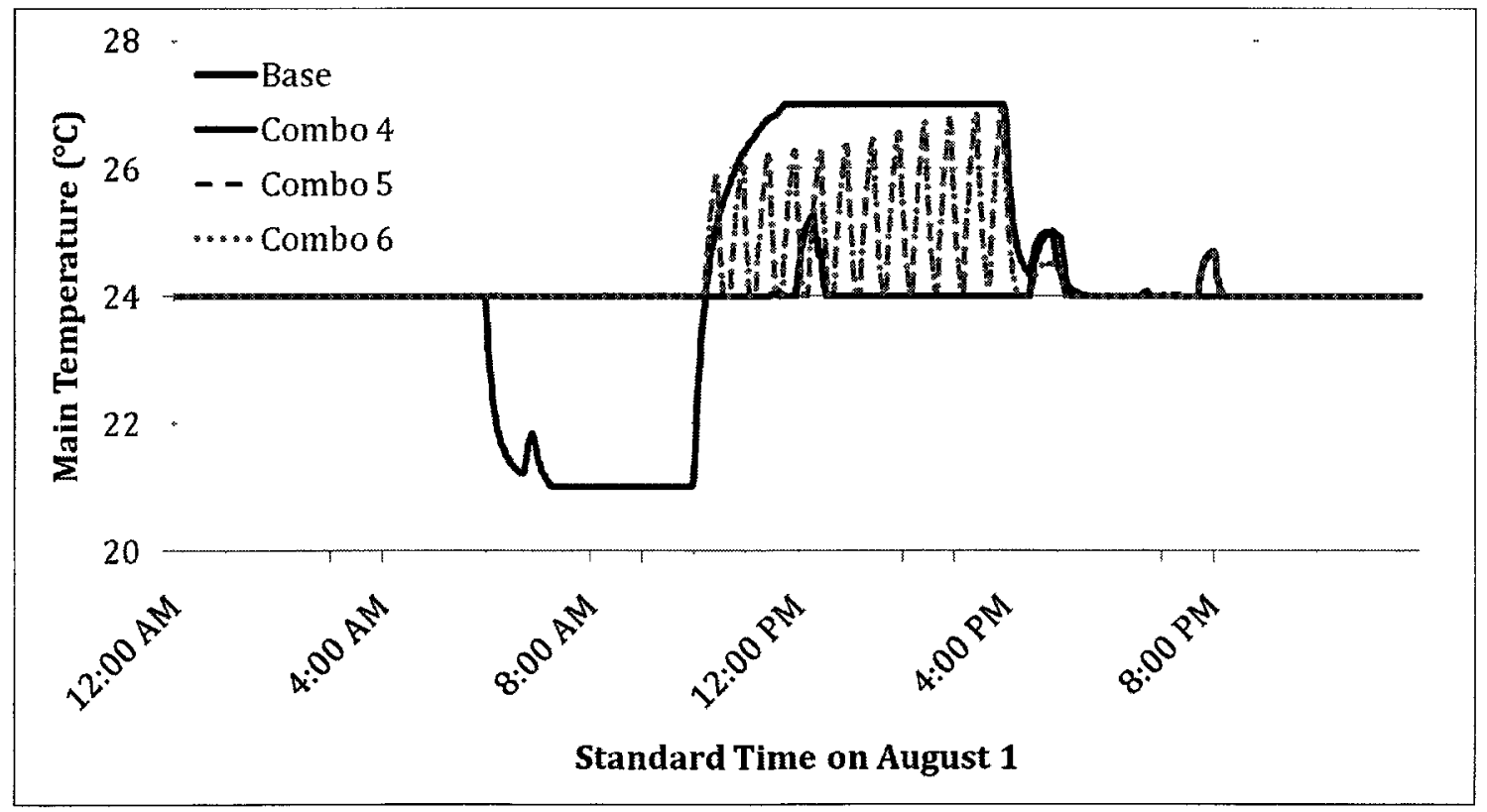

Figure B.51: The main zone temperature on August 1 for Combinations 4, 5 and, 6 compared to the base 


\section{Appendix C}

\section{ESP-r Input Files}

\section{C.1 Configuration File - *.cfg}

* CONFIGURATION3.0

\# ESRU system configuration defined by file

\# pomelo.cfg

*date Fri Jun 24 10:19:25 2011 \# latest file modification

*root pomelo

*zonpth ../zones \# path to zones

*netpth ../nets \# path to networks

*ctlpth ../ctl \# path to controls

*aimpth ./ \# path to aim2 files

* radpth ../rad \# path to radiance files

*imgpth ../images \# path to project images

*tmppth ../tmp \# path to project scratch folder

*docpth ../doc \# path to project documents

*dbspth ../dbs \# path to local databases

*hvacpth ./ \# path to hvac files

*bsmpth ./ \# path to BASESIMP files

*indx 3 \# Building \& Plant

43.670 -4.630 \# Latitude \& Longitude (diff from time meridian)

10.200 \# Site exposure \& ground reflectivity

* DATABASES

*mat ../dbs/pomelo.materialdb

*mlc ../dbs/pomelo.constrdb 
*opt ../dbs/pomelo.opticdb

*stdprs pressc.db1

*evn /usr/esru/esp-r/databases/pronles.db2.a

${ }^{*} \mathrm{clm}$../clm/torontopearsonint12006.clm

*mscldb /usr/esru/esp-r/databases/mscomp.db1

*stdpdb plantc.db1

*stdsbem SBEM.db1

*hvac ../hvac/pomelo.hvac

*aim ../aim-2/pomelo.aim

$*_{\mathrm{mvnt}} . . / \mathrm{mvnt} /$ pomelo.vnt

*slr half hr 1 \# solar timing half-hour centred

$*^{*}$ ctl ../cfg/std.ctl

*calename standard weekday Sat \& Sun

*calentag weekdays, weekdays (all year), 260

*calentag saturday, Saturdays (all year), 52

*calentag sunday, Sundays (all year), 53

*list 3

$3,1,1,1,1,1,2,3,1,1,1,1,1,2,3,1,1,1,1,1,2,3,1,1,1,1,1,2,3,1,1,1,1,1,2,3,1,1,1,1,1,2,3,1,1,1,1$, $1,2,3,1,1,1,1,1,2,3,1,1,1,1,1,2,3,1,1,1,1,1,2,3,1,1,1,1,1,2,3,1,1,1,1,1,2,3,1,1,1,1,1,2,3,1,1$, $1,1,1,2,3,1,1,1,1,1,2,3,1,1,1,1,1,2,3,1,1,1,1,1,2,3,1,1,1,1,1,2,3,1,1,1,1,1,2,3,1,1,1,1,1,2,3$, $1,1,1,1,1,2,3,1,1,1,1,1,2,3,1,1,1,1,1,2,3,1,1,1,1,1,2,3,1,1,1,1,1,2,3,1,1,1,1,1,2,3,1,1,1,1,1$, $2,3,1,1,1,1,1,2,3,1,1,1,1,1,2,3,1,1,1,1,1,2,3,1,1,1,1,1,2,3,1,1,1,1,1,2,3,1,1,1,1,1,2,3,1,1,1$, $1,1,2,3,1,1,1,1,1,2,3,1,1,1,1,1,2,3,1,1,1,1,1,2,3,1,1,1,1,1,2,3,1,1,1,1,1,2,3,1,1,1,1,1,2,3,1$, $1,1,1,1,2,3,1,1,1,1,1,2,3,1,1,1,1,1,2,3,1,1,1,1,1,2,3,1,1,1,1,1,2,3,1,1,1,1,1,2,3,1,1,1,1,1,2$, $3,1,1,1,1,1,2,3,1,1,1,1,1,2,3,1,1,1,1,1,2,3,1,1,1,1,1,2,3,1,1,1,1,1,2,3$

*end list

*year 2006 \# assessment year

*pnt ../nets/pomelo.enf

\# sim setup: no. sets startup zone ts plant ts save lv @ each ts

*sps 5360140

113112 year \# period \& name

*sblr pomelo.res

$*_{\text {sflr }}$

*splr pln res 
*selr elec

*end set

151151 Jan15 \# period \& name

*sblr pomeloSum.res

$*_{\text {sflr }}$

* splr pln res

*selr elec

*end set

317317 July31 \# period \& name

*sblr pomeloAug.res

$*_{\text {sflr }}$

*splr

*selr elec

*end set

166166 June16 \# period \& name

*sblr pomeloJune16.res

$*_{\text {sflr }}$

${ }^{*}$ splr

*selr elec

*end set

1818 Aug1 \# period \& name

*sblr pomeloAprday.res

$*_{\text {sflr }}$

*splr

*selr elec

*end set

*end sps

\# Name and address of building

*B-NAME not yet defined

*B-ADDRESS not yet defined

*B-CITY not yet defined

*B-POSTCODE not yet defined

\# Contact information for building owner

*O-NAME not yet defined 
*O-ADDRESS not yet defined

*O-CITY not yet defined

*O-POSTCODE not yet defined

*O-TELEPHONE not yet defined

\# Contact information for simulation team

*C-NAME not yet defined

${ }^{*}$ C-ADDRESS not yet defined

${ }^{*} \mathrm{C}$-CITY not yet defined

${ }^{*}$ C-POSTCODE not yet defined

${ }^{*}$ C-TELEPHONE not yet defined

* PROJ LOG

pomelo.log

* Building

model of an pomelo single family house

3 \# no of zones

*zon 1 \# reference for basement

*opr ../zones/basement.opr \# schedules

*geo ../zones/basement.geo \# geometry

*con ../zones/basement.con \# construction

${ }^{*}$ cfc ../zones/basement.cfc \# complex fenestration constr

*bsm ../zones/basement.bsm \# BASESIMP input

$*_{\text {zend }}$

*zon 2 \# reference for mainflr

*opr ../zones/mainflr.opr \# schedules

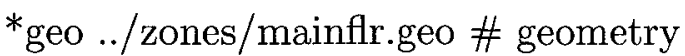

*con ../zones/mainflr.con \# construction

*cfc ../zones/mainflr.cfc \# complex fenestration constr

*zend

*zon 3 \# reference for atticspace

*opr ../zones/atticspace.opr \# schedules

*geo ../zones/atticspace.geo \# geometry

*con ../zones/atticspace.con \# construction

*zend

${ }^{*}$ cnn pomelo.cnn \# connections 
1 \# fluid flow network:

../nets/pomelo.afn \# leakage description

0 ,main, 0

* Plant

../nets/pomelo.pln \# plant network description

\section{C.2 Controls File - *.ctl}

no overall project control notes (yet)

* Building

no zone control description supplied

4 \# No. of functions

* Control function 1

\# senses the temperature of the current zone.

0004 \# sensor data

\# actuates the air point in basement.

100 \# actuator data

1 \# No. day types

1365 \# valid Sun-01-Jan - Sun-31-Dec

1 \# No. of periods in day: weekdays

020.000 \# ctl type, law (free floating), start @

0 . \# No. of data items

* Control function 2

\# senses the temperature of the current zone.

0004 \# sensor data

\# actuates the air point in mainflr.

200 \# actuator data

3 \# No. day types

1135 \# valid Sun-01-Jan - Mon-15-May

1 \# No. of periods in day: weekdays

010.000 \# ctl type, law (basic control), start @

7. \# No. of data items 
35000.0000 .00010500 .0000 .00021 .00080 .0000 .000

136273 \# valid Tue-16-May - Sat-30-Sep

1 \# No. of periods in day: sat urday

010.000 \# ctl type, law (basic control), start @

7. \# No. of data items

35000.0000 .00010500 .0000 .0000 .00024 .0000 .000

274365 \# valid Sun-01-Oct - Sun-31-Dec

1 \# No. of periods in day: sunday

010.000 \# ctl type, law (basic control), start @

7. \# No. of data items

35000.0000 .00010500 .0000 .00021 .00080 .0000 .000

* Control function 3

\# senses the temperature of the current zone.

0000 \# sensor data

\# actuates the air point in atticspace.

300 \# actuator data

1 \# No. day types

1365 \# valid Sun-01-Jan - Sun-31-Dec

1 \# No. of periods in day: weekdays

020.000 \# ctl type, law (free floating), start @

0 . \# No. of data items

* Control function 4

\# senses dry bulb temperature in mainflr.

2000 \# sensor data

\# actuates the air point in mainflr.

200 \# actuator data

3 \# No. day types

1135 \# valid Sun-01-Jan - Sun-31-Dec

1 \# No. of periods in day: weekdays

0250.000 \# ctl type, law (undefined control), start @

4. \# No. of data items

25.00023 .0001 .0003 .000

136273 \# valid Tue-16-May - Sat-30-Sep

1 \# No. of periods in day: weekdays 
0250.000 \# ctl type, law (undefined control), start @

4. \# No. of data items

50.00045 .0001 .0003 .000

274365 \# valid Sun-01-Oct - Sun-31-Dec

1 \# No. of periods in day: weekdays

0250.000 \# ctl type, law (undefined control), start @

4. \# No. of data items

25.00023 .0001 .0003 .000

\# Function:Zone links

$1,2,3$

\section{C.3 Air Infiltration File - *.aim}

\#-Leakage description

6 \# blower door input.

\# \# ACH @50Pa.

\# \# ELA given at 10Pa.

\# \# ELA specified 1.

\# \# ELA cm.

\#

\#-Leakage distribution-

0 \# Default leakage distribution.

\#-Shielding and terrain data

382210.0 \# Open flat terrain at weather station.

\# \# House in city center.

\# \# Light local shielding on walls.

\# \# Light local shielding on flue.

\# \# Height of anemometer at weather station.

\#-Height of building eaves (m)

\subsection{1}

\#-Flue diameters $(\mathrm{mm})$

0 0. 0.0 . 0 . \# furnace, fire\#1, fire\#2, dhw\#1, dhw\#2. 
\#-Zone indices-

2 \# Zone whose temperature used to calculate density of indoor air.

212 \# Total number of zones receiving infil; indices of zones receive infil.

103 \# Index of basement zone (=0 if no basement), crawlspace, and attic.

$\#$

\section{C.4 HVAC Input File - *.hvac}

2 114.0 \# Number of HVAC systems, site altitude

\# System \#1 - Furnace

111 \# SysType; Pri; Zones;

$8221350000.951-1755001$ \#

\# System \#2-AC

711 \# System/Priority/Num zones served

2121 \# HP Fn/HP Type/Num 1st zone/Frac of cap

10500 2.64 \#Heat Pump Cooling Capacity/Cooling COP

-1 -1 11 1 - 1 0 - 11 - 1 \# HP Flow Rate \& Rating/Circ Fan Mode \& Pos \& Pwr/Outdoor fan pwr/Circ Fan Pwr (Auto)/Circ Fan Pos at Rating/Fan Pwr at Rating

0.761 \# Sensible Heat Ratio/Cooling Type

1 \# Number of Outdoor Air Day Types

18760 \# OA Day Types Number of Periods/Finish Hour

240.0 \# Finish Hour Period 1/OA Flow Rate for Period 1

12 \# System Number for Heating Control Function Cooling

\section{C.5 HRV Input File - *.vnt}

\#

\# Sample ventilation system input file

\#

2 \# Central Ventilation System (CVS) type (1=None, $2=$ HRV, $3=$ Fans with no heat 
recovery)

\# HRV test data (temperature C, efficiency, fan + preheater power watts)

0.0064 .00125 .00 \# high

-25.0062 .00125 .00 \# low

\# CVS supply air flow rate $(\mathrm{L} / \mathrm{s})$

80.0080 .00

0.00 \# HRV efficiency in cooling mode (used by A/C model, included here for completeness)

0.00 \# Preheater capacity (watts)

\# CVS temperature control data (flag,low temperature trip, high temperature trip)

70.000 .00 \# flag $3=$ Temperature controlled, or 1,2,4,5,6,7 = N/A

\# HRV duct data

\# Vent. Duct Location: \# of zone in which duct is located

\# Duct Type: \# 1=Flexible, 2=Sheet metal with liner, 3=Ext. insulated Sheet metal

\# Sealing Characteristic: \# 1=Very Tight, 2=Sealed, 3=Unsealed

\#

\# Location,Type,Sealing,Length(m),Diameter(mm),Insul.RSI

2125.0152 .40 .7 \# Supply duct

2125.0152 .40 .7 \# Exhaust duct

\# End of Central ventilation system inputs

\#

$\#$

\#- Other fans (point exhaust and supply fans)

1 \# Type (1=None, $2=$ Other)

\# Supply, Exhaust flow(L/s), Total fan power(watts)

0.00 .00 .0

\section{C.6 AFN Input File - *.afn}

1615151.000 (nodes, components, connections, wind reduction) Node Fld. Type Height Temperature Data1 Data2 
front1 130.00000 .00009 .000045 .000

front2 130.00000 .00009 .000045 .000

front3 130.00000 .00009 .000045 .000

right1 130.00000 .00009 .0000135 .00

right2 130.00000 .00009 .0000135 .00

back1 130.00000 .00009 .0000225 .00

back2 130.00000 .00009 .0000225 .00

back3 130.00000 .00009 .0000180 .00

back4 130.00000 .00009 .0000180 .00

back5 130.00000 .00009 .0000225 .00

back6 130.00000 .00009 .0000225 .00

back7 130.00000 .00009 .0000270 .00

back8 130.00000 .00009 .0000270 .00

left1 130.00000 .00009 .0000315 .00

left2 130.00000 .00009 .0000315 .00

main 100.000020 .0000 .0000765 .50

Component Type C+ L+ Description

front1comp 11020 Specific air flow opening $m=$ rho.f(A,dP)

1.000000000 .13500001

front2comp 11020 Specific air flow opening $\mathrm{m}=\operatorname{rho.f}(\mathrm{A}, \mathrm{dP})$

1.000000000 .21200000

front3comp 11020 Specific air flow opening $\mathrm{m}=\operatorname{rho.f}(\mathrm{A}, \mathrm{dP})$

$1.000000007 .05000013 \mathrm{E}-02$

right1comp 11020 Specific air flow opening $\mathrm{m}=$ rho.f(A,dP)

1.000000000 .14100000

right2comp 11020 Specific air flow opening $\mathrm{m}=\operatorname{rho.f}(\mathrm{A}, \mathrm{dP})$

1.000000000 .36600000

back1comp 11020 Specific air flow opening $\mathrm{m}=\operatorname{rho.f}(\mathrm{A}, \mathrm{dP})$

$1.000000004 .36999984 \mathrm{E}-02$

back2comp 11020 Specific air flow opening $\mathrm{m}=$ rho.f(A,dP)

1.000000000 .47000000

back3comp 11020 Specific air flow opening $m=$ rho.f(A,dP)

$1.000000009 .60000008 \mathrm{E}-02$

back4comp 11020 Specific air flow opening $\mathrm{m}=\operatorname{rho.f}(\mathrm{A}, \mathrm{dP})$ 


\section{$1.000000009 .60000008 \mathrm{E}-02$}

back5comp 11020 Specific air flow opening $\mathrm{m}=\operatorname{rho.f}(\mathrm{A}, \mathrm{dP})$

1.000000000 .22200000

back6comp 11020 Specific air flow opening $\mathrm{m}=$ rho.f(A,dP)

1.000000000 .19400001

back7comp 11020 Specific air flow opening $\mathrm{m}=$ rho.f(A,dP)

$1.000000009 .60000008 \mathrm{E}-02$

back8comp 11020 Specific air flow opening $m=$ rho.f(A,dP)

$1.000000009 .60000008 \mathrm{E}-02$

left1comp 11020 Specific air flow opening $m=\operatorname{rho.f}(\mathrm{A}, \mathrm{dP})$

1.000000000 .13300000

left2comp 11020 Specific air flow opening $m=$ rho.f(A,dP)

1.000000000 .17200001

+ Node dHght -Node dHght via Component

main 0.000 front 10.000 front 1 comp

main 0.000 front 20.000 front 2 comp

main 0.000 front 30.000 front 3 comp

main 0.000 right1 0.000 right1comp

main 0.000 right 20.000 right 2 comp

main 0.000 back 10.000 back1comp

main 0.000 back2 0.000 back2comp

main 0.000 back 30.000 back3comp

main 0.000 back 40.000 back 4 comp

main 0.000 back 50.000 back5comp

main 0.000 back 6.000 back6comp

main 0.000 back7 0.000 back7comp

main 0.000 back 80.000 back 8 comp

main 0.000 left 10.000 left 1 comp

main 0.000 left2 0.000 left 2 comp 


\section{C.7 Electrical Networks Inputs File - *.enf}

* FileVersion

1.00

* electrical network

\# ESP-r Electrical network file created with configuration file:

urbandale.cfg

\# Network description:

none

* net type

balanced

* base power value (all nodes)

1000.00

* phase angles (each phase)

0.00120 .00240 .00

\# List and details of nodes in the network

$*$ nodes

2

\# No. Node name Phase type Phase Node type Base volt

1 grid 1-phase 1 fixedV 120.000

2 dalebus 1-phase 1 variable 120.000

** end nodes

\# List and details of load and generator connections to nodes

* hybrid components

0

** end hybrid

\# List and details of power only components

* power-only components

1

\# No. i.d. Comp. name Phase type links to nodes

110 elec 1-phase 000

\# description:

generated profile added to esp-r

\# no. of additional data items:

11 
1.0000

../elecloads/60minloads.fcl

** end power-only

\# Listing and Description of components connecting the nodes

* connecting components

1

\# No. i.d. Comp. name Phase type

12 wire 1-phase

\# description:

none

\# No. of additional data items:

6

0.10000E-05 0.10000E-05 0.10000E-05 0.10000E-05 0.10000E-05 15.000

** end connecting components

\# connections between nodes in the network

* connections

1

\# No. Conn. type Phase. Conn. com. Start nodes End nodes

1 1-phase 1001100200

** end connections

** electrical network end

\section{C.8 Complex Fenestration Construction Input File - *.gs1}

\#New 3-Layer System

3 \#i- number of layers

GLZ GLZ VBD \#i- Layer types, layer $1,2 \ldots$

CLEAR6.PGL 4009 a $7.830 \mathrm{e}-001 \quad 7.200 \mathrm{e}-002 \quad 7.200 \mathrm{e}-002 \quad 8.890 \mathrm{e}-001 \quad 8.100 \mathrm{e}-002$

8.100e-002 0.000e+000 8.400e-001 8.400e-001 5.920e-003 1.000e+000 \#i-Layer 1

LOW-E6.LOF 9924 a $6.620 \mathrm{e}-001 \quad 1.130 \mathrm{e}-001 \quad 1.000 \mathrm{e}-001 \quad 8.190 \mathrm{e}-001 \quad 1.080 \mathrm{e}-001$

1.020e-001 0.000e+000 1.570e-001 8.400e-001 5.639e-003 1.000e+000 \#i-Layer 2 
1/2IN LIGHT A 00001 v $0.000 \mathrm{e}+0008.500 \mathrm{e}-0018.500 \mathrm{e}-001 \quad 1.270 \mathrm{e}-0021.058 \mathrm{e}-002$

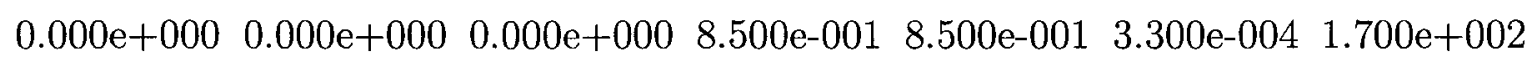
\#i-Layer 3

norm norm \#i- Gap types, gap $1,2 \ldots$

norm/000/100/000/000/000/000/none 1.2700e-002 \#i-name (char 40) and thickness (m) of $\operatorname{gap}(1)$

$039.9480 \# \mathrm{i}$ - molecular mass (g/gmole)

$+2.477 \mathrm{e}-003+5.071 \mathrm{e}-005 \#_{\mathrm{i}}-\mathrm{a}$ and b coefficients - conductivity (W/m.K(.K))

$+3.618 \mathrm{e}-006+6.440 \mathrm{e}-008 \#^{-} \mathrm{a}$ and $\mathrm{b}$ coefficients - viscosity $(\mathrm{kg} / \mathrm{m} . \mathrm{s}(. \mathrm{K})$ or N.s $/ \mathrm{m} 2(. \mathrm{K}))$

$+5.257 \mathrm{e}+002-1.376 \mathrm{e}-002 \#_{\mathrm{i}}-\mathrm{a}$ and $\mathrm{b}$ coefficients - specific heat $(\mathrm{J} / \mathrm{kg} \cdot \mathrm{K}(. \mathrm{K}))$

norm/100/000/000/000/000/000/none 1.2700e-002 \#i- name (char 40) and thickness (m) of $\operatorname{gap}(2)$

$028.9700 \#_{i}-$ molecular mass (g/gmole)

$+2.301 \mathrm{e}-003+7.987 \mathrm{e}-005 \#_{\mathrm{j}}-\mathrm{a}$ and b coefficients - conductivity (W/m.K(.K))

$+3.517 \mathrm{e}-006+4.980 \mathrm{e}-008 \#_{i-} \mathrm{a}$ and $\mathrm{b}$ coefficients - viscosity $(\mathrm{kg} / \mathrm{m} . \mathrm{s}(. \mathrm{K})$ or N.s $/ \mathrm{m} 2(. \mathrm{K}))$

$+1.002 \mathrm{e}+003+1.467 \mathrm{e}-002 \#_{\mathrm{i}}-\mathrm{a}$ and $\mathrm{b}$ coefficients - specific heat $(\mathrm{J} / \mathrm{kg} . \mathrm{K}(. \mathrm{K}))$

\#******** user-defined gas (UDG) data $* * * * * * * * * * * * * * * * *$

none $\# i^{-}$name of user-defined gas (UDG) component - if any

028.9700 \#i- molecular mass of UDG (g/gmole)

$+2.301 \mathrm{e}-003+7.987 \mathrm{e}-005 \# \mathrm{i}-\mathrm{a}$ and b coefficients - UDG conductivity (W/m.K(.K)) $+3.517 \mathrm{e}-003+4.980 \mathrm{e}-005 \mathrm{\# i}-\mathrm{a}$ and $\mathrm{b}$ coefficients - UDG viscosity $(\mathrm{g} / \mathrm{m} . \mathrm{s}(. \mathrm{K})$ or $\mathrm{mN} . \mathrm{s} / \mathrm{m} 2(. \mathrm{K}))$

$+2.902 \mathrm{e}+001+4.249 \mathrm{e}-004 \quad \# \mathrm{i}^{-} \mathrm{a}$ and $\mathrm{b}$ coefficients - UDG specific heat $(\mathrm{J} / \mathrm{gmole} . \mathrm{K}(. \mathrm{K}))$

\section{C.9 Basement Input File - *.bsm}

*FileVersion 1.0

2.11 \# height

2.0 \# depth 
17.97 \# length

7.73 \# width

1.90 \# overlap (only important for BCCN1 and BCCN2)

3.52 \# rsi

0.85 \# soilk

8 \# wtable 